\title{
The PROMise of remote monitoring to improve quality of care for inflammatory bowel disease
}

Citation for published version (APA):

de Jong, M. J. (2019). The PROMise of remote monitoring to improve quality of care for inflammatory bowel disease. [Doctoral Thesis, Maastricht University]. Maastricht University. https://doi.org/10.26481/dis.20190614mj

Document status and date:

Published: 01/01/2019

DOI:

10.26481/dis.20190614mj

Document Version:

Publisher's PDF, also known as Version of record

\section{Please check the document version of this publication:}

- A submitted manuscript is the version of the article upon submission and before peer-review. There can be important differences between the submitted version and the official published version of record.

People interested in the research are advised to contact the author for the final version of the publication, or visit the DOI to the publisher's website.

- The final author version and the galley proof are versions of the publication after peer review.

- The final published version features the final layout of the paper including the volume, issue and page numbers.

Link to publication

\footnotetext{
General rights rights.

- You may freely distribute the URL identifying the publication in the public portal. please follow below link for the End User Agreement:

www.umlib.nl/taverne-license

Take down policy

If you believe that this document breaches copyright please contact us at:

repository@maastrichtuniversity.nl

providing details and we will investigate your claim.
}

Copyright and moral rights for the publications made accessible in the public portal are retained by the authors and/or other copyright owners and it is a condition of accessing publications that users recognise and abide by the legal requirements associated with these

- Users may download and print one copy of any publication from the public portal for the purpose of private study or research.

- You may not further distribute the material or use it for any profit-making activity or commercial gain

If the publication is distributed under the terms of Article $25 \mathrm{fa}$ of the Dutch Copyright Act, indicated by the "Taverne" license above, 


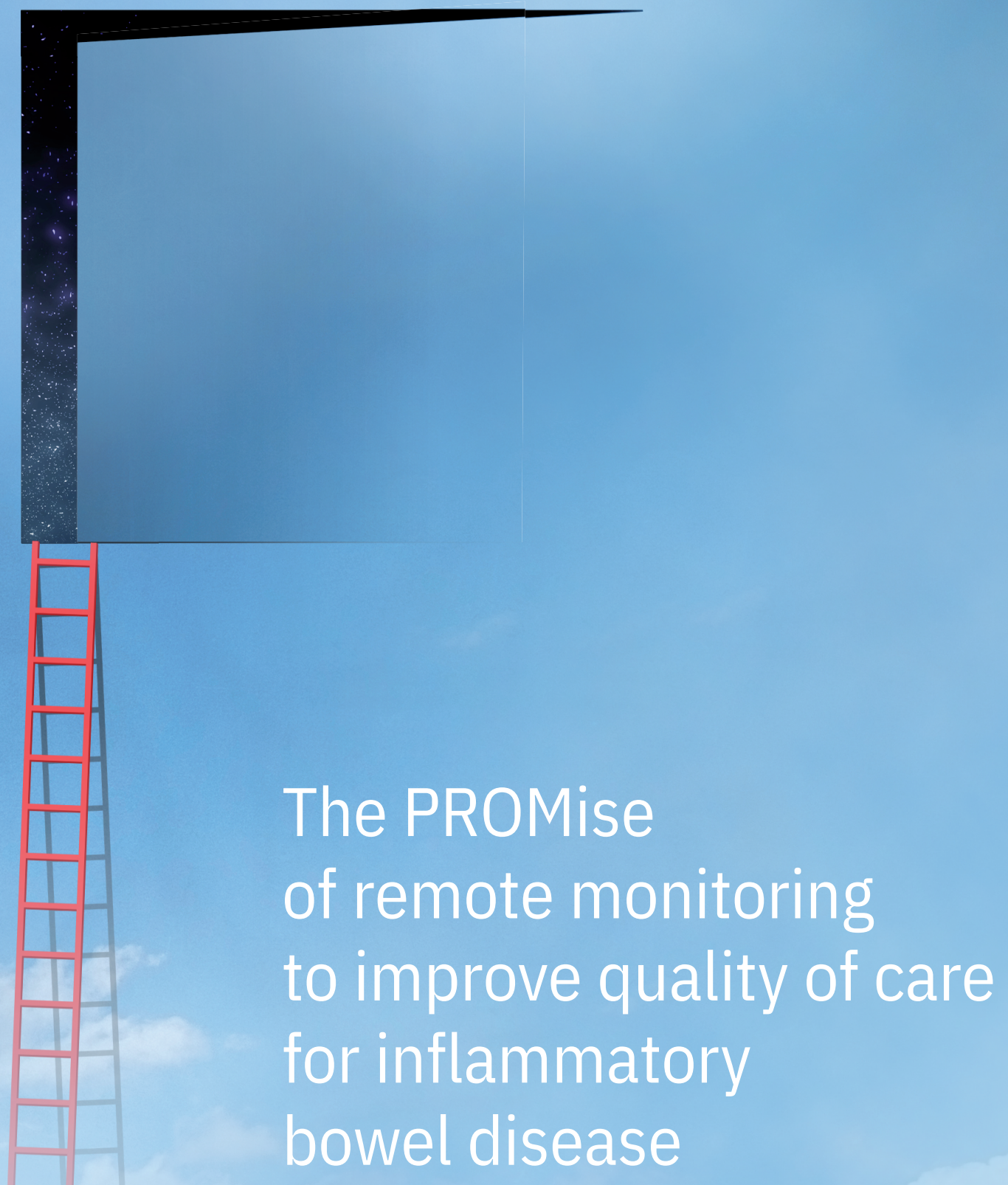

Marin de Jong 

The PROMise of remote monitoring to improve quality of care for inflammatory bowel disease 
Copyright $\odot$, Marin de Jong, Maastricht 2019. All rights reserved. No part of this book may be reproduced or transmitted in any form or by any means, without prior permission in writing by the author, or when appropriate, by the publishers of the publications.

ISBN 978-94-6361-272-2

Cover design, lay-out and printing: Optima Grafische Communicatie, Rotterdam

MylBDcoach was developed by Sananet BV using an unrestricted grant from Ferring BV. Financial support by Sananet, Ferring BV, Takeda, Tramedico, Immundiagnostik, Dr. Falk Pharma, Pfizer, Maastricht University and Nederlandse Vereniging voor Gastroenterologie for the publication of this thesis is gratefully acknowledged. 


\title{
The PROMise of remote monitoring to improve quality of care for inflammatory bowel disease
}

\author{
Proefschrift
}

ter verkrijging van de graad van doctor

aan de Universiteit Maastricht,

op gezag van Rector Magnificus, Prof. dr. Rianne M. Letschert,

volgens het besluit van het college van Decanen,

in het openbaar te verdedigen op

vrijdag 14 juni 2019 om 12.00 uur

door

Marin Joanne de Jong

Geboren op 21 mei 1988 te Wageningen 


\section{Promotor}

Prof. dr. A.A.M. Masclee

\section{Co-promotores}

Dr. M.J. Pierik

Dr. A.M. van Tubergen

\section{Beoordelingscommissie}

Prof. dr. M.P. Zeegers (voorzitter)

Prof. dr. S. Vermeire (Katholieke Universiteit Leuven)

Prof. dr. D.W. Hommes (Leids Universitair Medisch Centrum)

Prof. dr. H. P. Brunner-La Rocca

Dr. H.J.M.M. Mertens 



\section{CONTENTS}

Chapter 1 General introduction and outline of this thesis

\section{Part I}

Chapter 2 Patient-reported outcome measures for use in clinical trials and practice in inflammatory bowel diseases - a systematic review

Chapter 3 Development and validation of a patient-reported score to screen for mucosal inflammation in inflammatory bowel disease

\section{Part II}

Chapter 4 Development and feasibility study of a telemedicine tool for all patients with IBD: MylBDcoach

Chapter 5 Telemedicine for management of inflammatory bowel disease (mylBDcoach): a pragmatic, multicentre, randomised controlled trial

Building evidence for care beyond the medical centre - editorial commentary

Chapter 6 Telemedicine directed specialised care for inflammatory bowel disease is cost-effective. A cost-utility analysis of the mylBDcoach trial

\section{Part III}

Chapter $7 \quad$ Novel perceived stress and life events precede flares of inflammatory bowel disease: a prospective 12-month follow-up study

Chapter 8 The risk of an impaired nutritional status precedes flares in IBD outpatients

Chapter 9 Exploring conditions for redistribution of anti-TNFs to reduce spillage. A study on the quality of anti-TNF home storage

Chapter 10 The prevalence of latent tuberculosis and hepatitis B after systematic screening of patients prescribed biological therapy in a low-endemic area 
$\begin{array}{lll}\text { Epilogue } & \text { Summary } & 217\end{array}$

Samenvatting $\quad 223$

$\begin{array}{ll}\text { Valorisation } & 231\end{array}$

$\begin{array}{ll}\text { Publications, presentations and awards } & 241\end{array}$

Dankwoord 248

Curriculum Vitae $\quad 255$ 



\section{Chapter 1}

General introduction 



\section{Inflammatory bowel disease}

Inflammatory bowel diseases (IBD), comprising Crohn's disease (CD) and ulcerative colitis (UC), are chronic inflammatory disorders of the gastrointestinal tract characterised by periods of exacerbation and remission. Evidence shows that a complex interaction between intestinal microbiota, environmental factors and an altered immune response in genetically susceptible hosts causes IBD'. As a result of the complex aetiology, the clinical presentation of the diseases is very heterogeneous, as shown by variations in disease location and behaviour, relapse frequency, the occurrence of extra-intestinal manifestations, complications, and response to treatment among individuals (figure 1 and 2$)^{2,3}$. Worldwide, the incidence of IBD is increasing with highest rates reported in Western countries (up to 29.3/100,000 in CD, and 24.3/100,000 in UC), resulting in more than 2.5 million people suffering from IBD in the European continent ${ }^{4,5}$. As IBD affects young people in the most productive years of their lives(6) and requires life-long monitoring and therapy, the disease has a significant impact on patients' quality of life and constitutes an economic burden due to direct and indirect healthcare $\operatorname{costs}(7,8)$. IBD is also associated with an increased prevalence of psychological morbidity ${ }^{9}$.

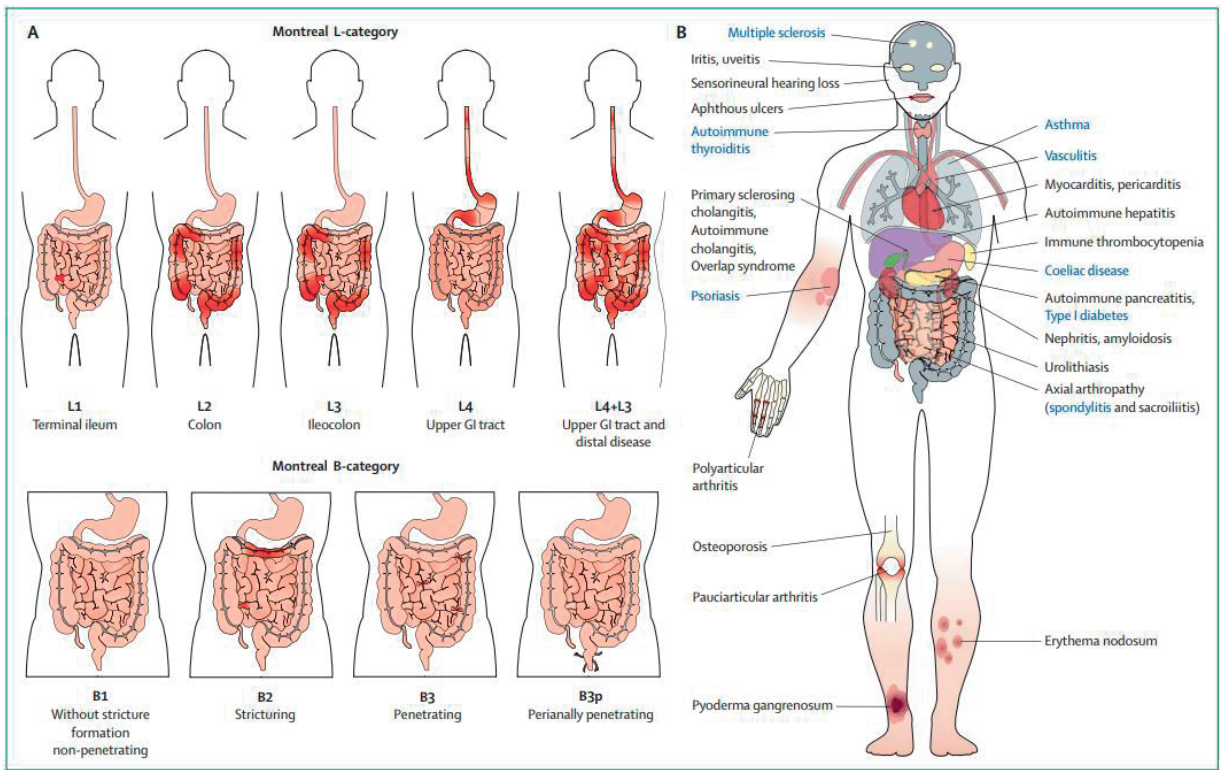

Figure 1. A) Phenotype of Crohn's disease following the Montreal classification; disease extent (L) and behaviour (B). B) Major extra intestinal manifestations and associated autoimmune disorders. Figure adapted from Baumgart et al. Lancet 2012; 380: 1590-1605.

The current treatment target for IBD is to achieve and maintain steroid-free clinical remission and to prevent structural bowel damage, such as fistulas, abscesses, intestinal strictures, and surgery. To achieve these targets, different therapeutic strategies are 
applied. The traditional treatment strategy is a step-up approach, in which therapy is started with the least potent and least toxic medication followed in sequence by escalation to more powerful agents with potentially more side-effects, if remission could not be achieved with therapy from the previous step ${ }^{10}$. Since the long-term outcome with this strategy was often unfavourable, a top-down strategy, especially for patients presenting with severe disease, was introduced for quick establishment of endoscopic remission (figure 3$)^{10-16}$. As a result, there has been an increase in the number of patients exposed to immunosuppressive agents and biological therapy earlier in their disease course. As these drugs can have serious side effects, such as severe infections, accurate monitoring of medication use and side effects in IBD patients is warranted.

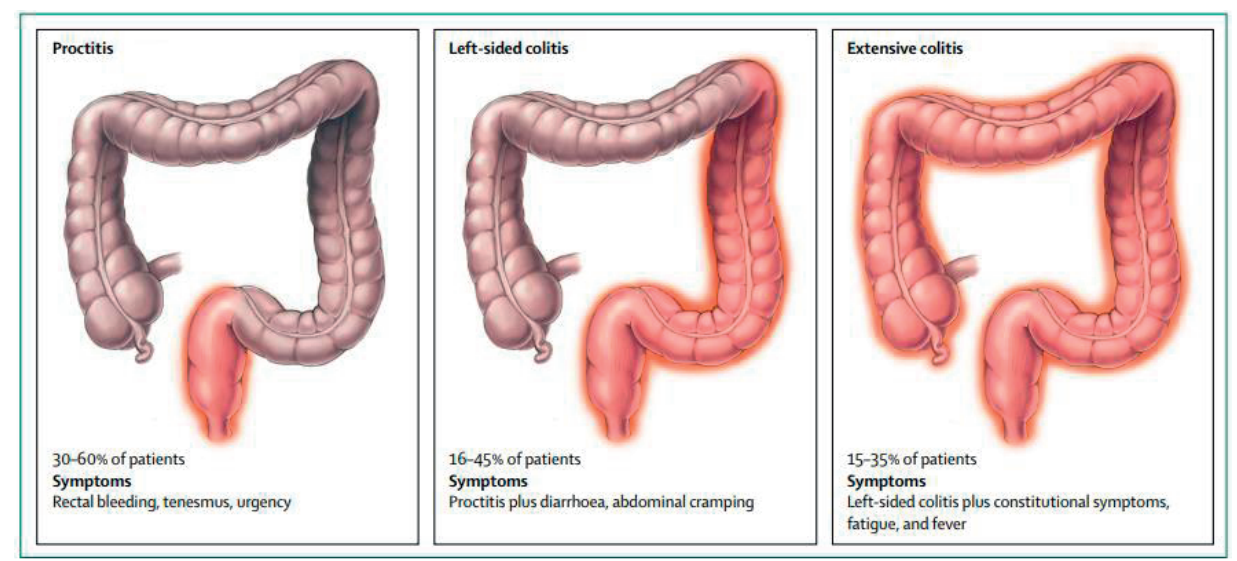

Figure 2. Phenotype of ulcerative colitis following the Montreal classification. Symptoms and treatment strategy can differ based on extent of disease. Figure adapted from Ungaro et al. Lancet 2017; 389: 1756-70.

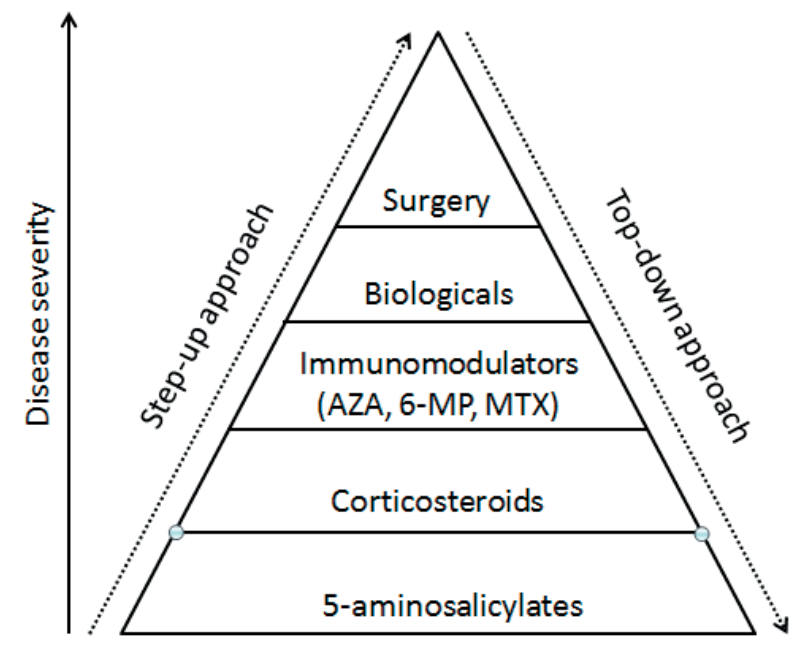

Figure 3. Treatment pyramid for inflammatory bowel disease. AZA, azathioprine; 6-MP, 6-mercaptopurine; MTX, methotrexate 


\section{Monitoring disease course and management strategies for IBD}

The most important long-term outcomes for IBD used in clinical trials are the number of flares, corticosteroid use, hospitalisations, complications (i.e. fistulas, abscesses and strictures) and surgery. Population based cohorts showed that the numbers of surgeries and hospitalisations decreased in parallel with more frequent and earlier prescription of immunosuppressives and biologicals ${ }^{17-19}$. However, despite high exposure of new and costly biological therapies, the risk of disease progression from an inflammatory to a stricturing or penetrating phenotype has not changed over the past decades ${ }^{17}$. Therefore, new management strategies are proposed to improve long-term disease outcome ${ }^{11}$.

Several studies showed that in patients with rheumatoid arthritis, serial monitoring with objective scoring tools and early treatment adjustment was found to result in lower disease activity and better long-term outcome ${ }^{20,21}$. In IBD, mounting evidence underlines the importance of tight control of disease activity and early intervention in case of recurrence of intestinal inflammation to prevent irreversible bowel damage ${ }^{11,22-25}$. In this context, the treatment target changed from clinical remission alone, to deep remission (endoscopic remission or even histologic remission) ${ }^{26}$. In addition, monitoring factors affecting disease activity, such as non-adherence to treatment, unfavourable nutritional status, smoking, and psychological factors have shown to improve disease outcome ${ }^{27-29}$. Targeted interventions on these aspects can contribute to a reduction of disease relapses, healthcare utilisation including hospitalisation and absence from work in subsets of patients ${ }^{27-29}$.

Objective measures of mucosal inflammation are important for implementation of a tight control strategy. In IBD, the gold standard for assessment of disease activity is endoscopy. This examination is however invasive, costly and time-consuming and therefore not suitable nor available for frequent evaluation. Non-invasive biomarkers such as C-reactive protein (CRP) and fecal calprotectin (FC) are among the best studied markers of inflammation in IBD. Multiple studies found that these markers predict a relapse of IBD with sensitivity and specificity values ranging from $50-90 \%$, with the highest values for FC and depending on cut-off values and clinical setting ${ }^{11}$. In addition, clinician-reported clinical activity indices as the Harvey Bradshaw Index (HBI), Crohn's Disease Activity Index (CDAl), or Simple Clinical Colitis Activity Index (SCCAI) are frequently used for monitoring of disease activity over time. However, these clinical indices only moderately correlate with endoscopy and have shown to poorly predict endoscopic remission ${ }^{30}$.

As an alternative, patient-reported outcome measures (PROMs) are increasingly of interest as incorporation of health outcomes that reflect patients' perspectives on healthcare is advocated to support patient-centered care and to improve value of healthcare $^{31,32}$. Systematic registration of these PROMs, and patient-reported experiences measures (PREMs) is increasingly requested by healthcare insurers and governments to 
measure quality of care, benchmark and guarantee reimbursement of expensive drugs or treatments. At the same time, patients themselves also demand empowerment and more involvement with their therapy. Different PROMs have been developed for followup of disease activity, such as the Manitoba IBD Index ${ }^{33}$, the single-item numeric rating $\mathrm{scale}^{34}$, the IBD-10 ${ }^{35}$ and questionnaires derived from the Harvey Bradshaw Index ${ }^{36-38}$, the Simple Clinical Colitis Activity Index ${ }^{37-41}$, the Crohn's Disease Activity Index ${ }^{42,43}$ and the Mayo Clinic Score ${ }^{44-46}$. However, their value in predicting mucosal inflammation is unknown as none of these have been validated relative to endoscopy.

\section{Current IBD healthcare organisation}

IBD is diagnosed through a combination of endoscopic, radiologic and laboratory tests ${ }^{47}$. After diagnosis and induction of remission, IBD care is traditionally organised by routinely scheduled follow-up visits and laboratory controls with a frequency based on medical treatment, but independent of the occurrence of unpredictable flares (figure 4). In the Netherlands, patients visit the outpatient clinic on average 3 times per year. In case of a flare, patients visit the outpatient clinic 2-3 times extra depending on the severity. For severe flares or complications, patients might be hospitalised or require surgery.

Due to a rising incidence of IBD over the past decades and a shortage of gastroenterologists in the Netherlands, outpatient clinics tend to be overburdened. As a result, implementation of tight control strategies and monitoring and intervening on factors affecting disease activity is impossible in the current healthcare organisation. In addition, analysis of the population based IBD hospitalised South Limburg cohort showed that direct healthcare costs continue to increase over time (figure 5). However, there is no data confirming whether these increased costs are accompanied by an increase in quality of life, reduction of (work)disability or improved disease outcomes. Therefore, insurance companies, governments and patient organisations increasingly demand registration of doctor-reported and patient-reported quality parameters. This has, however, not yet been systematically implemented in current clinical practice, because acquiring all the necessary information at the right moment for every individual patient remains a challenge. For these reasons, structural healthcare reorganisation is warranted. 


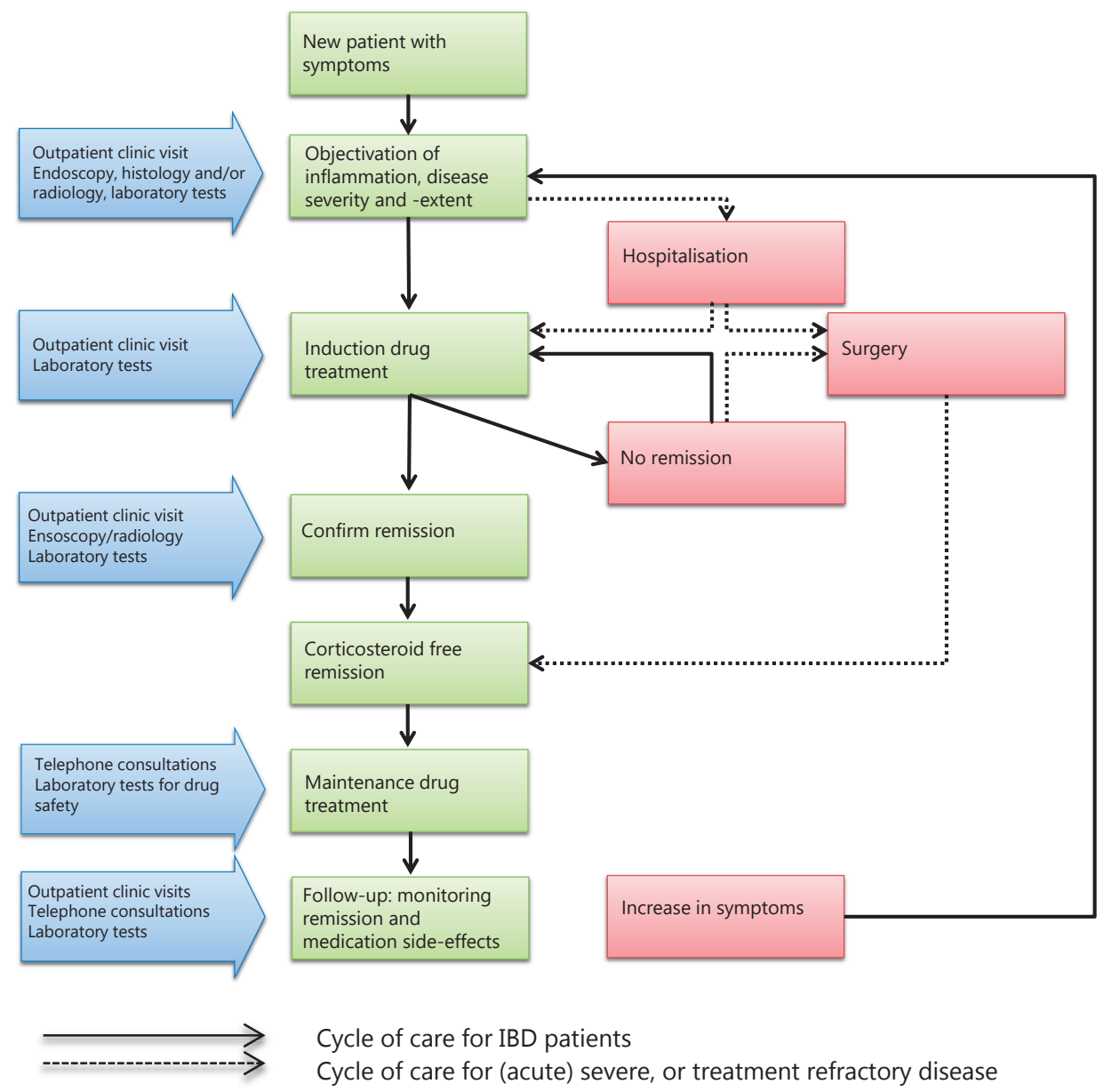

Figure 4. Organisation of IBD care. After the diagnosis of IBD, patients are classically followed at the outpatient clinic with visits and laboratory tests. An induction therapy is started and evaluated with endoscopy/ radiology or laboratory tests. When a patient achieves remission of the disease, follow-up consists of outpatient visits and phone consultations for monitoring of remission and medication side-effects. In case of a relapse, the cycle restarts. When a patients presents with acute severe disease or treatment refractory disease, hospitalisation and/or surgery might be needed. 


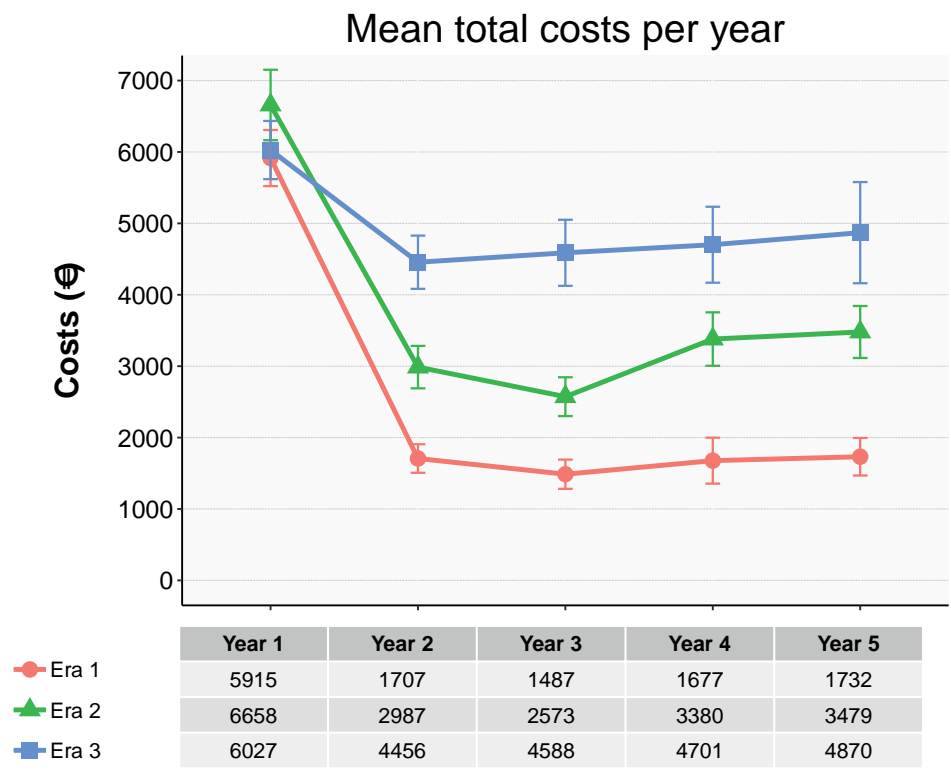

Figure 5. Mean direct healthcare costs for $C D$ patients per year after diagnosis over three different era's; era '91-98, era '99-'05 and era '06-11. Lalisang et al. The direct healthcare costs of Crohn's disease increased over the last two decades in a Dutch population-based cohort presented at ECCO 2018.

\section{Telemedicine}

As smartphone adoption is increasing rapidly worldwide, telemedicine is gaining ground. Telemedicine, literally defined as healthcare at distance, allows healthcare professionals to evaluate, diagnose and treat patients in remote locations using information and communication technologies (ICT). Many telemedicine tools are available, most of which provide health information or support data collection. However, over the past decade, telemedicine tools for chronic diseases attract attention as they assist in monitoring of symptoms or objective measurements as blood pressure or weight. Additionally, these tools aid healthcare professionals to implement a tight control strategy by monitoring patients at home between outpatient visits. They allow for strict and instantaneous follow-up of symptoms and intestinal inflammation, and facilitate timely, and personalised interventions. At the same time, these tools can automatically monitor factors influencing disease as medication (side-)effects, medication adherence, nutritional status, smoking, and psychological factors.

In other chronic relapsing-remitting diseases, such as chronic obstructive pulmonary disease and heart failure, telemedicine has shown to improve quality of care and to reduce the use of healthcare resources and related costs ${ }^{48,49}$. Also for IBD patients, data on several telemedicine systems was available at start of this project. Cross et al. developed a Home Telemanagement System for UC patients ${ }^{50-55}$, composed of a netbook computer and an electronic weight scale that monitors symptoms, medication use and 
side-effects. Elkjaer et al. developed a web-based system (Constant Care) to monitor disease activity and quality of life in patients with mild-to-moderate UC on 5-aminosalicylic acid (5-ASA) treatment ${ }^{56,57}$. This program was also used for individualisation of 5-ASA treatment and improvement of adherence in mild-to-moderate UC patients ${ }^{27}$ and for individualisation of infliximab (IFX) scheduling in CD patients on IFX maintenance treatment ${ }^{58}$. Overall, these systems were shown to be feasible, safe and well-accepted by IBD patients. However, they were developed for patients with specific subtypes of IBD with relatively mild disease and studies provide inconsistent results on the effects of these telemedicine systems on disease outcome ${ }^{53,56,59}$. This together compromises their use in real-world settings ${ }^{17,36-38,60}$. In addition, lack of a conceptual framework for the development, evaluation, and implementation of telemedicine systems ${ }^{59}$, a disconnect between users and developers of health IT systems ${ }^{61}$, and financial hurdles such as reimbursement of telemedicine consultations by insurance companies, contributed to a lack of implementation in daily care.

\section{Aim of this thesis}

This thesis describes the development and implementation of a telemedicine tool for all IBD patients in order to reorganise IBD care towards efficient, personalised and higher value care.

Part I of this thesis focuses on patient-reported disease activity measures. Chapter 1 reviews the available PROMs for assessment of IBD disease activity and their diagnostic accuracy. Chapter $\mathbf{2}$ describes the development and validation of a new patientreported disease activity score relative to the golden standard endoscopy.

Part II of this thesis focuses on the role of telemedicine for management of IBD. Chapter $\mathbf{3}$ describes the development and pilot-testing of mylBDcoach, the first telemedicine system that monitors and registers disease activity in patients with all subtypes of IBD. To investigate the effects of use of mylBDcoach compared to standard care on healthcare utilisation and patient-reported quality of care, a pragmatic randomised multicentre trial was carried out of which the results are presented in chapter 4. Subsequently, costeffectiveness of use of mylBDcoach is described in chapter $\mathbf{5}$.

Part III of this thesis covers the opportunities of telemedicine to collect data on factors believed to influence disease activity, such as psychological factors (chapter 6), nutrition (chapter 7), medication adherence and storage (chapter 8) and medication side-effects, such as severe infections (chapter $\mathbf{9}$ ).

The epilogue contains a general discussion of the results described in this thesis and provides opportunities and suggestions for further research. 


\section{REFERENCES}

1. Zhang YZ, Li YY. Inflammatory bowel disease: pathogenesis. World journal of gastroenterology. 2014 Jan 7;20(1):91-9. PubMed PMID: 24415861. Pubmed Central PMCID: 3886036.

2. Wolters FL, Russel MG, Sijbrandij J, Ambergen T, Odes S, Riis L, et al. Phenotype at diagnosis predicts recurrence rates in Crohn's disease. Gut. 2006 Aug;55(8):112430. PubMed PMID: 16361306. Pubmed Central PMCID: 1856253.

3. Zallot C, Peyrin-Biroulet L. Clinical risk factors for complicated disease: how reliable are they? Digestive diseases. 2012;30 Suppl 3:67-72. PubMed PMID: 23295694.

4. van den Heuvel TRA, Jeuring SFG, Zeegers $M P$, van Dongen DHE, Wolters AE, Masclee $A A$, et al. Evolution of IBD incidence, disease phenotype, and mortality; 20 years of epidemiologic research in the Dutch population based IBDSL cohort Journal of Crohn's and Colitis. 2016.

5. Molodecky NA, Soon IS, Rabi DM, Ghali WA, Ferris M, Chernoff G, et al. Increasing incidence and prevalence of the inflammatory bowel diseases with time, based on systematic review. Gastroenterology. 2012 Jan;142(1):46-54 e42; quiz e30. PubMed PMID: 22001864.

6. Johnston RD, Logan RF. What is the peak age for onset of IBD? Inflamm Bowel Dis. 2008 Oct;14 Suppl 2:S4-5. PubMed PMID: 18816745

7. Bernklev T, Jahnsen J, Lygren I, Henriksen M, Vatn M, Moum B. Health-related quality of life in patients with inflammatory bowel disease measured with the short form-36: psychometric assessments and a comparison with general population norms. Inflamm Bowel Dis. 2005 Oct;11(10):90918. PubMed PMID: 16189421.

8. van der Valk ME, Mangen MJ, Leenders M, Dijkstra G, van Bodegraven AA, Fidder $\mathrm{HH}$, et al. Healthcare costs of inflammatory bowel disease have shifted from hospitalisation and surgery towards anti-TNFalpha therapy: results from the COIN study. Gut. 2014 Jan;63(1):72-9. PubMed PMID: 23135759.

9. Walker JR, Ediger JP, Graff LA, Greenfeld JM, Clara I, Lix L, et al. The Manitoba IBD cohort study: a population-based study of the prevalence of lifetime and 12-month anxiety and mood disorders. The American journal of gastroenterology. 2008 Aug;103(8):1989-97. PubMed PMID: 18796096.

10. D'Haens G, Baert F, van Assche G, Caenepeel $\mathrm{P}$, Vergauwe $\mathrm{P}$, Tuynman $\mathrm{H}$, et al. Early combined immunosuppression or conventional management in patients with newly diagnosed Crohn's disease: an open randomised trial. Lancet. 2008 Feb 23;371(9613):660-7. PubMed PMID: 18295023.

11. Colombel JF, Narula N, Peyrin-Biroulet L. Management Strategies to Improve Outcomes of Patients With Inflammatory Bowel Diseases. Gastroenterology. 2017 Feb;152(2):351-61 e5. PubMed PMID: 27720840.

12. Baert F, Moortgat L, Van Assche G, Caenepeel P, Vergauwe P, De Vos M, et al. Mucosal healing predicts sustained clinical remission in patients with early-stage Crohn's disease. Gastroenterology. 2010 Feb;138(2):463-8; quiz e10-1. PubMed PMID: 19818785.

13. Colombel JF, Rutgeerts P, Reinisch W, Esser D, Wang Y, Lang Y, et al. Early mucosal healing with infliximab is associated with improved long-term clinical outcomes in ulcerative colitis. Gastroenterology. 2011 Oct;141(4):1194-201. PubMed PMID: 21723220.

14. Khanna R, Bressler B, Levesque BG, Zou G, Stitt LW, Greenberg GR, et al. Early combined immunosuppression for the 
management of Crohn's disease (REACT): a cluster randomised controlled trial. Lancet. 2015 Nov 07;386(10006):1825-34. PubMed PMID: 26342731.

15. Rogler G. Top-down or step-up treatment in Crohn's disease? Digestive diseases. 2013;31(1):83-90. PubMed PMID: 23797128.

16. Amezaga AJ, Van Assche G. Practical Approaches to "Top-Down" Therapies for Crohn's Disease. Current gastroenterology reports. 2016 Jul;18(7):35. PubMed PMID: 27184044.

17. Jeuring SF, van den Heuvel TR, Liu LY, Zeegers MP, Hameeteman WH, RombergCamps MJ, et al. Improvements in the Long-Term Outcome of Crohn's Disease Over the Past Two Decades and the Relation to Changes in Medical Management: Results from the Population-Based IBDSL Cohort. The American journal of gastroenterology. 2017 Feb;112(2):325-36. PubMed PMID: 27922024.

18. Rungoe $C$, Langholz E, Andersson M, Basit S, Nielsen NM, Wohlfahrt J, et al. Changes in medical treatment and surgery rates in inflammatory bowel disease: a nationwide cohort study 1979-2011. Gut. 2014 Oct;63(10):1607-16. PubMed PMID: 24056767.

19. Ramadas AV, Gunesh S, Thomas GA, Williams GT, Hawthorne AB. Natural history of Crohn's disease in a population-based cohort from Cardiff (1986-2003): a study of changes in medical treatment and surgical resection rates. Gut. 2010 Sep;59(9):12006. PubMed PMID: 20650924.

20. Grigor $C$, Capell $H$, Stirling $A$, McMahon $A D$, Lock $P$, Vallance $R$, et al. Effect of a treatment strategy of tight control for rheumatoid arthritis (the TICORA study): a single-blind randomised controlled trial. Lancet. 2004 Jul 17-23;364(9430):263-9. PubMed PMID: 15262104.

21. Schipper LG, van Hulst LT, Grol R, van Riel $\mathrm{PL}$, Hulscher ME, Fransen J. Meta-analysis of tight control strategies in rheumatoid arthritis: protocolized treatment has additional value with respect to the clinical outcome. Rheumatology. 2010 Nov;49(11):2154-64. PubMed PMID: 20671022.

22. Magro F, Gionchetti P, Eliakim R, Ardizzone S, Armuzzi A, Barreiro-de Acosta $M$, et al. Third European Evidence-based Consensus on Diagnosis and Management of Ulcerative Colitis. Part 1: Definitions, Diagnosis, Extra-intestinal Manifestations, Pregnancy, Cancer Surveillance, Surgery, and Ileo-anal Pouch Disorders. Journal of Crohn's \& colitis. 2017 Jun 01;11(6):649-70. PubMed PMID: 28158501.

23. Gionchetti $P$, Dignass $A$, Danese $S$, Magro Dias FJ, Rogler G, Lakatos PL, et al. 3rd European Evidence-based Consensus on the Diagnosis and Management of Crohn's Disease 2016: Part 2: Surgical Management and Special Situations. Journal of Crohn's \& colitis. 2017 Feb;11(2):135-49. PubMed PMID: 27660342.

24. Gomollon F, Dignass A, Annese V, Tilg $\mathrm{H}$, Van Assche G, Lindsay JO, et al. 3rd European Evidence-based Consensus on the Diagnosis and Management of Crohn's Disease 2016: Part 1: Diagnosis and Medical Management. Journal of Crohn's \& colitis. 2017 Jan;11(1):3-25. PubMed PMID: 27660341.

25. Colombel JF, Panaccione R, Bossuyt P, Lukas M, Baert F, Vanasek T, et al. Effect of tight control management on Crohn's disease (CALM): a multicentre, randomised, controlled phase 3 trial. Lancet. 2018 Dec 23;390(10114):2779-89. PubMed PMID: 29096949.

26. D'Haens G, Vermeire S, Lambrecht G, Baert $F$, Bossuyt $P$, Pariente $B$, et al. Increasing Infliximab Dose Based on Symptoms, Biomarkers, and Serum Drug Concentrations Does Not Increase Clinical, Endoscopic, and Corticosteroid-Free Remission in Patients With Active Luminal Crohn's Disease. 
Gastroenterology. 2018 Apr;154(5):134351 e1. PubMed PMID: 29317275.

27. Pedersen $N$, Thielsen $P$, Martinsen $L$, Bennedsen $M$, Haaber A, Langholz $E$, et al. eHealth: individualization of mesalazine treatment through a self-managed web-based solution in mild-to-moderate ulcerative colitis. Inflamm Bowel Dis. 2014 Dec;20(12):2276-85. PubMed PMID: 25248002.

28. Lakatos PL. Prevalence, predictors, and clinical consequences of medical adherence in IBD: how to improve it? World journal of gastroenterology. 2009 Sep 14;15(34):4234-9. PubMed PMID: 19750566. Pubmed Central PMCID: 2744179.

29. Reigada LC, Satpute A, Hoogendoorn CJ, Cohen BH, Lai J, Bao R, et al. Patientreported Anxiety: A Possible Predictor of Pediatric Inflammatory Bowel Disease Health Care Use. Inflamm Bowel Dis. 2016 Aug 1. PubMed PMID: 27482980.

30. Falvey JD, Hoskin T, Meijer B, Ashcroft A, Walmsley R, Day AS, et al. Disease activity assessment in IBD: clinical indices and biomarkers fail to predict endoscopic remission. Inflamm Bowel Dis. 2015 Apr;21(4):824-31. PubMed PMID: 25738372.

31. Porter ME. What is value in health care? The New England journal of medicine. 2010 Dec 23;363(26):2477-81. PubMed PMID: 21142528.

32. Bradley SM, Rumsfeld JS, Ho PM. Incorporating Health Status in Routine Care to Improve Health Care Value: The VA Patient Reported Health Status Assessment (PROST) System. Jama. 2016 Aug 2;316(5):487-8. PubMed PMID: 27483062.

33. Clara I, Lix LM, Walker JR, Graff LA, Miller $\mathrm{N}$, Rogala $\mathrm{L}$, et al. The Manitoba IBD Index: evidence for a new and simple indicator of IBD activity. The American journal of gastroenterology. 2009 Jul;104(7):175463. PubMed PMID: 19455122.
34. Surti B, Spiegel B, Ippoliti A, Vasiliauskas $E A$, Simpson $P$, Shih DQ, et al. Assessing health status in inflammatory bowel disease using a novel single-item numeric rating scale. Digestive diseases and sciences. 2013 May;58(5):1313-21. PubMed PMID: 23250673. Pubmed Central PMCID: 4161217.

35. Subramanian $\mathrm{S}$, Asher $\mathrm{R}$, Weston $\mathrm{W}$, Rimmer M, McConville A, Malin A, et al. Validation of a Simple 0 to 10 Numerical Score (IBD-10) of Patient-reported Inflammatory Bowel Disease Activity for Routine Clinical Use. Inflamm Bowel Dis. 2016 Aug;22(8):1902-7. PubMed PMID: 27243590.

36. Bennebroek Evertsz F, Hoeks CC, Nieuwkerk PT, Stokkers PC, Ponsioen CY, Bockting $\mathrm{CL}$, et al. Development of the patient Harvey Bradshaw index and a comparison with a clinician-based Harvey Bradshaw index assessment of Crohn's disease activity. J Clin Gastroenterol. 2013 Nov-Dec;47(10):850-6. PubMed PMID: 23632348.

37. Gracie DJ, Williams CJM, Sood R, Mumtaz S, Bholah MH, Hamlin PJ, et al. Poor Correlation Between Clinical Disease Activity and Mucosal Inflammation, and the Role of Psychological Comorbidity, in Inflammatory Bowel Disease. American Journal of Gastroenterology. 2016 Apr;111(4):541-51. PubMed PMID: WOS:000375442300021. English.

38. Larsen L, Drewes AM, Fallingborg J, Jacobsen BA, Jess T. Touch screens as a tool in patient care in the IBD outpatient clinic. Scand J Gastroentero. 2016;51(9):1 106-10. PubMed PMID: WOS:000381406800015. English.

39. Bennebroek Evertsz F, Nieuwkerk PT, Stokkers $\mathrm{PC}$, Ponsioen $\mathrm{CY}$, Bockting $\mathrm{CL}$, Sanderman $\mathrm{R}$, et al. The patient simple clinical colitis activity index (P-SCCAI) can detect ulcerative colitis (UC) disease activity in remission: a comparison of the 
P-SCCAI with clinician-based SCCAI and biological markers. Journal of Crohn's \& colitis. 2013 Dec;7(11):890-900. PubMed PMID: 23269224.

40. Jowett SL, Seal CJ, Phillips E, Gregory W, Barton JR, Welfare MR. Defining relapse of ulcerative colitis using a symptom-based activity index. Scand J Gastroenterol. 2003 Feb;38(2):164-71. PubMed PMID: 12678333.

41. Marin-Jimenez I, Nos P, Domenech E, Riestra S, Gisbert JP, Calvet X, et al. Diagnostic Performance of the Simple Clinical Colitis Activity Index Self-Administered Online at Home by Patients With Ulcerative Colitis: CRONICA-UC Study. The American journal of gastroenterology. 2016 Feb;111(2):2618. PubMed PMID: 26753886.

42. Timmer A, Kemptner D, Takses A, Klebl $\mathrm{F}$, Jockel $\mathrm{KH}$. A survey-based index was validated for measuring disease activity in inflammatory bowel disease. An evaluation study. Journal of clinical epidemiology. 2009 Jul;62(7):771-8. PubMed PMID: 19110402.

43. Khanna R, Zou G, D'Haens G, Feagan BG, Sandborn WJ, Vandervoort MK, et al. A retrospective analysis: the development of patient reported outcome measures for the assessment of Crohn's disease activity. Alimentary pharmacology \& therapeutics. 2015 Jan;41(1):77-86. PubMed PMID: 25348809.

44. Lewis JD, Chuai S, Nessel L, Lichtenstein GR, Aberra FN, Ellenberg JH. Use of the noninvasive components of the Mayo score to assess clinical response in ulcerative colitis. Inflamm Bowel Dis. 2008 Dec;14(12):1660-6. PubMed PMID: 18623174. Pubmed Central PMCID: 2597552.

45. Bewtra $M$, Brensinger CM, Tomov VT, Hoang TB, Sokach CE, Siegel CA, et al. An optimized patient-reported ulcerative colitis disease activity measure derived from the Mayo score and the simple clinical colitis activity index. Inflamm Bowel Dis. 2014 Jun;20(6):1070-8. PubMed PMID: 24810138. Pubmed Central PMCID: 4137887.

46. Jairath V, Khanna R, Zou GY, Stitt L, Mosli $M$, Vandervoort $M K$, et al. Development of interim patient-reported outcome measures for the assessment of ulcerative colitis disease activity in clinical trials. Alimentary pharmacology \& therapeutics. 2015 Nov;42(10):1200-10. PubMed PMID: 26388424.

47. Lennard-Jones JE. Classification of inflammatory bowel disease. Scand J Gastroenterol Suppl. 1989;170:2-6; discussion 16-9. PubMed PMID: 2617184.

48. de la Torre Diez I, Garcia-Zapirain B, Mendez-Zorrilla A, Lopez-Coronado M. Monitoring and Follow-up of Chronic Heart Failure: a Literature Review of eHealth Applications and Systems. Journal of medical systems. 2016 Jul;40(7):179. PubMed PMID: 27286984.

49. Jonkman $\mathrm{NH}$, Westland $\mathrm{H}$, Trappenburg JC, Groenwold RH, Bischoff EW, Bourbeau $J$, et al. Do self-management interventions in COPD patients work and which patients benefit most? An individual patient data meta-analysis. International journal of chronic obstructive pulmonary disease. 2016;11:2063-74. PubMed PMID: 27621612. Pubmed Central PMCID: 5012618.

50. Clarke M, Shah A, Sharma U. Systematic review of studies on telemonitoring of patients with congestive heart failure: a meta-analysis. J Telemed Telecare. 2011;17(1):7-14. PubMed PMID: 21097564.

51. Cross RK, Jr. Telemanagement for inflammatory bowel disease. Gastroenterol Hepatol (N Y). 2014 Apr;10(4):255-7. PubMed PMID: 24976810. Pubmed Central PMCID: 4073538.

52. Cross RK, Cheevers N, Finkelstein J. Home telemanagement for patients with ulcerative colitis (UC HAT). Digestive diseases 
and sciences. 2009 Nov;54(11):2463-72. PubMed PMID: 19104937.

53. Cross RK, Cheevers N, Rustgi A, Langenberg $\mathrm{P}$, Finkelstein J. Randomized, controlled trial of home telemanagement in patients with ulcerative colitis (UC HAT). Inflamm Bowel Dis. 2012 Jun;18(6):101825. PubMed PMID: 21688350. Pubmed Central PMCID: 3179574.

54. Cross RK, Finkelstein J. Feasibility and acceptance of a home telemanagement system in patients with inflammatory bowel disease: a 6-month pilot study. Digestive diseases and sciences. 2007 Feb;52(2):35764. PubMed PMID: 17211702.

55. Cross RK, Finkelstein J. Challenges in the design of a Home Telemanagement trial for patients with ulcerative colitis. Clin Trials. 2009 Dec;6(6):649-57. PubMed PMID: 19822631.

56. Elkjaer M, Shuhaibar M, Burisch J, Bailey $\mathrm{Y}$, Scherfig $\mathrm{H}$, Laugesen B, et al. E-health empowers patients with ulcerative colitis: a randomised controlled trial of the webguided 'Constant-care' approach. Gut. 2010 Dec;59(12):1652-61. PubMed PMID: 21071584.

57. Elkjaer $M$, Burisch J, Avnstrom S, Lynge E, Munkholm P. Development of a Web- based concept for patients with ulcerative colitis and 5-aminosalicylic acid treatment. European journal of gastroenterology \& hepatology. 2010 Jun;22(6):695-704. PubMed PMID: 19543101.

58. Pedersen N, Elkjaer M, Duricova D, Burisch J, Dobrzanski C, Andersen NN, et al. eHealth: individualisation of infliximab treatment and disease course via a self-managed web-based solution in Crohn's disease. Alimentary pharmacology \& therapeutics. 2012 Nov;36(9):840-9. PubMed PMID: 22971016.

59. Jackson BD, Gray K, Knowles SR, De Cruz P. EHealth Technologies in Inflammatory Bowel Disease: A Systematic Review. Journal of Crohn's \& colitis. 2016 Feb 29. PubMed PMID: 26928960.

60. Huang VW, Reich KM, Fedorak RN. Distance management of inflammatory bowel disease: systematic review and metaanalysis. World journal of gastroenterology. 2014 Jan 21;20(3):829-42. PubMed PMID: 24574756. Pubmed Central PMCID: 3921492.

61. Rudin RS, Bates DW, MacRae C. Accelerating Innovation in Health IT. The New England journal of medicine. $2016 \mathrm{Sep}$ 01;375(9):815-7. PubMed PMID: 27579633. 




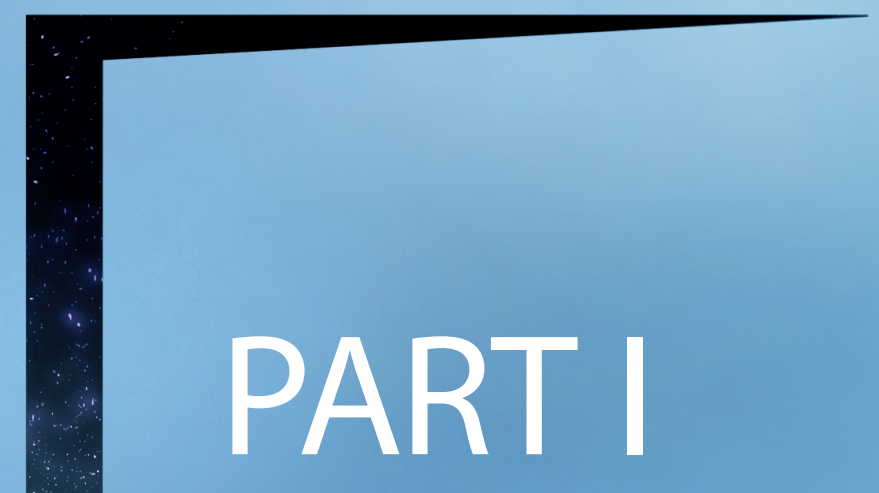





\section{Chapter 2}

Patient-Reported Outcome Measures for Use in Clinical Trials and Clinical Practice in Inflammatory Bowel Diseases:

A Systematic Review

Marin de Jong, Roxanne Huibregtse, Ad Masclee, Daisy Jonkers

and Marieke Pierik 


\section{ABSTRACT}

Background: Mucosal inflammation must be carefully monitored to improve the longterm outcomes of patients with inflammatory bowel diseases (IBD). Patient-reported outcome measures (PROMs) are used increasingly to monitor disease activity in clinical practice and as endpoints in clinical trials. We performed a systematic review to provide an overview of the available PROMs on IBD activity and to evaluate their diagnostic value.

Methods: A systematic search of the PubMed, Medline, Cochrane library, and Embase databases using defined keywords, identified 973 articles. These were screened by 2 independent reviewers, and 37 articles on development or validation of PROMs to assess IBD activity were identified for further analysis. Based on the recommendations of the Food and Drug Administration (FDA), the following measurement properties were evaluated: content, construct, and criterion validity; reliability; and responsiveness to change. In addition, data on ease of use in clinical practice were collected.

Results: Seventeen articles presenting 20 different PROMs were included in the final analysis, although none met all the FDA-recommended criteria. Only 2 PROMs (patientreported Harvey Bradshaw Index and Simple Clinical Colitis Activity Index scores) reported patient involvement during its development. Only 6 PROMs (patient-reported global assessment, patient assessment of disease activity, mobile health index for Crohn's disease, mobile health index for ulcerative colitis, patient-reported outcome derived from the Mayo score, and the 6-point Mayo score) were validated as markers of IBD activity, using findings from endoscopy as the reference standard; these PROMs identified patients with mucosal inflammation with area under the curve values of 0.63-0.82. The mobile health index for CD and UC scores had the best measurement properties for use in clinical practice and in clinical trials.

Conclusion: In a systematic review, we identified more than 20 PROMs that have been developed and tested for their ability to determine IBD activity. Further studies are needed to determine their accuracy and whether they can be used effectively in routine practice, clinical trials, telemedicine systems, and value-based healthcare programs. 


\section{INTRODUCTION}

Inflammatory bowel diseases (IBD), including the two main subtypes Crohn's disease (CD) and ulcerative colitis (UC), are characterised by a heterogeneous clinical manifestation and a chronic relapsing-remitting course ${ }^{1}$. Two important novel insights prompt the use of patient-reported outcome measures (PROMs) for optimal management of IBD patients. First, to prevent disease progression and improve the long-term disease outcome, including complications, hospitalisation and surgery, management of IBD is shifting from mere control of symptoms towards tight control of mucosal inflammation and early intervention in case of a relapse ${ }^{2}$. Mucosal inflammation, further referred to as disease activity, is ideally assessed by endoscopy; however, this examination is too invasive and costly for frequent evaluation. Therefore, non-invasive biomarkers such as C-reactive protein (CRP) and fecal calprotectin (FC) or clinician-reported activity indices as the Harvey Bradshaw Index ( $\mathrm{HBI})$, Crohn's Disease Activity Index (CDAl), or Simple Clinical Colitis Activity Index (SCCAI) are frequently used for monitoring of disease activity over time. As an alternative, PROMs, for instance incorporated in telemedicine systems, could assist healthcare professionals to implement a tight control strategy in a setting of an increasing IBD incidence with limited healthcare resources ${ }^{3,4}$. Secondly, the focus of healthcare is transitioning from volume-based towards value-based systems, in which patient outcomes are evaluated relative to cost of care ${ }^{5,6}$. Insurance companies, governments, and patient organisations demand registration of PROMs as efficacy endpoints of interventions in routine care. In addition, the use of patients' perspectives on the effectiveness of therapies in clinical trials is strongly recommended by the Food and Drug Administration (FDA) $)^{5,7,8}$.

The definition of a PROM is any report of the status of a patient's health condition that comes directly from the patient, without interpretation of the patient's response by a clinician or anyone else and without laboratory assessments ${ }^{8}$. The FDA has provided guidelines on how a PROM should be developed ${ }^{8}$. First, item generation of a PROM should be established by focus groups interviews containing a heterogeneous group of patients regarding population characteristics, condition and treatment. Thereafter, its construct validity, criterion validity, reliability and ability to detect change should be evaluated to finalize the instrument ${ }^{7,8}$.

For IBD it is important to distinguish PROMs monitoring disease activity, from PROMs evaluating patients' perspectives on for example disease control and quality of life. Systematic evaluation of both is important to improve the long-term outcome and value of care for IBD patients. A wide variety of PROMs for monitoring of disease activity in IBD patients has been developed over the past two decades. The aim of this review was to provide an overview on these PROMs and to evaluate their measurement properties. 


\section{MATERIALS AND METHODS}

\section{Search strategy for identification of studies}

A structured literature search up to December 2016 was conducted using Pubmed, Medline, Embase and the Cochrane Library to identify all articles on the development or validation of PROMs measuring disease activity in IBD patients. Both MeSH subject headings and truncated text-words including "Inflammatory bowel disease", "Crohn's disease", "ulcerative colitis", "disease activity", "score, "questionnaire", "index", "measurement", "patient-reported outcome measure", "self-reported", and similar keywords were used.

\section{Criteria for study selection}

Two authors (MJdJ, RH) independently reviewed titles and abstracts from the search strategies and identified eligible studies. Full texts were obtained and reviewed when articles met all of following criteria: 1) English language, 2) published in an international peer-reviewed journal, 3) assessing adult or pediatric IBD patients (UC, CD or both), 4) reported on patient-reported questionnaires measuring disease activity, 5) contained data regarding diagnostic accuracy of the questionnaire compared to endoscopy, or to laboratory parameters such as CRP, FC or Erythrocyte Sedimentation Rate (ESR), or to clinician-reported disease activity questionnaires, such as the physician global assessment (PGA), Crohn's Disease Activity Index (CDAl), Harvey Bradshaw Index (HBI), Simple Clinical Colitis Activity Index (SCCAI), Pediatric Ulcerative Colitis Activity Index (PUCAI), or Mayo score (full Mayo score: stool frequency, rectal bleeding, endoscopic examination and PGA (12-item), partial Mayo score: stool frequency, rectal bleeding and PGA (9-item)). A third reviewer was consulted to reach consensus in case of disagreement.

\section{Data collection}

Two reviewers carried out the data extraction using a standardised data extraction form and discussed the content in case of disagreement. Characteristics of the PROMs noted included: study population, language, items being measured, administration mode (paper or digital), recall-period, scoring and cut-off values. The FDA has provided guidelines on how a PROM should be developed and which measurement properties should be evaluated $^{8}$. First, content validity which is defined as the extent to which an instrument measures the concept of interest. Second, construct validity which is determined by evidence that a relationship exists with another accepted measure of disease activity. Third, criterion validity which represents the extent to which a PROM is related to a generally accepted gold standard measure, which is endoscopy for IBD disease activity. In addition, when a PROM is developed for measurements over time, for example in clinical practice or clinical trials, its adequacy also depends on its reliability to yield consistent scores over time when no change is expected in disease activity. At last, the ability of a 
PROM to detect differences in scores over time (responsiveness) in individuals who have changes in disease activity is important ${ }^{8}$. The abovementioned measurement properties were extracted from the included articles.

The following interpretations of statistical measures used to compare (clinical, endoscopic or biochemical) disease activity scores were applied: correlational measures ( $\rho$ ) were interpreted as $0.10-0.29$ no/negligible correlation, $0.30-0.49$ low correlation, 0.50-0.69 moderate correlation, 0.70-0.89 high correlation and 0.90-1.00 very strong correlation. For Cohen's kappa (к) measure of agreement the following definitions were used: $<0.4$ poor, 0.4-0.6 fair/moderate, 0.6-0.8 substantial/good and 0.8-1.0 excellent. Area under the curve (AUC) values were considered as 0.5-0.7 representing poor, 0.7-0.9 moderate and $>0.9$ high accuracy. A sensitivity of $\geq 80 \%$ and a specificity of $\geq 80 \%$ were considered positive indicators of the respective measurement property.

\section{RESULTS}

\section{Study selection}

The search strategy resulted in a total of 973 hits. Details on the selection process can be found in the flow chart (figure 1). After removing duplicates and screening articles by title and abstract, 37 studies remained for full text assessment. Twenty articles were excluded for the following reasons: the reported instrument was not patient-reported ${ }^{10}$; the reported instrument did not assess disease activity ${ }^{6}$; the article did not provide measurement properties of the $\mathrm{PROM}^{4}$. Finally, 17 articles were included covering the following instruments: self-administered SCCAI ${ }^{9}, 6$-point Mayo score ${ }^{10,11}$, patientassessment of disease activity ${ }^{11}$, Manitoba inflammatory bowel disease index (MIBDI) ${ }^{12}$, survey-index CDAI (S-CDAI) ${ }^{13}$, patient-based PUCAI ${ }^{14}$, patients' global assessment ${ }^{15}$, patient-SCCAI (p-SCCAI) ${ }^{16}$, patient-HBI $(p-H B I)^{17}$, Numeric Rating Scale (NRS) ${ }^{18}$, mobile health index $(\mathrm{mHI})^{19}$, patient-reported outcome derived from the Mayo score $(\mathrm{PRO} 2)^{20}$, patient-reported outcome derived from the CDAI (PRO3) ${ }^{21}$, simple 0-10 numerical score $(\mathrm{IBD}-10)^{22}$, patient-reported $\mathrm{HBI}^{23}$, patient-reported $\mathrm{SCCAI^{23 }}$, digital self-administered $\mathrm{SCCAI} \mathrm{I}^{24,25}$, digital self-administered $\mathrm{HBI}^{25}$.

\section{Study characteristics}

An overview of the study characteristics, including the reasons for PROM development, is given in table 1. Included studies were conducted between 1999 and 2016 with study populations varying from 46 to 566 patients. Three studies included CD patients $^{13,17,21}$, eight included UC patients ${ }^{9-11,14-16,20,24}$ and six included both CD and UC patients $^{12,18,19,22,23,25}$. The majority of studies included only adult patients, whereas two included children in their studies ${ }^{14,15}$. 
Table 1. Study characteristics of included articles investigating measurement properties of PROMs for IBD disease activity assessment.

\begin{tabular}{|c|c|c|c|c|}
\hline Population & PROM & Aim of the study & $\mathbf{N}$ & Age (years, mean (SD)) \\
\hline \multirow{8}{*}{ 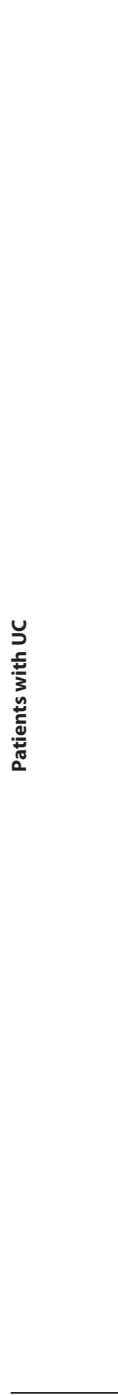 } & Self-administered SCCAI' & $\begin{array}{l}\text { To determine reliability and validity } \\
\text { of the SCCAI when self-administered. }\end{array}$ & $\begin{array}{l}\text { A: cross-sectional study } \\
-\mathrm{N}=63 \\
B: \text { longitudinal study } \\
-\mathrm{N}=191 \\
\text { C: segment of cohort A } \\
-\mathrm{N}=68\end{array}$ & $\begin{array}{l}\text { A: } 48(15.9) \\
\text { B: } 49(13.4) \\
\text { C: } 50(14.1)\end{array}$ \\
\hline & $\begin{array}{l}\text { 6-point Mayo score and } \\
\text { patients' assessment of } \\
\text { disease activity }^{2}\end{array}$ & $\begin{array}{l}\text { To investigate what amount of } \\
\text { change on the partial mayo score } \\
\text { reflects a clinical meaningful change } \\
\text { from the perception of the patient. }\end{array}$ & 105 & $\mathrm{~N} / \mathrm{A}$ \\
\hline & $\begin{array}{l}\text { Patients' global } \\
\text { assessment }^{15}\end{array}$ & $\begin{array}{l}\text { To clarify whether a patient- or } \\
\text { physician-based approach should be } \\
\text { preferred when measuring disease } \\
\text { activity in clinical studies. }\end{array}$ & $\begin{array}{l}\text { A: children } \\
\text { - } \mathrm{N}=94 \\
\text { B: adults } \\
-\mathrm{N}=86\end{array}$ & $\begin{array}{l}\text { A: } 11.8(4.1) \\
\text { B: } 37.6(13.7)\end{array}$ \\
\hline & Patient-based PUCAI ${ }^{14}$ & $\begin{array}{l}\text { To determine the extent of } \\
\text { agreement between patient- and } \\
\text { physician-completed PUCAI scores } \\
\text { and to validate these scores with } \\
\text { other markers of disease activity. }\end{array}$ & 70 & $14.3(4.6)$ \\
\hline & Patient-SCCAI ${ }^{16}$ & $\begin{array}{l}\text { To develop an easy to use patient- } \\
\text { based SCCAI questionnaire to } \\
\text { measure disease activity and to test } \\
\text { agreement between the patient- } \\
\text { SCCAI and the original clinician- } \\
\text { based SCCAI. }\end{array}$ & 149 & Median 48 (range 37-59) \\
\hline & 6-point Mayo score ${ }^{10}$ & $\begin{array}{l}\text { To assess the correlation of the } \\
6 \text {-point Mayo score with the SCCAI } \\
\text { and patient-defined disease activity } \\
\text { for use in clinical trials. }\end{array}$ & $\begin{array}{l}\text { A: initial cohort } \\
-\mathrm{N}=282 \\
\text { B: validation cohort } \\
-\mathrm{N}=59\end{array}$ & $\begin{array}{l}\text { A: } 47(16) \\
\text { B: } 39(14)\end{array}$ \\
\hline & $\begin{array}{l}\text { Patient-reported outcome } \\
\text { derived from the Mayo } \\
\text { score }(P R O 2)^{28}\end{array}$ & $\begin{array}{l}\text { To develop an interim PRO for } \\
\text { use in clinical trials in UC to allow } \\
\text { continuing evaluation of new } \\
\text { therapies. }\end{array}$ & $\begin{array}{l}\text { A: derivation cohort } \\
-N=194 \\
B: \text { validation cohort } \\
-N=181\end{array}$ & $\begin{array}{l}\text { A: } \\
\text { - Intervention: } 42.6(14.3) \\
\text { - Placebo: } 40.7 \text { (13.8) } \\
\text { B: } \\
\text { - Intervention 1: } 41.6(14.6) \\
\text { - Intervention 2: } 43.8(14.6) \\
\text { - Placebo: } 38.9(13.4)\end{array}$ \\
\hline & Self-administered SCCA ${ }^{24}$ & $\begin{array}{l}\text { To evaluate the diagnostic } \\
\text { performance of the SCCAI to assess } \\
\text { UC activity when self-administered } \\
\text { by the patient through a web } \\
\text { platform compared with in-clinic } \\
\text { assessment by the physician. }\end{array}$ & 199 & 38 \\
\hline \multirow{3}{*}{ 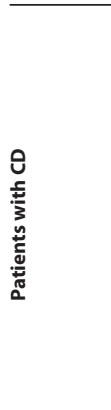 } & Survey-index $C D A I^{13}$ & $\begin{array}{l}\text { To develop a score that captures } \\
\text { disease activity in patients not } \\
\text { amenable to clinical assessment. }\end{array}$ & 106 & $35(\mathrm{~N} / \mathrm{A})$ \\
\hline & Patient-HBI ${ }^{17}$ & $\begin{array}{l}\text { To develop an easy and } \\
\text { undemanding patient-based } \\
\text { questionnaire to measure } C D \text { activity } \\
\text { and to test agreement between the } \\
\text { patient-HBI and the original clinician- } \\
\text { based } \mathrm{HBI} \text {. }\end{array}$ & 181 & Median 41 (range 30-52) \\
\hline & $\begin{array}{l}\text { Patient-reported outcome } \\
\text { derived from CDAI (PRO2 } \\
\text { and PRO3) }\end{array}$ & $\begin{array}{l}\text { To generate an interim measure } \\
\text { that can facilitate the continuing } \\
\text { evaluation of new medical therapies } \\
\text { until a new thoroughly developed } \\
\text { and validated PRO is available. }\end{array}$ & $\begin{array}{l}\text { A: development cohort } \\
-\mathrm{N}=402 \\
\text { B: validation cohort } \\
-\mathrm{N}=141\end{array}$ & $\begin{array}{l}\text { A: Placebo-med1-med2-med3 } \\
\text { (median age) } 37 \text { (18-72) - median } \\
\text { age } 32(18-66)-34(18-74) \text { - } 34 \\
(18-73) . \\
\text { B: } 36(11), 34(10)\end{array}$ \\
\hline
\end{tabular}




\begin{tabular}{|c|c|c|c|}
\hline Female (\%) & Disease duration (years, mean, (SD)) & Disease activity at baseline & Risk of bias assessment \\
\hline A: $51 \%$ & $A: N / A$ & A: 43 remission, 25 relapse $(11$ & - \\
\hline B: $49 \%$ & $B: N / A$ & mild, 11 moderate, 3 severe) & \\
\hline \multirow[t]{2}{*}{ C: $53 \%$} & $C: N / A$ & B: N/A & \\
\hline & & $C: N / A$ & \\
\hline \multirow[t]{2}{*}{ N/A } & N/A & $\begin{array}{l}\text { Mild to moderate defined as total } \\
\text { DAI score of 4-10: }\end{array}$ & $\begin{array}{l}\text { Selection bias: only patients with mild } \\
\text { to moderate disease activity at baseline } \\
\text { (active disease) were included }\end{array}$ \\
\hline & & Median baseline activity 7.0 & \\
\hline A: $54 \%$ & A: $1(0.1-2.9)$ & A: remission $32 \%$, mild $23 \%$, & - \\
\hline \multirow[t]{2}{*}{ B: $48 \%$} & B: $6.6(2.1-13.1)$ & moderate $31 \%$, severe $14 \%$ & \\
\hline & & $\begin{array}{l}\text { B: remission } 48 \% \text {, mild } 28 \% \text {, } \\
\text { moderate } 18 \% \text {, severe } 4 \%\end{array}$ & \\
\hline $46 \%$ & 26 months (N/A) & N/A & - \\
\hline \multirow[t]{2}{*}{$50.3 \%(n=75)$} & Median 12 (range 6-20 range) & $\begin{array}{l}\text { According to CRP: } 25 \text { active, } 49 \\
\text { remission }\end{array}$ & - \\
\hline & & $\begin{array}{l}\text { According to PGA: } 21 \text { active, } 25 \\
\text { remission }\end{array}$ & \\
\hline A: $59 \%$ & A: & Last active UC symptoms & - \\
\hline \multirow[t]{9}{*}{ B: $56 \%$} & $<1 \mathrm{yr}: 1$ & experienced & \\
\hline & $1-5 y r: 47$ & A: & \\
\hline & 5-10yr: 76 & -Within past 3 months: 98 & \\
\hline & $>10 y r: 152$ & $-3-6$ months ago: 27 & \\
\hline & B: & -6 months to $1 \mathrm{yr}$ ago: 30 & \\
\hline & $<1 \mathrm{yr}: 0$ & ->1yr ago: 113 & \\
\hline & $1-5 y r: 9$ & $B: N / A$ & \\
\hline & 5-10yr: 18 & & \\
\hline & $>10 y r: 32$ & & \\
\hline A: & A: & $100 \%$ of patients had mild to & Selection bias: only patients with mild \\
\hline - Intervention: $38.1 \%$ & - Intervention: $55.6 \pm 75.1$ months & moderately active disease (UCDAI & to moderate disease activity at baseline \\
\hline - Placebo: $42.5 \%$ & - Placebo: $52.8 \pm 76.4$ months & $4-10)$ & (active disease) were included \\
\hline B: & B: & & \\
\hline - Intervention 1: $43.1 \%$ & - Intervention 1: $78.0 \pm 84.9$ months & & \\
\hline - Intervention 2: 50\% & - Intervention 2:74.8 \pm 77.8 months & & \\
\hline - Placebo: $44.4 \%$ & - Placebo: $82.9 \pm 83.5$ months & & \\
\hline $56 \%$ & N/A & $63.8 \%$ remission & - \\
\hline
\end{tabular}

$\begin{array}{lll}61 \% & 9(3-15) & \text { N/A } \\ 62.4 \%(n=113) & \text { Median 12 (range 6-21) } & \text { N/A }\end{array}$

\begin{tabular}{|c|c|c|}
\hline $\begin{array}{l}\text { A: Placebo-med1-med2- N/ } \\
\text { med3 59\%-62\%-54\%- } \\
59 \%\end{array}$ & $\begin{array}{l}100 \% \text { of patients had mild } \\
\text { to moderately active disease } \\
(\text { CDAl } \geq 150))\end{array}$ & $\begin{array}{l}\text { Selection bias: only patients with mild } \\
\text { to moderate disease activity at baseline } \\
\text { (active disease) were included }\end{array}$ \\
\hline
\end{tabular}


Table 1. Study characteristics of included articles investigating measurement properties of PROMs for IBD disease activity assessment. (continued)

\begin{tabular}{|c|c|c|c|c|}
\hline Population & PROM & Aim of the study & $\mathbf{N}$ & Age (years, mean (SD)) \\
\hline \multirow{6}{*}{ 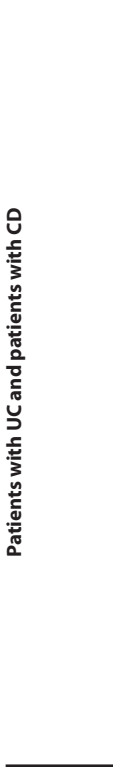 } & $\begin{array}{l}\text { Manitoba Inflammatory } \\
\text { Bowel Disease Index }\end{array}$ & $\begin{array}{l}\text { To propose a new self-report measure } \\
\text { of disease activity. }\end{array}$ & $353(\mathrm{CD} \mathrm{N}=184, \mathrm{UC} \mathrm{N}=169)$ & $41(14.5)$ \\
\hline & Numeric Rating Scale ${ }^{18}$ & $\begin{array}{l}\text { To assess the validity, reliability, and } \\
\text { responsiveness of the NRS compared } \\
\text { to disease activity indices, HRQOL } \\
\text { measurements, and inflammatory } \\
\text { markers. }\end{array}$ & $\begin{array}{l}\text { A: prospective study } \\
\text { - } N=46 \\
B: \text { retrospective study } \\
-N=216(C D N=135, \cup C N=81)\end{array}$ & $\begin{array}{l}\text { A: N/A } \\
\text { B: CD } 43(N / A), U C 46(N / A)\end{array}$ \\
\hline & Mobile Health Index ${ }^{19}$ & $\begin{array}{l}\text { To identify the most optimal PRO } \\
\text { score to use on an IBD disease- } \\
\text { monitoring app. }\end{array}$ & $\begin{array}{l}\text { A: development cohort } \\
-\mathrm{N}=219(\mathrm{CD} \mathrm{N}=110, \mathrm{UC} \mathrm{N}=109) \\
\mathrm{B}: \text { validation cohort } \\
-\mathrm{N}=566(\mathrm{CD} \mathrm{N}=301, \mathrm{UCN} \mathrm{N}=265)\end{array}$ & $\begin{array}{l}\text { Median age (range) } \\
\text { A: CD } 33(19-79), \text { UC } 35 \text { (18-81) } \\
\text { B: CD } 33(18-75), \text { UC } 42 \text { (18-86) }\end{array}$ \\
\hline & $I B D-10^{22}$ & $\begin{array}{l}\text { To assess the utility of a single-item } \\
\text { patient-reported global disease } \\
\text { control scale by comparing it to } \\
\text { conventional clinical indices of } \\
\text { disease activity. }\end{array}$ & $405(\mathrm{CD} \mathrm{N}=209, \mathrm{UC} \mathrm{N}=196)$ & 41 [IQR 27-55yr] \\
\hline & $\begin{array}{l}\text { Patient-reported } \mathrm{HBI} \text { en } \\
\mathrm{SCCA}^{23}\end{array}$ & $\begin{array}{l}\text { To better understand the relationship } \\
\text { between patient-reported clinical } \\
\text { disease activity indices and fecal } \\
\text { calprotectin as measures of } \\
\text { clinically active disease and mucosal } \\
\text { inflammation. }\end{array}$ & $356(C D N=191, \cup C N=165)$ & $\begin{array}{l}\text { CD: } 46.7(16.5) \\
\text { UC: } 51.2(16.3)\end{array}$ \\
\hline & $\begin{array}{l}\text { Self-administered SCCAI } \\
\text { and } \mathrm{HBl}^{25}\end{array}$ & $\begin{array}{l}\text { To compare a paper version of the } \\
\text { SCCAI and HBI with their digital } \\
\text { version with regard to total scores } \\
\text { and number of missing answers. }\end{array}$ & $128(\mathrm{CD} \mathrm{N}=74, \mathrm{UCN}=54)$ & $\begin{array}{l}\text { UC: median } 43 \text { ( range 19-74) } \\
\text { CD: median } 39 \text { (range 14-78) }\end{array}$ \\
\hline
\end{tabular}

CD, Crohn's Disease; CDAl, Crohn's Disease Activity Index; CRP, C-reactive protein; HBI, Harvey Bradshaw Index; N/A, not available; NRS, numeric rating scale; PGA, physician global assessment; PROM, patient-reported outcome measure, PUCAI, Pediatric Ulcerative Colitis Activity, SCCAI, Simple Clinical Colitis Activity Index; SD, standard deviation; UC, ulcerative colitis. 


\begin{tabular}{|c|c|c|c|}
\hline Female (\%) & Disease duration (years, mean, (SD)) & Disease activity at baseline & Risk of bias assessment \\
\hline $59 \%$ & $4.3(2.1)$ & $\mathrm{N} / \mathrm{A}$ & - \\
\hline$A: N / A$ & $A: N / A$ & N/A & - \\
\hline B: $55 \%$ & $\mathrm{~B}: \mathrm{CD} 13.5(\mathrm{~N} / \mathrm{A}), \mathrm{UC} 10.2(\mathrm{~N} / \mathrm{A})$ & & \\
\hline $\begin{array}{l}\text { A: } 48 \% \\
\text { B: } 51 \%\end{array}$ & $\begin{array}{l}\text { Median age (range) } \\
\text { A: CD } 8(0-46), \text { UC } 6(0-52) \\
\text { B: CD } 8(0-52), \text { UC } 7 \text { (0-59) }\end{array}$ & $\begin{array}{l}\text { Active disease defined as } \mathrm{HBI}>4 \\
\text { or Mayo }>2 \\
\text { A: CD } 30 \%, \text { UC } 37 \% \\
\text { B: CD } 27 \%, \text { UC } 31 \%\end{array}$ & - \\
\hline $54 \%$ & N/A & $\begin{array}{l}\text { Remission defined as } \mathrm{HBI} \leq 4 \text { : } \\
254(63 \%) \\
\text { Remission defined as } \\
\text { SCCAI } \leq 2: 149(37 \%)\end{array}$ & $\begin{array}{l}\text { The cut-off value for the IBD-10 was only } \\
\text { internally validated (in the same cohort) }\end{array}$ \\
\hline $\begin{array}{l}\text { CD: } 62.3 \% \\
\text { UC: } 53.9 \%\end{array}$ & N/A & $\begin{array}{l}\text { Active disease defined as fecal } \\
\text { calprotectin } \geq 250 \text { : } \\
\text { CD } 73(38.2), \text { UC } 65 \text { (39.4) }\end{array}$ & - \\
\hline UC: $48 \%$ CD: $53 \%$ & $\mathrm{~N} / \mathrm{A}$ & N/A & - \\
\hline
\end{tabular}




\section{Characteristics and measurement properties of PROMs}

\section{Characteristics of PROMs}

Characteristics of the included patient-reported questionnaires are demonstrated in supplementary table 1. Three categories of PROMs could be identified: those derived from existing clinical activity scores, i.e. the SCCAI $(n=5)$, the PUCAI $(n=1)$, and the HBI $(n=3)$, questionnaires using subcomponents of the Mayo Score $(n=3)$ and the CDAI $(n=2)$, and newly developed questionnaires $(n=6)$.

\section{Content validity}

Since the main purpose of a PROM is to capture patients' perspectives, the FDA recommends patient input during instrument development. Two articles reported on patients' experiences regarding the tested $\mathrm{PROM}^{9,18}$. However, only Bennebroek et al. documented qualitative patient interviews as part of the PROM development (table 2$)^{16,17}$.
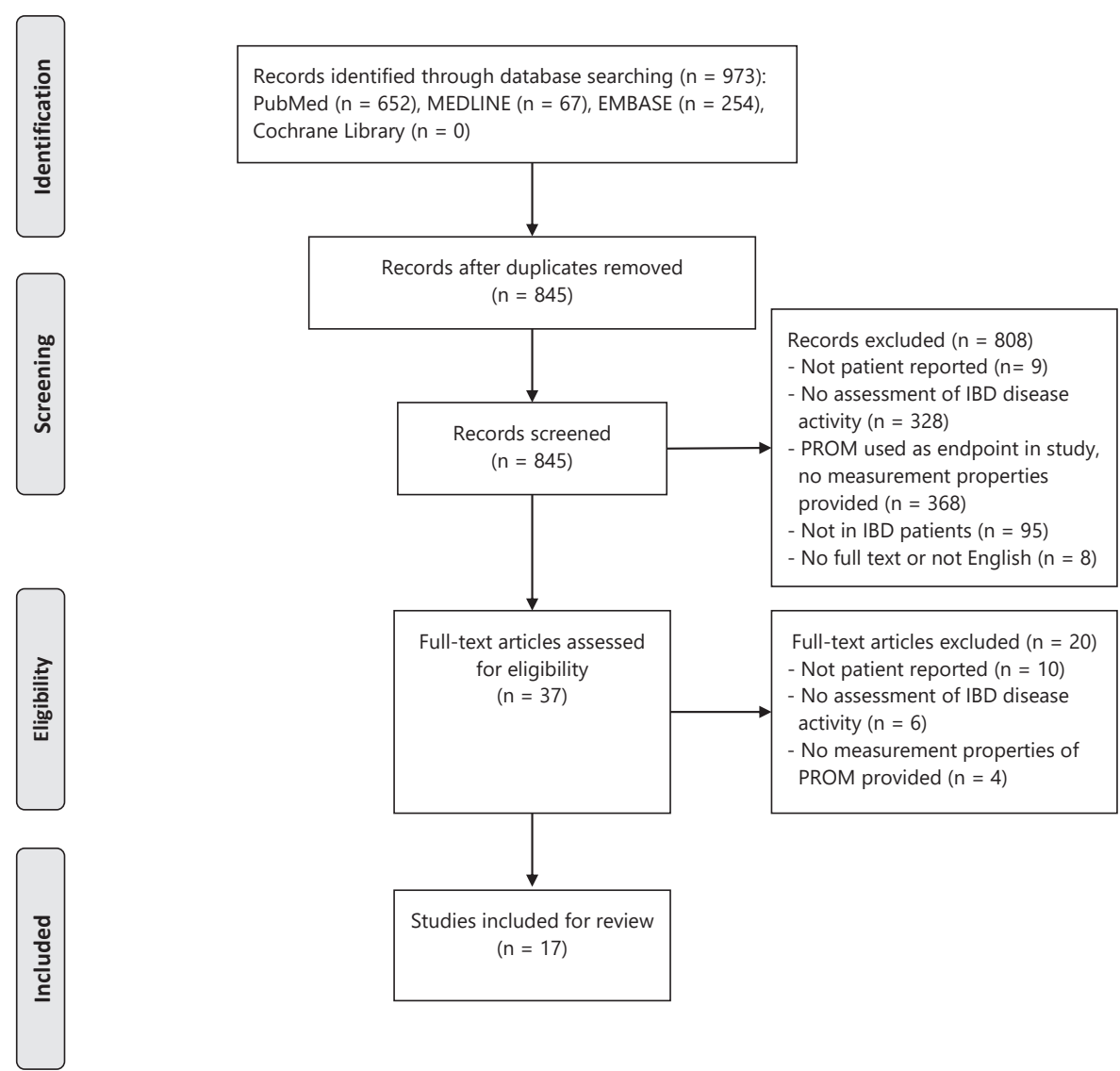

Studies included for review $(n=17)$

Figure 1. Flowchart illustrating published studies included in the systematic review. 


\section{Construct validity}

Seven articles investigated the correlation between clinician-reported indices and their patient-reported version (table 2). The SCCAI when self-administered by patients showed a high correlation and substantial to good agreement when compared to the clinicianreported version", ${ }^{9,16}$. The individual items "day-time frequency", "night-time frequency" and "blood in stool" showed better agreement than the items on "urgency", "well-being", and "extra-intestinal manifestations" ${ }^{\prime \prime}$. The self-administered SCCAI showed, however, a poor correlation with FC levels ${ }^{23}$. Patient-based and clinician-based $\mathrm{HBI}$-scores were also compared and showed a high correlation, but moderate agreement between the two questionnaires ${ }^{17}$. Additionally, the patient-reported $\mathrm{HBI}$ showed a poor correlation with FC levels (table 2). In children, Lee et al. found good agreement between the PUCAI when self-administered and when clinician-completed ${ }^{14}$. Compared to the physician's global assessment, the self-administered PUCAI showed moderate agreement ${ }^{14}$. Both patient- and clinician-completed PUCAI scores did correlate moderately with CRP and substantially with ESR (table 2$)^{14}$.

Two articles elaborated on the correlation between an online-administered questionnaire and a paper version (table 2). Both studies showed good agreement between the $\mathrm{HBI}$ and SCCAI filled out on paper and via a web tool ${ }^{24,25}$.

Five studies used subcomponents of a conventional clinical index to develop a new PROM. Three of these used the two patient-reported items from the Mayo score, i.e. stool frequency and rectal bleeding ${ }^{10,11,20}$. These items combined showed an AUC of 0.80 when compared with the endoscopic modified Baron score ${ }^{20}$, and strong correlations with the SCCAI ${ }^{10}$ and the full Mayo score ${ }^{11}$ (table 2). Two articles composed a new PROM using the items stool frequency, abdominal pain and general wellbeing from the CDAI ${ }^{13,21}$, showing moderate agreement and a relatively high correlation with the CDAI ${ }^{13,21}$ (table 2).

Six articles reported on the development and validation of a new PROM relative to conventional clinical indices and/or endoscopy (table 2) ${ }^{11,12,15,18,19,22}$. The MIBDI is a single-item self-reported question on symptom persistence in the previous 6 months. The MIBDI showed good sensitivity and modest specificity when compared with the $\mathrm{HBI}$ and the Powel Tuck Index ${ }^{12}$. Lewis et al. asked patients to grade their current disease activity on a 6-point Likert scale from minimal symptoms to severe symptoms and found a moderate to strong correlation compared to the full Mayo score ${ }^{11}$.

Three studies reported on a single-item numerical scale to capture disease activity for routine clinical use (table 2). The IBD-10, assessing "how would you rate your CD/UC today (on a scale of $0-10$ )" ${ }^{22}$, showed high correlation with the SCCAI and a moderate correlation with the HBI. Although a significant correlation was found between the IBD10 and CRP in UC patients, no correlation was observed between the IBD-10 and CRP in CD patients, nor with FC in both UC and CD patients ${ }^{22}$. The 11-point NRS, capturing patients' overall perception of health on a scale from 0 to 10 , showed a high correla- 
Table 2. Measurement properties of the included patient-reported questionnaires.

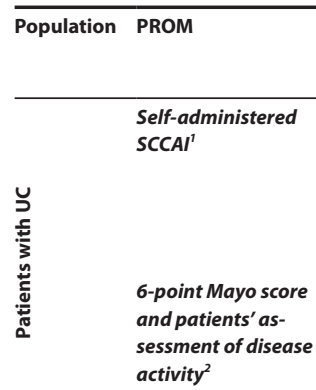

Patients' global assessment $^{15}$

Patient-based

PUCAI ${ }^{14}$

Patient-SCCAI ${ }^{16}$

6-point Mayo score ${ }^{10}$

Patient-reported

outcome derived

from the Mayo score

(PRO2) $^{20}$
Content validity

Construct validity

Criterion validity
N/A

ences regarding tested PROM clinicians considering relapse or remission of disease.

Correlation of self-administered SCCAI and Seo-index: $r=0.79, p<0.01$

N/A

N/A

Correlation of patients' global assessment using VAS scale compared to:

- PUCAI: $r=0.67$

- CRP: $r=0.34$

- Albumin: $r=-0.42$

- ESR: $r=0.39$

- Hb: $r=-0.24$

Agreement of self-administrated PUCAI

compared to:

- Clinician-completed PUCAI: $\mathrm{K}=0.78$

- Physician's global assessment: $\mathrm{k}=0.57$

Patient- and clinician completed PUCAI correlation with

- CRP: $r=0.50$

- ESR: $r=0.70$

Qualitative patient interviews: Self-administered SCCAI compared to quick to complete and ques- $\quad$ clinician-reported SCCAI: $r=0.79, \mathrm{k}=0.66$ tions clear

N/A

Correlation between patient-reported items of full Mayo score (stool frequency and rectal bleeding) and SCCAI: $r=0.71$

N/A

Self-administered N/A
SCCA ${ }^{24}$

Agreement online self-administered SCCA and physicians administered SCCAI: $r=0.79$ $-\mathrm{K}=0.66$ regarding remission/active disease - NPV $94.5 \%$

- PPV $68.0 \%$

Agreement between patient and physician after 3 months and 6 months: respectively $80.8 \%$ and $89.3 \%(p=0.027)$
Correlation between 6-point Mayo and full Mayo $r=0.88(p<0.0001)$

Patients' assessment of disease activity (6-point Likert scale from minimal to severe disease symptoms) compared to full Mayo score: $r=0.71$ $(\mathrm{p}<0.0001)$

Correlation with endoscopic inflammation (Beattie's grading system): $r=0.52$

- Full Mayo score: $r=0.70$

N/A

N/A

N/A

Patient-reported items of full Mayo score (stool frequency and rectal bleeding) showed an AUC of 0.80 compared with en doscopic modified Baron score and an $\mathrm{AUC}=0.80$ when compared to Mayo endoscopic subscore.

N/A 
Reliability

N/A

N/A

N/A

N/A

N/A

N/A
Ability to detect change

N/A

N/A

N/A

N/A

N/A

N/A

N/A
Ease of administration (number of items)

9 items, including extra-

intestinal manifestations

6-point Mayo: 2 items

Patients' assessment of disease activity: 1 item

1 item ment of disease activity: 4 Utility in clinical practice $^{\mathrm{a}}$ (max score: 8 ) 2 6-point Mayo: 4 6-point Mayo: 1

Patients' assessment of disease activity:1
Utility in clinical trials $^{\text {b }}$ (max score: 5 )

1


Table 2. Measurement properties of the included patient-reported questionnaires. (continued)

\begin{tabular}{|c|c|c|c|c|}
\hline Population & PROM & Content validity & Construct validity & Criterion validity \\
\hline \multirow{10}{*}{ 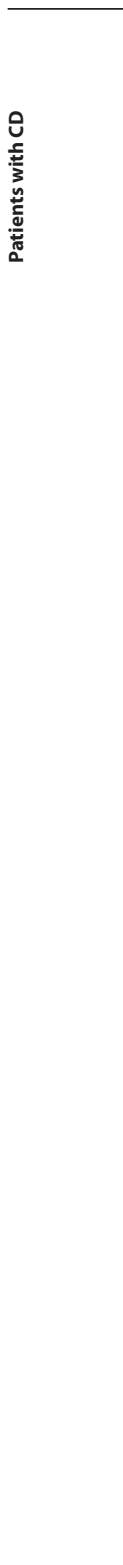 } & Survey-index $C D A I^{13}$ & $\mathrm{~N} / \mathrm{A}$ & $\begin{array}{l}\text { Agreement between survey-index CDAI (stool } \\
\text { frequency, abdominal pain, general wellbeing) } \\
\text { and CDAl: } \mathrm{k}=0.57\end{array}$ & $\mathrm{~N} / \mathrm{A}$ \\
\hline & Patient-HBI ${ }^{17}$ & $\begin{array}{l}\text { Qualitative patient interviews: } \\
\text { questions clear and easy to } \\
\text { complete }\end{array}$ & $\begin{array}{l}\text { Patient-based HBI compared to clinician-based } \\
\mathrm{HBI}: \mathrm{r}=0.82, \mathrm{~K}=0.52\end{array}$ & N/A \\
\hline & $\begin{array}{l}\text { Patient-reported } \\
\text { outcome derived } \\
\text { from } C D A I \text { (PRO2 and } \\
\text { PRO3) })^{21}\end{array}$ & $\mathrm{~N} / \mathrm{A}$ & $\begin{array}{l}\text { Correlation in case of } \mathrm{CDAl} \leq 150 \\
\text { PRO2: } r=0.76 \\
\text { PRO3: } r=0.89\end{array}$ & N/A \\
\hline & $\begin{array}{l}\text { Manitoba Inflamma- } \\
\text { tory Bowel Disease } \\
\text { Index }\end{array}$ & $\mathrm{N} / \mathrm{A}$ & $\begin{array}{l}\text { MIBDI compared after 0-12-24 months with } \\
\text { HBI: } \\
\text { Sensitivity: } 88 \%-85 \%-84 \% \\
\text { Specificity: } 51 \%-57 \%-66 \% \\
\text { Powel Tuck Index: } \\
\text { Sensitivity: } 84 \%-82 \%-66 \% \\
\text { Specificity: } 61 \%-68 \%-61 \%\end{array}$ & $\mathrm{~N} / \mathrm{A}$ \\
\hline & $\begin{array}{l}\text { Numeric Rating } \\
\text { Scale }^{18}\end{array}$ & N/A & $\begin{array}{l}\text { Correlation between NRS and: } \\
\text { - CDAl: } r=0.77 \\
\text { - HBI: } r=0.56 \\
\text { - SCCAI: } r=0.50 \\
\text { - CRP, ESR, } \\
\text { - FCP: no correlation }\end{array}$ & N/A \\
\hline & Mobile Health Index ${ }^{19}$ & $\mathrm{~N} / \mathrm{A}$ & $\begin{array}{l}\text { Correlation of } \mathrm{mHI}-\mathrm{CD} \text { with: } \\
\text { - CDAI: } \mathrm{r}=0.75, \mathrm{AUC}=0.95 \\
\text { - HBI: } \mathrm{r}=0.75, \mathrm{AUC}=0.90\end{array}$ & $\begin{array}{l}\text { Compared to SES-CD: } \\
- \text { CD: } A \cup C=0.63, r=0.30\end{array}$ \\
\hline & & & $\begin{array}{l}\text { Correlation of mHI-UC with: } \\
\text { - Partial Mayo score: } r=0.71, A U C=0.91\end{array}$ & $\begin{array}{l}\text { Compared to Mayo } \\
\text { endoscopic subscore: } \\
\text { - UC: } A U C=0.82, r=0.60\end{array}$ \\
\hline & $I B D-10^{22}$ & N/A & $\begin{array}{l}\text { Correlation of IBD-10 with: } \\
\text { - SCCAI: } r=-0.79 \\
\text { - HBI: } r=-0.69 \\
\text { Neither IBD-10 nor conventional clinical dis- } \\
\text { ease activity indices were able to discriminate } \\
\text { patients in remission as defined by FCP. }\end{array}$ & N/A \\
\hline & $\begin{array}{l}\text { Patient-reported HBI } \\
\text { en } S C C A I^{23}\end{array}$ & $\mathrm{~N} / \mathrm{A}$ & $\begin{array}{l}\text { Patient-reported } \mathrm{HBI} \geq 5 \text { compared to } \mathrm{FCP} \geq 250 \text { : } \\
\text { - Sensitivity: } 38.4 \% \\
\text { - Specificity: } 65.3 \% \\
\text { - PPV: } 40.6 \% \\
\text { - NPV: } 63.1 \%\end{array}$ & $\mathrm{~N} / \mathrm{A}$ \\
\hline & & & $\begin{array}{l}\text { Patient-reported SCCAl } \geq 5 \text { compared to } \\
\text { FCP } \geq 250 \\
\text { - Sensitivity: } 52.3 \% \\
\text { - Specificity: } 68.0 \% \\
\text { - PPV: } 51.5 \% \\
\text { - NPV: } 68.7 \%\end{array}$ & \\
\hline
\end{tabular}




\begin{tabular}{|c|c|c|c|c|}
\hline Reliability & Ability to detect change & $\begin{array}{l}\text { Ease of administration } \\
\text { (number of items) }\end{array}$ & $\begin{array}{l}\text { Utility in clinical } \\
\text { practice } \\
\text { (max score: 8) }\end{array}$ & $\begin{array}{l}\text { Utility in clinical } \\
\text { trials }^{\mathrm{b}} \\
\text { (max score: } 5 \text { ) }\end{array}$ \\
\hline $\begin{array}{l}\text { S-CDAl test-retest } \\
\text { reliability } \\
\text { after 2-6 weeks: } \\
\text { intraclass correlation } \\
\text { coefficient of } 0.81 .\end{array}$ & $\begin{array}{l}\text { Mean paired difference: } \\
\text { Unchanged health }(n=31):-23(95 \% \mathrm{Cl}-48,1) \\
\text { Improved health }(n=49):-88(95 \% \mathrm{Cl}-119,-56) \\
\text { Deterioration }(n=15): 22(95 \% \mathrm{Cl}-39,84)\end{array}$ & 3 items & 4 & 2 \\
\hline N/A & $\mathrm{N} / \mathrm{A}$ & $\begin{array}{l}\text { 9-items, including extra- } \\
\text { intestinal manifestations }\end{array}$ & 3 & 2 \\
\hline N/A & $\begin{array}{l}\text { PRO3 responsive to change with Guyatt } \\
\text { responsiveness statistics of } 0.49\end{array}$ & $\begin{array}{l}\text { PRO2: } 2 \text { item } \\
\text { PRO3: } 3 \text { item }\end{array}$ & $\begin{array}{l}\text { PRO2: } 3 \\
\text { PRO3: } 4\end{array}$ & $\begin{array}{l}\text { PRO2: } 1 \\
\text { PRO3: } 2\end{array}$ \\
\hline $\begin{array}{l}\text { MIBDI test-retest } \\
\text { reliability after } 1 \text { week: } \\
r=0.81(95 \% \mathrm{Cl} 0.76- \\
0.86), \mathrm{k}=0.76(95 \% \mathrm{Cl} \\
0.67-0.85)\end{array}$ & $\mathrm{N} / \mathrm{A}$ & 1 item & 3 & 2 \\
\hline N/A & $\begin{array}{l}\text { Responsiveness ( } n=10 \text { ) with mean between- } \\
\text { questionnaire time of } 108 \text { days (range } 24-243 \\
\text { days) } \\
\text { Changes in patient-reported NRS did not } \\
\text { correlate with changes in: } \\
\text { - CDAl: } r=0.20 \\
\text { - HBI: } r=0.33\end{array}$ & 1 item & 3 & 1 \\
\hline $\begin{array}{l}\text { Test-retest reliability } \\
\text { with a median time to } \\
\text { second questionnaire } \\
\text { of } 22 \text { hours: } \\
\mathrm{mHI}-\mathrm{UC} \text { and } \mathrm{mHI}-\mathrm{CD} \\
\text { intraclass correlation } \\
\text { coefficient of } 0.94\end{array}$ & $\begin{array}{l}\text { Significant difference in } \mathrm{mHl} \text {-score between } \\
\text { patients who clinically improved, remained } \\
\text { stable or worsened (UC: } p=0.0025 ; C D \text { : } \\
p=0.0030 \text { ) } \\
\text { Tested in } 50 \text { patients with median between- } \\
\text { questionnaire time of } 46 \text { days }\end{array}$ & $\begin{array}{l}\text { mHI-CD: } 4 \text { items } \\
\text { mHI-UC: } 4 \text { items }\end{array}$ & $\begin{array}{l}\text { mHI-CD: } 5 \\
\text { mHI-UC: } 6\end{array}$ & $\begin{array}{l}\text { mHI-CD: } 3 \\
\text { mHI-UC: } 4\end{array}$ \\
\hline N/A & N/A & 1 item & 3 & 1 \\
\hline \multirow[t]{2}{*}{ N/A } & $N / A$ & $\begin{array}{l}\text { Patient-reported HBI: } 7 \\
\text { items, including extra-intes- } \\
\text { tinal manifestations }\end{array}$ & $\begin{array}{l}\text { Patient-reported } \\
\text { HBI: } 1\end{array}$ & $\begin{array}{l}\text { Patient-reported } \\
\text { HBI: } 0\end{array}$ \\
\hline & & $\begin{array}{l}\text { Patient-reported SCCAI: } \\
9 \text { items, including extra- } \\
\text { intestinal manifestations }\end{array}$ & $\begin{array}{l}\text { Patient-reported } \\
\text { SCCAl: } 1\end{array}$ & $\begin{array}{l}\text { Patient-reported } \\
\text { SCCAI: } 0\end{array}$ \\
\hline
\end{tabular}


Table 2. Measurement properties of the included patient-reported questionnaires. (continued)

\begin{tabular}{|c|c|c|c|}
\hline Population & PROM & Content validity & Construct validity \\
\hline 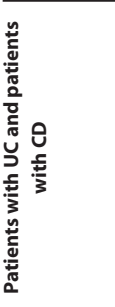 & $\begin{array}{l}\text { Self-administered } \\
\text { SCCAI and } H B T^{25}\end{array}$ & $\mathrm{~N} / \mathrm{A}$ & $\begin{array}{l}\text { Kappa-statistics of agreement online adminis- } \\
\text { tered and paper-based questionnaire (o other } \\
\text { conventional clinical activity indices) } \\
\text { HBI: } \\
\text { - Raw: } 65 \% \\
\text { - Weighted: } 97 \% \\
\text { SCCAl: } \\
\text { - Raw: } 78 \% \\
\text { - Weighted: } 98 \%\end{array}$ \\
\hline
\end{tabular}

AUC, area under the curve; CD, Crohn's disease; CDAl, Crohn's Disease Activity Index; $\mathrm{Cl}$, confidence interval; CRP, C-reactive protein; ESR, erythrocyte sedimentation rate; FCP, fecal calprotectin; $\mathrm{Hb}$, hemoglobin; $\mathrm{HBI}$, Harvey Bradshaw Index, IBD, inflammatory bowel disease; $\mathrm{mHI}$, Mobile Health Index; ICC, intra class correlation coefficient; MIBDI, Manitoba Inflammatory Bowel Disease Index; N/A, not available; NPV, negative predictive value; NRS, Numeric Rating Scale; PPV, positive predictive value; PROM, patient-reported outcome measure; PUCAI, Pediatric Ulcerative Colitis Activity Index; SCCAI, Simple Clinical Colitis Activity Index; SESCD, Simple Endoscopic Score for CD; UC, ulcerative colitis; VAS, visual analog scale.

a Indication for utility in clinical practice, judged on content validity (patient interviews $=1$ ), construct validity $(\rho \geq 0.70 / k \geq 0.60 / A \cup C \geq 0.70 /$ sens $\geq 80 \% /$ spec $\geq 80 \%=1)$, criterion validity $(\rho \geq 0.70 / k \geq 0.60 / A U C \geq 0.70 /$ sens $\geq 80 \% /$ spec $\geq 80 \%=2)$, reliability $(\rho \geq 0.70 / k \geq 0.60 / I C C>0.80=1)$, responsiveness $(\rho \geq 0.70 / k \geq 0.60 /$ other measures of responsiveness $=1$ ), ease of administration ( $\leq 5$ items/no questions on extra-intestinal manifestations $=1$ ), recall period $(\leq 1$ week $=1$ ).

${ }^{\mathrm{b}}$ Indication for utility in clinical trials, judged on FDA criteria (i.e. content validity (patient interviews $=1$ ), construct validity $(\rho \geq 0.70 / K \geq 0.60 / A U C \geq 0.70 /$ sens $\geq 80 \% /$ spec $\geq 80 \%=1)$, criterion validity $(\rho \geq 0.70 / K \geq 0.60 /$ AUC $\geq 0.70 /$ sens $\geq 80 \% /$ spec $\geq 80 \%=1)$, reliability $(\rho \geq 0.70 / K \geq 0.60 / I C C>0.80=1)$, responsiveness $(\rho \geq 0.70$ / $\mathrm{k} \geq 0.60$ /other measures of responsiveness $=1$ )). 


\begin{tabular}{|c|c|c|c|c|}
\hline Reliability & Ability to detect change & $\begin{array}{l}\text { Ease of administration } \\
\text { (number of items) }\end{array}$ & $\begin{array}{l}\text { Utility in clinical } \\
\text { practice }^{a} \\
\text { (max score: } 8 \text { ) }\end{array}$ & $\begin{array}{l}\text { Utility in clinical } \\
\text { trials }^{\text {b }} \\
\text { (max score: } 5 \text { ) }\end{array}$ \\
\hline \multirow[t]{2}{*}{ N/A } & $\mathrm{N} / \mathrm{A}$ & $\begin{array}{l}\text { Patient-reported HBI: } 7 \\
\text { items }\end{array}$ & $\begin{array}{l}\text { Patient-reported } \\
\mathrm{HBI}: 2\end{array}$ & $\begin{array}{l}\text { Patient-reported } \\
\mathrm{HBI}: 1\end{array}$ \\
\hline & & $\begin{array}{l}\text { Patient-reported SCCAI: } \\
9 \text { items }\end{array}$ & $\begin{array}{l}\text { Patient-reported } \\
\text { SCCAI: } 2\end{array}$ & $\begin{array}{l}\text { Patient-reported } \\
\text { SCCAI: } 1\end{array}$ \\
\hline
\end{tabular}

tion with the CDAl, moderate correlation with the $\mathrm{HBI}$ and no correlation with CRP, ESR and $\mathrm{FC}^{18}$. The latter study also tested a single-item self-reported question (yes/no) on remission of the disease and found a correlation with the CDAI and $\mathrm{HBI}$, but not with $\mathrm{CRP}^{18}$. A third study reported on a single-item question about patient-reported disease activity during the previous 2 days on a VAS-scale ${ }^{15}$. This "patient global assessment" was compared to the full mayo score, the PUCAI score, CRP, albumin, ESR and hemoglobin, showing correlation coefficients of $0.70,0.67,0.34,-0.42,0.39$, and -0.24 , respectively ${ }^{15}$.

Van Deen et al. developed and validated a PROM to monitor disease activity for use in mobile technologies (table 2). The $\mathrm{mHI}$ showed high correlation and high accuracy compared with the CDAI and the HBI for CD patients. Also for UC patients, the $\mathrm{mHI}$ showed high correlation and high accuracy compared to the partial Mayo score ${ }^{19}$.

\section{Criterion validity}

Only four articles reported on validation relative to endoscopic disease activity (table 2). The patient global assessment showed a moderate correlation with endoscopic inflammation scored with Beattie's grading system ${ }^{15}$. The single-item "patient assessment of disease activity" and the 6-point Mayo score showed high correlation with the full Mayo score ${ }^{11}$. Jairath et al. reported an AUC of 0.80 for the two-item (PRO2) Mayo score compared to the Mayo endoscopic subscore ${ }^{20}$. The $\mathrm{mHI}$-UC showed moderate accuracy in detecting mucosal inflammation compared to the Mayo endoscopic subscore, while the $\mathrm{mHI}-\mathrm{CD}$ showed poor accuracy identifying patients with active disease compared to the simple endoscopic score for CD (SES-CD) ${ }^{19}$.

\section{Reliability}

Three articles investigated this test-retest reliability (table 2). The MIBDI showed strong test-retest reliability when the question was re-administered after 1 week, with high correlation between the two MIBDI scores and good agreement for active versus inactive categorization at the two measurement occasions ${ }^{12}$. The S-CDAI was reliable when readministered after 2-6 weeks as shown by an intraclass correlation coefficient of $0.81^{13}$. 
For both the $\mathrm{mHI}-\mathrm{UC}$ and $\mathrm{mHI-CD}$, the intraclass correlation coefficient was 0.94 with a median time to second questionnaire of 22 hours $^{19}$.

\section{Responsiveness}

Ability to detect changes in disease activity (responsiveness) was tested in five studies (table 2). Timmer et al. reported good ability to detect change for the S-CDAI as the mean paired difference was different for patients whose disease activity improved or deteriorated; effect size statistics were not applied ${ }^{13}$. Surti et al. tested responsiveness of the NRS in 10 patients with a mean between-questionnaire time of 108 days. Changes in NRS did not correlate with changes in CDAI and $\mathrm{HBI}{ }^{18}$. Van Deen et al. assessed sensitivity to detect change in a subset of 50 patients with a median between-questionnaire time of 46 days and found a significant difference in $\mathrm{mHI}$-score between patients who clinically improved, remained stable or worsened ${ }^{19}$. Khanna et al. found their PRO3 derived from the CDAl to be responsive to change ${ }^{21}$. Marín-Jiménez et al. tested the responsiveness of online-administered SCCAI at 3 and at 6 months. The percentage of agreement with the physicians' assessment of disease activity measured with the SCCAI was $82.6 \%$ with a moderate correlation between the two questionnaires ${ }^{26}$.

\section{DISCUSSION}

In addition to the increasing focus on patient-centered care, tight monitoring of IBD disease activity is advocated to improve long-term disease outcome. This systematic review provides an overview on the current available patient-reported outcome measures for measurement of IBD disease activity based on their measurement properties. A wide variety of PROMs has been developed, but none of these meet all the criteria for PROM-development as recommended by the FDA ${ }^{8}$.

The adequacy and accuracy of a PROM extensively depend on its content- and on its criterion validity. As a PROM is aimed at the reflection of what is important to patients, evaluation of the completeness of item coverage, but also of its comprehensiveness, clarity and readability is crucial. Asking patients about their general well-being, for example, might be too susceptible for different interpretations for reliable assessment of IBD disease activity ${ }^{8}$. Patients might also experience difficulties in understanding of extra-intestinal manifestations, in interpretation of liquid or loose stools since they lack standardisation, and in examination of the presence of an abdominal mass. Furthermore, pain measurement on a four-point scale, for example, might be less suitable than on a visual analog scale, since response options need to offer a clear distinction between choices and should measure relevant nuances. The input of patients is especially important when PROMs are used to "value" health systems or interventions. However, patient 
input during development was only carried out in two articles (patient-HBI and patientSCCAI $)^{16,17}$. In addition, four of the reviewed PROMs comprise of one single question on current disease activity. As IBD disease activity is thought to manifest with a wide variety of symptoms, it could be discussed if a PROM consisting of one single global question captures all aspects of the complex process of disease activity. However, these singleitems PROMs show comparable accuracy relative to the conventional clinical indices as the multi-item PROMs.

For a PROM measuring disease activity, validation relative to the golden standard, which is endoscopy for IBD activity, is important. Only six PROMs were validated relative to endoscopy and showed moderate accuracy for detection of mucosal inflammation in UC patients and low accuracy in CD patients (patients' global assessment, patient assessment of disease-activity, $\mathrm{mHI}-\mathrm{CD}, \mathrm{mHI}-\mathrm{UC}, \mathrm{PRO} 2$ and 6-point Mayo score) ${ }^{11,15,19,20}$. Due to the fact that the development and validation of a new comprehensive PROM might take several years, many PROMs were derived or modified from existing clinical activity scores and validated relative to the original scores, and not to endoscopy. The mHI-UC and $\mathrm{mHI}-\mathrm{CD}$ were newly developed based on correlation coefficients between individual questions from different available clinical activity scores with the partial Mayo score and $\mathrm{HBI}$ respectively. The likelihood of establishing a PROM which reflects mucosal inflammation with a high accuracy may however increase when the selection of individual questions is driven by the correlation of these questions with endoscopic findings. For UC, for instance, rectal bleeding and to a lesser extent stool frequency were found to be essential in a UC-PROM ${ }^{20,27}$. Nevertheless, it remains challenging to develop an accurate PROM as $20 \%$ of UC patients in clinical remission still have endoscopic disease activity, whereas endoscopic healing is not always accompanied by normalisation of stool frequency ${ }^{28,29}$. For CD patients, even up to $50 \%$ of patients in clinical remission still have mucosal inflammation ${ }^{30}$.

The best patient-reported disease activity measure for a given situation may depend on research or clinical goals. For serial monitoring of disease activity in the context of tight control, high accuracy of a PROM compared to endoscopy is crucial. Specifically, such a disease activity index should have a high sensitivity, even if at the cost of falsepositive results. In addition, ease of administration, a short recall period, and a good reliability and responsiveness to changes in disease activity are important for use in clinical practice. In this regard, the $\mathrm{mHI}$-UC shows adequate measurement properties for assessing disease activity in UC patients ${ }^{19,20}$. For CD patients, no PROM which accurately reflects endoscopic disease activity is available. For registration of a patients' perspective on disease activity at fixed time-points or over a certain period, use of the single-item Manitoba IBD Index, asking patients about their disease activity over the past 6 months, could be convenient. In clinical trials, on the other hand, a PROM which 
is consistent with guidance from the FDA might be first choice. However, none of the reviewed PROMs meet all the FDA criteria.

In this review we provided an overview of the available PROMs for IBD disease activity assessment. None of the available PROMs meet all the criteria for PROM-development as recommended by the FDA. For the majority of PROMs, information on their correlation with endoscopy is lacking and their utility to predict mucosal inflammation remains therefore unclear. The few articles that reported on criterion validity showed low to moderate accuracy in identifying IBD patients at risk for active disease. In addition, only a minority of PROMs reported patient-input during its development which is crucial as PROMs are aimed at capturing patients' perspectives. With an increasing demand for use of PROMs in routine practice, clinical trials, telemedicine systems and value-based healthcare programs, there is an urgent need on data regarding the content and criterion validity of the available PROMs. 


\section{REFERENCES}

1. Burisch J, Munkholm P. The epidemiology of inflammatory bowel disease. Scand J Gastroenterol. 2015;50(8):942-51.

2. Colombel JF, Narula N, Peyrin-Biroulet L. Management Strategies to Improve Outcomes of Patients With Inflammatory Bowel Diseases. Gastroenterology. 2016.

3. Molodecky NA, Soon IS, Rabi DM, et al. Increasing incidence and prevalence of the inflammatory bowel diseases with time, based on systematic review. Gastroenterology. 2012;142(1):46-54 e42; quiz e30.

4. Jackson BD, Gray K, Knowles SR, et al. EHealth Technologies in Inflammatory Bowel Disease: A Systematic Review. Journal of Crohn's \& colitis. 2016.

5. Bradley SM, Rumsfeld JS, Ho PM. Incorporating Health Status in Routine Care to Improve Health Care Value: The VA Patient Reported Health Status Assessment (PROST) System. Jama. 2016;316(5):487-8.

6. van Deen WK, Esrailian E, Hommes DW. Value-based health care for inflammatory bowel diseases. Journal of Crohn's \& colitis. 2015;9(5):421-7.

7. Williet N, Sandborn WJ, Peyrin-Biroulet L. Patient-reported outcomes as primary end points in clinical trials of inflammatory bowel disease. Clinical gastroenterology and hepatology : the official clinical practice journal of the American Gastroenterological Association. 2014;12(8):1246-56 e6.

8. US Food and Drug Administration (FDA). Department of Health and Human Services (US) FDA CfDEaRC. Guidance for Industry. Patient-Reported Outcome Measures: Use in Medical Product Development to Support Labeling Claims. December 2009.

9. Jowett SL, Seal CJ, Phillips E, et al. Defining relapse of ulcerative colitis using a symptom-based activity index. Scand J Gastroenterol. 2003;38(2):164-71.

10. Bewtra M, Brensinger CM, Tomov VT, et al. An optimized patient-reported ulcerative colitis disease activity measure derived from the Mayo score and the simple clinical colitis activity index. Inflamm Bowel Dis. 2014;20(6):1070-8.

11. Lewis JD, Chuai S, Nessel L, et al. Use of the noninvasive components of the Mayo score to assess clinical response in ulcerative colitis. Inflamm Bowel Dis. 2008;14(12):1660-6.

12. Clara I, Lix LM, Walker JR, et al. The Manitoba IBD Index: evidence for a new and simple indicator of IBD activity. The American journal of gastroenterology. 2009;104(7):1754-63.

13. Timmer A, Kemptner D, Takses A, et al. A survey-based index was validated for measuring disease activity in inflammatory bowel disease. An evaluation study. Journal of clinical epidemiology. 2009;62(7):771-8.

14. Lee JJ, Colman RJ, Mitchell PD, et al. Agreement between patient- and physician-completed Pediatric Ulcerative Colitis Activity Index scores. Journal of pediatric gastroenterology and nutrition. 2011;52(6):708-13.

15. Turner D, Griffiths AM, Mack D, et al. Assessing disease activity in ulcerative colitis: patients or their physicians? Inflammatory bowel diseases. 2010;16(4):651-6.

16. Bennebroek Evertsz F, Nieuwkerk PT, Stokkers $\mathrm{PC}$, et al. The patient simple clinical colitis activity index (P-SCCAI) can detect ulcerative colitis (UC) disease activity in remission: a comparison of the P-SCCAI with clinician-based SCCAI and biological markers. Journal of Crohn's \& colitis. 2013;7(11):890-900.

17. Bennebroek Evertsz F, Hoeks CC, Nieuwkerk PT, et al. Development of the patient Harvey Bradshaw index and a comparison with a clinician-based Harvey Bradshaw index assessment of Crohn's disease activity. J Clin Gastroenterol. 2013;47(10):850-6.

18. Surti B, Spiegel B, Ippoliti A, et al. Assessing health status in inflammatory bowel 
disease using a novel single-item numeric rating scale. Digestive diseases and sciences. 2013;58(5):1313-21.

19. Van Deen $W K$, van der Meulen-de Jong $A E$, Parekh NK, et al. Development and Validation of an Inflammatory Bowel Diseases Monitoring Index for Use With Mobile Health Technologies. Clinical gastroenterology and hepatology : the official clinical practice journal of the American Gastroenterological Association. 2016;14(12):174250 e7.

20. Jairath V, Khanna R, Zou GY, et al. Development of interim patient-reported outcome measures for the assessment of ulcerative colitis disease activity in clinical trials. Alimentary pharmacology \& therapeutics. 2015;42(10):1200-10.

21. Khanna R, Zou G, D'Haens G, et al. A retrospective analysis: the development of patient reported outcome measures for the assessment of Crohn's disease activity. Alimentary pharmacology \& therapeutics. 2015;41(1):77-86.

22. Subramanian $\mathrm{S}$, Asher R, Weston W, et al. Validation of a Simple 0 to 10 Numerical Score (IBD-10) of Patient-reported Inflammatory Bowel Disease Activity for Routine Clinical Use. Inflamm Bowel Dis. 2016;22(8):1902-7.

23. Gracie DJ, Williams CJ, Sood R, et al. Poor Correlation Between Clinical Disease Activity and Mucosal Inflammation, and the Role of Psychological Comorbidity, in Inflammatory Bowel Disease. The American journal of gastroenterology. 2016;111(4):541-51.
24. Marin-Jimenez I, Nos P, Domenech E, et al. Diagnostic Performance of the Simple Clinical Colitis Activity Index Self-Administered Online at Home by Patients With Ulcerative Colitis: CRONICA-UC Study. The American journal of gastroenterology. 2016;111(2):261-8.

25. Larsen L, Drewes AM, Fallingborg J, et al. Touch screens as a tool in patient care in the IBD outpatient clinic. Scandinavian journal of gastroenterology. 2016;51(9):1 106-10.

26. Marin-Jimenez I, Nos P, Domenech E, et al. Corrigendum: Diagnostic Performance of the Simple Clinical Colitis Activity Index Self-Administered Online at Home by $\mathrm{Pa}$ tients With Ulcerative Colitis: CRONICA-UC Study. The American journal of gastroenterology. 2016;111(6):912.

27. Colombel JF, Keir ME, Scherl A, et al. Discrepancies between patient-reported outcomes, and endoscopic and histological appearance in UC. Gut. 2016.

28. Baars JE, Nuij VJ, Oldenburg B, et al. Majority of patients with inflammatory bowel disease in clinical remission have mucosal inflammation. Inflamm Bowel Dis. 2012;18(9):1634-40.

29. Jharap B, Sandborn WJ, Reinisch W, et al. Randomised clinical study: discrepancies between patient-reported outcomes and endoscopic appearance in moderate to severe ulcerative colitis. Alimentary pharmacology \& therapeutics. 2015;42(9):1082-92.

30. Peyrin-Biroulet L, Reinisch W, Colombel JF, et al. Clinical disease activity, C-reactive protein normalisation and mucosal healing in Crohn's disease in the SONIC trial. Gut. 2014;63(1):88-95. 


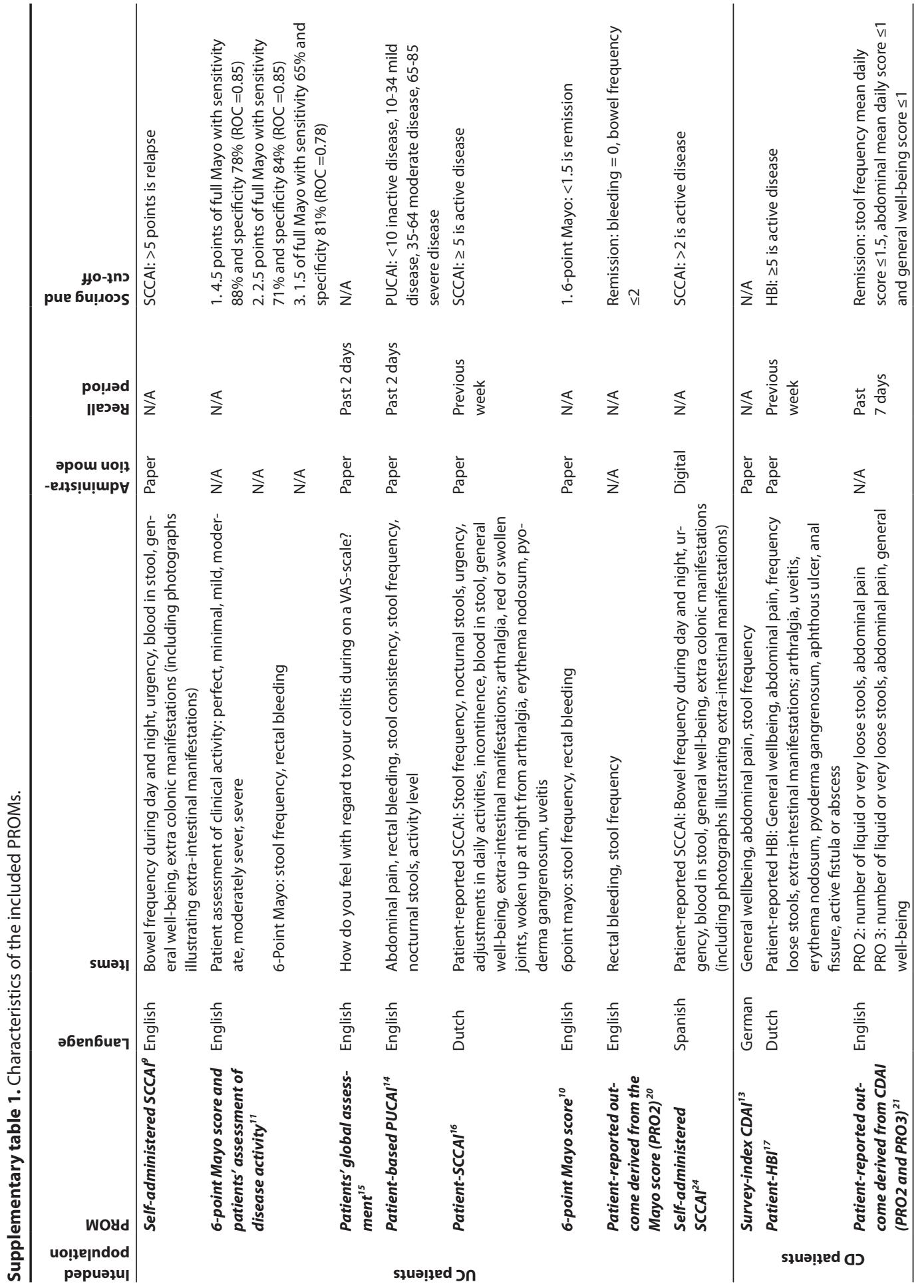




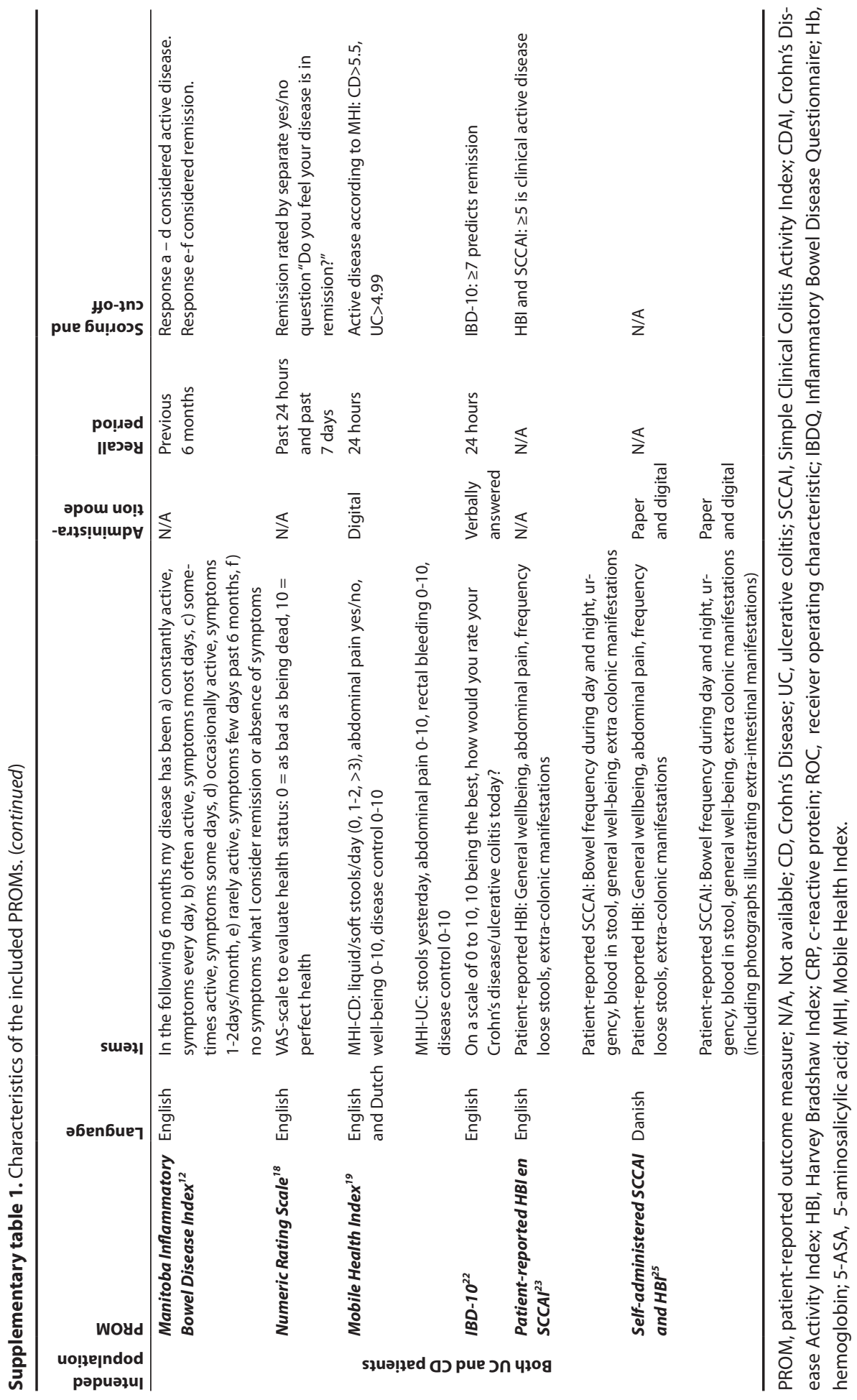






\section{Chapter 3}

Development and validation of a patientreported score to screen for mucosal inflammation in inflammatory bowel disease

Marin de Jong, Danielle Roosen, Juliette Degens, Tim van den Heuvel, Marielle Romberg - Camps, Wim Hameeteman, Alexander Bodelier, Igor Romanko, Milan Lukas, Bjorn Winkens, Tineke Markus, Ad Masclee, Astrid van Tubergen, Daisy Jonkers, Marieke Pierik 


\section{ABSTRACT}

Background: Patient-reported outcome measures (PROMs) assessing inflammatory bowel disease (IBD) activity are of interest for monitoring in clinical practice, telemedicine systems or trials. Different PROMs for follow-up of disease activity are available; however, none was developed with endoscopy as golden standard. The objective of this study was to develop and validate a PROM to predict endoscopic disease activity following the recommendations of the Food and Drug Administration.

Methods: During development, 178 IBD patients undergoing a colonoscopy were asked to fill out 13 clinical questions derived from the literature. During endoscopy, inflammation was assessed with the simplified endoscopic score for Crohn's disease (CD) and the Mayo endoscopic subscore for ulcerative colitis (UC). Based on correlation with endoscopic inflammation, questions were reduced to a total of 6 for $C D$ and 5 for UC. The newly developed Monitor IBD At Home questionnaire (MIAH) was validated in an independent cohort of 135 CD and 131 UC patients. Additionally, diagnostic accuracy of the MIAH combined with a fecal calprotectin home-test was assessed.

Results: The MIAH-CD includes questions on rectal bleeding, mucus, stool frequency, urgency, fatigue and patient-reported disease activity. The MIAH-UC contains items on rectal bleeding, stool frequency, urgency, abdominal pain and patient-reported disease activity. Both questionnaires showed to be valid, reliable, and responsive to changes. The MIAH and fecal calprotectin home-test combined had a sensitivity, specificity, NPV and PPV of $96.7 \%, 66.7 \%, 94.7 \%$, and $76.3 \%$ for CD and of $88.2 \%, 81.4 \%, 95.6 \%, 60.0 \%$ for UC, compared to endoscopy.

Conclusion: The MIAH is the first PROM developed to predict endoscopic inflammation in IBD patients. A combination of this questionnaire and a fecal calprotectin home-test shows excellent diagnostic accuracy to screen for patients who need further assessment of disease activity and can be used in daily practice, telemedicine systems and trials. 


\section{INTRODUCTION}

Inflammatory bowel diseases (IBD), which include Crohn's disease (CD) and ulcerative colitis (UC), are chronic relapsing inflammatory diseases of the gastrointestinal tract. They vary widely among individuals with regard to the clinical presentation, disease location and behaviour, frequency of relapses, and occurrence of extra-intestinal manifestations ${ }^{1}$. Over the past years, strategies for management of IBD have shifted from mere management of symptoms towards tight control of mucosal inflammation and personalised monitoring to improve long-term outcomes and quality of life $\mathrm{e}^{2-6}$.

Close disease monitoring is challenging in a traditional healthcare setting with limited medical and financial resources and more so since the incidence of IBD is increasing ${ }^{7,8}$. Patient-reported outcome measures (PROMs) used for symptom management, for instance incorporated in telemedicine systems, assist healthcare professionals to implement such a tight control strategy in IBD patients. In addition, use of PROMs is increasingly advocated as a means of supporting patient-centered care, in outcome measurement and in quality improvement ${ }^{9,10}$.

In the context of tight control, PROMs monitoring IBD activity should accurately reflect mucosal inflammation. Different PROMs have been developed for follow-up of disease activity in clinical trials and clinical practice, such as the Manitoba IBD Index ${ }^{11}$, the singleitem numeric rating scale ${ }^{12}$, the simple $0-10$ numerical score ${ }^{13}$, the mHealth index ${ }^{14}$ and questionnaires derived from the Harvey Bradshaw Index $(\mathrm{HBI})^{15-17}$, the Simple Clinical Colitis Activity Index (SCCAI) ${ }^{16-20}$, the Crohn's Disease Activity Index (CDAI) $)^{21,22}$ and the Mayo Clinic Score (MCS) $)^{23-25}$.

In order to develop an accurate PROM, content validity, construct validity, criterion validity, reliability and the ability to detect changes over time should be addressed, according to recommendations of the Food and Drug Administration (FDA) ${ }^{26,27}$. However, the PROMs developed to assess disease activity in IBD were generally not developed according these recommendations. Especially use of endoscopy as gold standard was lacking.

Therefore, we aimed to develop a new PROM for remote monitoring following the recommendations for PROM development from the FDA ${ }^{26}$ and validate this PROM relative to endoscopy.

\section{METHODS}

\section{Design}

This prospective, observational study was designed in three phases: a development and a validation phase of a new PROM, the Monitor IBD At Home (MIAH) questionnaire, and 
a third phase in which the MIAH was tested in combination with a fecal calprotectin (FC) home-test, together referred to as the MIAH score.

\section{Development phase}

To develop a new PROM for mucosal inflammation in CD and UC, all questions from available patient-reported disease activity scores were collected from the literature ${ }^{28}$. Of these, thirteen patient-reported questions regarding disease activity in IBD were selected by an expert panel (MP, WH, MR, AB) (supplementary table 1 and 2). Questions on extra-intestinal manifestations were excluded and in case of overlapping questions, the question with the clearest wording was selected. Between March 2013 and July 2014, consecutive IBD patients with a scheduled routine endoscopy at Maastricht University Medical Center+ (MUMC+), were invited to fill out this 13-item questionnaire before start of bowel cleansing. Patients with a medical history of extensive bowel surgery as an ileostomy, colostomy, ileoanal pouch anastomosis or ileorectal anastomosis were excluded as they require separate scoring. During endoscopy, mucosal inflammation was assessed by a trained endoscopist with the simplified endoscopic score (SES-CD) for CD or the Mayo endoscopic subscore (MES) for UC. An independent blinded gastroenterologist (MP) reviewed all endoscopic reports and images and video material if available. In case of disagreement, the independent gastroenterologist and endoscopist discussed the findings to reach consensus.

Spearman correlation coefficients were calculated between each of the 13 individual items and endoscopic disease activity. Based on these correlations and supported by expert opinion, a selection of best correlating items without overlap between the items was made and combined into four domains. We then performed a multivariable logistic regression analysis, using the items within one domain as independent variables and endoscopic disease activity as dependent variable, to form a scoring algorithm within each domain. The intra-domain weight factor (table 2) was then set equal to the regression coefficient of that item divided by the sum of the regression coefficients of the items to make sure that the weight factors within a domain add up to 1. As a next step, multivariable logistic regression, using the four domains as independent variables and endoscopic disease activity as dependent variable, was performed. Receiver-operator characteristics (ROC) curves were used to determine the best cut-off value for the predicted probability of having endoscopic disease activity. Because the main aim was to identify patients at risk for active disease, we defined the optimal cut-off for disease activity as the one with the highest specificity of those with a sensitivity of at least $85 \%$ and negative predicted value (NPV) of at least 95\%. A scoring algorithm was formed using the regression coefficients of independent predictors in the multivariable model.

After selection of relevant questions, qualitative cognitive interviews with 10 IBD outpatients were planned to check clarity, readability, intelligibility and completeness 
of the questionnaire. Based on these interviews, questions, response options and recall period were optimized if necessary.

\section{Validation phase}

In order to investigate the score's measurement properties, i.e. criterion validity, reliability and ability to detect change, a validation cohort was formed. Between March 2015 and December 2016, adult consecutive IBD patients with a scheduled routine endoscopy at the MUMC+, Zuyderland Medical Center Sittard (ZMC) and Amphia Hospital Breda $(\mathrm{AH})$, were eligible for inclusion. Patients with an ileostomy, colostomy, or ileoanal pouch anastomosis were again excluded. Eligible patients were invited to fill out the 5-item MIAH-UC questionnaire for UC or the 6-item MIAH-CD questionnaire for CD prior to bowel cleansing. During endoscopy, mucosal inflammation was scored with the SES-CD and the MES by trained endoscopists and again reviewed by an independent gastroenterologist. Criterion validity was evaluated by calculation of the MIAH questionnaires' sensitivity, specificity, positive predictive value (PPV) and NPV using the endoscopic activity scores as standard. To evaluate test-retest reliability, a subset of consecutive stable outpatients, i.e. no change in clinical situation or treatment, was asked to fill out the MIAH questionnaire during an outpatient visit and a second time at home within one week after the outpatient visit. Test-retest reliability of the MIAH questionnaires was assessed by the intra-class correlation coefficient (ICC). The score's ability to detect disease activity over time was assessed by inclusion of a subset of 54 patients from both the development and the validation cohort who underwent two routine endoscopies within the study period. The MIAH scores of patients who endoscopically improved, remained stable and deteriorated were compared with a Kruskal-Wallis test (i.e. the Kruskal Wallis test is the non-parametric alternative to the one way anova and determines whether the medians of two or more groups are different).

\section{Fecal calprotectin substudy}

A total of 109 patients from the validation cohort were asked to collect a stool sample prior to bowel cleansing. In this sample, FC was assessed with two different FC hometests and by the routine laboratory test of the MUMC+. These FC home-tests were the first ones available for commercial use. During the study period the tests were performed by the researchers to minimise test variability. Pearson correlation coefficients between the FC home-test values and FC routine laboratory measurements were calculated. To determine the optimal cut-off for the FC home-tests for predicting endoscopic disease activity, ROC curves were generated. We defined the optimal cut-off for disease activity as the one with the highest specificity of those with a sensitivity of at least $80 \%$. 
To assess diagnostic accuracy of the MIAH-UC and MIAH-CD in combination with the FC home-tests, sensitivity, specificity, PPV and NPV were calculated using endoscopic scores as standard.

\section{Measurements}

\section{Endoscopy}

For CD patients, endoscopic disease activity was defined as an SES-CD score $\geq 2$. For UC patients, endoscopic disease activity was defined as a MES $>1$. Endoscopic scoring was performed by a trained endoscopist. A second gastroenterologist independently scored mucosal inflammation based on reports, images and video material if available. In case of a disagreement in scores, the final decision was made through discussion and consensus.

\section{Fecal calprotectin}

Fecal calprotectin was measured using two different home-tests (QuantOn Cal (QoC) ${ }^{\circ}$ (Preventis, Germany) and Calpro Smart (CS) (CalproAS, Norway)) and by the routine laboratory test (Phadia ) of the MUMC+. Both FC home-tests consisted of an extraction kit with a dosing tip and a lateral flow device and were performed following manufacturer's instructions; the dosing tip was dipped 3-5 times into the stool to ensure homogeneity after which the dosing tip was transferred to the test tube with prefilled extraction fluid. The test tube was shaken to mix the stool with the fluid and a few drops were applied to the sample window of the lateral flow device and left for 15 minutes incubation. Finally, a picture of the lateral flow device was made with a smartphone, after which a test result was calculated. The lower and upper limits for FC detection were 25 and $2000 \mu \mathrm{g} / \mathrm{g}$ for the QuantOn Cal test and 70 and $1500 \mu \mathrm{g} / \mathrm{g}$ for the Calpro Smart test.

\section{Statistical analyses}

All described analyses were performed using IBM SPSS statistics 22.0. A two-sided pvalue $\leq 0.05$ was defined as statistically significant.

\section{Ethical considerations}

The study was approved by the Medical Research Ethics Committee of the Maastricht University Medical Center+. This approval was applicable to all participating centers. All patients gave written informed consent prior to participation. 


\section{RESULTS}

\section{Development phase}

During the development phase, 98 CD patients and 80 UC patients were included. Baseline characteristics are shown in table 1. In addition, 10 outpatients participated in the qualitative interviews to ensure content validity of the questionnaire. Patients judged the single questions on clarity, readability, intelligibility and completeness until saturation was reached. Patients indicated to prefer questions with a recall period of 24 hours over questions with a longer recall period and numeric rating scales or yes/no answers

Table 1. Patient characteristics.

\begin{tabular}{|c|c|c|c|c|c|c|}
\hline & \multicolumn{2}{|c|}{ Development phase } & \multicolumn{2}{|c|}{ Validation phase } & \multicolumn{2}{|c|}{$\begin{array}{l}\text { Fecal calprotectin } \\
\text { substudy }\end{array}$} \\
\hline & $C D(n=98)$ & UC $(n=80)$ & $C D(n=135)$ & $U C(n=131)$ & $C D(n=57)$ & UC $(n=52)$ \\
\hline Age (years), mean (SD) & $44.7(14.2)$ & $52.2(15.3)$ & $47.7(14.2)$ & $52.2(15.7)$ & $50.6(14.0)$ & $56.6(12.4)$ \\
\hline Male, N (\%) & $41(41.8)$ & $47(58.8 \%)$ & $56(41.5)$ & $75(57.3)$ & $27(47.4)$ & $30(57.7)$ \\
\hline Age at diagnosis, mean (SD) & $29.4(13.1)$ & $38.3(16.4)$ & $32.4(12.6)$ & $38.0(15.1)$ & $32.7(13.4)$ & $41.3(14.5)$ \\
\hline Disease duration (years), mean (SD) & $15.4(11.6)$ & $13.3(12.6)$ & $14.9(11.2)$ & $13.5(10.3)$ & $17.6(10.5)$ & $15.5(10.2)$ \\
\hline \multicolumn{7}{|l|}{ Phenotype, N (\%) } \\
\hline \multicolumn{7}{|l|}{ Localisation } \\
\hline E1 Proctitis & N/A & $15(18.8)$ & N/A & $7(5.3)$ & N/A & $0(0)$ \\
\hline E2 Left sided & N/A & $44(55.0)$ & N/A & $74(56.5)$ & N/A & $32(61.5)$ \\
\hline E3 Extensive & N/A & $21(26.2)$ & $\mathrm{N} / \mathrm{A}$ & $50(38.2)$ & N/A & $20(38.5)$ \\
\hline L1 Ileal & $24(24.5)$ & N/A & $34(25.2)$ & N/A & $18(31.6)$ & N/A \\
\hline L2 lleocolonic & $30(30.6)$ & N/A & $40(29.6)$ & N/A & $20(35.1)$ & $\mathrm{N} / \mathrm{A}$ \\
\hline L3 Colonic & $44(44.9)$ & N/A & $61(45.2)$ & N/A & $19(33.3)$ & N/A \\
\hline L4 Upper Gl & $10(10.2)$ & N/A & $6(4.4)$ & N/A & $2(3.5)$ & N/A \\
\hline \multicolumn{7}{|l|}{ Behaviour } \\
\hline $\begin{array}{l}\text { B1 Non-penetrating, } \\
\text { non-stricturing }\end{array}$ & $67(68.4)$ & N/A & $90(66.7)$ & N/A & $36(63.2)$ & N/A \\
\hline B2 Stricturing & $19(19.4)$ & N/A & $27(20.0)$ & N/A & $13(22.8)$ & N/A \\
\hline B3 Penetrating & $12(12.2)$ & N/A & $18(13.3)$ & N/A & $8(14.0)$ & N/A \\
\hline Perianal disease & $30(30.6)$ & N/A & 35 (25.9) & N/A & $15(26.3)$ & $\mathrm{N} / \mathrm{A}$ \\
\hline \multicolumn{7}{|l|}{ Treatment, N (\%) } \\
\hline No medication/5-ASA & NC & NC & $44(32.6)$ & $60(45.8)$ & $18(31.6)$ & $20(38.5)$ \\
\hline Immunosuppressives & NC & NC & $33(24.4)$ & $37(28.2)$ & $15(26.3)$ & $13(25.0)$ \\
\hline $\begin{array}{l}\text { Biologicals or } \\
\text { combination therapy }\end{array}$ & NC & NC & $58(43.0)$ & $34(26.0)$ & $24(42.1)$ & $19(36.5)$ \\
\hline Surgical history, N (\%)† & $39(39.8)$ & $5(6.2)$ & $49(36.6)$ & $7(5.3)$ & $24(42.1)$ & $3(5.8)$ \\
\hline Active disease, N (\%) & $54(55.1)$ & $27(33.8)$ & $62(44.9)$ & $44(33.6)$ & $30(52.6)$ & $17(32.7)$ \\
\hline
\end{tabular}

CD, Crohn's Disease; UC, ulcerative colitis; GI, gastro-intestinal; 5-ASA, 5-aminosalicylic acid; N/A, not applicable; NC, not collected; † ileocecal resection, hemicolectomy or sigmoid resection. 
over categorical response options. The question on "liquid or soft stool frequency" was found to be hard to interpret, as patients judged "liquid or soft" during these interviews with Bristol Stool Scale ratings ranging from 4 to 7 . Therefore and because of its lower correlation with endoscopic disease activity, we decided to exclude the question on "liquid or soft stools" and include a more general question on stool frequency (supplementary table 1 and 2). All numeric rating scales, i.e. on patient-reported disease activity, abdominal pain, and fatigue, were adjusted in the same direction, namely 0 as very poor and 10 as very well. The response options from the urgency-question were extended on patients' advice from "yes/no" to "no", "yes, urgent", and "yes, very urgent", to offer a clear distinction between choices.

For $C D$, patient-reported disease activity (domain 1), and questions on rectal bleeding and mucus loss (domain 2), stool frequency (domain 3), urgency and fatigue (domain 4) were selected as best predicting endoscopic disease activity (table 2), with an area under the curve (AUC) of 0.72 (figure $1 \mathrm{~A}$ ). The optimal cut-off value for the MIAH-CD was set at 3.6 , resulting in a sensitivity of $90.4 \%$ and specificity of $40.9 \%$. For UC, patientreported disease activity (domain 1), and questions on rectal bleeding (domain 2), stool frequency (domain 3), urgency and abdominal pain (domain 4) were selected as best predicting endoscopic disease activity (table 2), with an AUC of 0.81 (figure 1B). The optimal cut-off for the MIAH-UC was set at 3.5, resulting in a sensitivity and specificity of $92.6 \%$ and $67.9 \%$, respectively.

Table 2. Domains and individual items of the MIAH-CD and MIAH-UC questionnaire.

\begin{tabular}{|c|c|c|c|c|c|c|}
\hline Domain & MIAH-CD items & $\begin{array}{l}\text { Intra-domain } \\
\text { weight factor }\end{array}$ & $\begin{array}{l}\text { Inter-domain } \\
\text { weight factor }\end{array}$ & $\begin{array}{l}\text { MIAH-UC } \\
\text { items }\end{array}$ & $\begin{array}{l}\text { Intra-domain } \\
\text { weight factor }\end{array}$ & $\begin{array}{l}\text { Inter-domain } \\
\text { weight factor }\end{array}$ \\
\hline 1 & $\begin{array}{l}\text { Patient-reported } \\
\text { disease activity }\end{array}$ & 1 & 0.096 & $\begin{array}{l}\text { Patient-reported } \\
\text { disease activity }\end{array}$ & 1 & 0.160 \\
\hline 2 & $\begin{array}{l}\text { Rectal bleeding } \\
\text { Mucus loss }\end{array}$ & $\begin{array}{l}0.4 \\
0.6\end{array}$ & 0.097 & Rectal bleeding & 1 & 2.103 \\
\hline 3 & Stool frequency & 1 & 0.184 & Stool frequency & 1 & 0.167 \\
\hline 4 & $\begin{array}{l}\text { Urgency } \\
\text { Fatigue }\end{array}$ & $\begin{array}{l}0.7 \\
0.3\end{array}$ & 0.022 & $\begin{array}{c}\text { Urgency } \\
\text { Abdominal pain }\end{array}$ & $\begin{array}{l}0.5 \\
0.5\end{array}$ & 0.184 \\
\hline
\end{tabular}

CD, Crohn's disease; UC, ulcerative colitis; MIAH, Monitor IBD At Home.

\section{Validation phase}

During the validation phase, MIAH questionnaires from 135 CD patients ( 120 MUMC+, 7 ZMC, $8 \mathrm{AH}$ ) and $131 \mathrm{UC}$ patients (116 MUMC+, $11 \mathrm{ZMC}, 4 \mathrm{AH}$ ) were collected and analysed relative to endoscopic disease activity scores. Patient characteristics are shown in table 1. Using the preset cut-off of 3.6, the MIAH-CD showed a sensitivity of $67.6 \%$, specificity of $81.3 \%$, PPV of $69.3 \%$, and NPV of $80.0 \%$ (table 3 and supplementary table 3 ). Using the cut-off of 3.5, the MIAH-UC showed a sensitivity of $68.2 \%$, specificity of $80.5 \%$, PPV of $63.8 \%$, and NPV of $83.3 \%$ (table 3 and supplementary table 3 ). The test-retest reliability 
was assessed in a subset of 20 CD and 7 UC patients. In CD patients, the ICC was 0.81 (95\% Cl 0.52-0.93) and for UC patients the ICC was 0.88 (95\% Cl 0.27-0.98). The ability to detect disease activity was assessed in a subset of 29 CD and 25 UC patients with a mean between-endoscopies period of $19.1 \pm 11.1$ months. In total, 15 patients deteriorated $(27.8 \%), 24$ patients had stable disease activity (44.4\%), and 15 patients improved over time (27.8\%). The MIAH score differed significantly over time between patients who clinically improved, remained stable or worsened $(p<0.001)$.

\section{Fecal calprotectin substudy}

As the overall sensitivity scores were rather low, we evaluated the addition of a FC home-test to the MIAH questionnaire in 109 patients (57 CD and $52 \mathrm{UC}$ ) (table 1). For CD patients, ROC curve analysis for the QOC FC home-test compared to endoscopy revealed an AUC of 0.82 (figure 2A). An optimal cut-off level of $100 \mu \mathrm{g} / \mathrm{g}$ resulted in a sensitivity of $80.0 \%$ and a specificity of $70.4 \%$. The CS FC home-test revealed an AUC of 0.75 (figure $2 \mathrm{~A}$ ). The optimal cut-off level of $100 \mu \mathrm{g} / \mathrm{g}$ resulted in a sensitivity of $76.9 \%$ and a specificity of $58.3 \%$. For UC patients, ROC curve analysis for the QOC FC home-test compared to endoscopy revealed an AUC of 0.84 (figure 2B), with an optimal cut-off level of $250 \mu \mathrm{g} / \mathrm{g}$ and a sensitivity of $82.4 \%$ and a specificity of $87.1 \%$ compared to endoscopy. The CS FC home-test compared to endoscopy revealed an AUC of 0.89 (figure 2B), with an optimal cut-off level of $250 \mu \mathrm{g} / \mathrm{g}$ and a sensitivity of $87.5 \%$ and a specificity of $67.7 \%$ compared to endoscopy. A strong correlation was found between the QOC and CS FC home-tests and FC measured by routine lab, with a Pearson's correlation coefficient of $0.75(P<0.001)$ and $0.89(p<0.001)$, respectively.

When either the MIAH or the QOC home-test was positive in CD patients, the sensitivity, specificity, PPV and NPV were $96.7 \%, 66.7 \%, 76.3 \%$ and $94.7 \%$ compared to endos-

Table 3. Test characteristics of the MIAH-CD, MIAH-UC and the combinations of the MIAH and calprotectin home-tests compared to endoscopy.

\begin{tabular}{lcccc}
\hline & Sensitivity (95\% Cl) & Specificity (95\% Cl) & NPV (95\% CI) & PPV (95\% CI) \\
\hline MIAH-CD & $67.6(55.5-78.2)$ & $81.3(69.5-89.9)$ & $80.0(70.1-87.2)$ & $69.3(61.3-76.4)$ \\
MIAH-UC & $68.2(52.4-81.4)$ & $80.5(70.6-88.2)$ & $83.3(76.2-88.6)$ & $63.8(52.4-73.9)$ \\
& & & & \\
MIAH-CD & & & & \\
with QOC & $96.7(82.8-99.9)$ & $66.7(46.0-83.5)$ & $94.7(72.1-99.2)$ & $76.3(65.3-84.7)$ \\
with CS & $96.2(80.4-99.9)$ & $58.3(36.6-77.9)$ & $93.3(66.5-99.0)$ & $71.4(60.8-80.2)$ \\
MIAH-UC & & & & \\
with QOC & $88.2(63.6-98.5)$ & $71.4(53.7-85.4)$ & $92.6(77.0-97.9)$ & $60.0(46.4-72.3)$ \\
with CS & $87.5(61.7-98.5)$ & $63.3(43.9-80.1)$ & $90.5(71.6-97.3)$ & $56.0(43.4-67.8)$ \\
\hline
\end{tabular}

CD, Crohn's disease; UC, ulcerative colitis; MIAH, Monitor IBD At Home questionnaire; QOC, QuantOn Cal home-test; CS, Calpro Smart home-test; NPV, negative predictive value; PPV, positive predictive value; $\mathrm{Cl}$, confidence interval. 
copy, respectively (table 3, figure 3A, and supplementary table 3). For UC patients, when either the MIAH or the QOC home-test was positive a sensitivity of $88.2 \%$, a specificity of $71.4 \%$, a PPV of $60.0 \%$ and a NPV of $92.6 \%$ were obtained compared to endoscopy (table 3, figure 3B, and supplementary table 3). When the score was performed with the CS home-test, comparable results were obtained (table 3 and supplementary table 3 ).

A

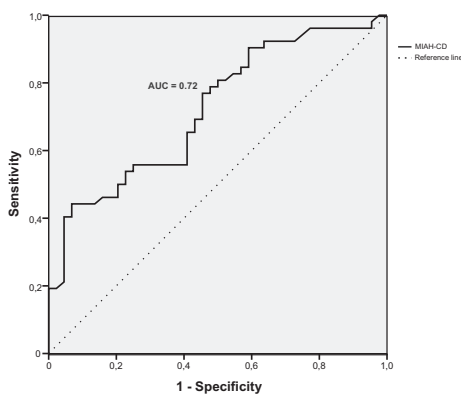

B

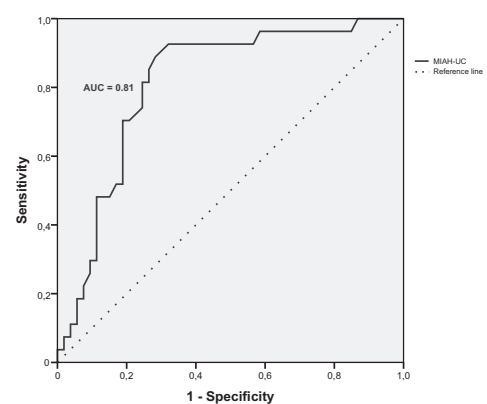

Figure 1. ROC curves of the MIAH questionnaire to predict endoscopic disease activity in $C D(A)$ and UC patients (B).

A

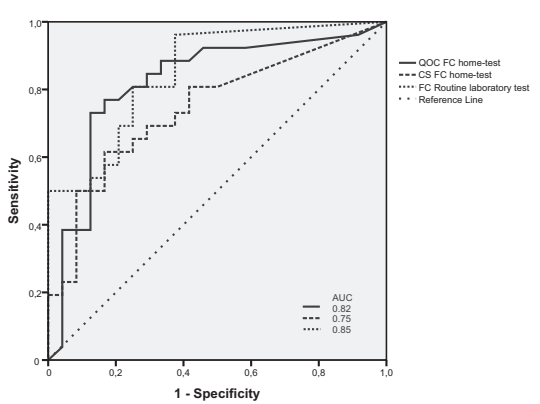

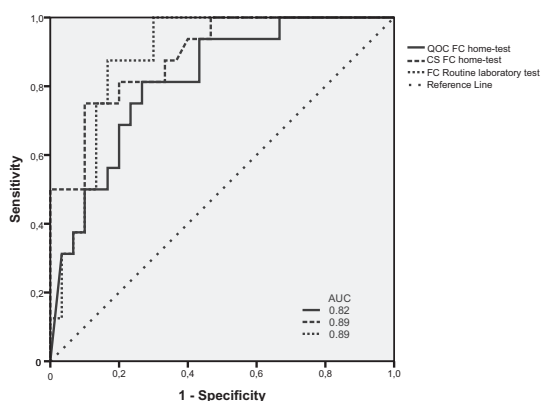

Figure 2. ROC curves of FC measured by the routine laboratory test and by the QOC and CS home-tests to predict endoscopic disease activity in CD patients (A) and in UC patients (B). 


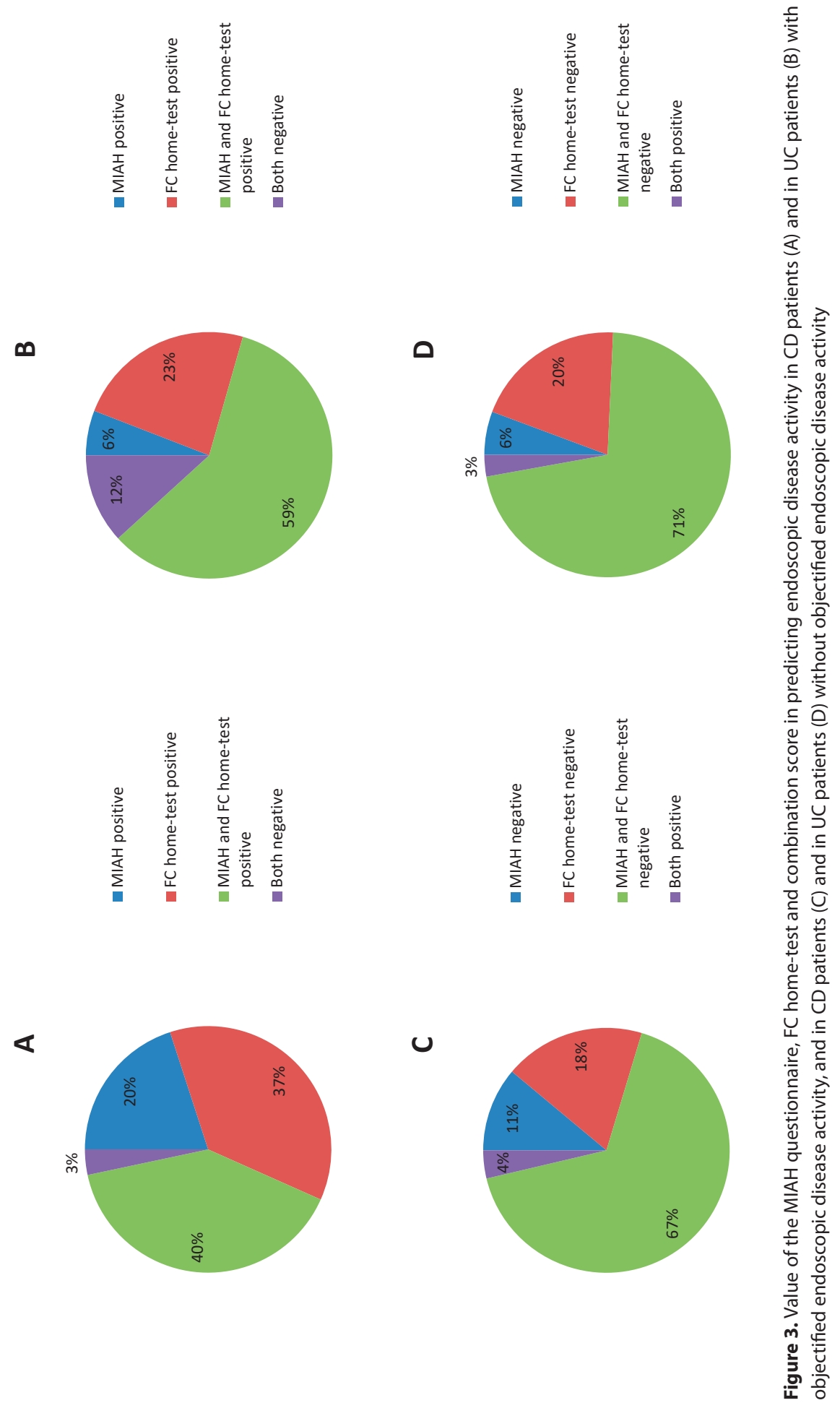




\section{DISCUSSION}

In this study, we developed and validated the Monitor IBD At Home questionnaire, a PROM developed for monitoring of IBD disease activity in clinical practice or in telemedicine systems. The combination of the patient-reported MIAH questionnaire and a calprotectin home-test predicted endoscopic disease activity with a sensitivity of $96.7 \%$ and NPV of $94.7 \%$ for CD patients and a sensitivity of $88.2 \%$ and NPV of $92.6 \%$ for UC patients.

Tight monitoring focusing on early recognition of mucosal inflammation and immediate treatment optimisation in case of disease activity is associated with better long-term outcome and therefore considered an emerging treatment goal for IBD patients ${ }^{4,5}$. The gold standard for assessment of mucosal inflammation is endoscopy, but this is an invasive, time-consuming and costly examination and therefore not suitable nor available for routine follow-up. When compared to endoscopy, the measurement properties of the developed MIAH questionnaire alone were unsatisfactory to screen patients for active disease. Nevertheless, the questionnaire showed higher predictive values compared to endoscopy than conventional clinical disease outcomes as the HBI, CDAI and the SCCAI 29,30 and similar results when compared to the patient-reported mHealth Index, which showed AUCs of 0.63 in patients with CD and 0.82 in patients with $U C^{14}$. Other patientreported outcomes have only been validated against conventional clinical disease outcomes and their utility to assess mucosal inflammation remains therefore unclear.

This study confirms that patient-reported questionnaires correlate moderately with endoscopic findings suggesting that disease control based on symptoms alone is not sufficient. The fact that $30 \%$ of IBD patients in clinical remission show inflammation during endoscopy and 30-50\% of IBD patients have IBS-like symptoms without having mucosal inflammation during endoscopy underscores this ${ }^{31,32}$. As a result, gastroenterologists frequently rely on objective biomarkers, such as C-reactive protein or FC. These biomarkers alone, however, show also insufficient accuracy to predict endoscopic disease activity and remission ${ }^{29}$.

In this study, the combination of a PROM and a FC test was shown to be an excellent screening tool for endoscopic disease activity, with a sensitivity of around $90 \%$ and specificity of around 70\%, The recently developed Utrecht Activity Index, which includes both symptoms and laboratory parameters, was also reliable (sensitivity $80 \%$, specificity $92 \%$ ) in predicting endoscopic disease activity in patients with $C D^{33}$. However, these laboratory parameters are not available at present for home-monitoring. The FC hometests used in this study had similar accuracy for detecting endoscopic disease activity compared to routine lab. In contrast to routine FC assessment in the hospital laboratory, home-test results are available within 15 minutes preventing a delay in treatment initiation. In addition, the procedure is less complicated and less time-consuming for patients 
as they do not have to bring their fecal sample to the hospital. A home-test, furthermore, empowers patients by more involvement in their disease management.

The main strength of this study was that we developed a PROM following the FDA recommendations, including patients' perspectives on the questions and testing of construct validity with endoscopy as golden standard. However, there are some limitations to be noted. We included a selected population of patients who had a clinical indication for endoscopy. Only a minority of patients was referred for a surveillance endoscopy or an endoscopy to confirm sustained remission in order to de-escalate therapy. As a result, a majority of included patients had symptoms, while only $40 \%$ of these patients had endoscopically active disease. This might have resulted in an overestimation of false positive MIAH questionnaires. Although we tried to minimise inter-endoscopist variability by training the endoscopists and by independently reviewing all endoscopic results, we cannot rule out any variation in test results. In addition, patient interviews were performed after the development phase, which might partially account for the differences observed between the sensitivity and specificity in the development versus validation cohort. Furthermore, the FC home-tests were performed by a researcher to minimise test variability, but also because these tests were not yet implementable for use by patients during the study period. Further studies need to focus on patients' evaluation with FC home-testing and on the best frequency of home-monitoring in order to enable tight disease control and prevent disease-related complications. Thereafter, validation studies are needed to evaluate the value of the composition of the MIAH questionnaire and a FC home-test in different patient cohorts.

In summary, we developed the MIAH questionnaire, which is the first patient-reported questionnaire to predict endoscopic inflammation in IBD patients developed according to the FDA guidelines. A combination of this questionnaire and a FC home-test shows excellent diagnostic accuracy to screen for patients who need further assessment of disease activity by clinical examination, endoscopy or imaging. This composite score is a valuable tool for tight disease control in routine clinical practice or in telemonitoring systems. 


\section{REFERENCES}

1. Burisch J, Munkholm P. The epidemiology of inflammatory bowel disease. Scand J Gastroenterol 2015;50:942-51.

2. Colombel JF, Narula N, Peyrin-Biroulet L. Management strategies to improve outcomes of patients with inflammatory bowel diseases. Gastroenterology 2016.

3. Sandborn WJ, Hanauer S, Van Assche G, et al. Treating beyond symptoms with a view to improving patient outcomes in inflammatory bowel diseases. Journal of Crohn's \& colitis 2014;8:927-35.

4. Baert F, Moortgat L, Van Assche G, et al. Mucosal healing predicts sustained clinical remission in patients with earlystage crohn's disease. Gastroenterology 2010;138:463-8; quiz e10-1.

5. Colombel JF, Rutgeerts $P$, Reinisch W, et al. Early mucosal healing with infliximab is associated with improved long-term clinical outcomes in ulcerative colitis. Gastroenterology 2011;141:1194-201.

6. Peyrin-Biroulet $L$, Ferrante $M$, Magro $F$, et al. Results from the 2nd scientific workshop of the ecco. I: Impact of mucosal healing on the course of inflammatory bowel disease. Journal of Crohn's \& colitis 2011;5:477-83.

7. Molodecky NA, Soon IS, Rabi DM, et al. Increasing incidence and prevalence of the inflammatory bowel diseases with time, based on systematic review. Gastroenterology 2012;142:46-54 e42; quiz e30.

8. van den Heuvel TRA, Jeuring SFG, Zeegers $M P$, et al. A 20 year temporal change analysis in incidence, presenting phenotype and mortality in the dutch ibdsl cohort can diagnostic factors explain the increase in ibd incidence? Journal of Crohn's \& colitis 2017.

9. Porter ME. What is value in health care? The New England journal of medicine 2010;363:2477-81.
10. Bradley SM, Rumsfeld JS, Ho PM. Incorporating health status in routine care to improve health care value: The va patient reported health status assessment (prost) system. Jama 2016;316:487-8.

11. Clara I, Lix LM, Walker JR, et al. The manitoba ibd index: Evidence for a new and simple indicator of ibd activity. The American journal of gastroenterology 2009;104:1754-63.

12. Surti B, Spiegel B, Ippoliti A, et al. Assessing health status in inflammatory bowel disease using a novel single-item numeric rating scale. Digestive diseases and sciences 2013;58:1313-21.

13. Subramanian S, Asher R, Weston W, et al. Validation of a simple 0 to 10 numerical score (ibd-10) of patient-reported inflammatory bowel disease activity for routine clinical use. Inflamm Bowel Dis 2016;22:1902-7.

14. Van Deen WK, van der Meulen-de Jong $A E$, Parekh NK, et al. Development and validation of an inflammatory bowel diseases monitoring index for use with mobile health technologies. Clinical gastroenterology and hepatology : the official clinical practice journal of the American Gastroenterological Association 2016;14:1742-50 e7.

15. Bennebroek Evertsz F, Hoeks CC, Nieuwkerk PT, et al. Development of the patient harvey bradshaw index and a comparison with a clinician-based harvey bradshaw index assessment of crohn's disease activity. J Clin Gastroenterol 2013;47:850-6.

16. Gracie DJ, Williams CJ, Sood R, et al. Poor correlation between clinical disease activity and mucosal inflammation, and the role of psychological comorbidity, in inflammatory bowel disease. The American journal of gastroenterology 2016;111:54151. 
17. Larsen L, Drewes AM, Fallingborg J, Jacobsen BA, Jess T. Touch screens as a tool in patient care in the ibd outpatient clinic. Scandinavian journal of gastroenterology 2016;51:1106-10.

18. Bennebroek Evertsz F, Nieuwkerk PT, Stokkers PC, et al. The patient simple clinical colitis activity index ( $p$-sccai) can detect ulcerative colitis (uc) disease activity in remission: A comparison of the p-sccai with clinician-based sccai and biological markers. Journal of Crohn's \& colitis 2013;7:890900.

19. Jowett SL, Seal CJ, Phillips E, et al. Defining relapse of ulcerative colitis using a symptom-based activity index. Scand J Gastroenterol 2003;38:164-71.

20. Marin-Jimenez I, Nos P, Domenech $E$, et al. Diagnostic performance of the simple clinical colitis activity index selfadministered online at home by patients with ulcerative colitis: Cronica-uc study. The American journal of gastroenterology 2016;111:261-8.

21. Timmer A, Kemptner D, Takses A, Klebl $\mathrm{F}$, Jockel $\mathrm{KH}$. A survey-based index was validated for measuring disease activity in inflammatory bowel disease. An evaluation study. Journal of clinical epidemiology 2009;62:771-8.

22. Khanna R, Zou G, D'Haens G, et al. A retrospective analysis: The development of patient reported outcome measures for the assessment of crohn's disease activity. Alimentary pharmacology \& therapeutics 2015;41:77-86.

23. Lewis JD, Chuai S, Nessel L, et al. Use of the noninvasive components of the mayo score to assess clinical response in ulcerative colitis. Inflamm Bowel Dis 2008;14:1660-6.

24. Bewtra M, Brensinger CM, Tomov VT, et al. An optimized patient-reported ulcerative colitis disease activity measure derived from the mayo score and the simple clini- cal colitis activity index. Inflamm Bowel Dis 2014;20:1070-8.

25. Jairath V, Khanna R, Zou GY, et al. Development of interim patient-reported outcome measures for the assessment of ulcerative colitis disease activity in clinical trials. Alimentary pharmacology \& therapeutics 2015;42:1200-10.

26. Administration FaD. Guidance for industry. Patient-reported outcome measures: Use in medical product development to support labeling claims. December 2009.

27. Patrick DL, Burke LB, Gwaltney CJ, et al. Content validity--establishing and reporting the evidence in newly developed patient-reported outcomes (pro) instruments for medical product evaluation: Ispor pro good research practices task force report: Part 1--eliciting concepts for a new pro instrument. Value in health : the journal of the International Society for Pharmacoeconomics and Outcomes Research 2011;14:967-77.

28. de Jong MJ, Huibregtse R, Masclee AAM, Jonkers D, Pierik MJ. Patient-reported outcome measures for use in clinical trials and clinical practice in inflammatory bowel diseases: A systematic review. Clinical gastroenterology and hepatology : the official clinical practice journal of the American Gastroenterological Association 2018; 16:648-63 e3.

29. Falvey JD, Hoskin T, Meijer B, et al. Disease activity assessment in ibd: Clinical indices and biomarkers fail to predict endoscopic remission. Inflamm Bowel Dis 2015;21:82431.

30. Jones J, Loftus EV, Jr., Panaccione R, et al. Relationships between disease activity and serum and fecal biomarkers in patients with crohn's disease. Clinical gastroenterology and hepatology : the official clinical practice journal of the American Gastroenterological Association 2008;6:1218-24.

31. Baars JE, Nuij VJ, Oldenburg B, Kuipers EJ, van der Woude CJ. Majority of patients 
with inflammatory bowel disease in clinical remission have mucosal inflammation. Inflamm Bowel Dis 2012;18:1634-40.

32. Tomita $\mathrm{T}$, Kato $\mathrm{Y}$, Takimoto $\mathrm{M}$, et al. Prevalence of irritable bowel syndrome-like symptoms in japanese patients with inactive inflammatory bowel disease. Journal of neurogastroenterology and motility 2016;22:661-9.
33. Minderhoud IM, Steyerberg EW, van Bodegraven AA, et al. Predicting endoscopic disease activity in crohn's disease: A new and validated noninvasive disease activity index (the utrecht activity index). Inflammatory bowel diseases 2015;21:2453-9. 
Supplementary table 1. Correlation coefficients of the individual questions with endoscopic disease activity in Crohn's disease patients.

\begin{tabular}{lccc}
\hline Questions & Response options & Correlation coefficient & P value \\
\hline Stool frequency (day) & Numerical & 0.513 & 0.000 \\
Liquid or soft stools frequency & Numerical & 0.324 & 0.001 \\
Patient-reported disease activity & VAS 0-10 & 0.278 & 0.006 \\
Urgency of defecation & No & 0.236 & 0.020 \\
& Yes, urgent & & 0.022 \\
Mucus loss & Yes, very urgent & & 0.082 \\
Rectal bleeding & Yes/no & 0.233 & 0.089 \\
Stool frequency (night) & Yes/no & 0.177 & 0.281 \\
Fatigue & Numerical & 0.173 & 0.369 \\
Fever & VAS 0-10 & 0.110 & 0.573 \\
General well-being & Yes/no & 0.092 & 0.604 \\
Perceived stress & VAS 0-10 & 0.058 & 0.992 \\
Weight loss & VAS 0-10 & 0.053 & 0.524 \\
Abdominal pain & Yes/no & -0.001 & -0.065 \\
\hline
\end{tabular}

Supplementary table 2. Correlation coefficients of the individual questions with endoscopic disease activity in ulcerative colitis patients.

\begin{tabular}{lccc}
\hline Questions & Response options & Correlation coefficient & P value \\
\hline Rectal bleeding & Yes/no & 0.584 & 0.000 \\
Stool frequency (day) & Numerical & 0.513 & 0.000 \\
Mucus loss & Yes/no & 0.477 & 0.000 \\
Patient-reported disease activity & VAS 0-10 & 0.000 \\
General well-being & VAS 0-10 & 0.396 & 0.005 \\
Liquid or soft stools frequency & Numerical & 0.314 & 0.023 \\
Urgency of defecation & No & 0.254 & 0.044 \\
& Yes, urgent & 0.226 & 0.066 \\
Weight loss & Yes, very urgent & & 0.117 \\
Stool frequency (night) & Yes/no & 0.206 & 0.165 \\
Abdominal pain & Numerical & 0.176 & 0.301 \\
Perceived stress & VAS 0-10 & 0.157 & 0.764 \\
Fatigue & VAS 0-10 & 0.117 & $\mathrm{~N} / \mathrm{A}$ \\
\hline Fever & VAS 0-10 & 0.034 & $\mathrm{~N} / \mathrm{A}$ \\
\hline
\end{tabular}

$\mathrm{N} / \mathrm{A}=$ not applicable (none of the ulcerative colitis patients reported fever). 
Supplementary table 3. Diagnostic accuracy of the MIAH questionnaire, the QOC home-test, the CS home-test and their combinations, compared to endoscopy.

\begin{tabular}{|c|c|c|c|c|}
\hline & $\begin{array}{c}\text { Mucosal } \\
\text { inflammation (n) }\end{array}$ & $\begin{array}{c}\text { Endoscopic } \\
\text { remission }(\mathbf{n})\end{array}$ & $\begin{array}{c}\text { Diagnostic } \\
\text { accuracy (\%) }\end{array}$ & $\begin{array}{c}\text { Number of patients } \\
\text { included (n) }\end{array}$ \\
\hline MIAH-CD positive & 48 & 12 & 74.1 & 135 \\
\hline MIAH-CD negative & 23 & 52 & & \\
\hline MIAH-UC positive & 30 & 17 & 76.3 & 131 \\
\hline MIAH-UC negative & 14 & 70 & & \\
\hline QOC-CD positive & 23 & 6 & 77.2 & 57 \\
\hline QOC-CD negative & 7 & 21 & & \\
\hline QOC-UC positive & 14 & 8 & 78.8 & 52 \\
\hline QOC-UC negative & 3 & 27 & & \\
\hline CS-CD positive & 20 & 10 & 68.0 & 50 \\
\hline CS-CD negative & 6 & 14 & & \\
\hline CS-UC positive & 14 & 10 & 73.9 & 46 \\
\hline CS-UC negative & 2 & 20 & & \\
\hline MIAH-CD and QOC positive & 12 & 1 & 82.5 & 57 \\
\hline MIAH-CD or QOC positive & 17 & 8 & & \\
\hline $\mathrm{MIAH}-\mathrm{CD}$ and QOC negative & 1 & 18 & & \\
\hline MIAH-CD and CS positive & 10 & 3 & 78.0 & 50 \\
\hline MIAH-CD or CS positive & 15 & 7 & & \\
\hline MIAH-CD and CS negative & 1 & 14 & & \\
\hline MIAH-UC and QOC positive & 10 & 1 & 76.9 & 52 \\
\hline MIAH-UC or QOC positive & 5 & 9 & & \\
\hline MIAH-UC and QOC negative & 2 & 25 & & \\
\hline MIAH-UC and CS positive & 10 & 1 & 71.7 & 46 \\
\hline MIAH-UC or CS positive & 4 & 10 & & \\
\hline MIAH-UC and CS negative & 2 & 19 & & \\
\hline
\end{tabular}






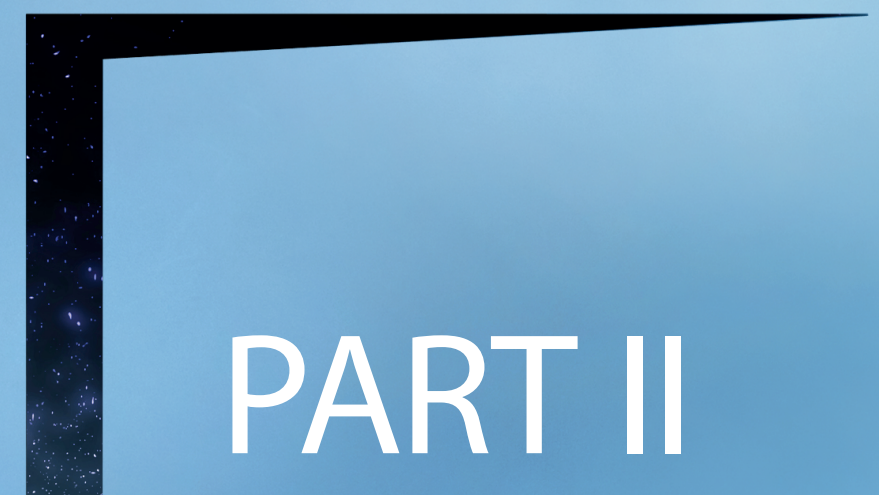





\section{Chapter 4}

Development and feasibility study of a telemedicine tool for all IBD patients: myIBDcoach

Marin de Jong, Andrea van der Meulen-de Jong,

Mariëlle Romberg-Camps, Juliette Degens, Marco Becx,

Tineke Markus, Henny Tomlow, Mia Cilissen, Nienke Ipenburg,

Marthe Verwey, Laurence Colautti-Duijsens, Wim Hameeteman,

Ad Masclee, Daisy Jonkers, Marieke Pierik

Inflamm Bowel Dis. 2017 Apr;23(4):485-493. 


\section{ABSTRACT}

Background: Tight control of disease activity, medication side-effects and adherence are crucial to prevent disease complications and improve quality of life (QoL) in inflammatory bowel disease (IBD) patients. The chronic nature and increasing incidence of IBD demand healthcare innovations to guarantee future high quality care. Previous research proved that integrated care by telemedicine can improve outcomes of chronic diseases. Currently available IBD telemedicine tools focus on specific patient subgroups. Therefore we aimed to 1) develop a telemedicine system suitable for all IBD patients in everyday practice and 2) to test this system's feasibility.

Methods: With a structured iterative process between patients, dietitians, IBD nursespecialists and gastroenterologists, mylBDcoach was developed. During 3 months, myIBDcoach's feasibility was tested by 30 consecutive IBD outpatients of three hospitals. Thereafter, patients and healthcare providers completed a questionnaire covering satisfaction, accessibility and experiences with mylBDcoach.

Results: MyIBDcoach enables continuous home-monitoring of IBD patients and optimises disease knowledge and communication between patients and healthcare providers. Besides disease activity, medication adherence and side-effects, mylBDcoach monitors malnutrition, smoking, QoL, fatigue, life-events, work participation, stress, anxiety and depression and provides e-learnings for patient-empowerment. Patients graded the system with a mean of 7.8 out of 10 and $93 \%$ would recommend mylBDcoach to other patients.

Conclusions: We developed mylBDcoach, which enables integrated care for all IBD patients, regardless of disease severity or medication use. This feasibility study showed high satisfaction and compliance of patients and healthcare providers. To study mylBDcoach's efficacy, a multicentre randomised controlled trial has been initiated. 


\section{INTRODUCTION}

Inflammatory bowel disease (IBD) is a chronic disorder of the gastrointestinal tract with a peak onset in early adulthood ${ }^{1}$. Crohn's disease (CD) and ulcerative colitis (UC) are the two main subtypes, but within these groups the clinical presentation is very heterogeneous with regard to disease location, disease behaviour, occurrence of extra-intestinal manifestations and therapy response ${ }^{2}$. IBD has a significant impact on quality of life and constitutes an economic burden due to direct and indirect healthcare costs ${ }^{3-5}$.

Recent studies show that tight control of disease activity and early interventions in case of recurrence of intestinal inflammation are important to shorten flare duration and prevent complications ${ }^{6}$. Furthermore, most available drugs are immunosuppressives which can have severe side-effects ${ }^{7,8}$. For these reasons, continuous and personalised monitoring of IBD patients with regard to disease activity, medication use and sideeffects is required. In addition, many aspects that may influence disease activity, such as stress, smoking, nutritional status and treatment adherence are not followed systematically in most IBD clinics. Interventions on these aspects may significantly improve the long-term outcome of $\mathrm{IBD}^{9,10}$. Furthermore, systematic registration of patient-reported outcome measures (PROMs) and work disability is increasingly requested by healthcare insurers to guarantee reimbursement of expensive drugs, while patients themselves also demand empowerment and more involvement with their therapy.

Continuous monitoring of this multifaceted, chronic and invasive disease, given the increasing incidence of $\mathrm{IBD}^{11-13}$, will put significant pressure on gastrointestinal healthcare capacities. To guarantee personalised, high quality, efficient and affordable healthcare for IBD patients in the future, innovative solutions are warranted.

Healthcare at a distance, also known as telemedicine or eHealth, is a possible innovation that may contribute to the quality and efficiency of care for IBD patients ${ }^{12,14,15}$. eHealth has already been implemented successfully for several other chronic diseases, such as congestive heart failure ${ }^{16,17}$, asthma ${ }^{18}$, hypertension ${ }^{19}$, chronic obstructive pulmonary disease $\mathrm{e}^{20,21}$ and diabetes mellitus ${ }^{22,23}$. Mounting evidence shows that direct involvement of healthcare providers, promotion of patient empowerment and integrated care improve the outcome of chronic diseases ${ }^{24-27}$.

Also for IBD patients, several telemedicine systems have been developed. Cross et al. developed a Home Telemanagement System for UC patients ${ }^{28-32}$, composed of a netbook computer and an electronic weight scale that monitors symptoms, medication usage and side-effects. Elkjaer et al. developed a web-based system (Constant Care) to monitor disease activity and quality of life in patients with mild-to-moderate UC on 5-aminosalicylic acid (5-ASA) treatment ${ }^{26,33}$. This program was also used for individualisation of 5-ASA treatment and improvement of adherence in mild-to-moderate UC patients ${ }^{10}$ and 
for individualisation of infliximab (IFX) scheduling in CD patients on IFX maintenance treatment ${ }^{34}$.

Overall, these systems were shown to be feasible, safe and well-accepted by IBD patients ${ }^{35,36}$, but are developed for subgroups of IBD patients with relatively mild disease. Therefore, we aimed 1) to develop a telemedicine system for all subtypes of IBD patients in everyday clinical practice through close collaboration of patients, IBD nurse-specialists and gastroenterologists using a structured approach and 2) to test the feasibility of this system in terms of compliance and satisfaction among patients and healthcare providers.

\section{MATERIALS AND METHODS}

\section{Development MylBDcoach}

\section{Design and content development}

Before start of the development phase, the need for an integrated eHealth system for IBD patients in the Netherlands was evaluated among different stakeholders, i.e. IBD patients from the Dutch IBD patients organization ${ }^{37}$, dietitians, representatives from the pharmaceutical industry, gastroenterologists and IBD nurse-specialists from academic as well as non-academic hospitals (figure 1, phase I). Subsequently, they discussed the design of the telemonitoring program further referred to as mylBDcoach, the relevant topics and questionnaires to be included as well as safety management of homemonitoring using a structured iterative process (figure 1, phase II-V). In addition, topics for e-learning modules were selected and subsequently developed by topic-specific experts and reviewed by an independent gastroenterologist (figure 1, phase VI).

To facilitate broad support and implementation of mylBDcoach and to improve cooperation between the various stakeholders, a foundation was instituted ${ }^{38}$. The director of the Dutch IBD patient organisation, two gastroenterologists, an accountant and an assistant professor health analytics systems constitute the board. Representatives of the aforementioned stakeholders, as well as of the IBD section of the NVGE (Dutch Association for Gastroenterology), the NVMDL (Dutch Association for Gastroenterologists) and the N-NIC (association of IBD nurse-specialists) form a separate committee which decides on the design and content of mylBDcoach.

\section{Technological development}

The technological development of mylBDcoach was conducted by Sananet BV ${ }^{39}$, specialised in development and implementation of telemedicine and self-management 
tools. They integrated relevant information and questionnaires into both a web-based and an HTML application and created a secure link between patients and the hospital.

The system includes so-called monitoring modules, intensified monitoring modules, outpatient visit modules, e-learning modules, a follow-up plan and an administrator page used by the healthcare provider (figure 2). The modules will be discussed in detail later. MylBDcoach meets all legal requirements in line with the European laws regarding security and confidentiality of patient data.

\section{Feasibility study mylBDcoach}

After the technological and content development, a feasibility study was planned in three clinical centres to evaluate compliance, satisfaction, accessibility and experiences with mylBDcoach from both healthcare providers and patients.

From November 2012 until March 2013, 30 patients were recruited from the tertiary referral centres Maastricht University Medical Centre+ and Leiden University Medical Centre, and from the non-academic hospital Zuyderland Medical Centre. Patients between 18 and 75 years of age, fulfilling the international diagnostic criteria for IBD $^{40}$, were eligible for inclusion. Exclusion criteria consisted of inability to read or understand the informed consent form, lack of internet access by computer, tablet or smartphone or a hospital admission due to IBD disease activity within two weeks prior to inclusion because of practical reasons.

Participating patients followed a short practical training on how to use mylBDcoach. Following this, participants received a unique username and password and were asked to log on to http://www.mijnibdcoach.nl. During a 3-month study period, patients were requested to complete the mylBDcoach monitoring module monthly. At the end of the study period, patients and healthcare providers from the participating hospitals were asked to fill out an evaluation questionnaire regarding satisfaction, accessibility and experiences with mylBDcoach.

\section{Ethical considerations}

The study was approved by the Medical Research Ethics Committee of the Maastricht University Medical Centre (METC azM/UM), which waived the requirement to obtain inform consent. The study protocol conformed to the provisions of the declaration of Helsinki.

\section{Data collection and outcome measures}

Feasibility data in terms of satisfaction, accessibility and experiences with mylBDcoach were collected from patients' and healthcare providers' evaluation questionnaires. Compliance with mylBDcoach in this pilot study was predefined as $\geq 70 \%$ adherence with the monthly monitoring modules. Demographic information was obtained from all patients at the time of recruitment. 


\section{Statistical analyses}

Descriptive analyses to evaluate demographic information and to assess feasibility with myIBDcoach were performed using IBM SPSS statistics 22.0.

\section{RESULTS}

\section{Development MylBDcoach}

\section{Technological development}

A personal web-based telemedicine system for IBD patients, mylBDcoach, was designed and developed as a secure webpage (http://www.mijnibdcoach.nl) and HTML application on a tablet or smartphone (figure 3). MylBDcoach can be used as a stand-alone programme, however, incorporation in different hospital electronic patient files is technically also possible. Sananet BV provides technical support for all participants (patients and healthcare providers).

\section{Content development}

During the first brainstorm meeting with the identified stakeholders (figure 1, phase II), patients emphasised the importance of better communication with the hospital, tailored information about their disease and medication, as well as patient-centred care. Gastroenterologists noticed that a more holistic approach to the IBD-patient was needed, since many disease-related aspects, including nutrition, work productivity, smoking, anxiety and depression were often not addressed in current practice, but are of relevance for disease outcome and health-related quality of life. Furthermore the importance to monitor disease activity and side-effects of (immunosuppressive) drugs was emphasised. Both gastroenterologists and the representatives from the pharmaceutical industry indicated better monitoring of therapy adherence to be of relevance to optimise treatment. At home monitoring of disease activity and disease-related aspects at regular intervals requires validated patient-reported outcome measures (PROMs), which are also demanded by governments for registration of efficacy endpoints for expensive drugs.

Based on literature review, validated PROMs on medication adherence, medication satisfaction, nutritional status, quality of life, work productivity, anxiety and depression, social support and fatigue, were selected. When different validated questionnaires on the same topic were available in the literature, the shortest applicable questionnaire was chosen if there were no major advantages of the other questionnaires, to constrain monitoring modules to a reasonable length. 


\section{Phase I: stake holder identification}

- 4 gastroenterologists (2 academic hospitals +2 non-academic hospitals)

- 5 IBD-nurses (2 academic hospitals +2 non-academic hospitals)

- 1 dietitian

- 2 representatives IBD patients' organization (CCUVN)

- Representatives pharmaceutical industry

Phase II: brainstorm

- Design: monitoring, information, communication

- Relevant topics

- Safety management

\section{Phase III: questionnaire selection}

- Review available (validated) questionnaires covering selected topics

- Selection suitable (validated) questionnaires

- Identification of topics without existing suitable questionnaire

\section{Phase IV: development questionnaires}

- Development missing questionnaires

\section{Phase V: content optimization and finalization}

- Balance between selected questionnaires and total amount of questions per module

\section{Phase VI: e-learning modules}

- Selection topics for e-learning modules

- E-learning modules development by experts

\section{Phase VII: testing}

- MylBDcoach was tested and optimized by gastroenterologists and IBD-nurses after every phase

Figure 1. Different phases of design and content development of mylBDcoach 
Validated PROMs for disease activity and infectious events were not available in the literature (figure 1, phase III). Existing-patient reported disease activity questionnaires, such as the Patient Harvey Bradshaw Index and the Patient Simple Clinical Colitis Activity Index, are not validated against endoscopy and show poor correlation with endoscopic disease activity ${ }^{41-44}$. Therefore, mylBDcoach utilises a newly developed Monitor IBD At Home questionnaire $(\mathrm{MIAH})^{45}$ (figure 1, phase IV). This is a symptom-based patientreported outcome measure that is validated against endoscopy and does not require laboratory tests or physical examination. The MIAH shows good diagnostic accuracy to screen for patients who need further assessment of disease activity with biochemical markers, imaging or endoscopy ${ }^{45}$, and excellent accuracy when combined with a fecal calprotectin home-test ${ }^{46}$. A score of $\leq 3.6$ is defined as remission. In addition, a new questionnaire on medication side-effects and infectious events was developed.

A schematic overview of the design of mylBDcoach is shown in figure 2 and an overview of questionnaires as well as their frequency of monitoring is given in table 1.

\section{Monitoring module}

Patients are requested to complete the regular 'monitoring module' monthly, which contains questions regarding disease activity $(\mathrm{MIAH})^{45}$, extra-intestinal manifestations, medication use, medication adherence (Morisky Medication Adherence Scale (MMAS-8)(47)), medication satisfaction (Treatment Satisfaction Questionnaire for Medication (TSQM)(48)) and medication side-effects including infections. In addition, the monitoring module measures general disease aspects as quality of life (EuroQol instrument (EQ-5D)(49) and Short Form Health Survey (SF-12)(50)), work productivity (Work Productivity and Activity Impairment (WPAI)(51)), nutritional status (Malnutrition Screening Tool (MST)(52)) and Short Nutritional Assessment Questionnaire (SNAQ)(53)), fatigue, physical exercise, stress, life-events, anxiety and depression, social support and self-management skills. When the disease is in remission, defined as three consecutive $\mathrm{MIAH}$-scores $\leq 3.6$, patients will be asked if they prefer to fill out the questionnaire once per three months. In case of a flare, defined as a MIAH-score $>3.6$, patients are requested to log on weekly and complete the 'intensified monitoring module' on disease activity and medication use until the symptoms subside.

\section{Back-office}

The administrator page, further referred to as back-office, is used by the patient's own healthcare provider, i.e. a gastroenterologist and/or an IBD nurse (specialist), and provides an overview of all participating patients per centre. As mylBDcoach is a selfmanagement system, patients are in the lead to contact the healthcare provider in case of symptoms or other questions. To ensure safety of home-monitoring, alerts (red flags) are created in the back-office when values recorded from the questions of the monitor- 
ing module exceed pre-defined thresholds. In case of an alert, the healthcare provider will contact the patient for further evaluation. Based on the extent and severity of the complaints they decide whether the patient should be seen at the outpatient clinic. At any time, patients can communicate easily with their healthcare provider by sending a message through the secure connection to the back-office of the healthcare provider. Every new message creates an alert in the back-office.

\section{Outpatient visit module}

When a routine outpatient visit is scheduled, patients are asked to prepare this visit by completing the 'outpatient visit module', which registers patient-reported disease activity $(\mathrm{MIAH})^{45}$, extra-intestinal manifestations ${ }^{54}$ and parameters which may influence long-term disease outcomes such as quality of life (Short Inflammatory Bowel Disease Questionnaire $(\mathrm{SIBDQ})^{55}$, smoking, work productivity (WPAI) ${ }^{51}$, intimacy and sexuality, anxiety and depression (Hospital Anxiety and Depression Scale $(\mathrm{HADS})^{56}$ ), medication adherence, social support (Social Support List $(S S L)^{57}$ ) and fatigue (Shortened fatigue questionnaire $(S F Q)^{58}$ ). The values recorded from these questionnaires are presented in a clear overview to make the consultation with the gastroenterologist as efficient as possible and to make sure all relevant topics will be discussed and patients will be referred to other specialists when necessary. Furthermore, patients are given the opportunity to note what they would like to discuss with their healthcare provider during the visit.

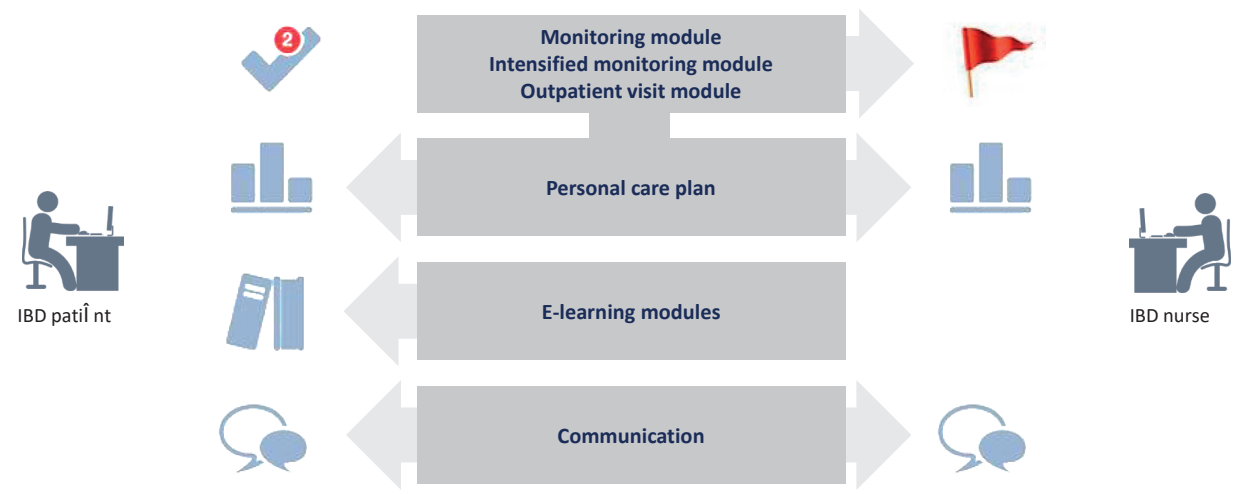

Figure 2. Schematic overview of different functions of mylBDcoach: monitoring, personal follow-up plan, e-learning modules and communication. An overview of content and frequency of modules is shown in table 1 . When values recorded from the questions of the monitoring modules exceed pre-defined thresholds, alerts (red flags) are created in the back-office.

\section{E-learning modules}

To improve patients' knowledge on IBD we developed patient-tailored interactive elearning modules about CD and UC in general, 5-ASA, immunosuppressives or anti-tumor necrosis factor therapy, medication adherence, smoking cessation, (mal)nutrition, 
how to prevent or reduce symptoms (self-management), fatigue, work productivity, pregnancy, intimacy, anxiety and depression, influenza vaccination and about how to receive adequate support from friends, family and colleagues (figure 1, phase VI). Both patients and healthcare providers can start an e-learning module, i.e. patients can be advised to perform a certain e-learning module whenever their healthcare provider considers it desirable or when the patients themselves are interested in a specific topic.

\section{Self-management}

All information derived from the monitoring and outpatient visit modules is presented in a personal follow-up plan. The follow-up plan summarises all disease aspects in tables and graphs for both the patient and the healthcare provider (figure 4). By providing insight in their follow-up plan, we aim to improve patients' self-management and stimulate patient-empowerment.

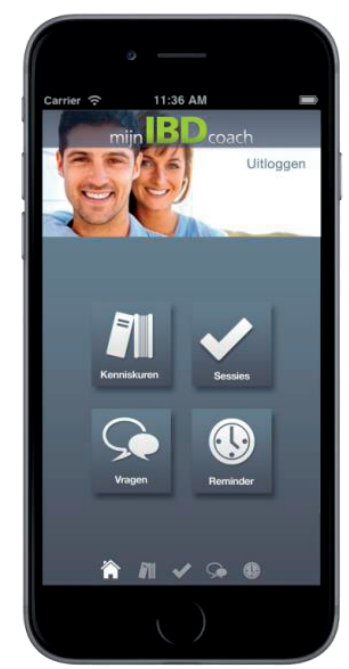

Figure 3. MylBDcoach 

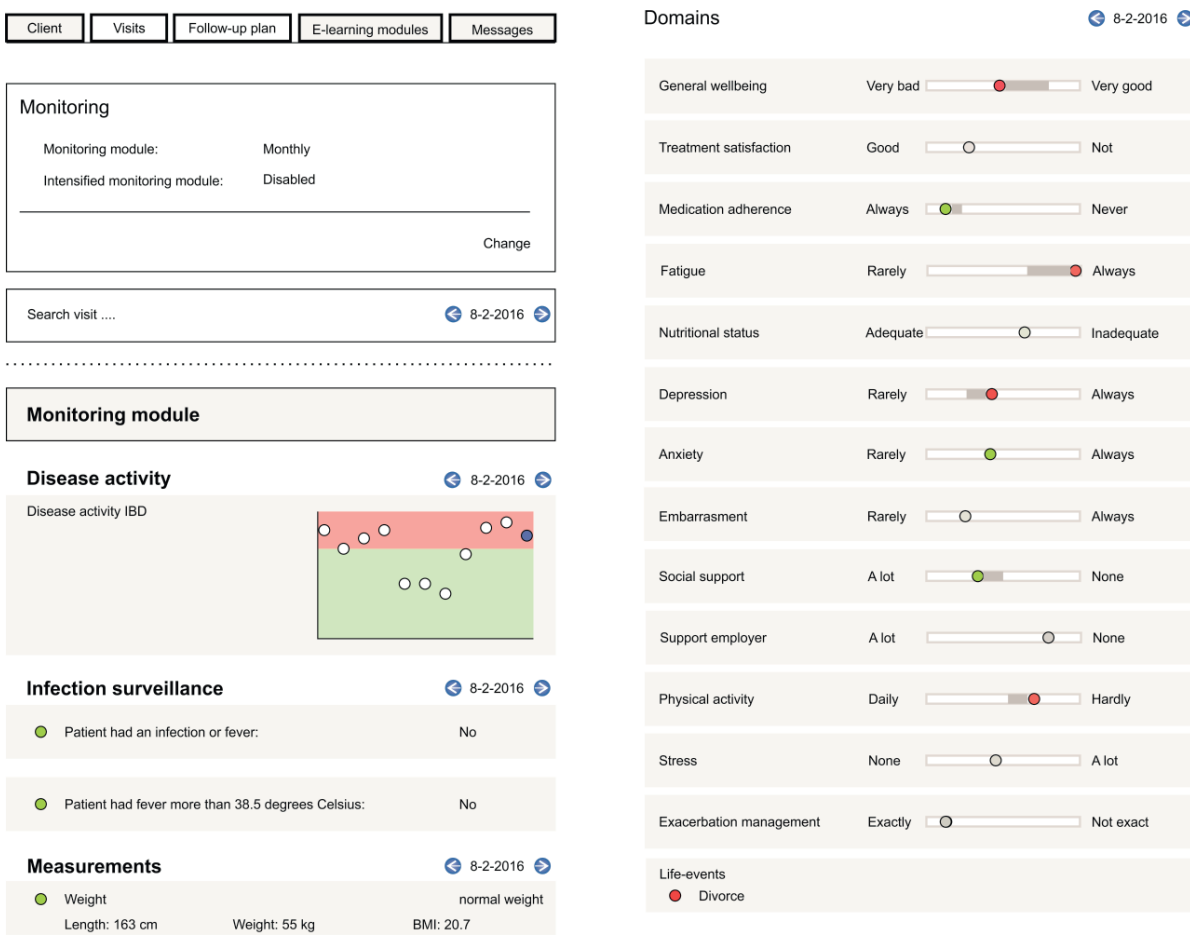

Figure 4. Follow-up plan of mylBDcoach.

\section{Results feasibility study myIBDcoach}

MyIBDcoach was pilot-tested by 30 IBD patients and 8 healthcare providers. Patient characteristics are shown in table 2 . Compliance with the monthly monitoring modules was $100 \%$. Patients judged mylBDcoach with a mean score of 7.8 out of 10 , and healthcare providers gave a mean score of 8.0 out of 10 . Both patients and healthcare providers found the design and accessibility of the system of high quality. One patient thought the system was time-consuming. Ninety-three percent of the patients would recommend mylBDcoach to other patients.

During the 3-month study period, $40 \%$ of the patients $(n=12)$ contacted their healthcare provider through mylBDcoach for urgent symptoms or general questions. Of these patients, $83 \%$ percent found that this contact had a positive contribution to the overall contact with their healthcare provider. Ninety percent of the patients completed at least one e-learning module. After completing the e-learning modules, a majority of these patients felt that their general knowledge about their disease had improved. 
Table 1. Design of mylBDcoach

\begin{tabular}{|c|c|c|}
\hline Section & Function & Frequency \\
\hline $\begin{array}{l}\text { Monitoring } \\
\text { module }\end{array}$ & $\begin{array}{l}\text { 1. Monitors patient-reported disease activity (MIAH (45)), extra-intestinal } \\
\text { manifestations, medication use, adherence (MMAS-8 (47)), satisfaction } \\
\text { (TSQM (48)) and side-effects } \\
\text { 2. Monitors general disease aspects: nutritional status (MST (52) and } \\
\text { SNAQ (53)), quality of life (EQ-5D (49), SF-12 (50)), work productivity } \\
\text { (WPAI (51)), infections and single questions on fatigue, physical exercise, } \\
\text { stress, life-events, anxiety and depression, social support and self- } \\
\text { management skills. }\end{array}$ & $\begin{array}{c}\text { Monthly or } \\
\text { every } 3 \text { months } \\
\text { when sustained } \\
\text { remission }\end{array}$ \\
\hline $\begin{array}{l}\text { Intensified } \\
\text { monitoring } \\
\text { module }\end{array}$ & $\begin{array}{l}\text { Monitors patient-reported disease activity (MIAH (45)) and medication } \\
\text { usage in case of a flare. }\end{array}$ & Weekly \\
\hline $\begin{array}{l}\text { Outpatient visit } \\
\text { module }\end{array}$ & $\begin{array}{l}\text { Registers patient-reported disease activity (MIAH (45)), extra-intestinal } \\
\text { manifestations, quality of life (SIBDQ (55)), smoking, work productivity } \\
\text { (WPAI (51)), intimacy and sexuality, anxiety and depression (HADS (56)), } \\
\text { medication adherence, nutritional status (MST (52) and SNAQ (53)), } \\
\text { social support (SSL (57)) and fatigue (SFQ (58)) and a topic patients } \\
\text { would like discuss with their healthcare provider during the upcoming } \\
\text { outpatient visit. }\end{array}$ & $\begin{array}{l}\text { Yearly/when } \\
\text { applicable }\end{array}$ \\
\hline $\begin{array}{l}\text { E-learning } \\
\text { module }\end{array}$ & Offers patient tailored information on 16 selected topics. & When applicable \\
\hline Communication & $\begin{array}{l}\text { Facilitates communication between patient and healthcare provider } \\
\text { and provides systematic documentation of communication. }\end{array}$ & 24/7 available \\
\hline Follow-up plan & $\begin{array}{l}\text { Gives a clear overview of follow-up for both patient and healthcare } \\
\text { provider. }\end{array}$ & 24/7 available \\
\hline
\end{tabular}

MIAH, Monitor IBD At Home; MMAS-8, Morisky Medication Adherence Scale; TSQM, Treatment Satisfaction Questionnaire for Medication; MST, Malnutrition Screening Tool; SNAQ, Short Nutritional Assessment Questionnaire; EQ-5D, EuroQol instrument; SF-12, Short Form Health Survey; WPAI, Work Productivity and Activity Impairment; SIBDQ, Short Inflammatory Bowel Disease Questionnaire; HADS, Hospital Anxiety and Depression Scale; SSL, Social Support List; SFQ, Shortened Fatigue Questionnaire.

Table 2. Baseline characteristics of the participating patients in the feasibility study

\begin{tabular}{lc}
\hline & Participating patients $(\mathbf{n}=\mathbf{3 0})$ \\
\hline Age, mean (SD) & $44.2(11.7)$ \\
Gender, N (\%) & $12(40.0)$ \\
Male & $14.7(13.8)$ \\
Disease duration (years), mean (SD) & \\
Phenotype, N (\%) & $17(56.7)$ \\
CD & $13(43.3)$ \\
UC & \\
\hline
\end{tabular}




\section{DISCUSSION}

This paper describes the systematic development of the first telemedicine system that enables home-monitoring for all subtypes of IBD patients. A pilot study proved that myIBDcoach is feasible for use in routine care and well-accepted by patients and healthcare providers. Patients were compliant with the programme, indicated that mylBDcoach facilitated communication with their healthcare providers and that the e-learning modules improved their knowledge about IBD.

During this pilot study, adherence to the system was very high. In the literature telemedicine tools faced attrition rates as high as $14-44 \%$ over time ${ }^{10,15,26,30,34}$. We aimed to increase compliance with mylBDcoach by involving patients in all stages of the development, by providing feedback to the patient in a follow-up plan and by constraining questionnaires to a reasonable length with individualised frequency. To increase patient empowerment, mylBDcoach contains e-learning modules, promotes patients' self-management and facilitates communication between patients and healthcare providers. The finding that $93 \%$ of patients would recommend mylBDcoach to other patients reflects a high patient satisfaction rate. Additionally, to enhance user friendliness, mylBDcoach can also be used on a smartphone or tablet.

Despite proven benefits of telemedicine for IBD and other chronic diseases, few systems are implemented in every day care. One possible reason might be that previously published tools monitor, educate or empower specific groups of patients ${ }^{10,26,30,34}$ (table 3). Contrary to this, we deliberately designed myIBDcoach for all subtypes of IBD patients in different settings, regardless of phenotype, disease activity or medication use. In addition, we wanted mylBDcoach to focus on all facets of this complex disease, i.e. not only directly IBD-related aspects, but also on stress, smoking, nutritional status and treatment adherence, which may impact disease outcome and quality of life. Prevention of treatment non-adherence for example, reported to be as high as $40-60 \%$ in IBD patients, has a significant impact on the risk of disease relapse, hospitalisation, healthcare costs and work absenteeism ${ }^{9,10}$.

Jackson et al. recently reviewed the entire spectrum of eHealth interventions used for IBD management and provided recommendations for the design of future IBD eHealth technologies to facilitate implementation ${ }^{15}$. They emphasised the importance of a framework for development, evaluation and implementation of eHealth interventions and the relevance of patient and clinician involvement in all stages. MylBDcoach was developed through close collaboration between patients, nurses and gastroenterologists during all phases of the development. The rights for the content of the system are governed by a nonprofit foundation. The board and content committee of the mylBDcoach foundation consist of patients and clinicians from all important Dutch stakeholders involved 
in IBD care. The foundation carefully monitored all phases of the developmental and implementation process.

Since the pilot study showed that IBD care with myIBDcoach is feasible and can be used for routine follow-up, we initiated a randomised controlled trial to investigate whether the integrated and holistic approach of mylBDcoach is safe and increases efficiency of IBD care compared to standard care. A total of 909 consecutive IBD outpatients from academic and non-academic hospitals, regardless of disease severity and activity and treatment strategies ranging from no treatment to combined immunosuppressives, were included and randomised to care via mylBDcoach or standard care for one year. The primary endpoints are the number of outpatient visits and patient-reported quality of IBD healthcare. Secondary endpoints include disease outcomes (i.e. flares, corticosteroid use, hospitalisations, emergency visits and IBD-related surgery), medication adherence and quality of life. We will also assess whether use of mylBDcoach leads to patient empowerment by an increase in knowledge about the disease and treatment and whether mylBDcoach is a suitable tool for structured collection of PROMs.

In conclusion, we developed mylBDcoach, which enables integrated and holistic care for all IBD patients in both academic and non-academic centres. This feasibility study showed high satisfaction of patients and healthcare providers with the system. Following these positive results, a large multicentre randomised controlled trial has been initiated. 


\section{REFERENCES}

1. Burisch J, Munkholm P. The epidemiology of inflammatory bowel disease. Scandinavian journal of gastroenterology. 2015;50:942-951

2. Cosnes J, Gower-Rousseau C, Seksik P, et al. Epidemiology and natural history of inflammatory bowel diseases. Gastroenterology. 2011;140:1785-1794

3. van der Valk ME, Mangen MJ, Leenders $M$, et al. Healthcare costs of inflammatory bowel disease have shifted from hospitalisation and surgery towards anti-TNFalpha therapy: results from the COIN study. Gut. 2014;63:72-79

4. Bernklev T, Jahnsen J, Lygren I, et al. Health-related quality of life in patients with inflammatory bowel disease measured with the short form-36: psychometric assessments and a comparison with general population norms. Inflammatory bowel diseases. 2005;11:909-918

5. Zand A, van Deen WK, Inserra EK, et al. Presenteeism in Inflammatory Bowel Diseases: A Hidden Problem with Significant Economic Impact. Inflammatory bowel diseases. 2015;21:1623-1630

6. Colombel JF, Narula N, Peyrin-Biroulet L. Management Strategies to Improve Outcomes of Patients with Inflammatory Bowel Diseases. Gastroenterology. 2016

7. Bodger K. Cost effectiveness of treatments for inflammatory bowel disease. Pharmacoeconomics. 2011;29:387-401

8. Di Sabatino A, Liberato L, Marchetti M, et al. Optimal use and cost-effectiveness of biologic therapies in inflammatory bowel disease. Intern Emerg Med. 2011;6 Suppl 1:17-27

9. Lakatos PL. Prevalence, predictors, and clinical consequences of medical adherence in IBD: how to improve it? World J Gastroenterol. 2009;15:4234-4239

10. Pedersen $\mathrm{N}$, Thielsen $\mathrm{P}$, Martinsen $\mathrm{L}$, et al. eHealth: individualization of mesalazine treatment through a self-managed webbased solution in mild-to-moderate ulcerative colitis. Inflammatory bowel diseases. 2014;20:2276-2285

11. Molodecky NA, Soon IS, Rabi DM, et al. Increasing incidence and prevalence of the inflammatory bowel diseases with time, based on systematic review. Gastroenterology. 2012;142:46-54 e42; quiz e30

12. Kemp K, Griffiths J, Campbell S, et al. An exploration of the follow-up up needs of patients with inflammatory bowel disease. Journal of Crohn's \& colitis. 2013;7:e386395

13. Huang VW, Reich KM, Fedorak RN. Distance management of inflammatory bowel disease: systematic review and meta-analysis. World J Gastroenterol. 2014;20:829-842

14. Williams JG, Cheung WY, Russell IT, et al. Open access follow up for inflammatory bowel disease: pragmatic randomised trial and cost effectiveness study. BMJ. 2000;320:544-548

15. Jackson BD, Gray K, Knowles SR, et al. EHealth Technologies in Inflammatory Bowel Disease: A Systematic Review. Journal of Crohn's \& colitis. 2016

16. Boyne JJ, Van Asselt AD, Gorgels AP, et al. Cost-effectiveness analysis of telemonitoring versus usual care in patients with heart failure: the TEHAF-study. J Telemed Telecare. 2013;19:242-248

17. Boyne JJ, Vrijhoef HJ, Wit R, et al. Telemonitoring in patients with heart failure, the TEHAF study: Study protocol of an ongoing prospective randomised trial. Int J Nurs Stud. 2011;48:94-99

18. Rasmussen LM, Phanareth $\mathrm{K}$, Nolte $\mathrm{H}$, et al. Internet-based monitoring of asthma: a long-term, randomized clinical study of 300 asthmatic subjects. J Allergy Clin Immunol. 2005;115:1137-1142

19. Omboni S, Ferrari R. The role of telemedicine in hypertension management: focus 
on blood pressure telemonitoring. Curr Hypertens Rep. 2015;17:535

20. Trappenburg JC, Koevoets L, de Weert-van Oene $\mathrm{GH}$, et al. Action Plan to enhance self-management and early detection of exacerbations in COPD patients; a multicenter RCT. BMC Pulm Med. 2009;9:52

21. Bartoli L, Zanaboni P, Masella C, et al. Systematic review of telemedicine services for patients affected by chronic obstructive pulmonary disease (COPD). Telemed J E Health. 2009;15:877-883

22. Weinstock RS, Teresi JA, Goland R, et al. Glycemic control and health disparities in older ethnically diverse underserved adults with diabetes: five-year results from the Informatics for Diabetes Education and Telemedicine (IDEATel) study. Diabetes Care. 2011;34:274-279

23. Cox D, Ritterband L, Magee J, et al. Blood glucose awareness training delivered over the internet. Diabetes Care. 2008;31:15271528

24. Wootton R, Geissbuhler A, Jethwani K, et al. Comparative performance of seven long-running telemedicine networks delivering humanitarian services. J Telemed Telecare. 2012;18:305-311

25. Sutherland D, Hayter M. Structured review: evaluating the effectiveness of nurse case managers in improving health outcomes in three major chronic diseases. J Clin Nurs. 2009;18:2978-2992

26. Elkjaer M, Shuhaibar M, Burisch J, et al. Ehealth empowers patients with ulcerative colitis: a randomised controlled trial of the web-guided 'Constant-care' approach. Gut. 2010;59:1652-1661

27. Keefer L, Kiebles JL, Taft TH. The role of selfefficacy in inflammatory bowel disease management: preliminary validation of a disease-specific measure. Inflammatory bowel diseases. 2011;17:614-620

28. Cross RK, Jr. Telemanagement for inflammatory bowel disease. Gastroenterol Hepatol (N Y). 2014;10:255-257
29. Cross RK, Cheevers N, Finkelstein J. Home telemanagement for patients with ulcerative colitis (UC HAT). Dig Dis Sci. 2009;54:2463-2472

30. Cross RK, Cheevers N, Rustgi A, et al. Randomized, controlled trial of home telemanagement in patients with ulcerative colitis (UC HAT). Inflammatory bowel diseases. 2012;18:1018-1025

31. Cross RK, Finkelstein J. Challenges in the design of a Home Telemanagement trial for patients with ulcerative colitis. Clin Trials. 2009;6:649-657

32. Cross RK, Jambaulikar $G$, Langenberg $P$, et al. TELEmedicine for Patients with Inflammatory Bowel Disease (TELE-IBD): Design and implementation of randomized clinical trial. Contemp Clin Trials. 2015;42:132144

33. Elkjaer M, Burisch J, Avnstrom S, et al. Development of a Web-based concept for patients with ulcerative colitis and 5-aminosalicylic acid treatment. Eur J Gastroenterol Hepatol. 2010;22:695-704

34. Pedersen N, Elkjaer $M$, Duricova $D$, et al. eHealth: individualisation of infliximab treatment and disease course via a self-managed web-based solution in Crohn's disease. Aliment Pharmacol Ther. 2012;36:840-849

35. Cross RK, Arora M, Finkelstein J. Acceptance of telemanagement is high in patients with inflammatory bowel disease. J Clin Gastroenterol. 2006;40:200-208

36. Cross RK, Finkelstein J. Feasibility and acceptance of a home telemanagement system in patients with inflammatory bowel disease: a 6-month pilot study. Dig Dis Sci. 2007;52:357-364

37. Crohn en Colitis Ulcerosa Vereniging Nederland (CCUVN) wc-cn.

38. Stichting mijnIBDcoach wsn.

39. Sananet BV wsn.

40. Lennard-Jones JE. Classification of inflammatory bowel disease. Scand J Gastroenterol Suppl. 1989;170:2-6; discussion 16-19 
41. Bennebroek Evertsz F, Hoeks CC, Nieuwkerk PT, et al. Development of the patient Harvey Bradshaw index and a comparison with a clinician-based Harvey Bradshaw index assessment of Crohn's disease activity. J Clin Gastroenterol. 2013;47:850-856

42. Bennebroek Evertsz F, Nieuwkerk PT, Stokkers $\mathrm{PC}$, et al. The patient simple clinical colitis activity index (P-SCCAI) can detect ulcerative colitis (UC) disease activity in remission: a comparison of the P-SCCAI with clinician-based SCCAI and biological markers. Journal of Crohn's \& colitis. 2013;7:890-900

43. Falvey JD, Hoskin T, Meijer B, et al. Disease activity assessment in IBD: clinical indices and biomarkers fail to predict endoscopic remission. Inflammatory bowel diseases. 2015;21:824-831

44. af Bjorkesten CG, Nieminen $U$, Turunen $U$, et al. Surrogate markers and clinical indices, alone or combined, as indicators for endoscopic remission in anti-TNF-treated luminal Crohn's disease. Scandinavian journal of gastroenterology. 2012;47:528537

45. M. de Jong JD, T. van den Heuvel, $M$. Romberg-Camps, B. Winkens, T. Markus, A. Masclee, A. van Tubergen, D. Jonkers, M. Pierik. Development of a patient reported disease activity score to screen for mucosal inflammation in inflammatory bowel disease. Journal of Crohn's and Colitis. 2 February 2015 ed; 2015

46. de Jong M. JDMAE, Romberg - Camps M., Bodelier A.G.L., van de Wetering A.J.P., van Etten T., Conjaerts S.H.P., Markus T., Masclee A.A.M., Pierik M.J. A combination of the Monitor IBD At Home questionnaire and a calprotectin home test as excellent screening tool for mucosal inflammation in IBD patients. United European Gastroenterology Journal; 2016: 2 (Supplement 1) 2016

47. Morisky DE, Green LW, Levine DM. Concurrent and predictive validity of a self-reported measure of medication adherence. Med Care. 1986;24:67-74

48. Atkinson MJ, Sinha A, Hass SL, et al. Validation of a general measure of treatment satisfaction, the Treatment Satisfaction Questionnaire for Medication (TSQM), using a national panel study of chronic disease. Health Qual Life Outcomes. 2004;2:12

49. EuroQol G. EuroQol--a new facility for the measurement of health-related quality of life. Health Policy. 1990;16:199-208

50. Ware J, Jr., Kosinski M, Keller SD. A 12-Item Short-Form Health Survey: construction of scales and preliminary tests of reliability and validity. Med Care. 1996;34:220-233

51. Reilly MC, Zbrozek AS, Dukes EM. The validity and reproducibility of a work productivity and activity impairment instrument. Pharmacoeconomics. 1993;4:353-365

52. Nursal TZ, Noyan T, Atalay BG, et al. Simple two-part tool for screening of malnutrition. Nutrition. 2005;21:659-665

53. Kruizenga HM, Seidell JC, de Vet HC, et al. Development and validation of a hospital screening tool for malnutrition: the short nutritional assessment questionnaire (SNAQ). Clin Nutr. 2005;24:75-82

54. Stolwijk C, Pierik M, Landewe $R$, et al. Prevalence of self-reported spondyloarthritis features in a cohort of patients with inflammatory bowel disease. Can J Gastroenterol. 2013;27:199-205

55. Irvine EJ, Zhou Q, Thompson AK. The Short Inflammatory Bowel Disease Questionnaire: a quality of life instrument for community physicians managing inflammatory bowel disease. CCRPT Investigators. Canadian Crohn's Relapse Prevention Trial. The American journal of gastroenterology. 1996;91:1571-1578

56. Zigmond AS, Snaith RP. The hospital anxiety and depression scale. Acta Psychiatr Scand. 1983;67:361-370

57. Bridges KR, Sanderman $R$, van Sonderen E. An English language version of the social 
support list: preliminary reliability. Psychol Rep. 2002;90:1055-1058

58. Alberts $M$, Smets EM, Vercoulen $\mathrm{JH}$, et al. ['Abbreviated fatigue questionnaire': a practical tool in the classification of fatigue]. Ned Tijdschr Geneeskd. 1997;141:1526-1530 



\section{Chapter 5}

\section{Telemedicine for management of inflammatory bowel disease (myIBDcoach): a pragmatic, multicentre, randomised controlled trial}

Marin de Jong, Andrea van der Meulen-de Jong,

Mariëlle Romberg-Camps, Marco Becx, Jeroen Maljaars,

Mia Cilissen, Ad van Bodegraven, Nofel Mahmmod, Tineke Markus, Wim Hameeteman, Gerard Dijkstra, Ad Masclee, Annelies Boonen, Bjorn Winkens, Astrid van Tubergen, Daisy Jonkers, Marieke Pierik 


\section{ABSTRACT}

Background Tight and personalised control of inflammatory bowel disease in a traditional setting is challenging because of the disease complexity, high pressure on outpatient clinics, and rising incidence. We compared the effects of self-management with a telemedicine system, which was developed for all subtypes of inflammatory bowel disease, on healthcare utilisation and patient-reported quality of care versus standard care.

Methods We did this pragmatic, randomised trial in two academic and two non-academic hospitals in the Netherlands. Outpatients aged 18-75 years with inflammatory bowel disease and without an ileoanal or ileorectal pouch anastomosis, who had internet access and Dutch proficiency, were randomly assigned $(1: 1)$ to care via a telemedicine system (mylBDcoach) that monitors and registers disease activity or standard care and followed up for 12 months. Randomisation was done with a computer-generated sequence and used the minimisation method. Participants, healthcare providers, and staff who assessed outcome measures were not masked to treatment allocation. Primary outcomes were the number of outpatient visits and patient-reported quality of care (assessed by visual analogue scale score 0-10). Safety endpoints were the numbers of flares, corticosteroid courses, hospital admissions, emergency visits, and surgeries. Analyses were by intention to treat. This trial is registered with ClinicalTrials.gov, number NCT02173002.

Findings Between Sept 9, 2014, and May 18, 2015, 909 patients were randomly assigned to telemedicine $(n=465)$ or standard care $(n=444)$. At 12 months, the mean number of outpatient visits to the gastroenterologist or nurse was significantly lower in the telemedicine group (1.55 [SD 1.50]) than in the standard care group (2.34 [1.64]; difference -0.79 [95\% $\mathrm{Cl}-0.98$ to -0.59 ]; $\mathrm{p}<0.0001$ ), as was the mean number of hospital admissions ( 0.05 [0.28] vs 0.10 [0.43]; difference -0.05 [ -0.10 to 0.00$]$; $p=0.046)$. At 12 months, both groups reported high mean patient-reported quality of care scores (8.16 [1.37] in the telemedicine group vs 8.27 [1.28] in the standard care group; difference 0.10 [-0.13 to 0.32 ]; $p=0.411$ ). The mean numbers of flares, corticosteroid courses, emergency visits, and surgeries did not differ between groups.

Interpretation Telemedicine was safe and reduced outpatient visits and hospital admissions compared with standard care. This self-management tool might be useful for reorganising care of inflammatory bowel disease towards personalised and value-based healthcare. 


\section{RESEARCH IN CONTEXT}

\section{Evidence before this study}

We searched PubMed and MEDLINE for randomised controlled trials of telemedicine in inflammatory bowel diseases published up to Dec 20,2016, with the terms "telemedicine", "eHealth", "mHealth", "inflammatory bowel disease", "randomised controlled trial", and "adults". This search retrieved two randomised studies, both of which were in patients with ulcerative colitis. The first trial compared self-testing of disease activity and weight measurements versus standard care in 47 patients; no differences were seen between groups in disease activity, medication adherence, and quality of life. The second trial included 333 patients with mild-to-moderate disease treated with mesalazine and found that tight disease monitoring and personalised treatment strategies resulted in an improvement of patient empowerment, quality of life, and medication adherence, and a reduction in outpatient visits and relapse duration compared with usual care. Because both studies reported data on the effects of telemedicine for a specific subgroup, no reliable conclusion could be drawn on the effectiveness of telemedicine for the entire population of patients with inflammatory bowel disease or on which subtypes of patients are likely to benefit most. This shortcoming compromises the use of telemedicine systems in real-world settings.

\section{Added value of this study}

Our study includes data on the effects of telemedicine in patients with all subtypes of inflammatory bowel disease, irrespective of phenotype, disease course, or medication use. Telemonitoring in combination with patient-tailored information, a personal care plan, easy, accessible contact with the inflammatory bowel disease nurse, and registration of patient-reported outcome measures resulted in a reduction in healthcare utilisation and hospital admissions. Furthermore, the telemedicine system mylBDcoach improved medication adherence and patients reported similar scores for quality of care compared with the standard care group. These results were consistent across different patient subtypes. Our findings accord with those in other chronic relapsing-remitting diseases and suggest that tight disease monitoring and early intervention in case of a relapse can prevent admission to hospital. Trials with a longer follow-up period are required to determine whether telemedicine can change the natural disease course of chronic diseases in the long-term. 


\section{Implications of all the available evidence}

Routine follow-up of patients with inflammatory bowel disease, traditionally consisting of prescheduled visits that are unlikely to correspond with its unpredictable clinical course, puts increasing pressure on outpatient clinics, compromising accessibility and quality of care. Implementation of telemedicine in inflammatory bowel disease care bridges the gap between the healthcare workers' requests for tight disease monitoring and continuity of care in an overburdened outpatient setting and patients' demands for more involvement in disease management. Telemedicine is safe, highly accepted by patients and healthcare workers, and can be used to reorganise care for patients with all subtypes of inflammatory bowel disease. In our clinic, mylBDcoach will be used in a value-based healthcare initiative. Furthermore, patients in remission or with mild disease will be monitored and guided with telemedicine supervised by a specialised nurse to guarantee adequate access to the gastroenterologists' outpatient clinic for those patients with complex disease or in need of urgent action.

\section{INTRODUCTION}

Inflammatory bowel disease is a group of chronic, relapsing inflammatory disorders of the gut, with Crohn's disease and ulcerative colitis being the main subtypes. The clinical presentations of these diseases vary widely among individuals, as shown by variations in disease location and behaviour, relapse frequency, extra-intestinal manifestations, complications, and responses to treatment. ${ }^{1}$

Traditionally, management of inflammatory bowel disease consists of standard scheduled follow-up visits, with a frequency based on medical treatment, but independent of the occurrence of unpredictable flares. ${ }^{2,3}$ Until recently, the primary treatment goal was induction and maintenance of clinical remission. However, disease management based on treating symptoms alone did not improve long-term outcomes, defined as the numbers of flares, courses of corticosteroid treatment, hospital admissions, complications, and surgeries. ${ }^{4,5}$ Therefore, recent guidelines advocate more stringent management, involving tight control of disease activity and early intervention in patients with intestinal inflammation. ${ }^{6}$ Other interventions address aspects of inflammatory bowel disease that might influence disease activity, such as non-adherence to treatment, unfavourable nutritional status, smoking, and psychological factors. ${ }^{7-9}$ These interventions were shown to reduce the rates of disease relapse, healthcare utilisation including hospital admission, and absence from work in subsets of patients. ${ }^{7-9}$ This approach, however, has not been systematically implemented in routine care, because acquiring all the necessary information at the right moment for every individual patient remains a challenge. 
Furthermore, the heterogeneous nature of inflammatory bowel disease, combined with an absence of adequate markers for patient stratification, can lead to the underuse or overuse of resources.

Tight control of disease activity and personalised monitoring of all relevant health parameters during traditional visits put substantial pressure on patients' time and the capacity of outpatient clinics. The incidence of inflammatory bowel disease is increasing and insurance companies, governments, and patient organisations increasingly demand registration of patient-reported outcome measures, patient-reported experience measures, and quality metrics. ${ }^{10-13}$ Therefore, reorganisation of healthcare for patients with inflammatory bowel disease is warranted.

Telemedicine systems, which have been used to manage chronic diseases, such as congestive heart failure and chronic obstructive pulmonary disease, have been shown to improve quality of care and could help optimise the use of available resources. ${ }^{14,15}$ Telemedicine allows for the strict and instantaneous follow-up of health parameters and timely, personalised interventions. Moreover, these systems can provide tailored information based on each patient's needs.

At present, few telemedicine systems that can improve disease outcomes, increase patients' empowerment, and reduce healthcare utilisation are available for patients with inflammatory bowel disease. ${ }^{7,16-21}$ However, these tools were developed for patients with specific subtypes of inflammatory bowel disease, consisting of those with mild-tomoderate disease activity. Studies provide inconsistent results on the effects of these telemedicine systems on disease outcomes, compromising their use in real-world settings.

We therefore developed a telemedicine system (mylBDcoach) that monitors and registers disease activity in patients with all subtypes of inflammatory bowel disease. This system, which can be used in both academic and non-academic hospitals, also monitors other disease-related parameters, including patient-reported outcome measures and quality metrics. This information is displayed in a manner understood by the user and his or her healthcare providers. Integrated care and patient empowerment are promoted by a communication function and a wide range of web-based learning methods. A pilot study showed that integration of mylBDcoach into routine care was feasible and well accepted by patients as well as healthcare providers. We postulated that use of this telemedicine system in routine care could reduce healthcare utilisation, while ensuring tight disease monitoring and high patient-experienced quality of care. We did a pragmatic, multicentre, randomised controlled trial to investigate the effect of care with this telemedicine system on outpatient visits, patient-reported quality of care, and disease outcomes, and compared these effects with those of standard care. 


\section{METHODS}

\section{Study design and participants}

This pragmatic randomised trial was done at four hospitals in the Netherlands: two academic hospitals (Maastricht University Medical Centre and Leiden University Medical Centre), and two large, non-academic, regional hospitals (Zuyderland Medical Centre, Sittard, and St Antonius Hospital, Nieuwegein). Each participating hospital serves 1500-2000 patients with inflammatory bowel disease, had one or two dedicated nurses or nurse specialists, and had an e-mail and telephone consultation structure for patients with inflammatory bowel disease to contact the hospital. Furthermore, each hospital provided patients with the opportunity to consult by telephone with a nurse (at least) three times per week at fixed timepoints. Patients were enrolled the outpatient clinic of the four participating hospitals. All consecutive patients between 18 and 75 years of age, fulfilling the international diagnostic criteria for inflammatory bowel disease, ${ }^{23}$ were eligible for inclusion. Exclusion criteria were an inability to read or understand the informed consent form, and lack of internet access by computer, tablet, or smartphone. Additionally, patients with a hospital admission within 2 weeks before inclusion were excluded for ethical reasons, because these patients were deemed unable to make an informed decision for participation. Patients with an ileoanal pouch or ileorectal anastomosis were also excluded. The study was approved by the medical research ethics committee of the Maastricht University Medical Centre. This approval was applicable to all participating centres. The study protocol is available online in Dutch.

\section{Randomisation and masking}

After signing the informed consent form, patients were randomly assigned (1:1) to care via the telemedicine system (intervention) or standard care (control). Randomisation was done with ALEA Screening and Enrolment Application Software using the minimisation method, stratified for medical centre, subtypes of inflammatory bowel disease (Crohn's disease or ulcerative colitis), and treatment (no medication or mesalazine; immunosuppressive drugs; or biological therapy). Participants, healthcare providers, and staff who assessed outcome measures were not masked to treatment allocation.

\section{Procedures}

The details of the telemedicine system mylBDcoach have been described elsewhere. ${ }^{22}$ MylBDcoach is a secured webpage with an HTML application for tablet or smartphone (figure 1). The system includes monthly monitoring modules, which contain questions regarding disease activity, medication use, treatment adherence, treatment satisfaction, and side-effects, including infections. The system also includes questions on factors affecting disease (including nutritional status, smoking, stress, life events, anxiety and 
depression, social support, physical exercise, and self-management skills), and patientreported outcome measures on quality of life and work productivity. In monitoring disease activity, myIBDcoach uses the newly developed Monitor IBD At Home (MIAH) questionnaire, a symptom-based patient-reported outcome measure validated relative to endoscopy. This questionnaire does not require laboratory tests or physical examination, and shows good diagnostic accuracy in screening for patients requiring further assessment of disease activity with biochemical markers, imaging, or endoscopy. When the disease was in remission, defined as three consecutive low monthly MIAH scores, patients were allowed to complete the monitoring module once every 3 months. Furthermore, the system includes intensified monitoring modules (weekly in case of flare), outpatient visit modules (to prepare for an outpatient visit), e-learning modules, a personal care plan, and an administrator page used by the healthcare provider (ie, gastroenterologist or nurse). When parameters recorded by the monitoring modules exceeded predefined thresholds, the safety and continuity of care were ensured by the creation of alerts (red flags) on the administrator page of each local hospital. In all participating centres, the administrator page was checked at least twice daily apart from weekend

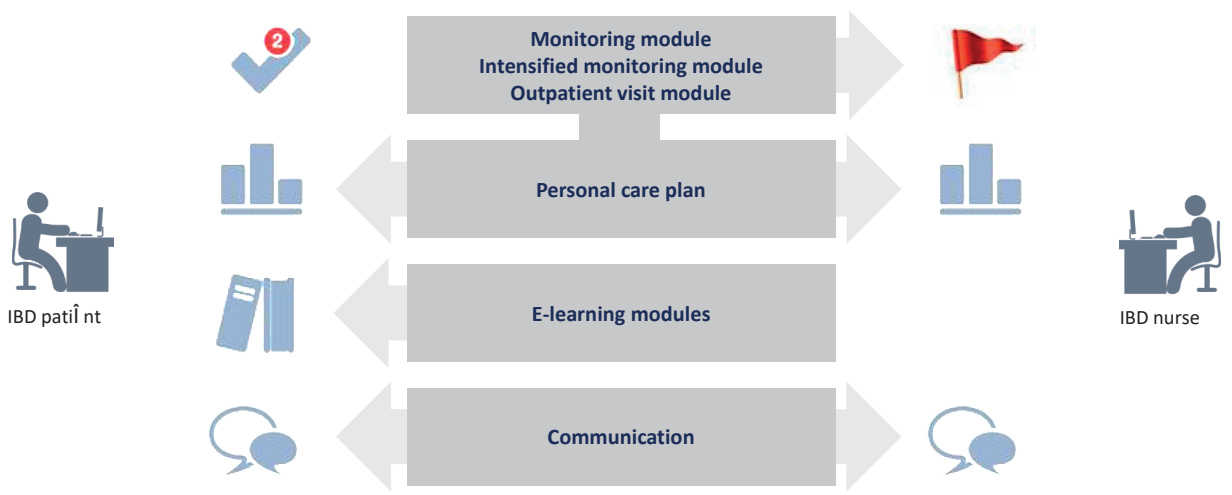

Figure 1. Overview of the elements of the telemedicine tool mylBDcoach: 1) Modules containing different questionnaires: standard monitoring (every month, or every 3 months when the disease is in remission), intensified monitoring (weekly in case of a flare) and outpatient visit monitoring (to prepare an outpatient visit). 2) Personal care plan: summary and visualisation of health parameters, PROMs and quality metrics. 3) e-learning modules: interactive patient-tailored information on topics such as medications, adherence to medication, smoking cessation, (mal)nutrition, methods to prevent or reduce symptoms (self-management), fatigue, work productivity, anxiety and depression. 4) Communication: secure message connection between patient and healthcare providers' back-office. 
days. If an alert was received, a healthcare provider on the local team contacted the patient for further assessment within two working days. Visits to the outpatient clinic were based on the nature and severity of the clinical complaints. At any time, patients were able to communicate easily with their healthcare provider by sending a message to the healthcare providers' administration office.

Patients assigned to the intervention group received instructions, a username, and a password for the telemedicine system. Participants used the system for 12 months and were instructed to plan at least one routine outpatient visit per year. Additional follow-up visits were scheduled on the basis of alarm symptoms recognised by the telemedicine system or at the requests of individual patients. Patients in the standard care group continued their routine follow-up visits following the local protocol, with an opportunity to schedule an extra visit if symptoms relapsed. At baseline and after 12 months, all participants received a paper questionnaire regarding perceived quality of care, medication adherence, quality of life, self-efficacy, disease-related and medicationrelated knowledge, and smoking behaviour.

\section{Outcomes}

The primary outcomes were the number of outpatient visits and patient-reported quality of care. The number of outpatient visits and telephone consultations with gastroenterologists and nurses during the 12 month period were retrieved from patients' electronic medical records. Because validated patient-reported quality of care questionnaires have insufficient content validity for telemedicine interventions, patient-reported quality of care was measured with seven relevant domains derived from different questionnaires. These domains included visual analogue scale (VAS) scores (0-10; higher score indicates higher quality) on patient satisfaction with healthcare, patients' experiences contacting their healthcare providers, and the extent to which healthcare meets patients' expectations. Questions were also included on the healthcare workers' timeliness of response to questions and symptoms, healthcare workers' fulfilment of agreements and attentiveness to acute situations, and hospital accessibility in case of symptoms. A mean score of 8 out of 10 or higher was predefined as perceived high quality.

Secondary outcomes were adherence to treatment, quality of life, self-efficacy, disease-related and medication-related knowledge, smoking behaviour, and disease outcomes. Disease outcomes were the numbers of flares and inflammatory bowel disease-related hospital admissions, emergency visits, surgeries, and corticosteroid use during the 12 months of follow-up. Flares were defined as clinical symptoms indicative of disease activity with, as a rule, concomitant calprotectin of more than $250 \mu \mathrm{g} / \mathrm{g}$ in the stool or active disease determined by endoscopy, MRI, or CT. In daily practice, in case of clinically severe symptoms suggestive for disease activity, the treating physician occasionally judged these symptoms to be evident enough to adjust therapy. Therefore, to 
capture all clinical flares, clinical episodes were defined as flares if symptoms suggestive of disease activity resulted in a dose escalation or initiation of a new drug to induce remission. Medication adherence was measured with the eight-item Morisky Medication Adherence Scale, ${ }^{25}$ with scores below 6 defined as low adherence, scores between 6 and 8 defined as moderate adherence, and a score of 8 defined as high adherence. Quality of life was measured with the Short Inflammatory Bowel Disease Questionnaire (SIBDQ), a ten-item questionnaire that covers four domains: bowel symptoms, systemic symptoms, emotional health, and social functions. ${ }^{26}$ Overall scores on the SIBDQ range from 10 to 70, with a lower score indicating lower quality of life. Self-efficacy, defined as the perception of one's ability to engage in skills required to master a new challenge despite obstacles, was measured with the 29-item inflammatory bowel disease self-efficacy scale (IBD-SES). ${ }^{27}$ Questions are grouped into four domains: managing stress and emotions, managing medical care, managing symptoms and disease, and maintaining remission. Overall scores on the IBD-SES range from 29 to 290, with higher scores indicating higher self-efficacy and thus better self-management and greater patient empowerment. Knowledge of inflammatory bowel disease and medication were both assessed by a VAS score (0-10; higher score indicates better knowledge), whereas smoking behaviour was assessed with a categorical question (non-smoker, active-smoker, or ex-smoker).

\section{Statistical analysis}

A sample size of 435 patients per group was estimated as sufficient to detect a difference of one outpatient visit per year (SD 2.4) and 0.5 difference in mean quality of care on a VAS scale (SD 1.4), with $80 \%$ power, a $5 \%$ significance level, and assuming a $10 \%$ dropout rate. Data were analysed on an intention-to-treat basis. Between-group differences in the number of outpatient consultations and disease outcomes were analysed by multivariable linear regression adjusted for the stratification criteria (medical centre [four centres], subtypes of inflammatory bowel disease [Crohn's disease or ulcerative colitis], and treatment [no medication or mesalazine; immunosuppressive drugs; or biological therapy]) and for age (numerical), sex (male or female), disease duration (numerical), disease activity at baseline (remission or active), smoking (non-smoker, active-smoker, or ex-smoker), and educational level (five levels). Because the normality assumption might be violated because of outliers, its effect on the results was checked by comparing the obtained confidence intervals with those after bootstrapping. The multiple imputation method was used for missing outcomes and covariates, in which 20 complete datasets were created using all other variables in the aforementioned analysis model (outcome and covariate, including study group) to impute the missing data. Linear mixed model analyses were used to assess differences in patient-reported outcomes at baseline and 12 months; outcomes analysed included quality of care, quality of life, medication adherence, self-efficacy, and disease-related and medication-related knowledge. 
An unstructured covariance structure for the two repeated measures was considered and a likelihood based approach was used for missing outcome variables. Results were corrected for stratification criteria and for age, sex, disease duration, disease activity at baseline, smoking, and educational level. The consistency of the intervention effect was assessed across subtypes of sex, age (18-30, 31-50, and $>50$ years), subtypes of inflammatory bowel disease (Crohn's disease and ulcerative colitis), setting (academic and non-academic), medication (no medication or mesalazine; immunosuppressive drugs; and biological therapy), and disease duration (0-5, 6-10, and $>10$ years), by post-hoc analyses where interaction terms of these variables with group (intervention and control) were added separately to the aforementioned linear regression and linear mixed models. The adjusted intervention effects that were estimated with these models are reported together with their $95 \% \mathrm{Cl}$ and $\mathrm{p}$ values. Logistic regression analysis was used to assess the intervention effect on smoking behaviour (active vs non-active [exsmoker or non-smoker]) and was corrected for baseline smoking behaviour (active vs non-active) and educational level. A two-sided $\mathrm{p} \leq 0.05$ was defined as statistically significant. All statistical analyses were done with SPSS version 22.0. This trial is registered with ClinicalTrials. gov, number NCT02173002.

\section{Role of the funding source}

The funding source had no role in study design, data collection, data analysis, data interpretation, or writing of the report. The corresponding author had full access to all the data in the study and had final responsibility for the decision to submit for publication.

\section{RESULTS}

Between Sept 9, 2014, and May 18, 2015, about 3000 outpatients with inflammatory bowel disease were asked to participate in this study, of whom $17 \%$ did not meet the inclusion criteria, $41 \%$ did not return the invitation letter, and $12 \%$ were not interested, providing reasons such as "too busy", "participating in other studies", "not now", "too much confrontation with the disease", and "impersonality of telemedicine" (figure 2). 909 eligible patients provided written informed consent and were randomly assigned, 465 to the telemedicine group and 444 to the standard care group. Neither protocol deviations nor adverse events related to use of the telemedicine intervention occurred. The baseline characteristics of the two study groups were similar and were representative of the general inflammatory bowel disease population in demographic characteristics and disease activity (table 1). ${ }^{28}$ At the end of the 12 month study period, 438 (94\%) patients in the telemedicine group continued to use the telemedicine system and 443 (99.8\%) in the standard care group continued their routine follow-up visits in the same hospital 


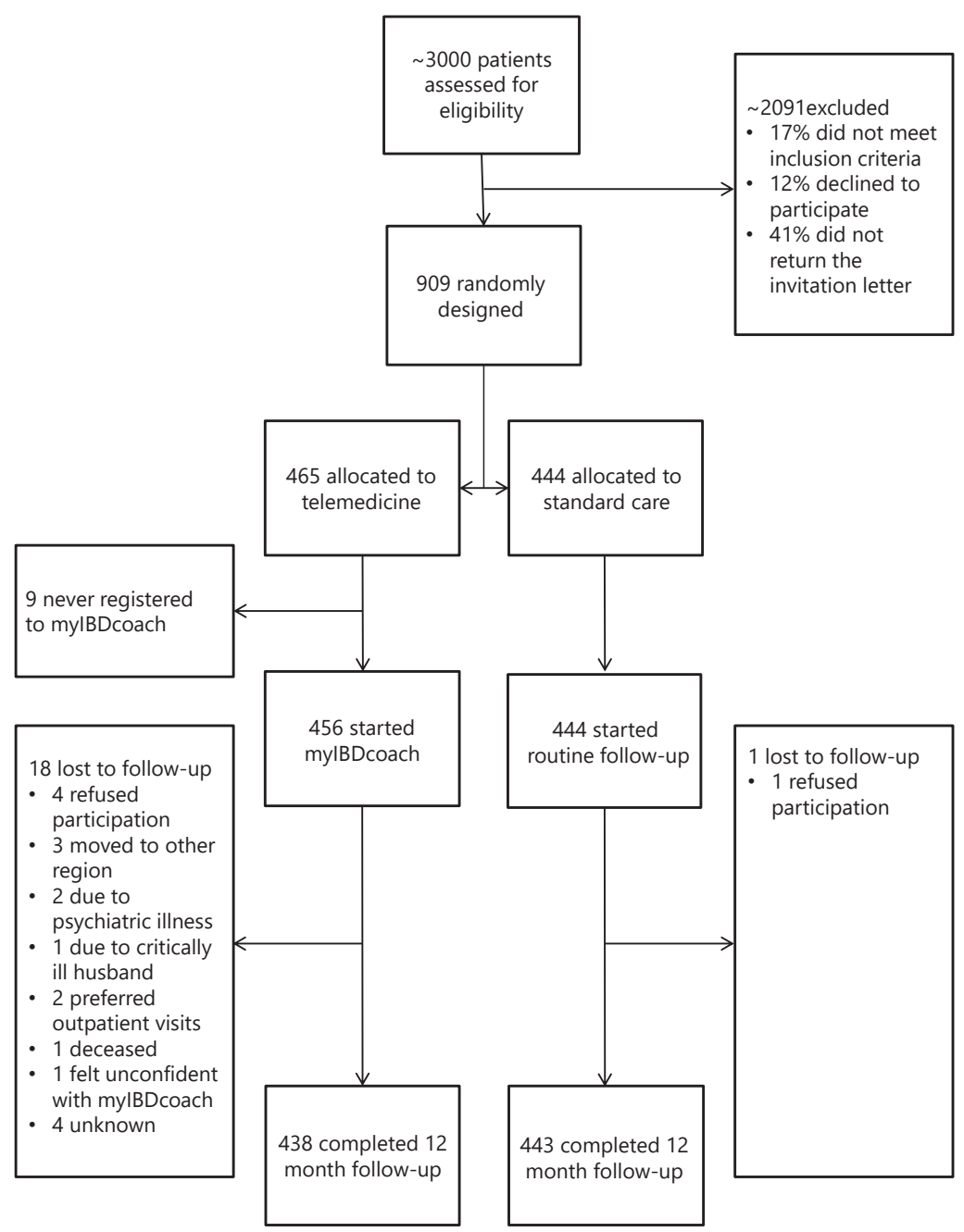

Figure 2. Trial profile.

(figure 2). At baseline, 382 (82\%) patients in the telemedicine group and 369 (83\%) in the standard care group completed the paper questionnaires about perceived quality of care, medication adherence, quality of life, self-efficacy, disease-related and medicationrelated knowledge, and smoking behaviour. At 12 months, these questionnaires were completed by 340 (73\%) patients in the telemedicine group and 331 (75\%) patients in the standard care group. All randomised patients were included in the analyses (intentionto-treat population). One patient in the telemedicine group died because of mucinous colorectal cancer, which was deemed to be unrelated to the study intervention.

At 12 months, the mean number of outpatient visits to the gastroenterologist was significantly lower in the telemedicine group than in the standard care group (1.26 [SD 
Table 1. Baseline characteristics

MylBDcoach $(n=465) \quad$ Standard care $(n=444)$

Centre, N

Maastricht University Medical Centre

133

144

117

71

St. Antonius Hospital Nieuwegein

Gender, N (\%)

\section{Male}

Female

Age at diagnosis, mean (SD)

Age at inclusion, mean (SD)

Disease duration (years), mean (SD)

Phenotype, N (\%)

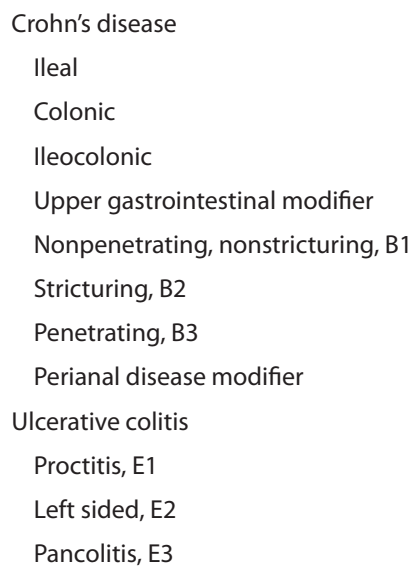

Treatment (N), (\%)

No medication/mesalazine

Immunosuppressives

Biologicals

Baseline disease activity, N (\%)

Remission

Active disease

Smokers, N (\%)

Non-smoker

Active smoker

Ex-smoker

Education, N (\%)

Academic
Higher vocational education
Intermediate vocational education
Secondary education
Primary education

$194(41.7)$
$271(58.3)$
$30.7(13.5)$
$44.0(14.1)$
$12.8(10.4)$
$282(60.6)$
$87 / 282(30.9)$
$67 / 282(23.8)$
$128 / 282(45.4)$
$34 / 282(12.1)$
$169 / 282(59.9)$
$76 / 282(27.0)$
$37 / 282(13.1)$
$67 / 282(23.8)$
$183(39.4)$
$26 / 183(14.2)$
$81 / 183(44.3)$
$76 / 183(41.5)$

$173 / 465(37.2)$

122/465 (26.2)

170/465 (36.6)

394/465 (84.7)

$71 / 465$ (15.3)

157/379 (41.4)

$65 / 379$ (17.2)

157/379 (41.4)

$54 / 379$ (14.2)

$103 / 379(27.2)$

160/379 (42.2)

$56 / 379$ (14.8)

6/379 (1.6)
131

152

102

59

$180(40.5)$

264 (59.5)

30.4 (13.6)

44.1 (14.2)

$13.1(10.8)$

262 (59.0)

$68 / 262(26.0)$

63/262 (24.0)

$131 / 262(50.0)$

26/262 (9.9)

152/262 (58.0)

70/262 (26.7)

40/262 (15.3)

62/262 (23.7)

182 (41.0)

27/182 (14.8)

70/182 (38.5)

85/182 (46.7)

147/444 (33.1)

$131 / 444$ (29.5)

$166 / 444$ (37.4)

380/444 (85.6)

64/444 (14.4)

159/367 (43.3)

50/367 (13.6)

158/367 (43.1)

49/367 (13.4)

98/367 (26.7)

157/367 (42.8)

$55 / 367(15.0)$

8/367 (2.1) 
1.18] in the telemedicine group vs 1.98 [1.19] in the standard care group; estimated intervention effect -0.72 [95\% Cl -0.87 to -0.56 ]; $p<0.0001$; table 2). Outpatient visits to the nurse, however, did not differ significantly between groups (table 2). The total number of outpatient visits (gastroenterologist or nurse) was significantly lower in the telemedicine group than in the standard care group (1.55 [1.50] in the telemedicine group vs 2.34 [1.64] in the standard care group; estimated intervention effect -0.79 [-0.98 to -0.59$] ; p<0.0001)$. The mean number of telephone consultations with the gastroenterologist was also significantly lower in the telemedicine group than in the standard care group, but the mean number of telephone consultations with the nurse did not differ significantly (table 2). These results were largely consistent across patients with Crohn's disease and ulcerative colitis, those treated in academic and non-academic settings, men and women, all age categories, all medication categories, and all disease duration categories (supplementary table 1). However, for patients in academic settings, the mean number of outpatient visits to the nurse was lower in the telemedicine group than in the standard care group (supplementary table 1).

Table 2. The effects of myIBDcoach on healthcare utilisation compared to standard care.

\begin{tabular}{lccccc}
\hline \multicolumn{7}{c}{$\begin{array}{c}\text { MylBDcoach } \\
\mathbf{n}=\mathbf{4 6 5}\end{array}$} & $\begin{array}{c}\text { Standard care } \\
\mathbf{n = 4 4 4}\end{array}$ & & & \\
\cline { 2 - 6 } & Mean (SD) & Mean (SD) & Estimated intervention effect $^{\text {a }}$ & 95\% Cl & P-value \\
\hline Outpatient visits & & & & & \\
Gastroenterologist & $1.26(1.18)$ & $1.98(1.19)$ & -0.72 & $-0.87,-0.56$ & $<0.001$ \\
Nurse & $0.29(0.68)$ & $0.36(0.84)$ & -0.07 & $-0.17,0.03$ & 0.173 \\
Total & $1.55(1.50)$ & $2.34(1.64)$ & -0.79 & $-0.98,-0.59$ & $<0.001$ \\
Phone consultations & & & & & \\
Gastroenterologist & $0.58(0.98)$ & $0.84(1.11)$ & -0.26 & $-0.40,-0.12$ & $<0.001$ \\
Nurse & $0.70(1.59)$ & $0.74(1.90)$ & -0.08 & $-0.30,0.13$ & 0.448 \\
Total & $1.28(2.06)$ & $1.57(2.44)$ & -0.34 & $-0.63,-0.06$ & 0.018 \\
\hline
\end{tabular}

a Adjusted for centre, treatment, phenotype, age, gender, disease duration, disease activity at baseline, smoking, and educational level. Bootstrap Cls were similar to those presented here. The estimated intervention effect, $95 \% \mathrm{Cl}$ and $\mathrm{p}$-value were obtained after multiple imputation.

Patients in the telemedicine and standard care groups reported similar and high scores for quality of care at 12 months (8.16 [SD 1.37] vs 8.27 [1.28], respectively; estimated intervention effect 0.10 [95\% Cl -0.13 to 0.32 ]; $p=0.411$; table 3 ). Results were similar in patients with Crohn's disease and ulcerative colitis, those treated in academic and non-academic settings, men and women, and in all age and disease duration categories. Patients in the telemedicine group using biological therapies reported lower scores for quality of care than did patients in the standard care group $(p=0.037$; supplementary table 2). 
Over the 12 month follow-up period, the mean numbers of flares, courses of corticosteroid treatment, emergency visits, and inflammatory bowel disease-related surgeries did not differ significantly between the two groups (table 4). The mean number of hospital admissions was significantly lower in the telemedicine group than in the standard care group (16 unique patients admitted to hospital in the telemedicine group vs 29 in the standard care group; estimated intervention effect -0.05 [ $95 \% \mathrm{Cl}-0.10$ to 0.00$] ; \mathrm{p}=0.046$ ). Reasons for admission to hospital included exacerbation of disease (six patients in the telemedicine group vs eight in the standard care group), surgery (eight vs ten), complications of the disease (ie, intestinal obstruction, active perianal disease, or ostomy dysfunction; six vs 14), medication side-effects (one vs six), and abdominal pain without evidence for active disease (none vs five). Analyses per subtype showed no significant differences between groups in numbers of flares, courses of corticosteroid treatment, emergency visits, and inflammatory bowel disease-related surgeries (supplementary

Table 3. The effects of mylBDcoach on patient-reported outcomes compared to standard care.

\begin{tabular}{|c|c|c|c|c|c|c|c|}
\hline & \multicolumn{2}{|c|}{ MylBDcoach } & \multicolumn{2}{|c|}{ Standard care } & \multirow[b]{2}{*}{$\begin{array}{c}\text { Estimated } \\
\text { intervention } \\
\text { effect }^{\mathrm{a}}\end{array}$} & \multirow[b]{2}{*}{$95 \% \mathrm{Cl}$} & \multirow[b]{2}{*}{ P-value } \\
\hline & $\mathrm{n}$ & $\begin{array}{l}\text { Mean score } \\
\text { (SD) }\end{array}$ & $\mathrm{n}$ & $\begin{array}{c}\text { Mean score } \\
\text { (SD) }\end{array}$ & & & \\
\hline \multicolumn{8}{|c|}{ Quality of care } \\
\hline Baseline & 382 & $8.25(1.24)$ & 369 & $8.26(1.05)$ & \multirow{2}{*}{0.10} & \multirow{2}{*}{$-0.13,0.32$} & \multirow{2}{*}{0.411} \\
\hline 12 months & 340 & $8.16(1.37)$ & 331 & $8.27(1.28)$ & & & \\
\hline \multicolumn{8}{|c|}{ Medication adherence } \\
\hline Baseline & 382 & $6.52(1.76)$ & 369 & $6.67(1.70)$ & \multirow{2}{*}{0.46} & \multirow{2}{*}{$0.22,0.70$} & \multirow{2}{*}{$<0.001$} \\
\hline 12 months & 340 & $7.01(1.40)$ & 331 & $6.77(1.61)$ & & & \\
\hline \multicolumn{8}{|l|}{ Quality of life } \\
\hline Baseline & 382 & $53.34(10.29)$ & 369 & $53.42(9.95)$ & \multirow{2}{*}{1.22} & \multirow{2}{*}{$-0.04,2.49$} & \multirow{2}{*}{0.057} \\
\hline 12 months & 340 & $54.44(9.05)$ & 331 & $53.71(9.87)$ & & & \\
\hline \multicolumn{8}{|l|}{ Self-efficacy } \\
\hline Baseline & 382 & $224.16(64.04)$ & 369 & $222.14(36.88)$ & \multirow{2}{*}{2.45} & \multirow{2}{*}{$-6.05,10.94$} & \multirow{2}{*}{0.572} \\
\hline 12 months & 340 & $223.35(32.11)$ & 331 & $220.28(35.08)$ & & & \\
\hline \multicolumn{8}{|c|}{ Knowledge on inflammatory bowel disease } \\
\hline Baseline & 383 & $7.66(1.30)$ & 369 & $7.57(1.36)$ & \multirow{2}{*}{0.20} & \multirow{2}{*}{$-0.19,0.41$} & \multirow{2}{*}{0.074} \\
\hline 12 months & 340 & $8.17(1.16)$ & 331 & $7.84(1.47)$ & & & \\
\hline \multicolumn{8}{|c|}{ Knowledge on medication } \\
\hline Baseline & 383 & $7.34(1.51)$ & 369 & $7.29(1.44)$ & \multirow{2}{*}{0.14} & \multirow{2}{*}{$-0.09,0.37$} & \multirow{2}{*}{0.235} \\
\hline 12 months & 340 & $7.75(1.58)$ & 331 & $7.58(1.51)$ & & & \\
\hline
\end{tabular}

Quality of care was assessed by a VAS-scale, medication adherence by the MMAS- ${ }^{25}$, quality of life by the

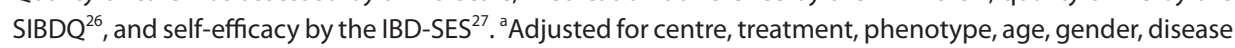
duration, disease activity at baseline, smoking, educational level, and baseline patient-reported values. Bootstrap Cls were similar to those presented here. The estimated intervention effect, $95 \% \mathrm{Cl}$ and $\mathrm{p}$-value were obtained from linear mixed models based on the likelihood approach for missing outcome data. 
table 3). However, patients in the telemedicine group with Crohn's disease (estimated intervention effect -0.09 [ $95 \% \mathrm{Cl}-0.17$ to -0.02$] ; \mathrm{p}=0.012$ ), or using biological therapies $(-0.12$ [ -0.22 to -0.02$] ; p=0.025)$, or with a disease duration of more than 10 years $(-0.08$ [ -0.17 to 0.00$] ; p=0.045$ ) were less often admitted to the hospital than their respective controls. Adherence to medication at the end of the trial was significantly higher in the telemedicine group than in the standard care group (table 3). Both groups reported normal values for quality of life and high scores for self- efficacy and disease-related and medication-related knowledge, with no significant differences between groups (table 3). Smoking behaviour at the end of the study period did not differ between groups (odds ratio 0.81 [95\% $\mathrm{Cl} 0.33-1.96] ; \mathrm{p}=0.633$, supplementary table 4).

Table 4. The effects of mylBDcoach on disease outcomes compared to standard care.

\begin{tabular}{|c|c|c|c|c|c|}
\hline & $\begin{array}{c}\text { MylBDcoach } \\
n=465\end{array}$ & $\begin{array}{c}\text { Standard care } \\
\mathrm{n}=\mathbf{4 4 4}\end{array}$ & & & \\
\hline & Mean, SD & Mean, SD & $\begin{array}{c}\text { Estimated intervention } \\
\text { effect }^{\mathrm{a}}\end{array}$ & $95 \% \mathrm{Cl}$ & P-value \\
\hline Flares & $0.19,0.42$ & $0.19,0.44$ & -0.01 & $-0.06,0.05$ & 0.819 \\
\hline Corticosteroid courses & $0.10,0.33$ & $0.12,0.37$ & -0.02 & $-0.07,0.02$ & 0.322 \\
\hline Hospital admissions & $0.05,0.28$ & $0.10,0.43$ & -0.05 & $-0.10,0.00$ & 0.046 \\
\hline Emergency visits & $0.07,0.35$ & $0.10,0.54$ & -0.03 & $-0.09,0.03$ & 0.366 \\
\hline $\begin{array}{l}\text { Inflammatory bowel disease- } \\
\text { related surgeries }\end{array}$ & $0.03,0.16$ & $0.03,0.16$ & 0.00 & $-0.02,0.02$ & 0.786 \\
\hline
\end{tabular}

Adjusted for center, treatment, phenotype, age, gender, disease duration, disease activity at baseline, smoking, and educational level. Bootstrap Cls were similar to those presented here. The estimated intervention effect, $95 \% \mathrm{Cl}$ and $\mathrm{p}$-valure obtained after multiple imputation.

\section{DISCUSSION}

This pragmatic, randomised controlled trial compared a telemedicine system versus standard outpatient care for patients with inflammatory bowel disease, irrespective of disease course or treatment. Our findings showed that use of the telemedicine system resulted in a reduction in outpatient visits, telephone consultations, and admissions to hospital, and increased adherence to medication. Additionally, the telemedicine system was safe and patient-reported quality of healthcare remained high.

Ameliorating quality of care for chronic diseases has been defined as improving long-term disease outcomes, creating a healthier population, and reducing healthcare costs. ${ }^{12,29}$ Our results showed that the use of a telemedicine system reduced the number of outpatient visits, while enabling tight follow-up of disease activity. Disease monitoring with the telemedicine system was safe, because there were no significant differences between groups in numbers of flares, corticosteroid courses, emergency visits, and surgeries. Moreover, use of the telemedicine system resulted in fewer hospital admissions. 
These results are in line with the improved care and monitoring with telemedicine in other (relapsing-remitting) chronic diseases, such as chronic obstructive pulmonary disease and heart failure. ${ }^{14,15}$ However, those studies were done in fairly small and specific patient subgroups, with differences in follow-up times and outcome measures, resulting in inconsistent results. This inconsistency complicates the ability to draw firm conclusions on the effectiveness of telemedicine in larger real-world populations.

To our knowledge, mylBDcoach is the first telemedicine tool for all subtypes of inflammatory bowel disease, irrespective of phenotype, setting, medical treatment, or disease severity. Two previous randomised controlled trials assessed the effect of telemedicine on the management of subtypes of inflammatory bowel disease with mild disease. ${ }^{19,20}$ One trial, in 47 patients with ulcerative colitis, compared self-testing of disease activity by questionnaires and weight measurements with standard care, but found no differences between groups in disease outcomes. ${ }^{20}$ The other trial, in 333 patients with mild-to-moderate ulcerative colitis who were being treated with mesalazine, showed that tight monitoring of disease activity and personalised treatment strategies reduced outpatient visits compared with usual care. ${ }^{19}$ By contrast with our findings, disease activity, relapse frequency, and rates of hospital admission and surgery did not differ in the two groups. However, active self-management shortened relapse duration. As in our study, telemedicine improved adherence to treatment, but we did not find differences in quality of life, self-efficacy, and disease-related and medication-related knowledge, which might have been caused by the high baseline scores on these questionnaires in both the telemedicine and standard care groups. ${ }^{26,27}$ Our study was done in four centres with well organised and accessible outpatient clinics with dedicated nurses and an email and telephone consultation structure. As a consequence, rates of outpatient visits were relatively low compared with other European clinics, ${ }^{30}$ suggesting that the effect of the telemedicine system on the reduction of outpatient visits might be larger in other clinics.

In addition to disease activity, mylBDcoach also monitors factors that affect disease outcomes, including adherence to treatment, psychosocial factors, smoking, and nutrition. Awareness of these factors and development of standard intervention procedures and educational programmes can further improve the long-term outcome of patients with inflammatory bowel disease. For example, improved medication adherence has been found to improve long-term disease outcomes. ${ }^{7,8}$ The telemedicine system offers interactive e-learning modules on various subjects, allowing patients to review modules when they or their healthcare providers consider it desirable. The system also registers patient-reported outcome measures on quality of life and work productivity, and quality metrics for value-based healthcare following the International Consortium for Health Outcomes Measurement recommendations. These findings can immediately be visualised and reported to both individual users and their healthcare providers in a personal 
care plan. Hospitals with value-based healthcare programmes could use telemedicine systems to measure patient-reported outcome measures and patient-reported experience measures. ${ }^{10}$ Furthermore, systematic registration of quality metrics and aggregation of these metrics from different practices might improve quality of care and reduce practice variability. ${ }^{11,31}$

The main strength of our study was its randomised and pragmatic design. An unselected heterogeneous group of patients, clinicians, and clinical practices were included to maximise the applicability of these results to everyday practice. A potential weakness of the study design was that neither patients nor clinicians were masked to group assignments. We discussed giving all patients the telemedicine system while only monitoring patients in the intervention group. However, we felt that it was not ethical to ask the control group to use the telemedicine system without monitoring possibly relevant information resulting from red flags, nor to instruct those patients to plan follow-up visits only when necessary rather than traditionally booked appointments. The fairly short follow-up period can also be considered a limitation of the study. Intervention trials with 12 month follow-up are, however, regarded sufficient for maintenance drug therapy for registration purposes. Nevertheless, clinicians and patients require time to adapt to an altered clinical workflow. Interventions based on aberrant patient-reported outcome measure values require new procedures and protocols. Trials with longer follow-up periods are required to determine whether the telemedicine system can control costs and improve long-term disease outcomes.

Although telemedicine shows many benefits in managing patients with chronic diseases, few "tele-systems" have been implemented in everyday care. Among the reasons are the absence of a framework for the development, evaluation, and implementation of eHealth interventions; ${ }^{18}$ a disconnect between users and developers of health IT systems; ${ }^{32}$ the development of telemedicine programmes aimed at specific subgroups of patients with regard to treatment regimen, disease severity, or healthcare setting $i^{7,19-21}$ and financial hurdles such as reimbursement of telemedicine consultations by insurance companies. To overcome these barriers, mylBDcoach was developed and pilot-tested with a structured iterative process and through close collaboration between the developer, delegates from the Dutch inflammatory bowel disease patient organisation (CCUVN), nurses, and gastroenterologists working in secondary and tertiary referral centres. ${ }^{22}$ Additionally, we deliberately assessed the effects of telemedicine on quality of care in a large unselected population of patients with all subtypes of inflammatory bowel disease, representative of a general inflammatory bowel disease population in a specialised care setting, ${ }^{28}$ thereby providing external validity of the results for entire populations of patients with inflammatory bowel disease. Although this study was done in patients with inflammatory bowel disease, the results suggest that telemedicine can 
measure and improve the quality and value of healthcare in patients with other chronic relapsing-remitting diseases.

Our results show that telemedicine with mylBDcoach was safe, reduced outpatient visits and hospital admissions, and improved adherence to medication with similar patient-reported quality of care compared with standard care. These results were consistent across different subtypes of inflammatory bowel disease. This telemedicine tool systematically monitors and registers disease activity and factors affecting disease, patient-reported outcome measures, drug side-effects, and quality metrics. In an era of healthcare cost reduction and a rising incidence of inflammatory bowel disease, telemedicine systems could be a valuable tool for reorganising inflammatory bowel disease care towards more personalised and value-based healthcare. 


\section{REFERENCES}

1. Burisch J, Munkholm P. The epidemiology of inflammatory bowel disease. Scand J Gastroenterol 2015; 50(8): 942-51.

2. Dignass A, Lindsay JO, Sturm A, et al. Second European evidence-based consensus on the diagnosis and management of ulcerative colitis part 2: current management. Journal of Crohn's \& colitis 2012; 6(10): 991-1030.

3. Dignass A, Van Assche G, Lindsay JO, et al. The second European evidence-based Consensus on the diagnosis and management of Crohn's disease: Current management. Journal of Crohn's \& colitis 2010; 4(1): 28-62.

4. Jeuring SF, van den Heuvel TR, Liu LY, et al. Improvements in the Long-Term Outcome of Crohn's Disease Over the Past Two Decades and the Relation to Changes in Medical Management: Results from the Population-Based IBDSL Cohort. The American journal of gastroenterology 2016.

5. Jeuring SF, Bours PH, Zeegers MP, et al. Disease Outcome of Ulcerative Colitis in an Era of Changing Treatment Strategies: Results from the Dutch Population-Based IBDSL Cohort. Journal of Crohn's \& colitis 2015; 9(10): 837-45.

6. Colombel JF, Narula N, Peyrin-Biroulet L. Management Strategies to Improve Outcomes of Patients With Inflammatory Bowel Diseases. Gastroenterology 2016.

7. Pedersen $\mathrm{N}$, Thielsen $\mathrm{P}$, Martinsen $\mathrm{L}$, et al. eHealth: individualization of mesalazine treatment through a self-managed web-based solution in mild-to-moderate ulcerative colitis. Inflamm Bowel Dis 2014; 20(12): 2276-85.

8. Lakatos PL. Prevalence, predictors, and clinical consequences of medical adherence in IBD: how to improve it? World J Gastroenterol 2009; 15(34): 4234-9.
9. Reigada LC, Satpute A, Hoogendoorn CJ, et al. Patient-reported Anxiety: A Possible Predictor of Pediatric Inflammatory Bowel Disease Health Care Use. Inflamm Bowel Dis 2016.

10. Porter ME. What is value in health care? The New England journal of medicine 2010; 363(26): 2477-81.

11. Bradley SM, Rumsfeld JS, Ho PM. Incorporating Health Status in Routine Care to Improve Health Care Value: The VA Patient Reported Health Status Assessment (PROST) System. JAMA 2016; 316(5): 487-8.

12. Siegel CA, Allen Jl, Melmed GY. Translating improved quality of care into an improved quality of life for patients with inflammatory bowel disease. Clin Gastroenterol Hepatol 2013; 11(8): 908-12.

13. Melmed GY, Siegel CA, Spiegel BM, et al. Quality indicators for inflammatory bowel disease: development of process and outcome measures. Inflamm Bowel Dis 2013; 19(3): 662-8.

14. de la Torre Diez I, Garcia-Zapirain B, Mendez-Zorrilla A, Lopez-Coronado M. Monitoring and Follow-up of Chronic Heart Failure: a Literature Review of eHealth Applications and Systems. J Med Syst 2016; 40(7): 179.

15. Jonkman $\mathrm{NH}$, Westland $\mathrm{H}$, Trappenburg JC, et al. Do self-management interventions in COPD patients work and which patients benefit most? An individual patient data meta-analysis. International journal of chronic obstructive pulmonary disease 2016; 11: 2063-74.

16. Aguas M, Del Hoyo J, Faubel R, Nos P. Telemedicine in Inflammatory Bowel Disease: Opportunity Ahead. Inflamm Bowel Dis 2016; 22(2): E4-5.

17. Huang VW, Reich KM, Fedorak RN. Distance management of inflammatory bowel disease: systematic review and meta-analysis. World J Gastroenterol 2014; 20(3): 829-42. 
18. Jackson BD, Gray K, Knowles SR, De Cruz P. EHealth Technologies in Inflammatory Bowel Disease: A Systematic Review. Journal of Crohn's \& colitis 2016.

19. Elkjaer M, Shuhaibar M, Burisch J, et al. Ehealth empowers patients with ulcerative colitis: a randomised controlled trial of the web-guided 'Constant-care' approach. Gut 2010; 59(12): 1652-61.

20. Cross RK, Cheevers N, Rustgi A, Langenberg $P$, Finkelstein J. Randomized, controlled trial of home telemanagement in patients with ulcerative colitis (UC HAT). Inflamm Bowel Dis 2012; 18(6): 1018-25.

21. Pedersen N, Elkjaer $M$, Duricova $D$, et al. eHealth: individualisation of infliximab treatment and disease course via a selfmanaged web-based solution in Crohn's disease. Aliment Pharmacol Ther 2012; 36(9): 840-9.

22. de Jong $M$, van der Meulen-de Jong $A$, Romberg-Camps $M$, et al. Development and Feasibility Study of a Telemedicine Tool for All Patients with IBD: MylBDcoach. Inflamm Bowel Dis 2017; 23(4): 485-93.

23. Lennard-Jones JE. Classification of inflammatory bowel disease. Scand J Gastroenterol Suppl 1989; 170: 2-6; discussion 16-9.

24. M. de Jong JD, T. van den Heuvel, $M$. Romberg-Camps, B. Winkens, T. Markus, A. Masclee, A. van Tubergen, D. Jonkers, M. Pierik. Development of a patient reported disease activity score to screen for mucosal inflammation in inflammatory bowel disease. Journal of Crohn's and Colitis. 2 February 2015 ed; 2015.

25. Morisky DE, Green LW, Levine DM. Concurrent and predictive validity of a self-reported measure of medication adherence. Med Care 1986; 24(1): 67-74.
26. Irvine EJ, Zhou Q, Thompson AK. The Short Inflammatory Bowel Disease Questionnaire: a quality of life instrument for community physicians managing inflammatory bowel disease. CCRPT Investigators. Canadian Crohn's Relapse Prevention Trial. The American journal of gastroenterology 1996; 91(8): 1571-8.

27. Keefer L, Kiebles JL, Taft TH. The role of selfefficacy in inflammatory bowel disease management: preliminary validation of a disease-specific measure. Inflamm Bowel Dis 2011; 17(2): 614-20.

28. van den Heuvel TR, Jonkers DM, Jeuring $\mathrm{SF}$, et al. Cohort Profile: The Inflammatory Bowel Disease South Limburg Cohort (IBDSL). International journal of epidemiology 2015.

29. Berwick DM, Nolan TW, Whittington J. The triple aim: care, health, and cost. Health Aff (Millwood) 2008; 27(3): 759-69.

30. Sulz MC, Siebert U, Arvandi M, et al. Predictors for hospitalization and outpatient visits in patients with inflammatory bowel disease: results from the Swiss Inflammatory Bowel Disease Cohort Study. Eur J Gastroenterol Hepatol 2013; 25(7): 790-7.

31. Feuerstein JD, Castillo NE, Siddique SS, et al. Poor Documentation of Inflammatory Bowel Disease Quality Measures in Academic, Community, and Private Practice. Clin Gastroenterol Hepatol 2016; 14(3): 421-8 e2.

32. Rudin RS, Bates DW, MacRae C. Accelerating Innovation in Health IT. The New England journal of medicine 2016; 375(9): 815-7. 


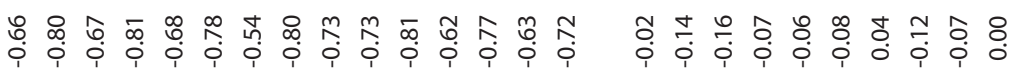

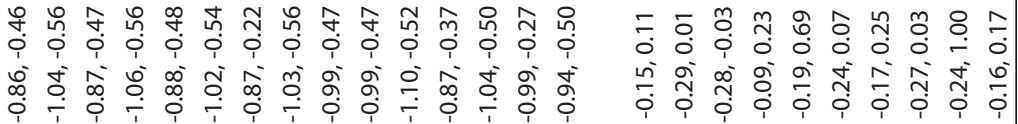

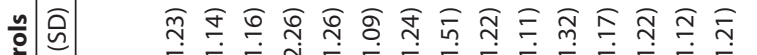

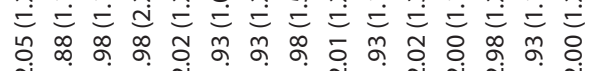
๙

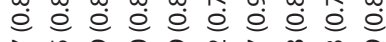

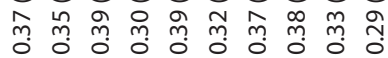

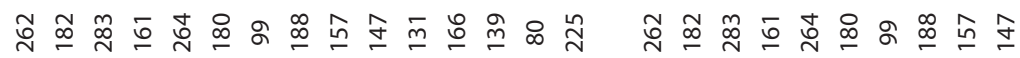

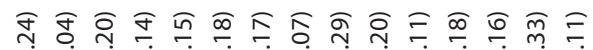

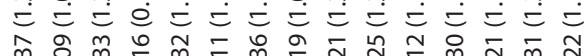

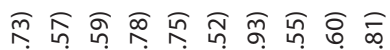
ṃ 仓 







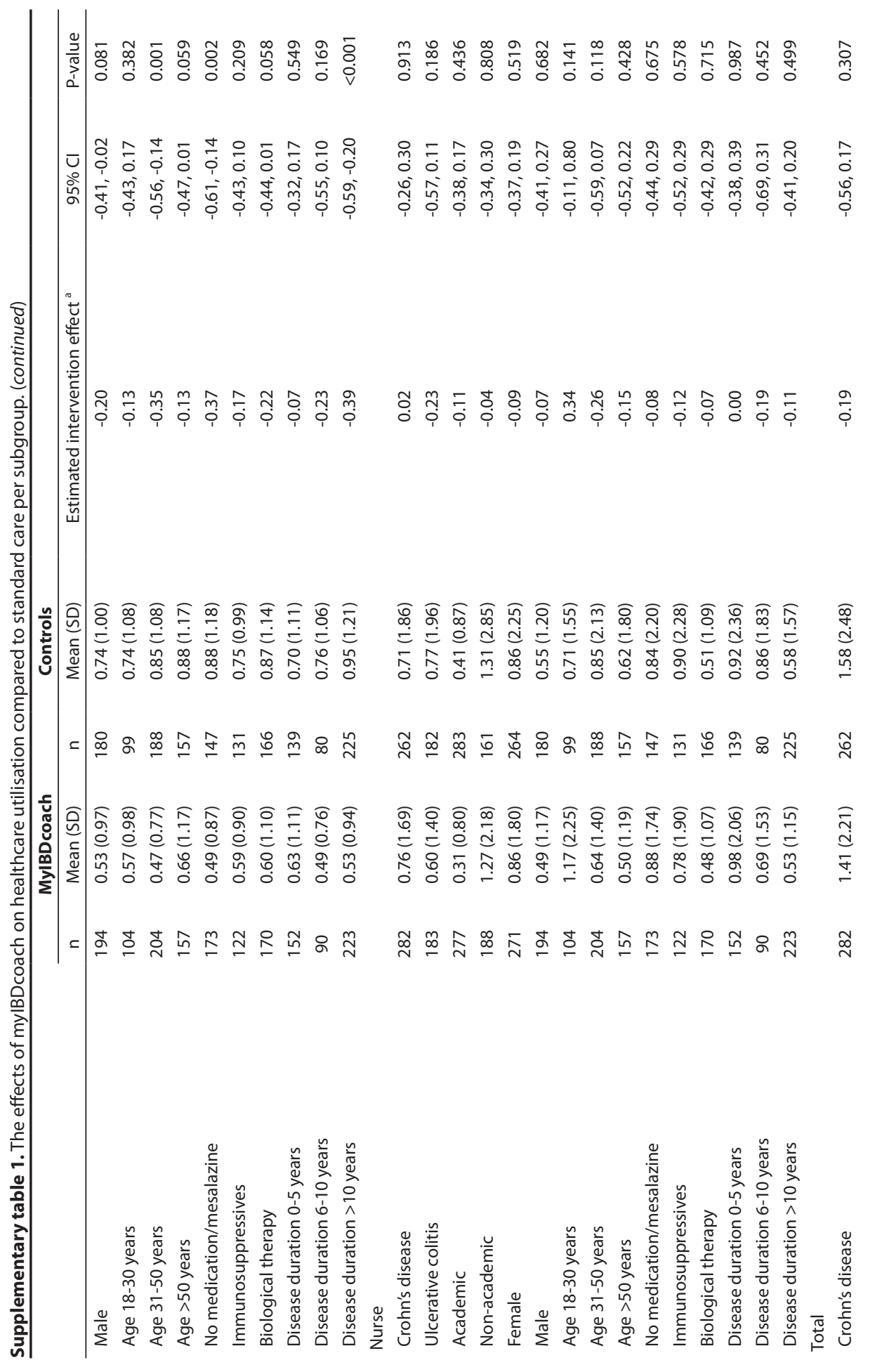




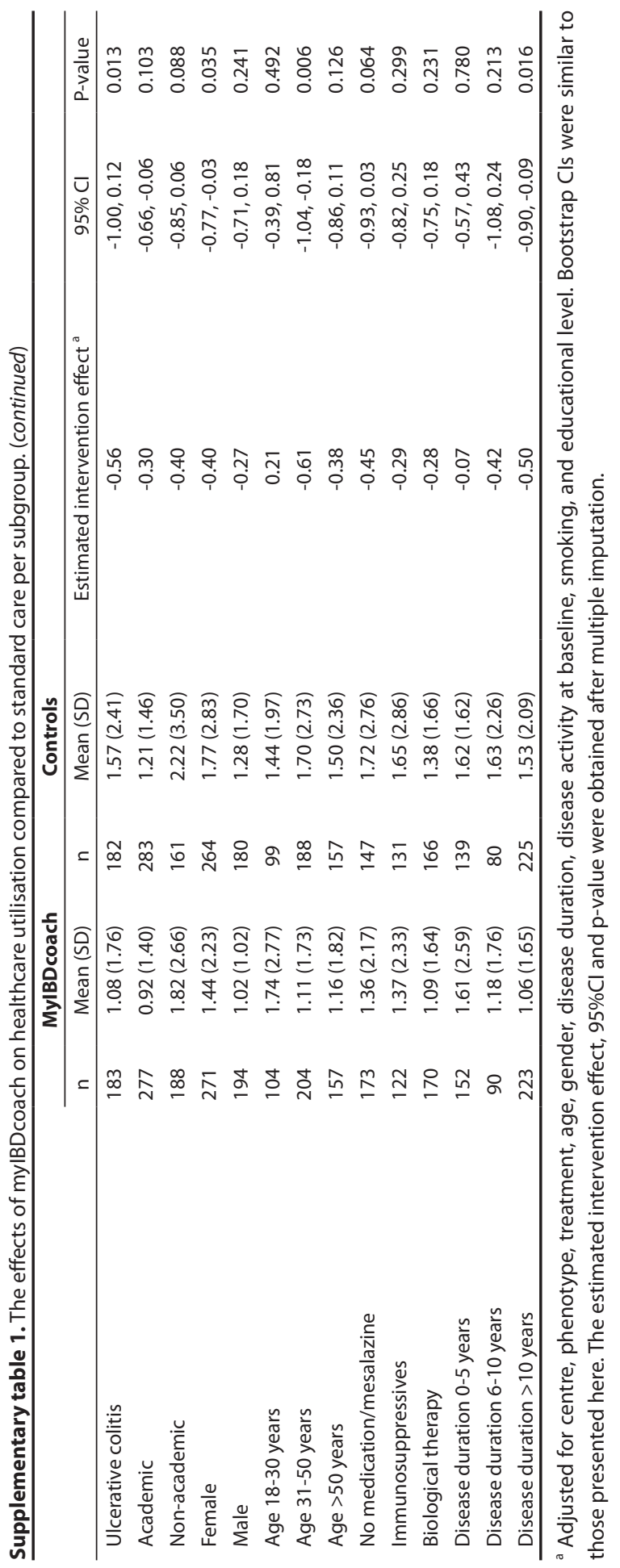


Supplementary table 2. The effects of mylBDcoach on patient-reported quality of care compared to standard care per subgroup.

\begin{tabular}{|c|c|c|c|c|c|c|c|}
\hline & \multicolumn{2}{|c|}{ MylBDcoach } & \multicolumn{2}{|c|}{ Standard care } & \multirow[b]{2}{*}{$\begin{array}{c}\text { Estimated } \\
\text { intervention } \\
\text { effect }^{a}\end{array}$} & \multirow[b]{2}{*}{$95 \% \mathrm{Cl}$} & \multirow[b]{2}{*}{ P-value } \\
\hline & $\mathrm{n}$ & $\begin{array}{c}\text { Mean score } \\
\text { (SD) }\end{array}$ & $\mathrm{n}$ & $\begin{array}{c}\text { Mean score } \\
\text { (SD) }\end{array}$ & & & \\
\hline \multicolumn{8}{|c|}{ Crohn's disease } \\
\hline Baseline & 207 & $8.14(1.32)$ & 206 & $8.31(1.00)$ & \multirow{2}{*}{0.04} & \multirow{2}{*}{$-0.26,0.34$} & \multirow{2}{*}{0.796} \\
\hline 12 months & 172 & $8.27(1.34)$ & 167 & $8.22(1.43)$ & & & \\
\hline \multicolumn{8}{|c|}{ Ulcerative colitis } \\
\hline Baseline & 143 & $8.51(0.95)$ & 138 & $8.15(1.12)$ & \multirow{2}{*}{0.16} & \multirow{2}{*}{$-0.40,0.18$} & \multirow{2}{*}{0.368} \\
\hline 12 months & 131 & $8.23(1.37)$ & 117 & $8.34(1.04)$ & & & \\
\hline \multicolumn{8}{|l|}{ Academic } \\
\hline Baseline & 198 & $8.15(1.35)$ & 215 & 8.19 (1.09) & \multirow{2}{*}{0.19} & \multirow{2}{*}{$-0.11,0.49$} & \multirow{2}{*}{0.211} \\
\hline 12 months & 176 & $8.22(1.38)$ & 185 & $8.27(1.30)$ & & & \\
\hline \multicolumn{8}{|c|}{ Non-academic } \\
\hline Baseline & 152 & $8.47(0.93)$ & 129 & $8.33(1.00)$ & \multirow{2}{*}{-0.05} & \multirow{2}{*}{$-0.41,0.31$} & \multirow{2}{*}{0.783} \\
\hline 12 months & 127 & $8.30(1.33)$ & 99 & $8.28(1.25)$ & & & \\
\hline \multicolumn{8}{|l|}{ Female } \\
\hline Baseline & 207 & $8.25(1.12)$ & 207 & $8.26(1.05)$ & \multirow{2}{*}{0.08} & \multirow{2}{*}{$-0.21,-0.38$} & \multirow{2}{*}{0.581} \\
\hline 12 months & 183 & $8.27(1.40)$ & 168 & $8.22(1.31)$ & & & \\
\hline \multicolumn{8}{|l|}{ Male } \\
\hline Baseline & 143 & $8.20(1.30)$ & 137 & $8.22(1.07)$ & 017 & & \\
\hline 12 months & 120 & $8.23(1.27)$ & 116 & $8.35(1.24)$ & 0.12 & $-0.24,0.4 /$ & $0.5<9$ \\
\hline Age $18-30$ ye & & & & & & & \\
\hline Baseline & 79 & $8.08(1.88)$ & 71 & $8.14(0.95)$ & $=18$ & & \\
\hline 12 months & 65 & $8.28(1.17)$ & 59 & $8.02(1.34)$ & -0.18 & $-0.08,0.31$ & 0.467 \\
\hline Age $31-50$ ye & & & & & & & \\
\hline Baseline & 145 & $8.29(1.30)$ & 140 & 8.22 (1.09) & $=00$ & $=03$ & 0983 \\
\hline 12 months & 126 & $8.32(1.19)$ & 122 & $8.24(1.40)$ & -0.00 & o & 0.005 \\
\hline Age $>\mathbf{5 0}$ yea & & & & & & & \\
\hline Baseline & 126 & $8.42(1.06)$ & 133 & $8.33(1.07)$ & & & \\
\hline 12 months & 112 & $8.16(1.61)$ & 103 & $8.45(1.07)$ & לנ. & $-0.02,0.12$ & 0.007 \\
\hline No medicatio & & & & & & & \\
\hline Baseline & 135 & $8.27(1.31)$ & 119 & 8.17 (1.08) & ( & 03 & 0804 \\
\hline 12 months & 109 & $8.15(1.62)$ & 95 & $8.29(1.14)$ & ת & $-0.04,0.44$ & 0.004 \\
\hline Immunosupp & & & & & & & \\
\hline Baseline & 92 & $8.48(1.01)$ & 101 & $8.19(0.93)$ & - & $=06$ & 21 \\
\hline 12 months & 85 & $8.49(1.02)$ & 83 & $8.06(1.56)$ & 0.20 & - & 0.221 \\
\hline Biological the & & & & & & & \\
\hline Baseline & 123 & 8.17 (1.19) & 124 & 8.35 (1.12) & 048 & מח & 037 \\
\hline 12 months & 109 & $8.17(1.28)$ & 106 & $8.43(1.14)$ & 0.40 & $0.02,0.17$ & ונד \\
\hline
\end{tabular}


Supplementary table 2. The effects of mylBDcoach on patient-reported quality of care compared to standard care per subgroup. (continued)

\begin{tabular}{|c|c|c|c|c|c|c|c|}
\hline & \multicolumn{2}{|c|}{ MylBDcoach } & \multicolumn{2}{|c|}{ Standard care } & \multirow[b]{2}{*}{$\begin{array}{c}\text { Estimated } \\
\text { intervention } \\
\text { effect }^{a}\end{array}$} & \multirow[b]{2}{*}{$95 \% \mathrm{Cl}$} & \multirow[b]{2}{*}{ P-value } \\
\hline & $\mathrm{n}$ & $\begin{array}{c}\text { Mean score } \\
\text { (SD) }\end{array}$ & $\mathrm{n}$ & $\begin{array}{c}\text { Mean score } \\
\text { (SD) }\end{array}$ & & & \\
\hline \multicolumn{8}{|c|}{ Disease duration $0-5$ years } \\
\hline Baseline & 121 & $8.12(1.37)$ & 104 & $8.32(0.92)$ & \multirow{2}{*}{0.20} & \multirow{2}{*}{$-0.21,0.61$} & \multirow{2}{*}{0.334} \\
\hline 12 months & 96 & $8.30(1.03)$ & 86 & $8.36(1.28)$ & & & \\
\hline \multicolumn{8}{|c|}{ Disease duration 6-10 years } \\
\hline Baseline & 66 & $8.32(1.09)$ & 56 & $8.25(1.04)$ & \multirow{2}{*}{-0.41} & \multirow{2}{*}{$-0.97,0.16$} & \multirow{2}{*}{0.157} \\
\hline 12 months & 56 & $8.20(1.09)$ & 44 & $7.92(1.59)$ & & & \\
\hline \multicolumn{8}{|c|}{ Disease duration $>10$ years } \\
\hline Baseline & 163 & $8.40(1.09)$ & 184 & $8.20(1.13)$ & \multirow{2}{*}{0.18} & \multirow{2}{*}{$-0.14,0.50$} & \multirow{2}{*}{0.261} \\
\hline 12 months & 151 & $8.24(1.61)$ & 154 & $8.32(1.17)$ & & & \\
\hline
\end{tabular}

Patient-reported quality of care was assessed by a VAS-scale. 'Adjusted for centre, treatment, phenotype, age, gender, disease duration, disease activity at baseline, smoking, educational level, and baseline patientreported quality of care. Bootstrap Cls were similar to those presented here. The estimated intervention effect, $95 \% \mathrm{Cl}$ and $\mathrm{p}$-value were obtained from linear mixed models based on the likelihood approach for missing outcome data. 


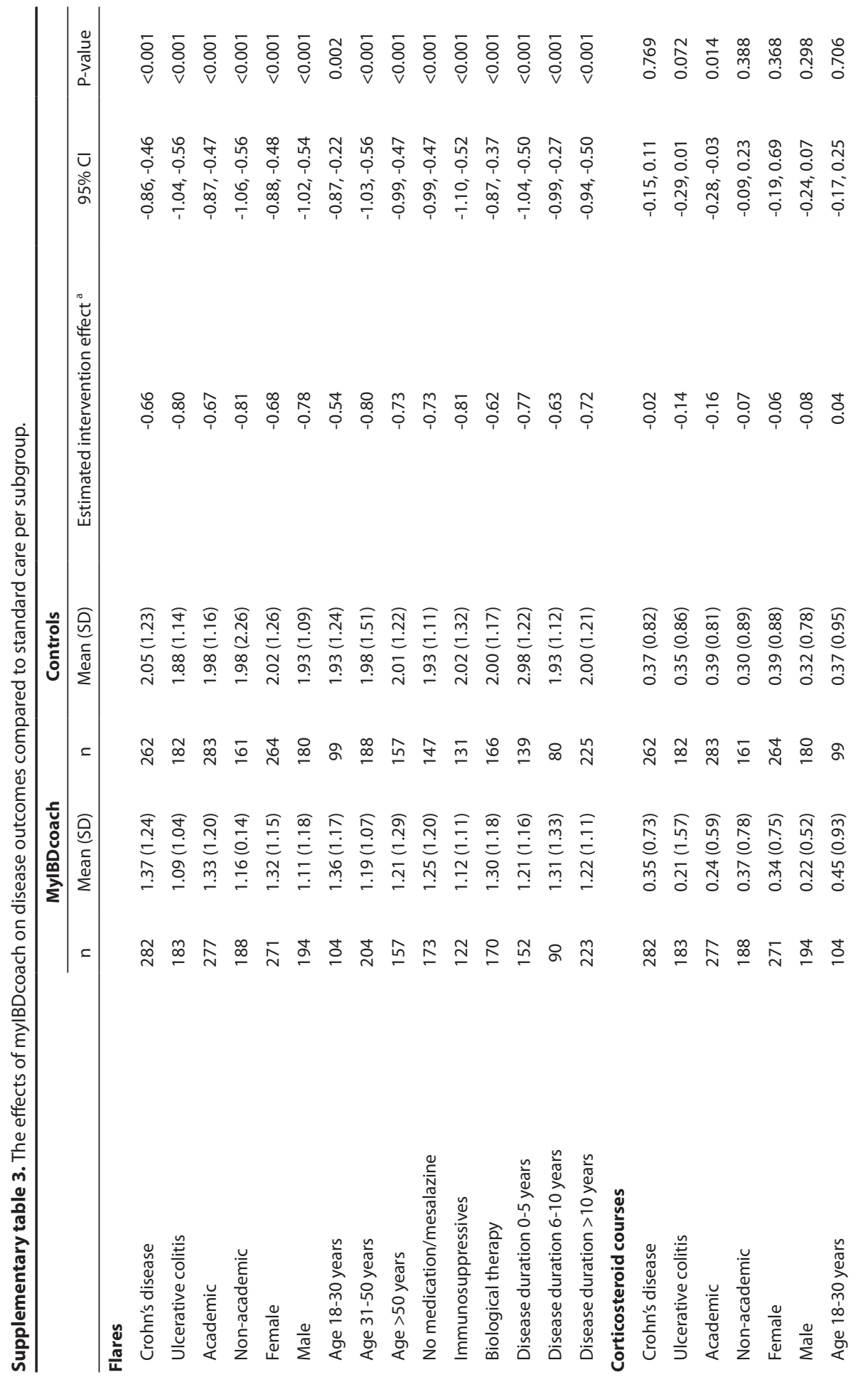




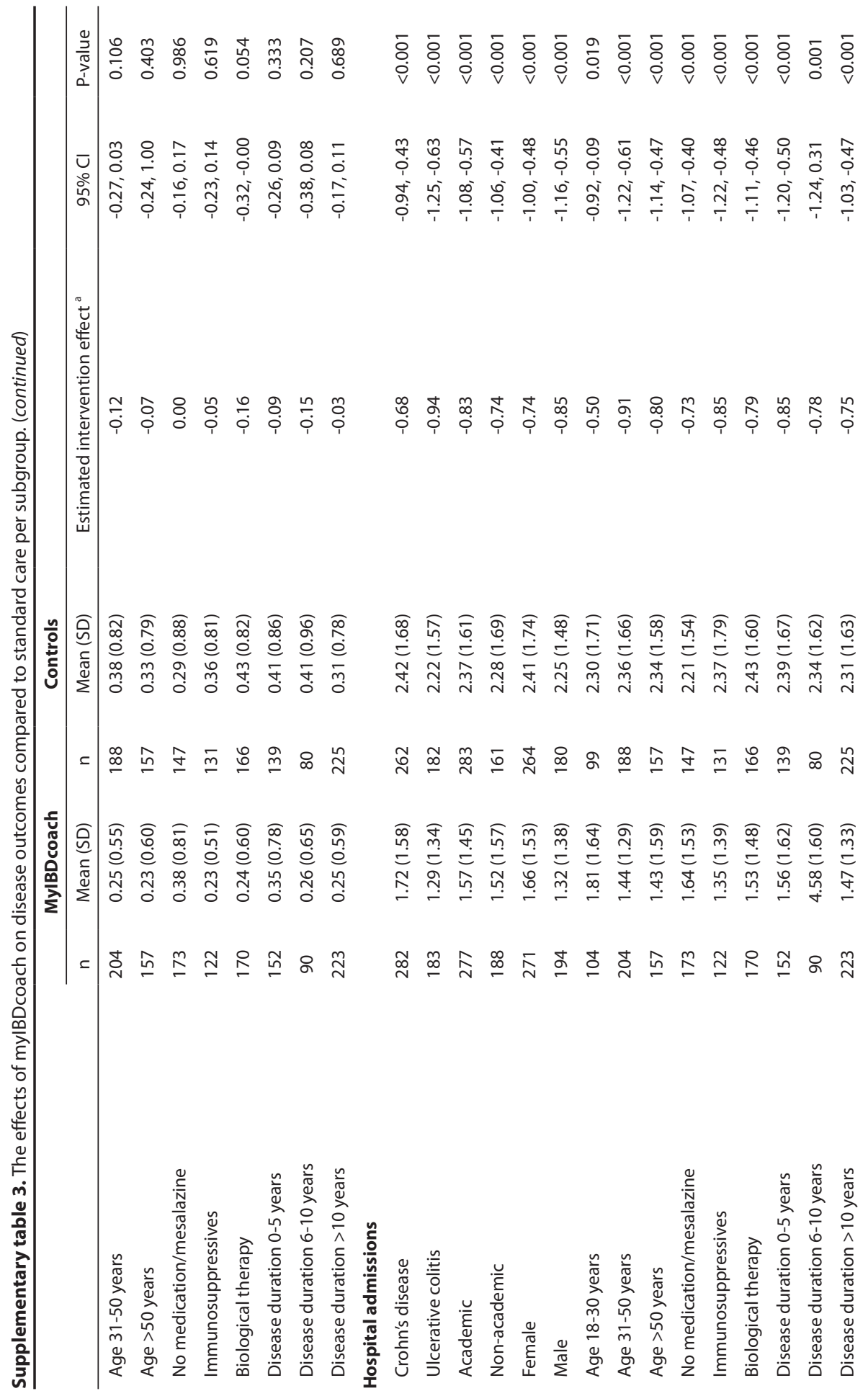




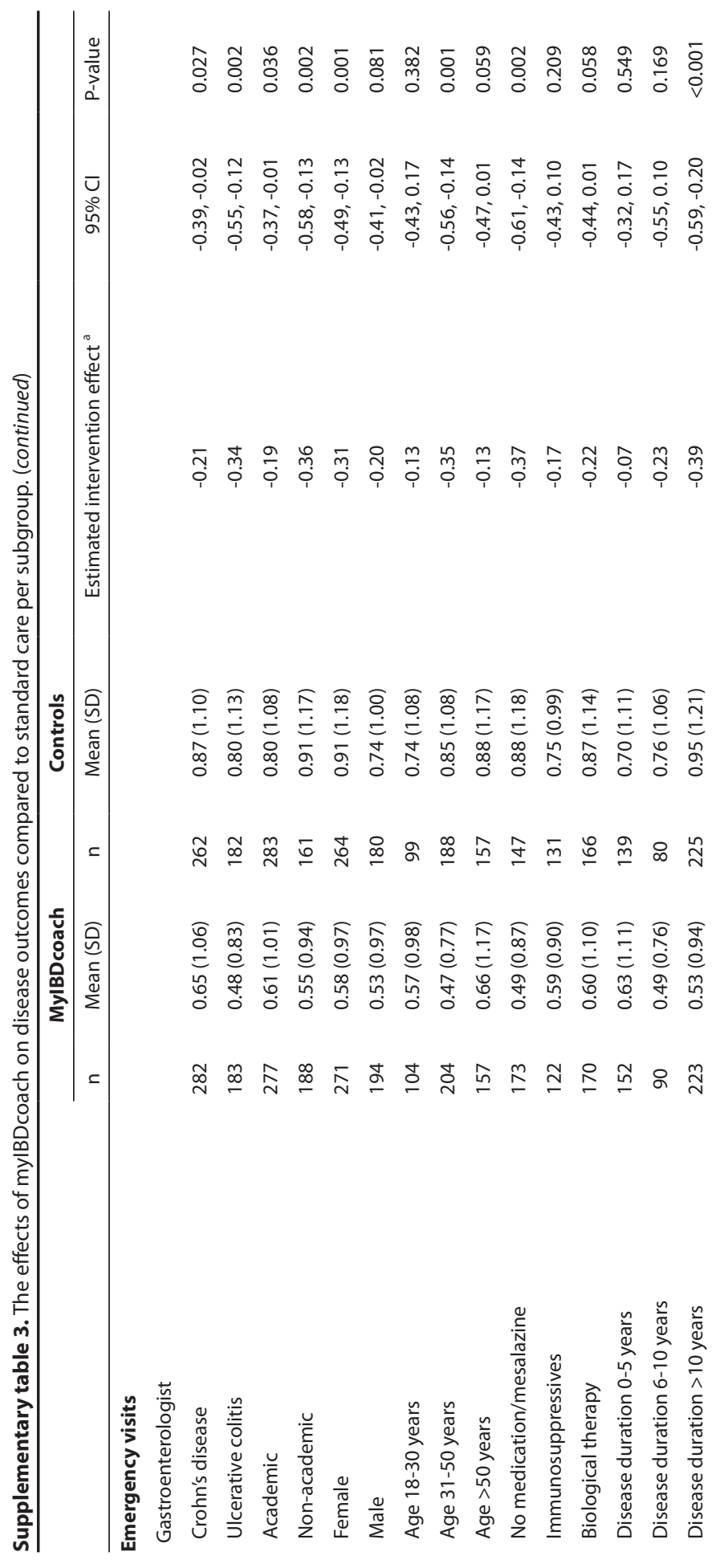




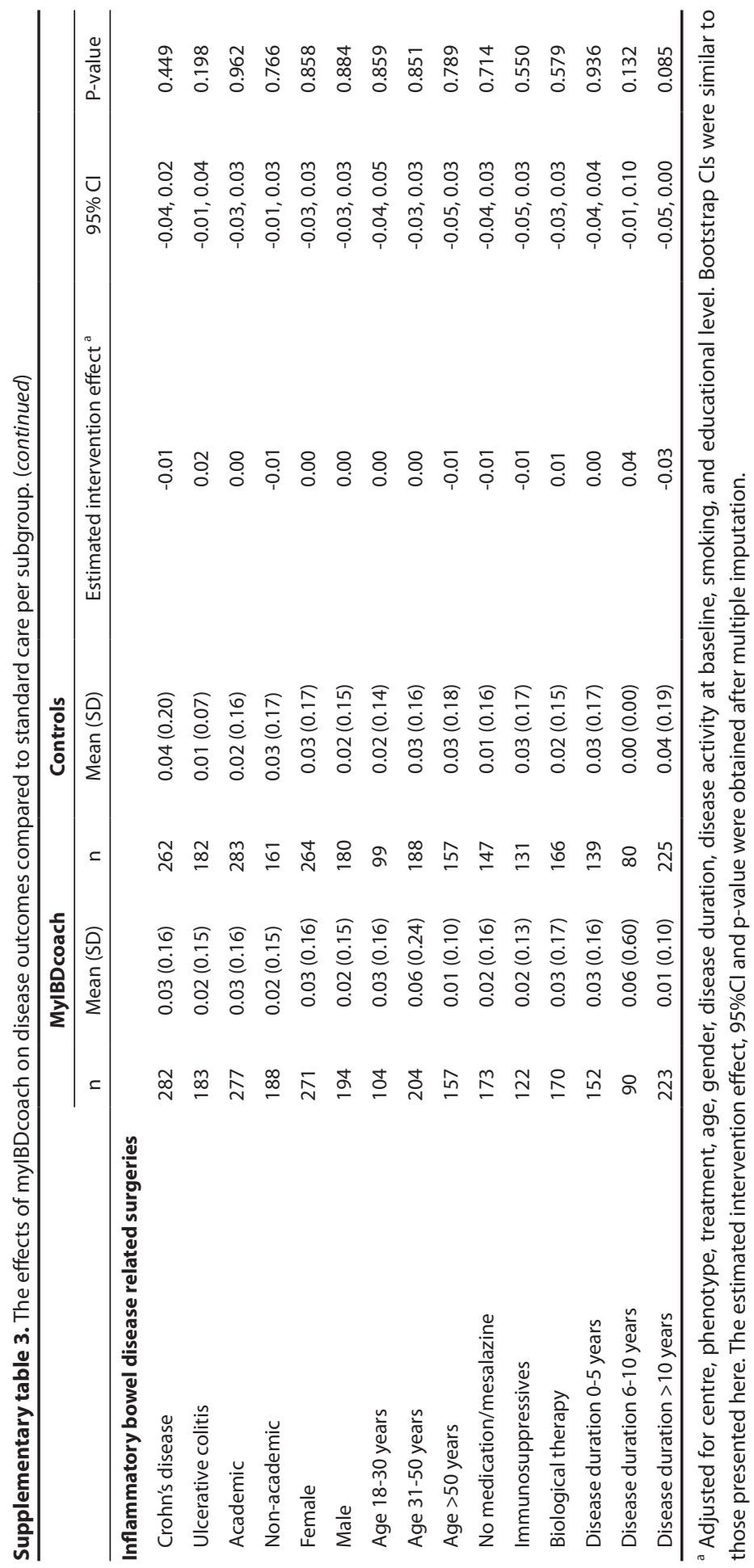


Supplementary table 4. The effects of mylBDcoach on smoking behaviour compared to standard care. MylBDcoach (n) Standard care (n) Odds ratio ${ }^{a}$

$95 \% \mathrm{Cl}$

p-value

Baseline $^{\mathrm{b}}$

Active smoker

65

50

Non-active smoker

317

12 months $^{c}$

$34 \quad 31$

Active smoker 304 298

Non-active smoker

0.81

$0.33,1.96$

0.633

${ }^{a}$ Adjusted for baseline smoking behaviour and educational level. ${ }^{b} 86$ and 77 values were missing at baseline in the mylBDcoach group and standard care group, respectively. ${ }^{\mathrm{C}} 127$ and 115 values were missing at 12 months in the mylBDcoach group and standard care group, respectively. 



\section{Editorial commentary}

\section{Building evidence for care beyond}

the medical centre

Thomas Ullman, Ashish Atreja

Icahn School of Medicine at Mount Sinai, New York, NY 10029, USA thomas.ullman@mssm.edu 

Digital health has been defined as the "convergence of the digital and genomic revolutions with health, healthcare, living, and society". ${ }^{1}$ The term is often used interchangeably with mHealth or mobile health because of the central role played by mobile devices. Remote patient monitoring and telemedicine constitute a subset of digital health technologies that enable monitoring of patients outside conventional clinical settings, such as in the comfort of their own homes. Evidence regarding the efficacy, effectiveness, economics, and clinical preferences of remote patient monitoring and telemedicine is growing in many chronic diseases, including heart failure, diabetes, chronic obstructive pulmonary disease, and stroke diagnosis, and in post-surgical care, rehabilitation, and behavioural medicine. ${ }^{2-5}$

In The Lancet, Marin de Jong and colleagues ${ }^{6}$ report the results of a randomised trial among outpatients in two academic and two non-academic hospitals in the Netherlands showing substantial benefits of remote patient monitoring with patient use of a tablet or smartphone application called mylBDcoach compared with standard care in adults with inflammatory bowel disease. Designed to assist in lessening the burden of illness through regular monitoring away from the office, improve adherence to quality metrics, personalise care on the basis of patient-reported outcome measures, enhance remote communication with the care team, educate the patient through web-based learning tools, enable value-based healthcare, and even promote self-efficacy, the investigators achieved many of their stated aims. At 12 months, the use of the telemedicine system mylBDcoach resulted in significantly fewer outpatient visits to the gastroenterologist or nurse than standard care (1.55 [SD 1.50] vs 2.34 [1.64], respectively; difference -0.79 [95\% Cl -0.98 to -0.59 ]; $p<0.0001)$, fewer telephone consultations (1.28 [2.06] vs 1.57 [2.44]; $\mathrm{p}=0.018$ ), and improved medication adherence (mean score on the eight-item Morisky Medication Adherence Scale 7.01 [1.40] vs 6.77 [1.61]; $p=0.0002$ ). The mean number of hospital admissions was also lower in patients using mylBDcoach than in those receiving standard care. No substantial differences between groups were noted in the mean number of corticosteroid courses, emergency visits, flares, or inflammatory bowel disease-related surgeries, or in quality-of-life scores. In view of the heterogeneity of these disorders and the complexity and variability of their treatments, these findings are a remarkable achievement.

Living with chronic illnesses such as Crohn's disease and ulcerative colitis is no small challenge for affected patients. Pain, inconvenience, physical and emotional difficulties, and persistent reliance on family and friends for support constitute just a few of the regular hardships patients face-sometimes on a daily basis. Inadequately treated inflammatory bowel diseases can result in a substantially diminished quality of life, increased work disability (or absence from school), and an outsized financial burden, made up mostly of medication costs, hospital admissions, surgeries, and emergency care-some of the measures de Jong and colleagues captured with mylBDcoach. Usual 
care for inflammatory bowel disease over the years has been limited to episodic office visits in which interim results and events are reviewed, and plans are made for adjusting care as needed on the basis of new information acquired at the visit-all in an effort to allow patients to pursue and live their lives outside of office and emergency visits, and with minimal impact on work or school. But why in 2017 should the primary site of care be the physician's office? If the goal is to unburden the patient, then most care in the modern, digital world should be provided at the convenience of the engaged patient. The hypothesis is that an increase in regular information sharing can lessen expensive care, achieve a personalised approach to treatment plans, optimise the use of expensive medications, accelerate the discontinuation of medicines that are no longer useful, and provide more freedom from burdensome office visits, emergency visits, and surgeries. de Jong and colleagues have achieved these outcomes with the use of mylBDcoach.

Without question, smartphone-based remote patient monitoring and telemedicine remain in their infancy. These technologies will proliferate and embed themselves in unpredictable and varying ways. de Jong and colleagues' demonstration of effectiveness closes some of the missing scientific evidence around these applications. We look forward to seeing new applications that will reduce symptoms, promote convenience, and keep patients well at home, work, or school. 
1. Sonnier P. Story of digital health: definition. http://storyofdigitalhealth. com/definition (accessed May 10, 2017).

2. Hanlon P, Daines L, Campbell C, McKinstry B, Weller D, Pinnock H. Telehealth interventions to support self-management of longterm conditions: a systematic metareview of diabetes, heart failure, asthma, chronic obstructive pulmonary disease, and cancer. J Med Internet Res 2017; 19: e172.

3. Nakamura N, Koga T, Iseki H. A metaanalysis of remote patient monitoring for chronic heart failure patients. J Telemed Telecare 2014; 20: 11-17.

4. van Beugen S, Ferwerda M, Hoeve D, et al. Internet-based cognitive behavioral therapy for patients with chronic somatic conditions: a meta-analytic review. J Med Internet Res 2014; 16: e88.
5. Tildesley HD, Po MD, Ross SA. Internet blood glucose monitoring systems provide lasting glycemic benefit in type 1 and 2 diabetes: a systematic review. Med Clin North Am 2015; 99: 17-33.

6. de Jong $M J$, van der Meulen-de Jong $A E$, Romberg-Camps MJ, et al. Telemedicine for management of inflammatory bowel disease (mylBDcoach): a pragmatic, multicentre, randomised controlled trial. Lancet 2017; published online July 14. http://dx.doi.org/10.1016/ S01406736(17)31327-2. 



\section{Chapter 6}

Cost-effectiveness of telemedicinedirected specialised care versus standard care for inflammatory bowel disease: the myIBDcoach trial.

Marin de Jong, Annelies Boonen, Mariëlle Romberg-Camps,

Ad van Bodegraven, Nofel Mahmmod, Tineke Markus, Gerard Dijkstra, Ad Masclee, Bjorn Winkens, Astrid van Tubergen, Daisy Jonkers, Andrea van der Meulen-de Jong, Marieke Pierik 


\section{ABSTRACT}

Objective: Telemedicine is a powerful tool to monitor determinants and outcomes of health in chronic diseases and can contribute to quality and value of care. For inflammatory bowel diseases (IBD), telemedicine was found to reduce outpatient visits and hospital admissions. Since a full economic evaluation of telemedicine interventions in IBD is lacking, we evaluated the cost-utility of telemedicine versus standard care.

Design: A pragmatic multicentre randomised controlled trial was carried out in two academic and two non-academic hospitals in the Netherlands. In total, 909 IBD patients were randomised to telemedicine $(n=465)$ or standard outpatient care $(n=444)$ and followed for 12 months. Costs were measured from a societal perspective. Direct healthcare costs were based on actual resource utilisation. Indirect costs comprised self-reported hours sick leave from work, intervention costs (annual license fee of $€ 40$ per patient), and utility costs (assessed using EQ5D). Cost-utility and uncertainty were estimated using the non-parametric bootstrapping method.

Results: Telemedicine resulted in lower mean annual costs of $€ 547 /$ patient $(95 \% \mathrm{Cl}$, $[€-1,029, € 2,143]$; mean costs of $€ 9481$ for standard care and $€ 8924$ for telemedicine) without changing quality adjusted life years (QALY). At the Dutch threshold of $€ 80,000$ per QALY, the intervention had a favorable incremental cost-effectiveness over standard care in $83 \%$ of replications and showed an incremental net monetary benefit of $€ 707 /$ patient $(95 \% \mathrm{Cl},[€-1,241, € 2,544])$.

Conclusion: Telemedicine with mylBDcoach was cost-effective in $83 \%$ of replications. This self-management tool enables continuous registration of quality indicators and (patient-reported) outcomes and is therefore promising to reorganise IBD care towards value-based healthcare. 


\section{INTRODUCTION}

Improving quality of care is a continuous task for every healthcare professional and institution, and is especially challenging when increasing healthcare expenditures force professionals to constrain costs. Over the recent years, value-based healthcare has been considered a way forward to control costs while improving quality by emphasising the value for patients as the common goal of all stakeholders (patient, healthcare professional, insurance company, and society) ${ }^{1}$. In this framework, regular measurement of clinical and patient-reported health outcomes is necessary. In a traditional healthcare organisation frequent monitoring of these outcomes is challenging due to time constraints and a further increase of the administrative burden. Telemedicine enables regular collection of health outcomes without disrupting the clinical workflow ${ }^{2,3}$. However, no data are available regarding cost-effectiveness of telemedicine.

The inflammatory bowel disease (IBD), Crohn's disease (CD) and ulcerative colitis (UC), are debilitating, chronically relapsing, inflammatory disorders primarily affecting the gastrointestinal tract. As IBD is typically diagnosed in young people during the most productive years of their lives ${ }^{4}$ and requires life-long medical therapy and monitoring, the disease has a significant impact on patients' quality of life. It constitutes a high economic burden on society ${ }^{5,6}$. Cost-of-illness studies report total annual healthcare costs in Western-European countries ranging from $€ 6,338-€ 8,004$ for $C D$ and $€ 3,600-€ 4,819$ for UC patients ${ }^{6,7,8}$. Today, the direct healthcare costs for IBD are mainly driven by medication costs, hospitalisations, and outpatient clinic visits, while diagnostic procedures and surgery account for a relatively small portion ${ }^{6,7,8}$. In addition, productivity losses resulting from sick leave and work disability account for up to $50 \%$ of the total costs-ofillness in IBD'.

IBD care is traditionally organised by standard scheduled outpatient visits, with a frequency predominantly based on medical treatment, but independent of the occurrence of unpredictable flares ${ }^{9,10}$. This might result in an inefficient and potentially costly way of medical resource use and patients' time. In addition, treatment strategies for IBD are shifting from mere management of symptoms towards tight and personalised control of intestinal inflammation and timely intervention if inflammation (re-)occurs in order to prevent structural bowel damage and eventually improve long-term disease outcome ${ }^{9,10,11}$. This, together with the rising incidence of IBD, results in overburdened IBD clinics and escalating costs ${ }^{12,13}$.

Implementation of telemedicine for IBD can improve efficiency of care, enable tight disease monitoring and registration of PROMs, and answers to patients' demands for more participation in disease management. A pragmatic randomised multicentre trial with the telemedicine tool mylBDcoach showed that personalised telemonitoring re- 
duced the number of outpatient visits by $36 \%$ and the number of hospitalisations by $50 \%$, while increasing adherence to medication when compared to standard care ${ }^{14}$.

Although this trial convincingly showed that the telemedicine tool reduced healthcare utilisation, broad implementation is currently hindered by some barriers of which reimbursement is considered to be the key determinant ${ }^{3}$. Therefore, research focusing on economic evaluation of telemedicine interventions is warranted to aid decision makers in estimating the value of healthcare reorganisation towards reimbursement of telemedicine ${ }^{2}$. The objective of this study was therefore to calculate, from a societal perspective, the cost-effectiveness of telemedicine with mylBDcoach compared to standard care for IBD patients.

\section{METHODS}

\section{Study design and participants}

The mylBDcoach study design and data collection are described previously ${ }^{14}$. In brief, this study was carried out in two academic and two non-academic hospitals in the Netherlands, each caring for 1,500-2,000 IBD patients, with one or two dedicated nurses or nurse specialists, as well as an e-mail and telephone consultation structure for patients to contact the IBD team. IBD patients, between 18 and 75 years of age, were eligible for inclusion when they had no history of an ileoanal pouch or ileorectal anastomosis. Illiterate patients, those unable to understand the informed consent form or those without internet access by computer, tablet or smartphone, were excluded. Patients were randomised in a 1:1 ratio to care via mylBDcoach (intervention group) or standard care (control group) and were followed for 12 months. The details of the telemedicine system mylBDcoach, which was designed in close collaboration with patients, have been described previously ${ }^{15}$. Besides telemonitoring of disease activity and disease-related aspects, such as nutrition, medication adherence, or smoking, mylBDcoach provides patient-tailored information, a personal care plan, and easy, accessible contact with the inflammatory bowel disease nurse. At baseline and after 12 months, all participants received a paper questionnaire regarding health-related quality of life, and work-productivity. Patients were involved in all stages of research and the development of mylBDcoach. At 12 months an additional questionnaire on healthcare utilisation (number of e-mail and phone consultations) was sent to the participants. The study has been approved by the Medical Ethics Committee of the Maastricht University Medical Centre+ and all subjects gave written informed consent prior to participation. This approval was applicable to all participating centres. This trial was registered at ClinicalTrials.gov (NCT02173002). 


\section{Clinical and demographic data}

Demographic and clinical data, i.e. patient characteristics, disease phenotype, disease duration, baseline disease activity, were obtained from patients' electronic medical records.

\section{Direct healthcare costs}

Information on IBD-related healthcare utilisation over the 12-month study period, i.e. outpatient service, inpatient service, medication use, diagnostic procedures, and surgery, was collected from patients' electronic medical records and hospital information systems. Outpatient services included the number of visits to a gastroenterologist or IBD-nurse, scheduled phone consultations, and visits to the emergency department. Inpatient service was defined as the number of days hospitalised. Medication use for IBD was calculated using the mean number of daily dosages per type of drug used. Diagnostic procedures included the number and type of endoscopies and radiological procedures. Furthermore, the number and type of surgeries were retrieved. Information regarding the number of additional unscheduled phone consultations and e-mail contacts with the IBD-nurse was obtained from the 12-months follow-up questionnaire. For each of the abovementioned resource categories, the annual costs per patient were calculated by multiplying units of resource use by their unit $\operatorname{costs}^{16}$. For most healthcare resources, unit costs were available from the Dutch Guideline for Economic Evaluations in Healthcare and the Healthcare Insurance Board (supplementary table 1) 17, 18, 19. Unscheduled phone consultations and e-mail contacts with the nurses were charged as 15 minutes of their hourly wage ${ }^{17}$. Medication costs were calculated based on the individual dosage and their dose-prices (supplementary table 1) $16,19,20$. Non-healthcare costs, i.e. transport and parking costs related to an outpatient visit, were calculated using standardised prices ${ }^{17,19}$. Finally, for patients using mylBDcoach an estimated annual license fee of $€ 40$ was added to their total direct healthcare costs. The total annual direct (healthcare and non-healthcare) costs per patient equaled the sum of all these cost-categories.

\section{Indirect healthcare costs}

To estimate the indirect healthcare costs only productivity loss because of sick leave for those with a paid job were included. A time horizon of one year would not provide reliable information on the effect of the intervention on work disability. Self-reported hours absence from work due to health problems were measured using the Work Productivity and Activity Impairment questionnaire (WPAI) ${ }^{21}$. Hours absent per week were extrapolated for the trial duration and multiplied by the average hourly Dutch wage retrieved from the Dutch Guideline for Economic Evaluations in Healthcare ${ }^{18}$. 


\section{Health utility}

Changes in value of health over the 12-month study period were captured using the EuroQoL 5-dimensions (EQ-5D) ${ }^{22}$, filled out by all participants at baseline and at 12-months follow-up. The health utilities were computed using the Dutch tariffs for EQ-5D ${ }^{23}$. The change in utility at 12 months compared to baseline equals the change in qualityadjusted life-years (QALYs).

\section{Statistical analyses}

Incremental costs, utilities, and cost-utility were assessed by the non-parametric bootstrapping method as recommended by the International Society for Pharmacoeconomics and Outcomes Research (ISPOR) for cost-effectiveness analysis alongside trials ${ }^{24}$. Between 3\% (data derived from electronical medical records) and 26\% (data derived from questionnaires) of observations contained missing values for costs or utilities. Preceding the bootstrap analyses, where 5,000 bootstrap replications were generated, these were replaced with estimates using stochastic imputation (SI). The variables medical centre (four centres), subtypes of inflammatory bowel disease (Crohn's disease or ulcerative colitis), treatment (no medication or mesalazine; immunosuppressive drugs; or biological therapy), age (numerical), sex (male or female), disease duration (numerical), disease activity at baseline (remission or active), smoking (non-smoker, active smoker, or ex-smoker), and educational level (five levels) were used as predictors in the SI model. All randomised patients were included in the analyses (intention-to-treat population). The results of the bootstrap iterations were presented in an incremental cost-utility ratio (iCUR) plane, an incremental net monetary benefit (iNMB) curve, and a costeffectiveness acceptability curve (CEAC), representing the probability the intervention is cost-effective. The iNMB was calculated as iNMB $=\lambda * \Delta Q A L Y-\Delta$ Cost where $\lambda$ is the decision maker's maximum willingness to pay for a QALY. An iNMB above zero indicates the intervention generates monetary benefits at the chosen $\lambda$. In the Netherlands, a willingness-to-pay (WTP) threshold of $€ 80,000$ per QALY is used. As many bootstrapped iCUR replications indicated cost-savings but minor loss in QALY, we furthermore used a willingness-to-accept (WTA) threshold of $€ 100,000$ savings per QALY lost. A two-sided $\mathrm{p}$-value $\leq 0.05$ was defined as statistically significant. All statistical analyses were performed using SPSS version 22.0.

\section{RESULTS}

In total, 909 patients were included in the mylBDcoach study, of whom 465 were randomised to the intervention group and 444 to the control group. The baseline characteristics of the two study groups were similar and were representative for the general 
IBD population in the Netherlands with regard to demographics and disease activity (table 1$)^{25}$. At the end of the 12-month study period, 27 patients $(6 \%)$ in the intervention group and 1 patient $(0.02 \%)$ in the control group were lost to follow-up. At baseline, 382 patients (82\%) in the intervention group and 369 (83\%) in the control group completed the paper questionnaires on healthcare utilisation, health-related quality of life, and work-productivity. At 12 months, these questionnaires were completed by 340 (73\%) patients in the intervention group and 331 (75\%) patients in the control group.

\section{Direct and indirect annual costs and QALYs}

The mean annual direct costs in the intervention group were $€ 7,048$ per patient compared to $€ 7,423$ per patient in the control group, while the mean indirect costs were $€ 1,886$ in the intervention group compared to $€ 2,058$ in the control group. This resulted in a mean annual cost saving of $€ 547$ per patient $(95 \% \mathrm{Cl} €-1,029$ to $€ 2,143)$ favouring telemedicine. Table 2 shows averages of the main annual direct cost categories, sick leave costs, and of QALYs per year in the two treatment strategies. Within the direct healthcare costs, outpatient visits and drug costs were the main cost savers, responsible for an annual saving of $€ 104(95 \% \mathrm{Cl} € 79$ to $€ 129)$ and $€ 216(95 \% \mathrm{Cl} €-776$ to $€ 1,209)$ respectively. Patients in the intervention group showed a mean gain in quality adjusted life years (QALY) of $0.002(95 \% \mathrm{Cl}-0.022$ to 0.018$)$.

Table 1. Patient characteristics.

\begin{tabular}{lrr}
\hline & MylBDcoach ( $\mathbf{n = 4 6 5 )}$ & Standard care (n=444) \\
\hline Center, N & & 131 \\
Maastricht University Medical Center & 133 & 152 \\
Leiden University Medical Center & 144 & 102 \\
Zuyderland Medical Center Sittard & 117 & 59 \\
St. Antonius Hospital Nieuwegein & 71 & \\
Gender, N (\%) & & $180(40.5)$ \\
Male & $194(41.7)$ & $264(59.5)$ \\
Female & $271(58.3)$ & $30.4(13.6)$ \\
Age at diagnosis, mean (SD) & $30.7(13.5)$ & $44.1(14.2)$ \\
Age at inclusion, mean (SD) & $44.0(14.1)$ & $13.1(10.8)$ \\
Disease duration (years), mean (SD) & $12.8(10.4)$ & \\
Phenotype, N (\%) & & $262(59.0)$ \\
Crohn's disease & $282(60.6)$ & $68 / 262(26.0)$ \\
lleal & $87 / 282(30.9)$ & $63 / 262(24.0)$ \\
Colonic & $67 / 282(23.8)$ & $131 / 262(50.0)$ \\
Ileocolonic & $128 / 282(45.4)$ & $26 / 262(9.9)$ \\
Upper gastrointestinal modifier & $34 / 282(12.1)$ & $152 / 262(58.0)$ \\
Nonpenetrating, nonstricturing & $169 / 282(59.9)$ & $70 / 262(26.7)$ \\
Stricturing & $76 / 282(27.0)$ & $40 / 262(15.3)$ \\
Penetrating & $37 / 282(13.1)$ & $62 / 262(23.7)$ \\
Perianal disease modifier & $67 / 282(23.8)$ &
\end{tabular}


Table 1. Patient characteristics. (continued)

\begin{tabular}{lrr}
\hline & MylBDcoach (n=465) & Standard care ( $\mathbf{n = 4 4 4 )}$ \\
\hline Ulcerative colitis & $183(39.4)$ & $182(41.0)$ \\
$\quad$ Proctitis & $26 / 183(14.2)$ & $27 / 182(14.8)$ \\
$\quad$ Left sided & $81 / 183(44.3)$ & $70 / 182(38.5)$ \\
$\quad$ Pancolitis & $76 / 183(41.5)$ & $85 / 182(46.7)$ \\
Treatment, N (\%) & & $147 / 444(33.1)$ \\
No medication/mesalazine & $173 / 465(37.2)$ & $131 / 444(29.5)$ \\
Immunosuppressives & $122 / 465(26.2)$ & $166 / 444(37.4)$ \\
Biologicals & $170 / 465(36.6)$ & $380 / 444(85.6)$ \\
Baseline disease activity, N (\%) & & $64 / 444(14.4)$ \\
Remission & $394 / 465(84.7)$ & $235 / 372(63.2)$ \\
Active disease & $71 / 465(15.3)$ & $59.1(218.4)$ \\
Employment at baseline, N (\%) & $241 / 384(62.7)$ & $0.81(0.17)$ \\
Work-productivity (WPAl; mean hours of productivity & $54.3(232.6)$ & \\
loss per study year, (SD)) & & \\
Utility (EQ5D; mean score, (SD)) & $0.83(0.15)$ & \\
\hline
\end{tabular}

WPAl, work productivity and activity impairment; EQ5D, EuroQoL 5-dimensions; SD, standard deviation.

Table 2. Mean costs (in Euro) and QALY per patient in the two groups during the study period.

\begin{tabular}{lrrr}
\hline & $\begin{array}{r}\text { Intervention group } \\
\text { (SD) }\end{array}$ & $\begin{array}{r}\text { Control group } \\
\text { (SD) }\end{array}$ & $\begin{array}{r}\text { Incremental } \\
(\mathbf{9 5 \%} \text { Cl) }\end{array}$ \\
\hline Direct healthcare costs & $7,048(8,458)$ & $7,423(8,522)$ & $375(-742,1,501)$ \\
Non-drug healthcare costs & $762(2,412)$ & $960(2,386)$ & $198(-157,554)$ \\
Drug costs & $6,244(7,487)$ & $6,460(7,757)$ & $216(-776,1,209)$ \\
Out-of-pocket costs & $2(1.9)$ & $3(2.2)$ & $1(0.8,1.3)$ \\
IBD-coach related & 40 & 0 & +40 \\
Indirect healthcare costs & $1,886(8,084)$ & $2,058(7,587)$ & $172(-848,1,192)$ \\
Total costs & $8,934(12,256)$ & $9,481(11,757)$ & $547(-1,029,2,143)$ \\
QALY gains & $0.034(0.150)$ & $0.032(0.162)$ & $0.0020(-0.022,0.018)$ \\
\hline
\end{tabular}

IBD, inflammatory bowel disease; QALY, quality-adjusted life year.

\section{Incremental cost-effectiveness and uncertainty}

The scatter plot of the iCURs resulting from the 5,000 bootstrapped replications for the imputed data set from a societal perspective is provided in figure 1 (for the costeffectiveness planes from a healthcare perspective see supplemental figure 1 and 2). Using a WTP threshold of $€ 80,000$ and a WTA threshold of $€ 100,000$, the intervention was cost-effective in $83 \%$ of all replications. In only $6 \%$ of replications the intervention was accompanied by higher cost and lower health utility. At the Dutch cost-effectiveness threshold of $€ 80,000$ per QALY, the intervention has an iNMB of $€ 707$ per patient $(95 \% \mathrm{Cl}$ $-1,241$ to 2,544 ) per year (figure 2). Figure 3 shows the uncertainty analyses of the iCUR and iNMB. While myIBDcoach dominates usual care even at a WTP threshold of $€$ zero per QALY, some uncertainty remains and as there is no threshold at which mylBDcoach is $100 \%$ certain cost-effective. 


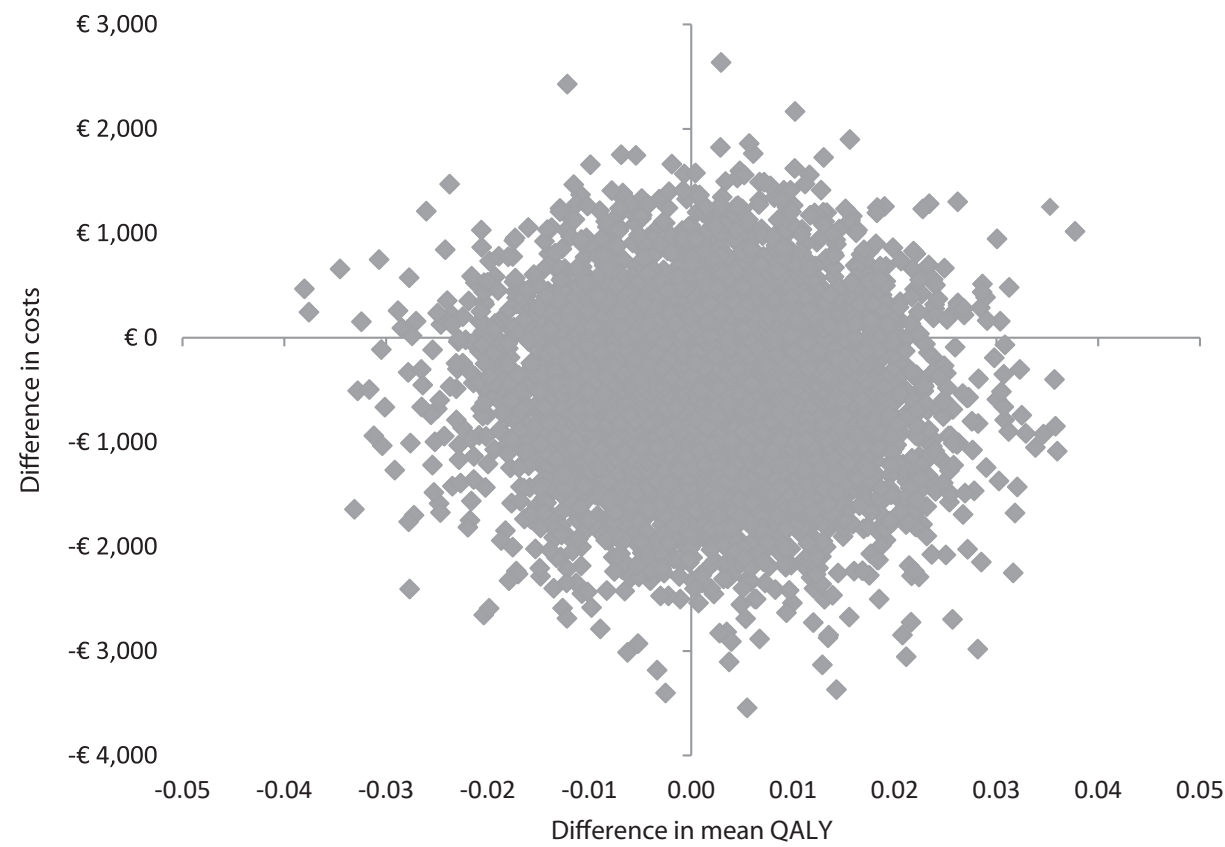

Figure 1. Scatter plot of incremental mean cost against incremental mean QALYs of telemedicine compared to standard care. Each data point was obtained from one bootstrap.

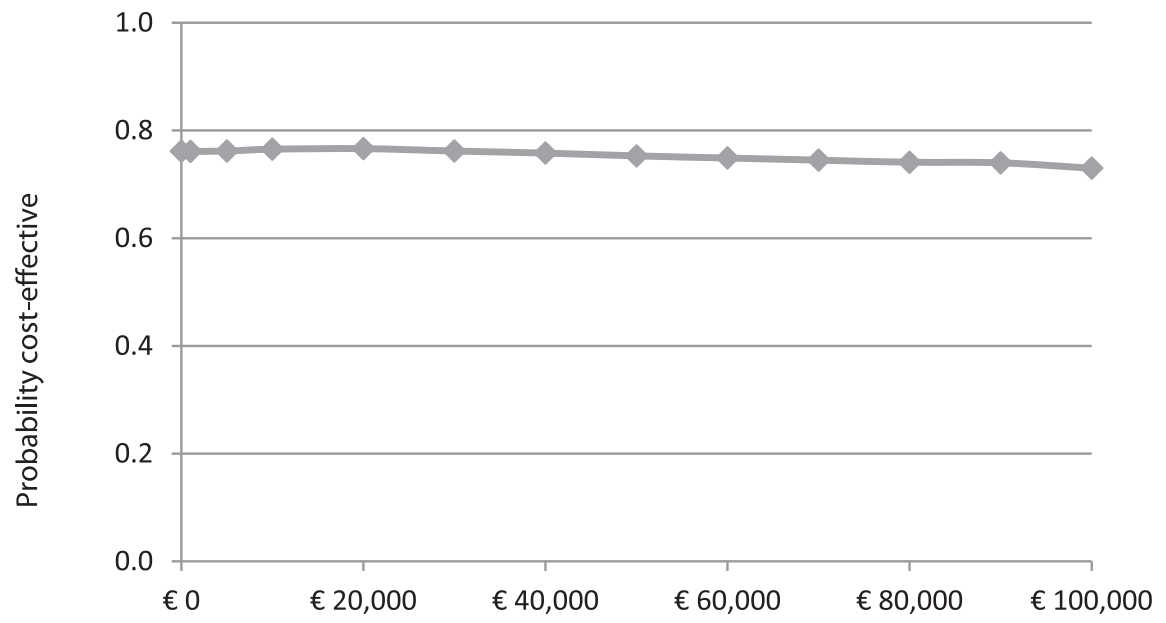

\section{Willingness to pay (in EUR per QALY)}

Figure 2. Incremental net monetary benefit (iNMB) curve for telemedicine versus standard care. 


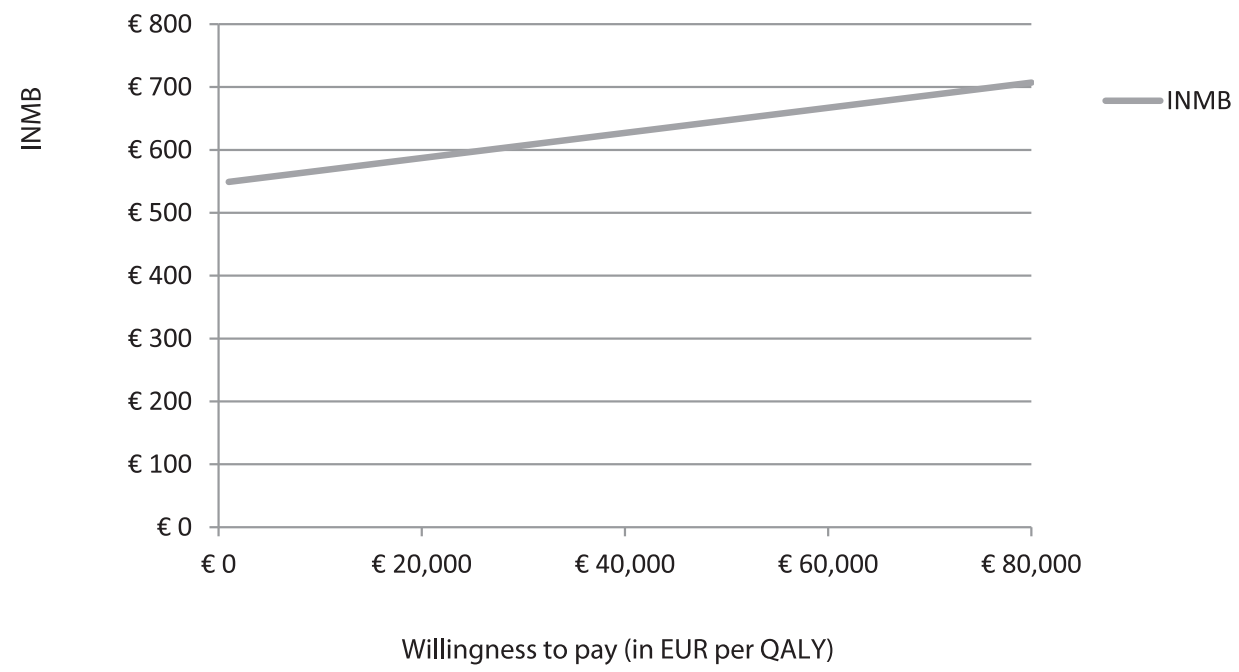

Figure 3. Cost-effectiveness acceptability curve (CEAC) for telemedicine versus standard care.

\section{DISCUSSION}

In this cost-utility analysis regarding data from a pragmatic, randomised controlled trial, we showed that telemedicine with mylBDcoach was cost effective compared to standard care for IBD patients. Positive effects of telemedicine on IBD outcome have extensively been demonstrated. However, broad implementation is currently hindered as a result of lacking evidence on cost-effectiveness. To the best of our knowledge, this was the first complete economic evaluation of a telemedicine intervention versus standard care for IBD patients.

Telemedicine with mylBDcoach resulted in lower mean annual costs and a small mean gain in quality adjusted life years. At the Dutch threshold of $€ 80,000$ per QALY, the incremental net monetary benefit was $€ 707$ per patient per year. Benefits of telemedicine in IBD have been evaluated in two previous studies. The first trial, in which 333 patients in Denmark with mild-to-moderate UC treated with mesalazine were randomised to care via a telemedicine tool or standard care and followed for 12 months, showed that tight monitoring of disease activity and personalised treatment strategies resulted in cost savings of $€ 189$ per patient per year, mostly due to fewer outpatient visits ${ }^{26}$. In addition, improvement in disease-specific quality of life was found. As quality of life was not measured by the EQ-5D, cost per QALY could not be calculated. Regarding indirect healthcare costs, no statistically significant difference in number of work days lost through illness was observed between the two groups. The second study by the same group, a 12-month observational study in 92 (23 web-based care) CD patients, found lower direct 
costs of $€ 699$ per patient per year when infliximab treatment was personally scheduled by web-administration, as compared to standard scheduled infliximab administration in the outpatient clinic $^{27}$. However, this web-based strategy did not show an improvement in quality of life nor a change in time missed from work due to $C D^{28}$. In line with our results, both studies showed that individualisation of disease management enabled by telemedicine was accompanied by a reduction of direct healthcare costs due to more efficient use of resources. Additionally, telemedicine can contribute to earlier identification of patients with insufficiently controlled disease who tend to be undertreated in current practice. Mounting evidence underscores that tight control of disease activity and optimisation of medication adherence prevents chronic uncontrolled mucosal inflammation, subsequent irreversible bowel damage, surgeries, and hospitalisation $29,30,31$. By implementing such a strategy with telemedicine, flares can be detected earlier and the delay to treatment minimised. The abovementioned UC study indeed showed that implementation of guided self-management with personalised action plans by which patients could immediately self-initiate treatment in case of symptoms shortened flare duration ${ }^{26}$. The combination of close monitoring and immediate intervention in case of a relapse might also have contributed to the reduction in hospitalisations in our study.

The cost savings in our study were mainly due to a reduction in outpatient visits and medication costs. We speculate that the latter might have been due to a reduction in flare duration and thereby a shortened therapy window. Additionally, timely optimisation of conventional therapy might prevent escalation to more expensive biologicals. Currently, several trials assess the possibilities for de-escalation of biological treatment in patients with sustained remission in order to improve safety and reduce healthcare costs. Proposed strategies include reducing dosage, increasing dosage intervals, or by discontinuation of biological therapy. Long-term studies are presently carried out to evaluate the safety, effects, and costs of these strategies ${ }^{32,33}$. Telemedicine can add value to these strategies by closely monitoring disease activity and immediate re-escalation when indicated.

The main strength of this economic evaluation was that the data were obtained from a trial with a pragmatic randomised design, thus based on common daily practice. $\mathrm{A}$ large unselected heterogeneous group of patients, clinicians, and clinical practices were included to maximise the generalisability of the results to everyday practice. A possible limitation of this study was the lack of detailed information regarding laboratory tests as they were not systematically reported in medical records. However, these tests were previously found to account for a small proportion of the total costs and are therefore unlikely to have major impact on the reported results. Furthermore, as laboratory tests are regularly linked to outpatient visits, the total costs related to these tests are probably lower in the telemedicine group. In addition, some parameters were collected by questionnaires, resulting in possible selection bias. Yet, we found no statistically significant 
differences in gender, age, phenotype, disease severity or educational level between patients who returned their questionnaires and those who did not. We calculated the indirect healthcare costs using the self-reported hours of sick leave from work over the past 7 days obtained from the WPAI and extrapolated these data for 1 year. This method could have under- or overestimated the total amount of indirect healthcare costs. However, in view of the large sample size and under the assumption that weekly sickness absence would occur at a constant rate throughout the observation period in each treatment group, the indirect costs estimated can be considered accurate. Additionally, we might have slightly overestimated the total net monetary benefit as we calculated a plain annual license fee of $€ 40$ per patient using telemedicine. These costs were based on the first version of mylBDcoach, without costs for implementation and without additional costs related to any potential healthcare reorganisation (e.g. extra hours work for an IBD-nurse). However, we expect that the additional actions related to mylBDcoach performed by the IBD-nurses, i.e. analysis of the monitoring module and subsequent actions, and answering to patients' messages, are at least partly compensated by the information and education function of the e-learning modules, which is normally a faceto-face task of the IBD-nurse.

Implementation telemedicine assists healthcare providers in delivering high-quality, and high-value care. For IBD, telemedicine furthermore enables gastroenterologists to implement a tight control strategy despite the currently overburdened outpatient clinics. We believe that broad implementation of telemedicine in parallel with reorganisation of care can improve long-term disease outcome and reduce healthcare costs. Additionally, interventions based on aberrant patient-reported values, such as smoking, an unfavourable nutritional status, or medication non-adherence, might contribute to better outcome. Furthermore, by systematic registering of PROMs and quality indicators, telemedicine can contribute to improving quality of care by benchmarking and evaluating practice variations. Lastly, shifting tasks from doctors to nurses, for example by telemonitoring of patients with a mild disease course or those in remission supervised by a specialised nurse, could further constrain costs.

Ameliorating quality of care for chronic diseases has been defined as improving patients' experience of care, improving long-term disease outcomes, creating a healthier population, and reducing costs of healthcare ${ }^{20,34,35}$. Telemedicine with mylBDcoach has previously shown to improve patient experience of care and to improve disease outcomes $^{14,15}$. The current study showed that implementation of telemedicine has an $83 \%$ chance to be cost-effective. Therefore, telemedicine may be a promising tool in restructuring IBD care towards more personalised, efficient and value-based healthcare. 


\section{REFERENCES}

1. Huber M, Knottnerus JA, Green $L$, et al. How should we define health? Bmj. Jul 26 2011;343:d4163.

2. Jaboli F, Pouillon L, Bossuyt P, Danese S, Peyrin-Biroulet L. Telehealth in Inflammatory Bowel Disease: Every Patient May Need a Coach! Gastroenterology. Mar 2018;154(4):1196-1198.

3. Tuckson RV, Edmunds $M$, Hodgkins ML. Telehealth. The New England journal of medicine. Oct 19 2017;377(16):1585-1592.

4. Johnston RD, Logan RF. What is the peak age for onset of IBD? Inflamm Bowel Dis. Oct 2008;14 Suppl 2:S4-5.

5. Bernklev T, Jahnsen J, Lygren I, Henriksen M, Vatn M, Moum B. Health-related quality of life in patients with inflammatory bowel disease measured with the short form-36: psychometric assessments and a comparison with general population norms. Inflamm Bowel Dis. Oct 2005;11(10):909918.

6. van der Valk ME, Mangen MJ, Leenders $M$, et al. Healthcare costs of inflammatory bowel disease have shifted from hospitalisation and surgery towards anti-TNFalpha therapy: results from the COIN study. Gut. Jan 2014;63(1):72-79.

7. van der Valk ME, Mangen MJ, Severs M, et al. Evolution of Costs of Inflammatory Bowel Disease over Two Years of FollowUp. PloS one. 2016;11(4):e0142481.

8. Bassi A, Dodd S, Williamson P, Bodger K. Cost of illness of inflammatory bowel disease in the UK: a single centre retrospective study. Gut. Oct 2004;53(10):14711478.

9. Dignass A, Lindsay JO, Sturm A, et al. Second European evidence-based consensus on the diagnosis and management of ulcerative colitis part 2: current management. Journal of Crohn's \& colitis. Dec 2012;6(10):991-1030.
10. Dignass A, Van Assche G, Lindsay JO, et al. The second European evidencebased Consensus on the diagnosis and management of Crohn's disease: Current management. Journal of Crohn's \& colitis. Feb 2010;4(1):28-62.

11. Colombel JF, Narula N, Peyrin-Biroulet L. Management Strategies to Improve Outcomes of Patients With Inflammatory Bowel Diseases. Gastroenterology. Oct 05 2016.

12. Molodecky NA, Soon IS, Rabi DM, et al. Increasing incidence and prevalence of the inflammatory bowel diseases with time, based on systematic review. Gastroenterology. Jan 2012;142(1):46-54 e42; quiz e30.

13. van den Heuvel TRA, Jeuring SFG, Zeegers $M P$, et al. A 20 year temporal change analysis in incidence, presenting phenotype and mortality in the Dutch IBDSL cohort - Can diagnostic factors explain the increase in IBD incidence? Journal of Crohn's \& colitis. Apr 202017.

14. de Jong MJ, van der Meulen-de Jong $A E$, Romberg-Camps MJ, et al. Telemedicine for management of inflammatory bowel disease (mylBDcoach): a pragmatic, multicentre, randomised controlled trial. Lancet. Sep 02 2017;390(10098):959-968.

15. de Jong $M$, van der Meulen-de Jong $A$, Romberg-Camps $M$, et al. Development and Feasibility Study of a Telemedicine Tool for All Patients with IBD: MylBDcoach. Inflamm Bowel Dis. Apr 2017;23(4):485493.

16. Health Insurance Board, avalaible at www. medicijnkosten.nl, 2018.

17. Zorginstituut Nederland. Richtlijn voor het uitvoeren van economische evaluaties in de gezondheidszorg. Diemen: Zorginstituut Nederland. 2015.

18. Hakkaart-van Roijen L, Tan S, Bouwmans C. Handleiding voor kostenonderzoek, methoden en standaard kostprijzen voor 
economische evaluaties in de gezondheidszorg. College voor zorgverzekeringen. Geactualiseerde versie 2015. 2015.

19. Dutch healthcare authority. Available at www.nza.nl. 2018.

20. Farmacotherapeutisch Kompas. Available at http://farmacotherapeutischkompas.nl. Accessed 29 January 2018.

21. Reilly MC, Zbrozek AS, Dukes EM. The validity and reproducibility of a work productivity and activity impairment instrument. PharmacoEconomics. Nov 1993;4(5):353-365.

22. EuroQol G. EuroQol--a new facility for the measurement of health-related quality of life. Health policy. Dec 1990;16(3):199-208.

23. Lamers LM, McDonnell J, Stalmeier PF, Krabbe PF, Busschbach JJ. The Dutch tariff: results and arguments for an effective design for national EQ-5D valuation studies. Health economics. Oct 2006;15(10):11211132.

24. Ramsey S, Willke R, Briggs A, et al. Good research practices for cost-effectiveness analysis alongside clinical trials: the ISPOR RCT-CEA Task Force report. Value in health : the journal of the International Society for Pharmacoeconomics and Outcomes Research. Sep-Oct 2005;8(5):521-533.

25. van den Heuvel TR, Jonkers DM, Jeuring $\mathrm{SF}$, et al. Cohort Profile: The Inflammatory Bowel Disease South Limburg Cohort (IBDSL). International journal of epidemiology. Jun 42015.

26. Elkjaer M, Shuhaibar M, Burisch J, et al. Ehealth empowers patients with ulcerative colitis: a randomised controlled trial of the web-guided 'Constant-care' approach. Gut. Dec 2010;59(12):1652-1661.

27. Pedersen N, Elkjaer M, Duricova $D$, et al. eHealth: individualisation of infliximab treatment and disease course via a selfmanaged web-based solution in Crohn's disease. Alimentary pharmacology \& therapeutics. Nov 2012;36(9):840-849.
28. Cross RK, Cheevers N, Rustgi A, Langenberg P, Finkelstein J. Randomized, controlled trial of home telemanagement in patients with ulcerative colitis (UC HAT). Inflamm Bowel Dis. Jun 2012;18(6):10181025.

29. Pedersen N, Thielsen P, Martinsen L, et al. eHealth: individualization of mesalazine treatment through a self-managed web-based solution in mild-to-moderate ulcerative colitis. Inflamm Bowel Dis. Dec 2014;20(12):2276-2285.

30. Lakatos PL. Prevalence, predictors, and clinical consequences of medical adherence in IBD: how to improve it? World journal of gastroenterology. Sep 14 2009;15(34):4234-4239.

31. Colombel JF, Panaccione R, Bossuyt $P$, et al. Effect of tight control management on Crohn's disease (CALM): a multicentre, randomised, controlled phase 3 trial. Lancet. Dec 23 2018;390(10114):2779-2789.

32. Peyrin-Biroulet L, Danese S. Stopping infliximab in Crohn's disease: still an ongoing STORI. Inflamm Bowel Dis. Nov 2012;18(11):2201-2202.

33. Reenaers C, Mary JY, Nachury M, et al. Outcomes 7 Years After Infliximab Withdrawal for Patients With Crohn's Disease in Sustained Remission. Clinical gastroenterology and hepatology : the official clinical practice journal of the American Gastroenterological Association. Feb 2018;16(2):234-243 e232.

34. Siegel CA, Allen Jl, Melmed GY. Translating improved quality of care into an improved quality of life for patients with inflammatory bowel disease. Clinical gastroenterology and hepatology : the official clinical practice journal of the American Gastroenterological Association. Aug 2013;11(8):908-912.

35. Berwick DM, Nolan TW, Whittington J. The triple aim: care, health, and cost. Health Aff (Millwood). May-Jun 2008;27(3):759-769. 




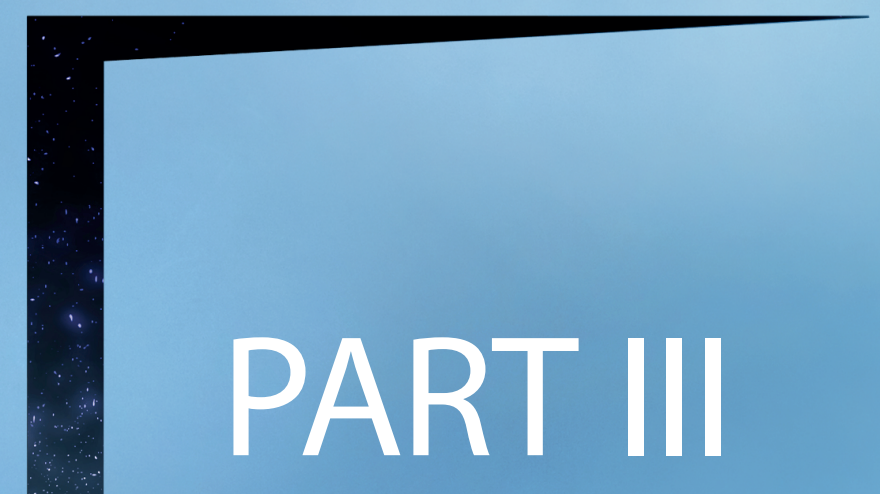





\section{Chapter 7}

Novel perceived stress and life events precede flares of inflammatory bowel disease: a prospective 12-month follow-up study

Dion Wintjens, Marin de Jong, Andrea van der Meulen-de Jong, Mariëlle Romberg-Camps, Marco Becx, Jeroen Maljaars, Ad van Bodegraven, Nofel Mahmmod, Tineke Markus, Jeoffrey Haans, Ad Masclee, Bjorn Winkens, Daisy Jonkers, Marieke Pierik 


\section{ABSTRACT}

Background: Inflammatory bowel disease (IBD) is characterised by recurrent disease flares. The impact of psychosocial wellbeing on the occurrence of flares is unclear. In this prospective study, we aimed to evaluate the association between patient-reported psychosocial wellbeing and disease flares using continuous monitoring.

Methods: Consecutive IBD patients were recruited from the myIBDcoach telemedicine study cohort. During 12 months, participants reported on disease activity and anxiety, depression, fatigue, perceived stress, and life events every one to three months. Flares were defined using a combination of clinical disease activity and additional measurements. Generalised estimating equation models were used to assess associations between psychosocial wellbeing and flares over time. The influences of both the presence of psychosocial symptoms in general and novel psychosocial symptoms were analysed.

Results: In total, 417 patients were included. Forty-nine patients (11.8\%) experienced a flare during the study period. The occurrence of life events in the preceding three months was positively associated with flares (odds ratio [OR] 1.81; 95\% confidence interval [CI] 1.04-3.17), while the presence of anxiety, depression, fatigue and perceived stress in general was not. However, novel perceived stress (OR 2.92; 95\% Cl 1.44-5.90) was associated with flares.

Conclusions: The occurrence of life events and novel perceived stress are associated with disease flares in the next three months, while the presence of perceived stress in general is not. These findings underline the importance of continuous personalised monitoring of IBD patients and may contribute to the prevention of disease flares. 


\section{INTRODUCTION}

Inflammatory bowel disease (IBD), comprising Crohn's disease (CD) and ulcerative colitis (UC), is a chronic and disabling disease characterised by recurrent periods of disease activity. These flares warrant escalation of medical treatment and often require hospitalisations or surgery. Recurrent flares may also lead to irreversible bowel damage and disease progression (e.g. the occurrence of complications like fistula and stenosis). ${ }^{1,2}$ Although biochemical markers are available for early detection of disease activity ${ }^{3}$, identification of factors contributing to the emergence of flares might be an even more interesting approach to improve the outcome of IBD.

Regarding potentially flare-inducing factors, psychosocial wellbeing of patients is of interest. While not systematically monitored by healthcare professionals in routine care, a high prevalence of psychological disorders such as anxiety and depression is reported in the IBD population. ${ }^{4,5}$ This may be a consequence of the chronic disease itself, but it is also hypothesised that impaired psychosocial wellbeing can negatively impact gut health through multiple immune-neuroendocrine brain-gut interaction pathways. ${ }^{6,7}$

A large number of studies have investigated the association between psychosocial wellbeing and disease activity in IBD, although many are limited by their cross-sectional design, thereby potentially neglecting the aforementioned bi-directionality of the braingut axis. When taking into account only the longitudinal studies, contradictive results have been reported regarding the effects of anxiety and depression on flares. ${ }^{8}$ Perceived stress and life events have been studied more extensively and it has been reported that a positive association exists between flares and perceived stress in most longitudinal studies. ${ }^{9-14}$ Though, in many studies, careful interpretation is advocated due to low sample size and the sole use of clinical disease activity indices to define flares, because these indices are poor predictors of mucosal inflammation. ${ }^{15}$ Also, perceived stress may affect intestinal motility and may magnify visceral sensitivity, leading to worsening of abdominal symptoms in the absence of inflammation. ${ }^{16,17}$ It remains debatable to what extent mood disorders and perceived stress are associated with disease flares. Since, for instance, depression and perceived stress can both be present for longer periods ${ }^{13,18}$, it may be relevant to focus on within-subject changes in psychosocial wellbeing rather than to analyse only the presence of impaired psychosocial wellbeing preceding flares, which has, to our knowledge, not been done before.

Recently, de Jong et al. showed that continuous monitoring at home with the telemedicine tool 'MylBDcoach' is safe and even reduced outpatient visits and hospital admissions. ${ }^{19}$ MylBDcoach continuously monitors patient-reported disease activity and psychosocial wellbeing through questionnaires. This method of data collection may provide important insights in psychosocial wellbeing over time. In this prospective 
study, we aimed to evaluate which domains of psychosocial wellbeing, when impaired, were associated with future disease flares based on data from the mylBDcoach trial.

\section{MATERIALS AND METHODS}

\section{Design and procedures}

All data used in this study were derived from the mylBDcoach study cohort. The design of this randomised controlled telemedicine study has previously been described in detail.(19) In short, IBD patients were included in four hospitals in the Netherlands (i.e. two academic hospitals, Maastricht University Medical Centre and Leiden University Medical Centre, and two regional hospitals, Zuyderland Medical Centre Sittard and St. Antonius Hospital Nieuwegein). Patients between 18 and 75 years of age who had a histopathologically corroborated diagnosis of IBD were eligible for inclusion. Exclusion criteria comprised insufficient knowledge of the Dutch language, lack of internet access by computer, tablet or smartphone, or a hospital admission within 2 weeks prior to inclusion. Also, patients with an ileoanal pouch or ileorectal anastomosis, or IBD unclassified (IBD-U) were excluded. After inclusion, patients were randomised in a 1:1 ratio to standard care (control group) or to care through mylBDcoach (intervention group) and followed for at least 12 months. The details of the telemedicine system mylBDcoach have been described elsewhere.(20) In brief mylBDcoach is a secured webpage which is accessible through computer, tablet or smartphone. The system provides monthly monitoring modules, including questions regarding disease activity, use of medication, treatment adherence, smoking status and psychosocial wellbeing. When patients achieved sustained remission (i.e. low clinical activity for three consecutive months), it was allowed to complete the monitoring module once every three months. When predefined thresholds, for instance on clinical disease activity, were exceeded, a healthcare provider of the local team contacted the patient for further assessment. The study was approved by the Medical Research Ethics Committee of the Maastricht University Medical Centre+, being applicable to all participating centres. This trial was registered at ClinicalTrials.gov (NCT02173002).

For the present study, we included all patients who received care through mylBDcoach (i.e. the intervention arm of the randomised study). Patients without a single period of documented remission during follow-up were excluded since this period of remission was required to analyse the association between the development of disease flares and preceding psychosocial wellbeing. Detailed baseline data the time of inclusion in MylBDcoach (i.e. patient characteristics, disease phenotype, disease duration and previous treatments) were collected by scrutinising patient files using standardised registration forms. During the 12 months of follow-up, questionnaires on disease activ- 
ity (MIAH-questionnaire ${ }^{21}$ and psychosocial wellbeing (i.e. anxiety, depression, fatigue, perceived stress, and life-events) were completed every 1-3 months.

\section{Definitions}

In line with previous analyses based on the mylBDcoach tool, flares were defined as clinical symptoms (i.e. positive score on the MIAH-questionnaire or symptoms during outpatient visits) indicative of disease activity in combination with at least one of the following: concurrent calprotectin $>250 \mu \mathrm{g} / \mathrm{g}$ in the stool or active disease determined by endoscopy, magnetic resonance imaging or computed tomography. In daily practice, in case of clinically severe symptoms suggestive for IBD disease activity, the treating physician occasionally judged these symptoms to be evident enough to adjust therapy. Therefore, to capture all flares, also clinical episodes were defined as flares if symptoms suggestive of IBD disease activity resulted in a dose escalation or initiation of a new drug to induce remission. Psychosocial parameters were assessed through a patient-reported questionnaire containing one question for each psychosocial domain of interest (table 1). For anxiety, depression, and fatigue, questions were answered on a 5-point Likertscale (i.e. 'seldom or never', 'occasionally', 'regularly', 'often', or 'always or almost always'). Cut-offs were determined based on the smallest Euclidian distances compared to validated questionnaires (i.e. HADS-A 22, HADS-D 22, and VVS23). The performance of the questionnaire is shown in table 1. For perceived stress, we used a VAS-scale on which a patient could report on their current stress level (range from 1 to 10) in which a higher score reflects higher stress levels. This scale showed a moderate though significant cor-

Table 1. Overview of psychosocial questionnaire used in the mylBDcoach telemedicine tool.

\begin{tabular}{|c|c|c|c|c|}
\hline Domain & Question & Scale & Cut-off & $\begin{array}{c}\text { Performance versus } \\
\text { validated questionnaire } \\
\text { (sens/spec) }\end{array}$ \\
\hline Anxiety & $\begin{array}{l}\text { In the past two weeks I . .. felt } \\
\text { anxious. }\end{array}$ & Likert (1-5) & 2 (occasionally) & HADS-A ${ }^{24}(64 / 82)$ \\
\hline Depression & $\begin{array}{l}\text { In the past two weeks I ... felt } \\
\text { miserable or depressed. }\end{array}$ & Likert (1-5) & 3 (frequently) & HADS-D ${ }^{24}(73 / 93)$ \\
\hline Fatigue & $\begin{array}{l}\text { In the past two weeks I . . f felt } \\
\text { fatigue. }\end{array}$ & Likert (1-5) & 3 (frequently) & $\operatorname{VVV}^{25}(90 / 100)$ \\
\hline Perceived stress & $\begin{array}{l}\text { Rate your current stress level } \\
\text { on a scale from } 1 \text { to } 10, \text { what } \\
\text { number would you give? }\end{array}$ & VAS (1-10) & NA & $\mathrm{PSS}^{26}(\mathrm{R}=0.654)$ \\
\hline Life events & $\begin{array}{l}\text { Did you experience any } \\
\text { important or drastic events } \\
\text { during the last period which } \\
\text { influenced your feelings? }\end{array}$ & Dichotomous & NA & NA \\
\hline
\end{tabular}

VAS, visual analogue scale; NA, not applicable; sens, sensitivity; spec, specificity; HADS-D, Hospital Anxiety and Depression Scale - Depression; HADS-A, Hospital Anxiety and Depression Scale - Anxiety; VVV, Verkorte VermoeidheidVragenlijst (translated: Short Fatigue Questionnaire); PSS, Perceived Stress Scale 
relation with the Cohen's Perceived Stress Scale (PSS; $r=0.654) .(24)$ However, it should be noted that the PSS is based on perceived stress during the previous month, while our scale measures current stress levels. A cut-off point of 4 , based on expert opinion of our team of gastroenterologists and our population's average, was used to differentiate low versus high perceived stress levels. The occurrence of life events was scored in a binary approach (i.e. yes/no). The underlying reason for the life event was answered as an open-end question and was therefore neglected in the analysis.

\section{Statistical analysis}

Baseline characteristics are presented as means with corresponding standard deviations (SD) for numerical variables with a normal distribution, as medians with corresponding interquartile ranges (IQR) for numerical variables without a normal distribution, and as number of patients (\%) for categorical variables. For comparison between groups, the independent-samples t-test and Chisquare test or Fisher's exact test, when appropriate, were used for numerical and categorical variables, respectively.

Generalised estimating equations (GEE) models were used to identify associations between psychosocial wellbeing and the subsequent development of flares over time. This method is used to account for repeated measures within the same patient, where the covariance pattern was unstructured. Since it was unknown how long a patient was in remission when entering the study, the first three months of all patients were ignored in the analyses. Next, each month of follow-up was considered either as positive or negative with respect to flares, according to the aforementioned definition. Also, patient-reported psychosocial wellbeing was assessed with intervals of one month using the aforementioned cut-offs. When active disease was present at baseline or when a flare occurred during follow-up, the subsequent six months were excluded from the analysis to correct for a potential effect of disease activity and the subsequent remissioninduction therapy on the psychosocial wellbeing of a patient. This can be considered as a wash-out period for both gastrointestinal inflammation and psychosocial imbalance caused by the preceding flare. Since patients could choose to fill in the questionnaires either once every month or once every three months, all models estimate the effect of psychosocial wellbeing on disease activity in the next quarter.

In the first GEE model, the association between flares and the presence of psychosocial symptoms in general was assessed. Predefined cut-offs were used to indicate the presence or absence of all psychosocial factors available in mylBDcoach, regardless of the prior psychosocial wellbeing of the patient. In the second GEE model, the association between flares and novel psychosocial symptoms was assessed. Here, differences in psychosocial parameters over time were determined to separate novel symptoms from pre-existing symptoms. At each time point the alteration in psychosocial parameters was regarded positive when this change exceeded the cut-off values of these 
parameters (e.g. from 'seldom or never feeling depressed' (i.e. score 1) to 'often feeling depressed' (i.e. score 4)) in the three months preceding this time point. Life events were only analysed in the first model, since life events are 'novel' by definition and therefore the second model is not applicable. To ensure a prospective association between the psychosocial parameters and subsequent flares, psychosocial parameters were not taken into account as predictors when positive at the same time point as the flare. For example, when a patient experienced a flare between time point 5 and 6 , the latter was regarded as 'time point of flare' and psychosocial scores from time point 3 to 5 were used in the model as explanatory variables.

All results were analysed using a multivariable model including gender, disease phenotype, disease duration at baseline, and smoking status at baseline to correct for their potential confounding effect on disease flares. Although our study was underpowered for additional confounders, medication use at baseline was added to the model as a sensitivity analysis. All analyses were conducted using a significance level of 0.05 . Twosided $p$-values $\leq 0.05$ were considered as statistically significant.

\section{RESULTS}

In total, 465 patients were allocated to the mylBDcoach intervention.(19) Of these, 9 never started using the application and 18 were lost to follow-up. After exclusion of these patients and patients with IBD-U $(n=3)$, patients without any completed questionnaire $(n=11)$, and patients without a single period of remission $(n=7), 417$ patients were eligible for this study. Of these, 49 patients (11.8\%) developed a flare during follow-up (i.e. change from inactive to active disease). Two of these patients developed a second flare after remission was re-obtained. Flares were defined by clinical symptoms in combination with an elevated fecal calprotectin, active disease on endoscopy or imaging, and adjustment of therapy by a gastroenterologist in 14 (27.4\%), 21 (41.2\%), and 16 (31.4\%) cases, respectively. Baseline characteristics of these patients (i.e. relapsers) compared to those not developing a flare during follow-up (i.e. non-relapsers) are presented in table 2. No significant differences in baseline characteristics were found between relapsers and non-relapsers, except for a greater proportion of smokers in the latter group $(p=0.005)$. The average time from inclusion to their first disease flare for relapsers was $6.4(\mathrm{SD}=2.6)$ months.

Regarding the presence of psychosocial symptoms in general, only the occurrence of life events (Odds ratio (OR) 1.81, 95\% Confidence Interval $(95 \% \mathrm{Cl}) 1.04-3.17)$ was associated with flare development in the next three months (table 3). Neither anxiety (OR 0.73, $95 \% \mathrm{Cl} 0.38-1.39$ ), nor depression (OR $1.33,95 \% \mathrm{Cl} 0.70-2.55)$, nor fatigue (OR $1.91,95 \% \mathrm{Cl}$ $0.98-3.73$ ), and perceived stress (OR $1.09,95 \% \mathrm{Cl} 0.62-1.91$ ) were statistically significantly 
Table 2. Baseline characteristics, stratified by occurrence of disease flares.

\begin{tabular}{|c|c|c|c|}
\hline & $\begin{array}{c}\text { Relapsers } \\
(n=49)\end{array}$ & $\begin{array}{l}\text { Non-relapsers } \\
\quad(n=368)\end{array}$ & p-value \\
\hline Crohn's disease n (\%) & $26(53.1)$ & $222(60.3)$ & 0.331 \\
\hline Male, n (\%) & $15(30.6)$ & $158(42.9)$ & 0.100 \\
\hline \multicolumn{4}{|l|}{ Montreal at diagnosis^ } \\
\hline Age (CD \& UC) & & & 0.600 \\
\hline $\mathrm{A} 1, \mathrm{n}(\%)$ & $8(16.3)$ & $60(16.3)$ & \\
\hline $\mathrm{A} 2, \mathrm{n}(\%)$ & $26(53.1)$ & $219(59.5)$ & \\
\hline$A 3, n(\%)$ & $15(30.6)$ & $89(24.2)$ & \\
\hline Disease location (CD) & & & 0.741 \\
\hline L1 , n (\%) & 7 (26.9) & $73(32.9)$ & \\
\hline $\mathrm{L} 2, \mathrm{n}(\%)$ & $6(23.1)$ & $55(24.8)$ & \\
\hline L3, n (\%) & $13(50.0)$ & $94(42.3)$ & \\
\hline Disease behavior (CD) & & & 0.958 \\
\hline $\mathrm{B} 1(\mathrm{CD}), \mathrm{n}(\%)$ & $16(61.5)$ & $134(60.6)$ & \\
\hline B2 (CD), n (\%) & 7 (26.9) & $57(25.8)$ & \\
\hline B3 (CD), n (\%) & $3(11.5)$ & 30 (13.6) & \\
\hline Disease extent (UC) & & & 0.768 \\
\hline E1 (UC), n (\%) & $2(8.7)$ & $19(12.8)$ & \\
\hline E2 (UC), n (\%) & $10(43.5)$ & $69(46.3)$ & \\
\hline E3 (UC), n (\%) & $11(47.8)$ & $61(40.9)$ & \\
\hline Age at baseline (years), mean (SD) & $46.08(15.24)$ & $43.95(13.71)$ & 0.313 \\
\hline Disease duration at baseline (years), mean (SD) & $13.45(10.93)$ & $13.39(10.40)$ & 0.971 \\
\hline Active disease at baseline, $\mathrm{n}(\%)$ & $4(7.7)$ & $28(8.2)$ & 0.908 \\
\hline Medication use at baseline & & & 0.434 \\
\hline No medication/5-ASA, $n$ (\%) & $15(30.6)$ & $142(39.3)$ & \\
\hline Immunomodulators, n (\%) & $16(32.7)$ & $93(25.8)$ & \\
\hline Biologics, n (\%) & $18(36.7)$ & $126(34.9)$ & \\
\hline Current smoking at baseline, $\mathrm{n}(\%)$ & $1(2.0)$ & $65(17.7)$ & $0.005^{*}$ \\
\hline History of IBD-related surgery at baseline, n (\%) & $5(16.7)$ & $41(23.3)$ & 0.420 \\
\hline
\end{tabular}

$\mathrm{N}$, number of patients; CD, Crohn's disease; UC, Ulcerative colitis; SD, standard deviation; 5-ASA, 5-aminosalicylic acid; *, p-value below $0.05 ; \wedge$, classification according to Montreal Classification. ${ }^{39}$ Age was defined as below 17 (A1), between 17 and 40 (A2) and above 40 (A3). Disease location of CD was defined as ileal involvement (L1), exclusive colonic involvement (L2), ileocolonic involvement (L3). Disease behaviour of CD was defined as non-stricturing/non-penetrating (B1), stricturing (B2), penetrating (B3). Disease extent of UC was defined as ulcerative proctitis (E1), left sided UC (E2) and extensive UC (E3).

associated with flare development. Regarding novel psychosocial symptoms (i.e. alteration exceeding cut-off), only perceived stress (OR 2.92, 95\% Cl 1.44-5.90) was associated with subsequent flares (table 3 ), independent of the presence of other psychosocial factors in general. No statistically significant association with subsequent flares was found in this second GEE model for anxiety (OR 1.12, 95\% Cl 0.50-2.51), depression (OR 1.28, 
$95 \% \mathrm{Cl} 0.54-3.07)$, and fatigue (OR $1.58,95 \% \mathrm{Cl} 0.79-3.15)$. All results were adjusted for gender, disease phenotype, disease duration, and smoking status. When results were analysed for CD and UC separately, the association between flares and both life events and perceived stress tended to be stronger in CD. However, due to the small number of relapses, the study was not powered to analyse these associations and the results should be interpreted with care.

In a first sensitivity analysis, medication use at baseline was added to the model. By applying this, all results remained similar. As a second sensitivity analysis, different cutoffs of the questions regarding depression, anxiety, fatigue, and perceived stress were used. For depression, anxiety, and fatigue, both higher and lower cut-offs did not change the results. For novel perceived stress, a difference was observed. In case cut-offs higher than 4 were chosen, perceived stress was not statistically significant anymore (cut-off 5: OR $1.52,95 \% \mathrm{Cl}$ 0.67-3.45), while cut-offs below 4 remained statistically significant (cutoff 3: OR 2.24, 95\%Cl 1.02-4.90).

Table 3. Association between both the presence of psychosocial symptoms in general (GEE model 1) and novel psychosocial symptoms (GEE model 2) and disease flares.

\begin{tabular}{lcccc}
\hline & \multicolumn{2}{c}{$\begin{array}{c}\text { GEE model 1: presence of psychosocial } \\
\text { symptoms in general }\end{array}$} & $\begin{array}{c}\text { GEE model 2: novel psychosocial } \\
\text { symptoms only }\end{array}$ \\
\cline { 2 - 5 } & OR & $95 \%-C l$ & OR & $95 \%-\mathrm{Cl}$ \\
\hline Anxiety & 0.73 & $0.38-1.39$ & 1.12 & $0.50-2.51$ \\
Depression & 1.33 & $0.70-2.55$ & 1.28 & $0.54-3.07$ \\
Fatigue & 1.91 & $0.98-3.73$ & 1.58 & $0.79-3.15$ \\
Perceived stress & 1.09 & $0.62-1.91$ & 2.92 & $1.44-5.90^{* *}$ \\
Life events & 1.81 & $1.04-3.17^{*}$ & $\mathrm{NA}$ & $\mathrm{NA}$ \\
\hline
\end{tabular}

OR, Odds ratio; 95\%-Cl, 95\%-Confidence Interval; ${ }^{*}$, p-value below 0.05; ${ }^{* *}$, p-value below 0.01 All analyses were adjusted for gender, disease phenotype, disease duration at baseline, and smoking status at baseline.

\section{DISCUSSION}

In this prospective continuous telemedicine monitoring study we evaluated the effect of psychosocial wellbeing on subsequent disease flares. A positive association was found between both life events as well as perceived stress and disease flares. We hereby identified a relevant difference between the presence of perceived stress in general, irrespective of changes over time, and novel perceived stress. Only the latter was prospectively associated with occurrence of disease flares in the next three months. Anxiety, depression and fatigue were not associated with disease flares.

The observed association between disease activity and perceived stress has previously been described. However, the power of many studies was limited due to methodological flaws such as cross sectional analyses, small sample size, and the lack of 
objective measurements of disease activity.(25) Since IBD patients often experience IBS-like complaints, the sole use of clinical disease activity indices to define flares may give an overestimation of relapses and therefore additional markers of inflammation are needed. So far, only a limited number of longitudinal studies have used a combination of symptoms and additional measurements (e.g. calprotectin or endoscopy) to define flares. ${ }^{11,13,14,26}$ In a longitudinal study using combined a clinical disease activity index and fecal calprotectin concentration, short-term perceived stress was positively associated with subsequent IBD symptoms, but not with 'objectively' assessed inflammation by fecal calprotectin measurement.(13) These findings may explain some contradictory results from earlier studies and support our findings concerning the absence of an association between the presence of perceived stress in general and flares. Nonetheless, a difference between the presence of perceived stress in general and novel perceived stress was currently observed. In many studies, 'short-term' perceived stress has been analysed by using a questionnaire comprising the past month (e.g. Cohen Perceived Stress Scale ${ }^{24}$ or Perceived Stress Questionnaire ${ }^{27}$ ). Unfortunately, these questionnaires are insensitive for perceived stress in the period prior to this month. Therefore, exposure time to perceived stress is unknown and both 'novel' and 'longer lasting' stress are measured. To analyse the effect of intra-individual changes of perceived stress over time, longitudinal follow-up of both the outcome variable (i.e. disease flares) and perceived stress is necessary. To our knowledge, in only a few studies, both variables were repeatedly measured during follow-up. ${ }^{9-13,26}$ Of these, none used the repetitive assessments to differentiate novel perceived stress from chronic or pre-existing perceived stress.

In the present study, we observed a clear difference between the effect of perceived stress in general and the effect of novel perceived stress. In healthy individuals, both internal and well as external stressors are in balance with behavioral and physiologic adaptive responses. Perceived stress may become detrimental when this balance is disturbed (e.g. via acute stressors).(28) It is hypothesised that perceived stress may affect the brain-gut axis through (I) activation of the hypothalamic-pituitary-adrenal axis and subsequent release of corticotropin releasing factor and cortisol, which have direct and indirect gastrointestinal immunostimulatory effects, (II) decreased activity of the vagal nerve and thereby a decreased anti-inflammatory effect, (III) increased activation of the sympathetic nervous system and subsequent increase of inflammatory cytokines, activation of the NF-kB pathway, and activation of mast cells, and (IV) peripheral release of substance $P$ by the enteric nervous system, acting as an inflammatory cytokine and stimulator of mast cells. ${ }^{6,16}$ It is hypothesised that after such disturbance, homeostasis usually returns in most individuals. ${ }^{28}$ Therefore it may be put forward that during prolonged stress, individuals can adapt to this new situation. This might explain why, in our study, only novel perceived stress was associated with flares. Though, another longitudinal study observed long-term perceived stress (i.e. covering two years prior to 
measurement) to be associated with flares in the following 8 months, while short-term perceived stress (i.e. covering the month prior to measurement) was not. ${ }^{26}$ However, their explanation of a proposed lengthy time scale for the evolution of effects of stress on the intestines was primarily based on animal studies. Coping strategies and consequent adaptation to chronic stress may be different in humans. It is hypothesised that chronic stress enhances the effects of acute stress through greater and more prolonged increases in sympathetic activation following a stressor although supporting evidence is scarce. ${ }^{16}$ Future studies regarding perceived stress and disease flares, using the same methodology as the present study, should be performed to validate our findings.

The occurrence of life events was also associated with the development of a flare in the next three months. The most frequently answered type of life events were work-related (19.4\%; e.g. dismissal or reorganisation), personal health issues (10.9\%), to move house or renovate a house $(10.9 \%)$, or the death of relatives or good friends $(9.1 \%)$. The effect of life events on future disease activity is smaller when compared to perceived stress. Although life events by definition are correlated with perceived stress, the way of coping will determine whether the life event as a stressor leads to more perceived stress or not. We speculate that only patients with insufficient coping strategies will experience an increase in perceived stress. Unfortunately, our study is not designed to analyse these effects. Though, this hypothesis is supported by findings of another prospective study in which a combination of low stress and a good coping strategy was associated with the lowest risk of a disease flares. ${ }^{12}$ Debate remains as contradictory results on the influence of life events have been reported by others, possibly due to differences in study design and methodology., 29

In this study, no association was found between anxiety, depression or fatigue and subsequent disease flares. Anxiety and depression as comorbidities have extensively been studied in IBD patients and in a recent systematic review it has been shown that the prevalence rate of anxiety (20\%) and depression (15\%) is high in IBD compared to prevalence rates in the general population ( $7.3 \%$ and $3.2 \%$, respectively). ${ }^{5,30,31}$ Though, a meta-analysis of prospective studies on the impact of a depressive state on disease activity showed no statistically significant association, which is in line with our study. ${ }^{32}$ The association between both anxiety and disease flares as well as fatigue and disease flares has not very frequently been studied. Anxiety seemed not to be associated, as in our study, with disease flares. ${ }^{11,12,33}$ Although longitudinal evidence for an association between fatigue and flares is lacking, a high prevalence of fatigue in active IBD has been observed. ${ }^{34}$ In our study, this association could not be confirmed.

The strength of this study is the systematic and continuous monitoring of both disease activity and psychosocial wellbeing over a 12-month period in a large study population. Additionally, we were able to analyse within-subject changes of psychosocial wellbeing. Also, we defined disease flares using a combination of clinical disease activity (i.e. MIAH- 
questionnaire) and additional parameters (i.e. fecal calprotectin, imaging or outpatient clinic visit with treatment adjustment). Some limitations also need to be addressed. First and most importantly, we did not use validated questionnaires for psychosocial wellbeing in the telemedicine tool. The questionnaires in MylBDcoach were designed to screen for several relevant aspects potentially associated with patients' wellbeing and these questionnaires had to be concise for repeated use in a daily clinical practice setting. We therefore chose to apply only one 'screening' question per domain to limit loss of adherence. Though, previous studies have shown that single-question questionnaires can correlate well with comprehensive questionnaires (e.g. for perceived stress ${ }^{35}$ ). Second, we were not able to obtain reliable data on the use of NSAIDs, the use of antibiotics or incident infections from the mylBDcoach tool, while several studies suggest that these variables are associated with disease flares. ${ }^{29}$ On the other hand, a large longitudinal population-based study showed no effect of either of these variables and therefore we believe that the potential confounding effect, if present, is only minimal. ${ }^{9}$

Currently, we believe that the merit of psychosocial wellbeing in IBD patients is underestimated and hardly routinely assessed in daily practice. In this study, we addressed that special attention should be paid to novel perceived stress and life events and our data underline a possible need for tight psychosocial monitoring of IBD patients. Our findings concerning the association between novel perceived stress and disease flares need confirmation by future studies and such studies should take coping strategies into account. Eventually, personalised interventions in those who are at risk to develop flares is worth looking further into.

In conclusion, occurrence of recent life events and novel perceived stress were prospectively associated with the incidence of IBD disease flares in the next three months, while the presence of perceived stress in general is not. Also, no association was found between disease flares and anxiety, depression, or fatigue. This study underlines the importance of continuous personalised monitoring of IBD patients and may contribute to the prevention of disease flares. 


\section{REFERENCES}

1. Torres J, Mehandru S, Colombel JF, Peyrin-Biroulet L. Crohn's disease. Lancet. 2017;389(10080):1741-55.

2. Ungaro R, Mehandru S, Allen PB, PeyrinBiroulet L, Colombel JF. Ulcerative colitis. Lancet. 2017;389(10080):1756-70.

3. Yarur AJ, Strobel SG, Deshpande AR, Abreu MT. Predictors of aggressive inflammatory bowel disease. Gastroenterol Hepatol (N Y). 2011;7(10):652-9.

4. Walker JR, Ediger JP, Graff LA, Greenfeld JM, Clara I, Lix L, et al. The Manitoba IBD cohort study: a population-based study of the prevalence of lifetime and 12-month anxiety and mood disorders. Am J Gastroenterol. 2008;103(8):1989-97.

5. Neuendorf R, Harding A, Stello N, Hanes $D$, Wahbeh H. Depression and anxiety in patients with Inflammatory Bowel Disease: A systematic review. J Psychosom Res. 2016;87:70-80.

6. Bonaz BL, Bernstein CN. Brain-gut interactions in inflammatory bowel disease. Gastroenterology. 2013;144(1):36-49.

7. Martin-Subero M, Anderson G, Kanchanatawan B, Berk M, Maes M. Comorbidity between depression and inflammatory bowel disease explained by immune-inflammatory, oxidative, and nitrosative stress; tryptophan catabolite; and gut-brain pathways. CNS Spectr. 2016;21(2):184-98.

8. Triantafillidis JK, Merikas E, Gikas A. Psychological factors and stress in inflammatory bowel disease. Expert Rev Gastroenterol Hepatol. 2013;7(3):225-38.

9. Bernstein CN, Singh S, Graff LA, Walker JR, Miller N, Cheang M. A prospective populationbased study of triggers of symptomatic flares in IBD. Am J Gastroenterol. 2010;105(9):1994-2002.

10. Langhorst J, Hofstetter A, Wolfe F, Hauser W. Short-term stress, but not mucosal healing nor depression was predictive for the risk of relapse in patients with ulcerative colitis: a prospective 12- month follow-up study. Inflamm Bowel Dis. 2013;19(11):2380-6.

11. Bitton, A. Psychosocial determinants of relapse in ulcerative colitis: a longitudinal study. The American Journal of Gastroenterology. 2003;98(10):2203-8.

12. Bitton A, Dobkin PL, Edwardes MD, Sewitch MJ, Meddings JB, Rawal S, et al. Predicting relapse in Crohn's disease: a biopsychosocial model. Gut. 2008;57(10):1386-92.

13. Sexton KA, Walker JR, Graff LA, Bernstein MT, Beatie B, Miller N, et al. Evidence of Bidirectional Associations Between Perceived Stress and Symptom Activity: A Prospective Longitudinal Investigation in Inflammatory Bowel Disease. Inflamm Bowel Dis. 2017;23(3):473-83.

14. Camara RJ, Schoepfer AM, Pittet V, Begre $\mathrm{S}$, von Kanel R, Swiss Inflammatory Bowel Disease Cohort Study G. Mood and nonmood components of perceived stress and exacerbation of Crohn's disease. Inflamm Bowel Dis. 2011;17(11):2358-65.

15. Gracie DJ, Williams CJ, Sood R, Mumtaz S, Bholah MH, Hamlin PJ, et al. Poor Correlation Between Clinical Disease Activity and Mucosal Inflammation, and the Role of Psychological Comorbidity, in Inflammatory Bowel Disease. Am J Gastroenterol. 2016;111(4):541-51.

16. Mawdsley JE, Rampton DS. Psychological stress in IBD: new insights into pathogenic and therapeutic implications. Gut. 2005;54(10):1481-91.

17. Agostini A, Ballotta D, Righi S, Moretti M, Bertani A, Scarcelli A, et al. Stress and brain functional changes in patients with Crohn's disease: A functional magnetic resonance imaging study. Neurogastroenterol Motil. 2017.

18. Trindade IA, Ferreira C, Moura-Ramos M, Pinto-Gouveia J. An 18-month study of the 
effects of IBD symptomatology and emotion regulation on depressed mood. Int J Colorectal Dis. 2017;32(5):651-60.

19. de Jong $M J$, van der Meulen-de Jong $A E$, Romberg-Camps MJ, Becx MC, Maljaars $J P$, Cilissen $M$, et al. Telemedicine for management of inflammatory bowel disease (mylBDcoach): a pragmatic, multicentre, randomised controlled trial. Lancet. 2017.

20. de Jong $M$, van der Meulen-de Jong $A$, Romberg-Camps M, Degens J, Becx M, Markus T, et al. Development and Feasibility Study of a Telemedicine Tool for All Patients with IBD: MyIBDcoach. Inflamm Bowel Dis. 2017;23(4):485-93.

21. de Jong $M$, Van den Heuvel T, RombergCamps M, Winkens B, Markus T, Masclee A, et al. Development of a patient reported disease activity score to screen for mucosal inflammation in inflammatory bowel disease. Journal of Crohn's and Colitis. 2015.

22. Zigmond AS, Snaith RP. The hospital anxiety and depression scale. Acta Psychiatr Scand. 1983;67(6):361-70.

23. Bleijenberg G KH, Gielissen M. De Verkorte VermoeidheidsVragenlijst voor het vaststellen van de ernst van chronische vermoeidheid. Bijblijven. 2009;25(1):1921.

24. Cohen S, Kamarck T, Mermelstein R. A global measure of perceived stress. J Health Soc Behav. 1983;24(4):385-96.

25. Keefer L, Keshavarzian A, Mutlu E. Reconsidering the methodology of "stress" research in inflammatory bowel disease. J Crohns Colitis. 2008;2(3):193-201.

26. Levenstein S, Prantera C, Varvo V, Scribano ML, Andreoli A, Luzi C, et al. Stress and exacerbation in ulcerative colitis: a prospective study of patients enrolled in remission. Am J Gastroenterol. 2000;95(5):1213-20.

27. Levenstein S, Prantera C, Varvo V, Scribano $M L$, Berto E, Luzi C, et al. Development of the Perceived Stress Questionnaire: a new tool for psychosomatic research. J Psychosom Res. 1993;37(1):19-32.

28. Chrousos GP. Stress and disorders of the stress system. Nat Rev Endocrinol. 2009;5(7):374- 81.

29. Singh S, Graff LA, Bernstein CN. Do NSAIDs, antibiotics, infections, or stress trigger flares in IBD? Am J Gastroenterol. 2009;104(5):1298-313; quiz 314.

30. Baxter AJ, Scott KM, Vos T, Whiteford HA. Global prevalence of anxiety disorders: a systematic review and meta-regression. Psychol Med. 2013;43(5):897-910.

31. Moussavi S, Chatterji S, Verdes E, Tandon A, Patel V, Ustun B. Depression, chronic diseases, and decrements in health: results from the World Health Surveys. Lancet. 2007;370(9590):851-8.

32. Alexakis C, Kumar S, Saxena S, Pollok R. Systematic review and meta-analysis: the impact of a depressive state on disease course in adult inflammatory bowel disease. Aliment Pharmacol Ther. 2017.

33. Dhingra R, Kedia S, Venigalla PM, Kumar $S$, Singh N, Bopanna S, et al. Evaluating clinical, dietary and psychological risk factors for relapse of ulcerative colitis in clinical, endoscopic and histological remission. J Gastroenterol Hepatol. 2017.

34. Huppertz-Hauss G, Hoivik ML, JelsnessJorgensen LP, Opheim R, Henriksen M, Hoie $\mathrm{O}$, et al. Fatigue in a population-based cohort of patients with inflammatory bowel disease 20 years after diagnosis: The IBSEN study. Scand J Gastroenterol. 2017;52(3):351-8.

35. Littman AJ, White E, Satia JA, Bowen DJ, Kristal AR. Reliability and validity of 2 single-item measures of psychosocial stress. Epidemiology. 2006;17(4):398-403. 36. Satsangi J, Silverberg MS, Vermeire S, Colombel JF. The Montreal classification of inflammatory bowel disease: controversies, consensus, and implications. Gut. 2006;55(6):749-53. 




\section{Chapter 8}

\section{Risk of impaired nutritional status and flare occurrence in IBD outpatients.}

Corinne Spooren, Dion Wintjens, Marin de Jong,

Andrea van der Meulen-de Jong, Mariëlle Romberg-Camps,

Marco Becx, Jeroen Maljaars, Ad van Bodegraven, Nofel Mahmmod,

Tineke Markus, Wim Hameeteman, Ad Masclee, Bjorn Winkens,

Daisy Jonkers, Marieke Pierik 


\section{ABSTRACT}

Background: Inflammatory bowel disease (IBD) patients are at risk of an impaired nutritional status. The impact thereof on the IBD relapse risk is clinically relevant, though sparsely investigated. Our aim was to explore the association between the risk of an impaired nutritional status and the occurrence of disease flares in IBD outpatients participating in a longitudinal telemedicine study.

Methods: IBD outpatients were recruited from the myIBDcoach study cohort, with one year clinical follow-up. Through mylBDcoach, a telemedicine tool, patients reported every 1-3 months on disease activity and risk of impaired nutritional status (i.e. Short Nutritional Assessment Questionnaire $>1$ and/or BMI $<18.5 \mathrm{~kg} / \mathrm{m}^{2}$ ). Data were analysed by generalised estimating equation modelling.

Results: In total, 417 patients were included. During follow-up, 49 patients (11.8\%) flared after initial clinical remission and 53 patients (12.7\%) showed an increased risk of an impaired nutritional status. The risk of an impaired nutritional status was associated with flare occurrence (OR 2.61 (95\% Cl 1.02-6.69)).

Conclusions: The risk of an impaired nutritional status was associated with subsequent flares in IBD outpatients. This emphasises the importance of monitoring disease activity in IBD patients at risk of an impaired nutritional status. 


\section{INTRODUCTION}

Inflammatory bowel disease (IBD) is a chronic inflammatory disease of the gastrointestinal tract with Crohn's disease (CD) and ulcerative colitis (UC) as main subtypes. The disease course is characterised by a wide variation between patients in duration and frequency of relapsing and quiescent periods. Several factors have been associated with relapse risk, such as a high frequency of flares within the first year of diagnosis ${ }^{1,2}$, poor medication adherence ${ }^{3}$, and active smoking in CD patients. ${ }^{4}$ However, these do not sufficiently predict the disease course. Identification of further factors contributing to the development of relapses is therefore warranted.

IBD patients are at risk of an impaired nutritional status due to disease-related changes in absorption and/or requirements, often in combination with an unbalanced dietary intake. ${ }^{5}$ Reported prevalences range from $16-75 \%$ in IBD patients. ${ }^{6-8}$ The variation may be due to heterogeneity in study methods and definitions used for defining an impaired nutritional status, in many publications often referred to as malnutrition. Defining malnutrition remains challenging. Therefore, the American Society of Parenteral and Enteral Nutrition (ASPEN) https://www.nutritioncare.org/ recommends diagnostic characteristics to identify malnutrition in adults, by which two of the following six criteria need to be fulfilled: i.e. low energy intake, weight loss, loss of muscle mass, loss of subcutaneous fat, fluid accumulation, and handgrip strength. ${ }^{9}$ However, validated screening tools to identify patients at risk of malnutrition, such as the Short Nutritional Assessment Questionnaire (SNAQ) and the Malnutrition Universal Screening Tool (MUST) are more often used, since these are less time consuming. ${ }^{10}$

An impaired nutritional status may impact disease course. Malnutrition, defined by the Subjective Global Assessment which is a nutritional assessment instrument, has been found to be related to a diminished quality of life in hospitalised patients with IBD ${ }^{11}$, and radiological assessed loss of muscle mass was associated with an increased risk of intestinal resection and postoperative complications in IBD patients. ${ }^{12-15}$ Furthermore, higher disease activity was associated with a lower skeletal muscle index among UC patients. ${ }^{13}$ In previous cross-sectional and longitudinal studies active disease was reported to affect body composition in both CD and UC patients. ${ }^{16,17}$ However, both CD and UC patients with quiescent disease can also suffer from an altered body composition (i.e. fat mass and fat free mass) ${ }^{18,19}$ and in a previous study the nutritional status of recently diagnosed IBD patients was already affected negatively. ${ }^{20}$ So it can be hypothesised that the development of an impaired nutritional status could be a risk factor for the development of disease activity. Therefore, as an explorative study, we aimed to analyse whether the risk of an impaired nutritional status was associated with flare occurrence in quiescent IBD outpatients in a longitudinal, observational study. 


\section{MATERIALS AND METHODS}

\section{Study Design}

For the present longitudinal study, available data from the mylBDcoach study were used in an explorative analysis. MylBDcoach is a telemedicine tool, accessible on a secured webpage through computer, tablet or smartphone, for monitoring of IBD patients at home. ${ }^{21}$ In the mylBDcoach trial, the effect of disease monitoring with mylBDcoach on healthcare utilisation and quality of care was investigated. All consecutive IBD patients between 18-75 years, with sufficient knowledge of the Dutch language and internet access, from two tertiary referral centres and two non-academic hospitals in the $\mathrm{Ne}$ therlands were eligible for inclusion for this trial and randomised in the mylBDcoach or standard care group. All patients had an established diagnosis of CD or UC, fulfilling the international diagnostic criteria. ${ }^{22}$

Every single month patients in the telemedicine arm completed monitoring modules, including questions on e.g. disease activity, use of medication, smoking status, weight, and malnutrition risk based on the SNAQ. When a patient achieved remission (i.e. low clinical activity for three consecutive months) patients were allowed to complete the monitoring module once every three months. The study design is described in detail elsewhere. $^{23}$

The myIBDcoach study was approved by the Medical Research Ethics Committee of the Maastricht University Medical Centre+ (NL47697.068.14) and registered at ClinicalTrials. gov (NCT02173002) and the study protocol conformed to the provisions of the declaration of Helsinki. All patients gave written informed consent prior to participation. ${ }^{21,23}$

Patients who were randomised to the mylBDcoach intervention group were included in the present study. Baseline characteristics (e.g. height, disease phenotype, duration, and medication use) were extracted from patient files using standardised registration forms. During the 12 months of follow-up, every 1-3 months information on weight (to determine $\mathrm{BMI}$ ), disease activity by a symptom-based patient-reported outcome measure (the Monitor IBD At Home (MIAH) questionnaire ${ }^{24}$ ), and risk for malnutrition (by the SNAQ) was obtained.

In line with the myIBDcoach trial, flares were defined as clinical symptoms indicative of disease activity (MIAH) in combination with either a fecal calprotectin $>250 \mu \mathrm{g} / \mathrm{g}$, disease activity on endoscopy, magnetic resonance imaging or computed tomography, or dose escalation or initiation of a new drug to induce remission. ${ }^{21}$

The SNAQ is developed as a non-invasive screening tool to assess malnutrition in both in- and outpatient setting ${ }^{25} 26$ and compromises 3 questions, i.e. unintentional weight loss over a predefined time period (depending on weight loss 2 or 3 points), experience of decreased appetite during the last month (1 point), and/or use of supplemental drinks or tube feeding during the last month (1 point). For the present study, the risk of 
an impaired nutritional status was defined as a SNAQ $\geq 2$ points and/or $B M l<18.5 \mathrm{~kg} / \mathrm{m}^{2}$. Both parameters were determined every 1-3 months.

\section{Statistical Analysis}

Numerical variables were presented as means with corresponding standard deviation (SD) and categorical variables as numbers with percentages. Baseline characteristics were compared between groups (patients who relapse versus who do not relapse) by the independent-samples t-test for numerical variables, and Chi-square test or Fisher's exact test when appropriate, for categorical variables. Generalised estimating equations model was used to identify an association between the risk of an impaired nutritional status and the development of flares in the following three months. This method accounts for repeated measures within the same patient, with an unstructured covariance pattern.

At each time-point of measurement, the flare status (yes/no) as well as the risk of an impaired nutritional status (yes/no) was recorded. In patients with quiescent disease, the first three months were excluded from the analyses to prevent potential carry-over effects of histological inflammation in clinical inactive patients at time of inclusion. When active disease was present at inclusion or during follow up, the following six months were excluded from the analyses as a wash-out period and to start the follow-up from a remissive state onwards.

For the generalised estimating equations model, all positive values on the risk of an impaired nutritional status in the three months preceding a flare were regarded as possible predictors.

Since we aimed to assess the prospective association, the risk of an impaired nutritional status measured at the same measurement moment as a flare was not considered as a predictor. Since patients were able to complete the questionnaires either every one or three months, the flare status was determined for the subsequent three months after the risk of an impaired nutritional status was assessed. The generalised estimating equations model was adjusted for potential confounding effects of sex, disease phenotype, disease duration at inclusion, and smoking status at inclusion. Two-sided P-values $\leq 0.05$ were considered statistically significant. Statistical analysis was performed using IBM SPSS statistics for Windows, Version 22 (IBM, Armonk, NY).

\section{RESULTS}

In total, 465 IBD patients were allocated to the intervention group in the mylBDcoach trial. ${ }^{21}$ Patients who were not eligible, i.e. never started using the application, never 
achieved a period of remission or were lost to follow-up for other reasons were excluded from further analyses. Finally, 417 patients were included in the present study.

Baseline characteristics at inclusion, stratified by flare status during follow up, are presented in table 1. During follow-up, $49(11.8 \%)$ individual patients $(C D=26, U C=23)$ experienced a flare after initial remission. There were fewer active smokers at inclusion among those that relapsed during follow-up compared to the 'non-relapsers' $(p=0.005)$. There were no other differences in baseline characteristics between these groups.

Table 1. Patient characteristics, stratified by occurrence of disease flares.

\begin{tabular}{|c|c|c|c|}
\hline & $\begin{array}{c}\text { Relapsers } \\
(n=49)\end{array}$ & $\begin{array}{c}\text { Non-relapsers } \\
(\mathrm{n}=\mathbf{3 6 8})\end{array}$ & p-value \\
\hline Crohn's disease n (\%) & $26(53.1)$ & $222(60.3)$ & 0.331 \\
\hline Male, n (\%) & $15(30.6)$ & $158(42.9)$ & 0.100 \\
\hline BMI $\left(\mathrm{kg} / \mathrm{m}^{2}\right)$, mean $(\mathrm{SD})$ & $25.37(4.3)$ & $25.14(4.0)$ & 0.705 \\
\hline \multicolumn{4}{|l|}{ Montreal at diagnosis* } \\
\hline Age (CD \& UC) & & & 0.600 \\
\hline $\mathrm{A} 1,<17$ years, $\mathrm{n}(\%)$ & $8(16.3)$ & $60(16.3)$ & \\
\hline$A 2,17-40$ years, $n(\%)$ & $26(53.1)$ & $219(59.5)$ & \\
\hline$A 3,>40$ years, $n(\%)$ & $15(30.6)$ & $89(24.2)$ & \\
\hline Disease location (CD) & & & 0.741 \\
\hline L1, ileal, n (\%) & $7(26.9)$ & $73(32.9)$ & \\
\hline L2, colonic, n (\%) & $6(23.1)$ & $55(24.8)$ & \\
\hline L3, ileocolonic, n (\%) & $13(50.0)$ & $94(42.3)$ & \\
\hline Disease behaviour (CD) & & & 0.958 \\
\hline B1, non-stricturing non-penetrating, $\mathrm{n}(\%)$ & $16(61.5)$ & $134(60.6)$ & \\
\hline B2, stricturing, $\mathrm{n}(\%)$ & $7(26.9)$ & $57(25.8)$ & \\
\hline B3, penetrating, n (\%) & $3(11.5)$ & $30(13.6)$ & \\
\hline Disease extent (UC) & & & 0.768 \\
\hline E1, proctitis, n (\%) & $2(8.7)$ & $19(12.8)$ & \\
\hline E2, left-sided, n (\%) & $10(43.5)$ & $69(46.3)$ & \\
\hline E3, pancolitis, n (\%) & $11(47.8)$ & $61(40.9)$ & \\
\hline Age at inclusion (years), mean (SD) & $46.08(15.2)$ & $43.95(13.7)$ & 0.313 \\
\hline Disease duration at inclusion (years), mean (SD) & $13.45(10.9)$ & $13.39(10.4)$ & 0.971 \\
\hline Active disease at inclusion, $\mathrm{n}(\%)$ & $4(7.7)$ & $28(8.2)$ & 0.908 \\
\hline Medication use at inclusion & & & 0.434 \\
\hline No medication/5-ASA, n (\%) & $15(30.6)$ & $142(39.3)$ & \\
\hline Immunomodulators, n (\%) & $16(32.7)$ & $93(25.8)$ & \\
\hline Biologics, n (\%) & $18(36.7)$ & $126(34.9)$ & \\
\hline Current smoking at inclusion, $\mathrm{n}(\%)$ & $1(2.0)$ & $65(17.7)$ & $0.005^{\wedge}$ \\
\hline
\end{tabular}

n, number of patients; SD, standard deviation; BMI, body mass index; 5-ASA, 5-aminosalicylic acid; SNAQ, Short Nutritional Assessment Questionnaire; $\wedge$, p-value below 0.05; *, classification according to Montreal Classification. ${ }^{44}$; ${ }^{\text {, different patients }}$ 
At inclusion, six (1.4\%) patients had a BMI $<18.5 \mathrm{~kg} / \mathrm{m}^{2}, 216(51.8 \%)$ patients had a BMI of $18.5-25 \mathrm{~kg} / \mathrm{m}^{2}, 147$ (35.3\%) patients had a BMI of $25-30 \mathrm{~kg} / \mathrm{m}^{2}$, and $48(11.5 \%)$ patients had a BMI $>30 \mathrm{~kg} / \mathrm{m}^{2}$. In total, $53(12.7 \%)$ individual IBD patients were at risk of an impaired nutritional status based on a positive SNAQ score $(\mathrm{n}=45), \mathrm{BMI}<18.5 \mathrm{~kg} / \mathrm{m}^{2}$ $(n=5)$, or both $(n=3)$ during follow-up.

In the generalised estimating equations analyses, the risk of an impaired nutritional status was found to be associated with the occurrence of a flare in the following three months (OR 2.61 (95\% Cl 1.02-6.69, p=0.046)). Furthermore, in this model also female sex (OR $2.12(95 \% \mathrm{Cl}$ 1.08-4.15, p=0.029)) was identified as a risk factor for the development of a flare, while active smoking showed a negative association (OR 0.14 (95\% Cl 0.020.97, $\mathrm{p}=0.047$ )) (table 2). In the generalised estimating equations model, medication use at time of inclusion was not incorporated as confounder due to the small number of relapsing patients during follow up. When medication use at time of inclusion was added to the model for IBD patients, a comparable increased risk was found (OR 2.48 (95\% Cl 0.96-6.41, $\mathrm{p}=0.061)$ ), though not significant.

Table 2. Multivariable generalised estimating equations model: association between impaired nutritional status risk in IBD and disease flares.

\begin{tabular}{lccc}
\hline & OR & $\mathbf{9 5 \% C l}$ & p-value \\
\hline Impaired nutritional status & 2.61 & $1.02-6.69$ & $0.046^{\mathrm{b}}$ \\
UC phenotype & 1.43 & $0.78-2.65$ & 0.251 \\
Sex, female & 2.12 & $1.08-4.148$ & $0.029^{\mathrm{b}}$ \\
Active smoker $^{\mathrm{a}}$ & 0.14 & $0.02-0.97$ & $0.047^{\mathrm{b}} \wedge$ \\
Disease duration $^{\mathrm{a}}$ & 1.01 & $0.98-1.04$ & 0.642 \\
\hline
\end{tabular}

OR, Odds ratio; $95 \% \mathrm{Cl}, 95 \%$ Confidence Interval; ${ }^{a}$, at inclusion; ${ }^{\mathrm{b}}, \mathrm{p}$-value below 0.05 .

\section{DISCUSSION}

In this longitudinal study in daily practice, the risk of an impaired nutritional status, defined by a positive SNAQ or BMI $<18.5 \mathrm{~kg} / \mathrm{m}^{2}$, was found to be associated with the occurrence of a flare.

Previous studies reported that a decreased skeletal muscle index increases the risk of an intestinal resection in hospitalised CD with an exacerbation ${ }^{12}$, increases the need for colectomy in UC patients ${ }^{13}$, predicts the need for rescue therapy in acute severe UC patients ${ }^{27}$, is associated with postoperative complications in IBD patients ${ }^{14,15}$, and is associated with anti-TNF treatment failure in IBD patients. ${ }^{28}$ Furthermore, active disease affects body composition in both CD and UC patients, as found in previous crosssectional as well as longitudinal studies. ${ }^{16,17}$ However, to our knowledge, the current study is the first specifically analysing the association of impaired nutritional status risk 
on flare occurrence. An impaired nutritional status may contribute to the development of a flare by malnutrition-induced changes in the immune system, by the altered cytokines (interleukin- 6 and tumour necrosis factor- $\alpha$ ), hormones (leptin), and/or increased intestinal permeability. ${ }^{29-32} \mathrm{~A}$ mice study on the effects of fasting showed that changes in immune response occur rather early after inducing nutritional deficiency. ${ }^{30}$

In the present study, the SNAQ in combination with BMI was used as screening method for risk of an impaired nutritional status, since the SNAQ alone may lead to underreporting in an outpatient setting. ${ }^{33}$ The SNAQ and MUST both contain questions on unintentional weight loss and food intake. In contrast to the SNAQ, a low BMI (18.5-20 or $<18.5$ $\mathrm{kg} / \mathrm{m}^{2}$ ) is taken into account in the MUST questionnaire. The MUST may however lead to overreporting of patients at risk in the outpatient setting. ${ }^{33}$ Therefore, in line with one of the diagnostic criteria for malnutrition by the European Society for Clinical Nutrition and Metabolism (ESPEN) ${ }^{10}$, only a BMI $<18.5 \mathrm{~kg} / \mathrm{m}^{2}$ was added to the SNAQ to capture all patients at risk for an impaired nutritional status in the current study. Fifty-three patients were at risk of an impaired nutritional status during follow up, of which the majority of the patients $(\mathrm{n}=45)$ had a positive SNAQ and BMI $>18.5 \mathrm{~kg} / \mathrm{m}^{2}$, five patients had a BMI $<18.5 \mathrm{~kg} / \mathrm{m}^{2}$ and negative SNAQ, and three patients had both a positive SNAQ score and $\mathrm{BMI}<18.5 \mathrm{~kg} / \mathrm{m}^{2}$.

The overall distribution of our patients over the different weight categories (according to the World Health Organization definitions) ${ }^{34}$ were comparable with percentages of overweight and obesity in a representative healthy population in South Limburg, a province in the Netherlands. ${ }^{35}$ The majority of the IBD patients in the present study had a normal BMI (51.8\%) and a significant proportion was overweight (35.3\%) or obese (11.5\%). Due to an unfavourable fat-muscle ratio, which is not necessarily reflected by $\mathrm{BMI}$, it cannot be excluded that patients with a BMI $18.5-25 \mathrm{~kg} / \mathrm{m}^{2}$ do not have a decreased muscle mass and are thereby being at risk of an impaired nutritional status.

A commonly used model for analysing the body composition is the two-compartment model in which body weight is subdivided in fat mass and fat free mass. Skeletal muscle mass represents a large proportion of the fat free mass. Prior studies reported that changes in fat free mass, are not always captured by malnutrition screening questionnaires in IBD patients. ${ }^{19,} 36$ This underlines the necessity in future studies to combine a malnutrition screening questionnaire with a simple, non-invasive body composition analysis, and also, to incorporate changes in fat free mass for timely identification of patients at risk. A technique which can be considered is the handgrip strength, as parameter of muscle strength. ${ }^{37}$

In the present study, flare development was also found to be positively associated with female sex, and negatively with smoking status at inclusion. In CD for example, smoking is found to increase the risk of a flare, whereas in UC smoking cessation is. ${ }^{38}$ Our finding may be affected by analysis of the total IBD population. Separate analyses 
for CD and UC were not performed due to the limited sample size, but should be taken into account in future studies.

A major strength of the present study is the longitudinal design of the study in a relatively large, unselected outpatient study population. The study population was found to be representative for the general IBD population in the South Limburg area. ${ }^{21,39}$ Furthermore, by the use of telemedicine, disease activity, and malnutrition screening risk were measured repeatedly and standardised. Though, some limitations of this study should be addressed. For the present explorative study, available data from the mylBDcoach study were used. Therefore, no sample size calculation has been performed and we were not able to correct for all potential confounders for flare development, such as prior surgery, time since last flare, and prior smoking status. The present study shows a significant association between impaired nutritional status risk and flare occurrences in the entire IBD cohort. Separate analyses for CD and UC were not performed due to small numbers of patients. However, these analyses are of interest since factors influencing flare occurrence may differ between these phenotypes, and should be included in future studies. Furthermore, ongoing histological inflammation at inclusion and during follow up cannot be completely excluded since disease activity was monitored by clinical parameters. However, to prevent carry-over effects of histological inflammation, the first three months from patients with quiescent disease were excluded from the analyses. Finally, it should be taken into account that flares can be affected by enteral nutrition, particularly in $\mathrm{CD} .{ }^{40}$ However, in the present study, use of enteral nutrition was limited and was not found to impact our findings (data not shown).

The aim of the present explorative study was to investigate an association between the risk of an impaired nutritional status and flare occurrence. In clinical practice, it has already been shown that early treatment of malnourished inpatients for any disease or operation, based on screening, leads to a shorter length of hospital stay and is costeffective. ${ }^{41}$ Since this is the first longitudinal study analysing the association of impaired nutritional status risk on flare occurrences, our results should be confirmed in other cohorts. Larger longitudinal studies on the impact of an impaired nutritional status risk, incorporating body composition analysis and muscle strength, and taking confounders and separate analysis for CD and UC into account, are of special interest to confirm the actual effect on disease activity. Additionally, studies on timely dietary and/or physiotherapy interventions, aiming to improve nutritional status and treatment outcome are warranted.

In conclusion, in the present longitudinal observational study, we found an association between the presence of the risk of an impaired nutritional status and IBD flare occurrence. This emphasises the importance of monitoring disease activity in IBD patients at risk of an impaired nutritional status. 


\section{REFERENCES}

1. Munkholm P, Langholz E, Davidsen $M$, et al. Disease activity courses in a regional cohort of Crohn's disease patients. Scand J Gastroenterol. 1995;30:699-706.

2. Hoie O, Wolters F, Riis L, et al. Ulcerative colitis: patient characteristics may predict 10-yr disease recurrence in a Europeanwide population-based cohort. Am J Gastroenterol. 2007;102:1692-701.

3. Feagins LA, Iqbal R, Spechler SJ. Casecontrol study of factors that trigger inflammatory bowel disease flares. World J Gastroenterol. 2014;20:4329-34.

4. Dutta $A K$, Chacko A. Influence of environmental factors on the onset and course of inflammatory bowel disease. World J Gastroenterol. 2016;22:1088-100.

5. Hartman C, Eliakim R, Shamir R. Nutritional status and nutritional therapy in inflammatory bowel diseases. World J Gastroenterol. 2009;15:2570-8.

6. Scaldaferri F, Pizzoferrato M, Lopetuso LR, et al. Nutrition and IBD: Malnutrition and/ or Sarcopenia? A Practical Guide. Gastroenterol Res Pract. 2017;2017:8646495.

7. Casanova MJ, Chaparro M, Molina B, et al. Prevalence of Malnutrition and Nutritional Characteristics of Patients With Inflammatory Bowel Disease. Journal of Crohn's \& colitis. 2017;11:1430-9.

8. Mijac DD, Jankovic GL, Jorga J, et al. Nutritional status in patients with active inflammatory bowel disease: prevalence of malnutrition and methods for routine nutritional assessment. European journal of internal medicine. 2010;21:315-9.

9. White JV, Guenter P, Jensen G, et al. Consensus statement: Academy of Nutrition and Dietetics and American Society for Parenteral and Enteral Nutrition: characteristics recommended for the identification and documentation of adult malnutrition (undernutrition). JPEN J Parenter Enteral Nutr. 2012;36:275-83.
10. Cederholm T, Barazzoni R, Austin P, et al. ESPEN guidelines on definitions and terminology of clinical nutrition. Clin Nutr. 2017;36:49-64.

11. Norman $\mathrm{K}$, Kirchner $\mathrm{H}$, Lochs $\mathrm{H}$, et al. Malnutrition affects quality of life in gastroenterology patients. World J Gastroenterol. 2006;12:3380-5.

12. Bamba S, Sasaki M, Takaoka A, et al. Sarcopenia is a predictive factor for intestinal resection in admitted patients with Crohn's disease. PLoS One. 2017;12:e0180036.

13. Zhang T, Ding C, Xie T, et al. Skeletal muscle depletion correlates with disease activity in ulcerative colitis and is reversed after colectomy. Clin Nutr. 2017;36:1586-92.

14. Pedersen M, Cromwell J, Nau P. Sarcopenia is a Predictor of Surgical Morbidity in Inflammatory Bowel Disease. Inflamm Bowel Dis. 2017;23:1867-72.

15. Zhang T, Cao L, Cao T, et al. Prevalence of Sarcopenia and Its Impact on Postoperative Outcome in Patients With Crohn's Disease Undergoing Bowel Resection. JPEN J Parenter Enteral Nutr. 2017;41:592-600.

16. Rocha R, Santana GO, Almeida N, et al. Analysis of fat and muscle mass in patients with inflammatory bowel disease during remission and active phase. $\mathrm{Br} J$ Nutr. 2009;101:676-9.

17. Benjamin J, Makharia G, Ahuja V, et al. Body composition in Indian patients with Crohn's disease during active and remission phase. Tropical gastroenterology : official journal of the Digestive Diseases Foundation. 2011;32:285-91.

18. Geerling BJ, Badart-Smook A, Stockbrugger RW, et al. Comprehensive nutritional status in patients with long-standing Crohn disease currently in remission. Am J Clin Nutr. 1998;67:919-26.

19. Valentini L, Schaper L, Buning C, et al. Malnutrition and impaired muscle strength in patients with Crohn's disease and 
ulcerative colitis in remission. Nutrition. 2008;24:694-702.

20. Geerling BJ, Badart-Smook A, Stockbrugger RW, et al. Comprehensive nutritional status in recently diagnosed patients with inflammatory bowel disease compared with population controls. European journal of clinical nutrition. 2000;54:514-21.

21. de Jong MJ, van der Meulen-de Jong $A E$, Romberg-Camps MJ, et al. Telemedicine for management of inflammatory bowel disease (mylBDcoach): a pragmatic, multicentre, randomised controlled trial. Lancet. 2017;390:959-68.

22. Lennard-Jones JE. Classification of inflammatory bowel disease. Scandinavian journal of gastroenterology Supplement. 1989;170:2-6; discussion 16-9.

23. de Jong $M$, van der Meulen-de Jong $A$, Romberg-Camps $M$, et al. Development and Feasibility Study of a Telemedicine Tool for All Patients with IBD: MylBDcoach. Inflamm Bowel Dis. 2017;23:485-93.

24. De Jong $M$, Van den Heuvel $T$, RombergCamps M, et al. Development of a patient reported disease activity score to screen for mucosal inflammation in inflammatory bowel disease. Journal of Crohn's and Colitis. 2015;9:S192-3.

25. Kruizenga HM, Seidell JC, de Vet HC, et al. Development and validation of a hospital screening tool for malnutrition: the short nutritional assessment questionnaire (SNAQ). Clin Nutr. 2005;24:75-82.

26. Neelemaat F, Kruizenga HM, de Vet HC, et al. Screening malnutrition in hospital outpatients. Can the SNAQ malnutrition screening tool also be applied to this population? Clin Nutr. 2008;27:439-46.

27. Cushing KC, Kordbacheh $\mathrm{H}$, Gee MS, et al. Sarcopenia is a Novel Predictor of the Need for Rescue Therapy in Hospitalized Ulcerative Colitis Patients. Journal of Crohn's \& colitis. 2018.

28. Holt DQ, Varma P, Strauss BJG, et al. Low muscle mass at initiation of anti-TNF therapy for inflammatory bowel disease is associated with early treatment failure: a retrospective analysis. European journal of clinical nutrition. 2017;71:773-7.

29. Gerriets VA, Danzaki K, Kishton RJ, et al. Leptin directly promotes T-cell glycolytic metabolism to drive effector T-cell differentiation in a mouse model of autoimmunity. Eur J Immunol. 2016;46:1970-83.

30. Saucillo DC, Gerriets VA, Sheng J, et al. Leptin metabolically licenses $T$ cells for activation to link nutrition and immunity. Journal of immunology. 2014;192:136-44.

31. Cohen S, Danzaki K, Maclver NJ. Nutritional effects on T-cell immunometabolism. Eur J Immunol. 2017;47:225-35.

32. van der Hulst RR, von Meyenfeldt MF, van Kreel BK, et al. Gut permeability, intestinal morphology, and nutritional depletion. Nutrition. 1998;14:1-6.

33. Leistra E, Langius JA, Evers AM, et al. Validity of nutritional screening with MUST and SNAQ in hospital outpatients. European journal of clinical nutrition. 2013;67:73842.

34. Physical status: the use and interpretation of anthropometry. Report of a WHO Expert Committee. World Health Organ Tech Rep Ser. 1995;854:1-452.

35. Ministerie van Volksgezondheid Welzijn en Sport. Gezondheidsmonitor Volwassenen en Ouderen. 2018.

36. Csontos AA, Molnar A, Piri Z, et al. Malnutrition risk questionnaire combined with body composition measurement in malnutrition screening in inflammatory bowel disease. Rev Esp Enferm Dig. 2017;109:2632.

37. Lu ZL, Wang TR, Qiao YQ, et al. Handgrip Strength Index Predicts Nutritional Status as a Complement to Body Mass Index in Crohn's Disease. Journal of Crohn's \& colitis. 2016;10:1395-400.

38. Cosnes J. Smoking and Diet: Impact on Disease Course? Digestive diseases. 2016;34:72-7. 
39. van den Heuvel TR, Jonkers DM, Jeuring $\mathrm{SF}$, et al. Cohort Profile: The Inflammatory Bowel Disease South Limburg Cohort (IBDSL). International journal of epidemiology. 2017;46:e7.

40. Levine A, Sigall Boneh R, Wine E. Evolving role of diet in the pathogenesis and treatment of inflammatory bowel diseases. Gut. 2018;67:1726-38.

41. Kruizenga HM, Van Tulder MW, Seidell JC, et al. Effectiveness and cost-effectiveness of early screening and treatment of malnourished patients. Am J Clin Nutr. 2005;82:1082-9.

42. Satsangi J, Silverberg MS, Vermeire $S$, et al. The Montreal classification of inflammatory bowel disease: controversies, consensus, and implications. Gut. 2006;55:749-53. 




\section{Chapter 9}

Exploring conditions for redistribution of anti-TNFs to reduce spillage. A study on the quality of anti-TNF home storage.

Marin de Jong, Marieke Pierik, Andy Peters, Mark Roemers,

Veronique Hilhorst, Astrid van Tubergen 


\section{ABSTRACT}

Background: Biologicals are potent drugs for immune mediated inflammatory diseases (IMIDs). After discontinuation or switch of therapy, many patients have unused biological injectors left. We aimed to evaluate potential redistribution of unused injectors to prevent spillage of these costly drugs by assessing 1) the quality of transport and home storage through the proportion of injectors stored within the recommended temperature range $\left(2^{\circ} \mathrm{C}-8^{\circ} \mathrm{C}\right)$ and 2$)$ acceptance of redistribution by patients.

Methods: All golimumab users, irrespective of the indication, at Maastricht University Medical Centre were eligible for inclusion. Patients received golimumab in a sealed bag containing a validated temperature sensor, measuring temperature every 5 minutes. $\mathrm{Pa}$ tients were asked to store their medication as usual. Deviations from the recommended range were defined as any duration below $0^{\circ} \mathrm{C}$ and $>30$ minutes below $2^{\circ} \mathrm{C}$ or above $8^{\circ} \mathrm{C}$. After 3 months, patients completed a questionnaire on their opinion towards potential redistribution of unused biologicals.

Results: Fifty patients ( $42.0 \%$ male, mean age $53.2 \pm 14.3$ years) received 276 injectors. The mean storage time was $30.9 \pm 33.1$ days. Only $11.6 \%$ of the injectors were stored within the recommended temperature range. In addition, $11.2 \%$ were stored $>30 \mathrm{~min}$ utes below $0^{\circ} \mathrm{C}$ and $33.2 \%$ were stored $>1$ week above $8^{\circ} \mathrm{C}$. Of all patients, $95 \%$ would accept redistributed medication when product quality is ensured.

Conclusion: During transport and home-storage, only one in eight biological injectors was stored within the recommended temperature range. This hinders redistribution of unused injectors, but also raises concern regarding drug effectiveness in IMID-patients. 


\section{INTRODUCTION}

Over the past decades, the main direct healthcare costs in chronic immune-mediated inflammatory diseases (IMIDs) have shifted from outpatient visits, hospitalisation and surgery towards pharmacological treatment with biologicals ${ }^{1-4}$.

Biologicals are complex human proteins that modulate the immune system by interfering with cytokine function, inhibition of T-cell activation, depletion of B-cells or by preventing migration of immune cells. The introduction of these drugs has significantly improved long-term outcome of IMIDs such as rheumatoid arthritis (RA), spondyloarthritis (SpA), inflammatory bowel disease (IBD) and plaque psoriasis.

Approximately 55,000 people in the Netherlands use biologicals for IMIDs, with prices ranging from $€ 538$ to $€ 1159$ per injector ${ }^{5}$, accounting for 623 million Euros per year ${ }^{6}$. Due to expanding indications for biologicals and advocating intensive treatment strategies aimed at complete remission of the disease, in which biologicals are frequently prescribed, further increase of costs is expected.

Strict guidelines exist for the production, storage and transportation of biologicals. According to the summary of product characteristics (SmPC), biologicals should be stored between $2^{\circ} \mathrm{C}$ and $8^{\circ} \mathrm{C}^{7-10}$. Extreme temperature conditions can lead to protein denaturation and may affect treatment effectiveness ${ }^{11-14}$. Drug transport between manufacturer, wholesaler and pharmacy is monitored to guarantee product quality until dispensing. However, after the drug is dispensed to the patient, storage conditions are no longer monitored, precluding the guarantee of the product's safety and effectiveness.

When patients discontinue or switch biological treatment because of no response, loss of response or adverse events, $26-49 \%$ of the patients still have unused biologicals in their possession ${ }^{15}$. Currently, these injectors are destroyed and thus spilled accounting for millions of Euros lost each year ${ }^{16}$.

To reduce spillage, the number of injectors delivered to the patient at a time can be limited, however this results in more complex logistics and higher expenses both for pharmacies and patients. Alternatively, unused injectors could be redistributed. This requires proper storage, controlled distribution and guaranteed drug quality.

The aims of this study were to assess 1 ) the quality of transport and home storage by evaluating the proportion of biological injectors stored within the recommended temperature range and 2) acceptation of patients to receive redistributed injectors in order to prevent costly spillage. 


\section{METHODS}

\section{Design and study population}

Between April and October 2015, all subcutaneous golimumab users, irrespective of the indication, at the Maastricht University Medical Centre+, were asked to participate in this prospective study. Patients used golimumab as prescribed by their physician, i.e. every 4 weeks, unless otherwise specified. During the study period, patients received three golimumab injectors at a time, stored in the original package. Each package for one single injector was wrapped in a sealed bag containing a validated temperature sensor. As usual, patients were instructed to store their medication in the fridge. After the study period, patients completed a questionnaire on their medication storage conditions at home and their opinion on potential redistribution of unused injectors.

\section{Temperature sensor}

The temperature sensor (AntTail, Utrecht, the Netherlands) was designed to specifically measure temperature in a home environment. The sensor measures the temperature every 5 minutes for a period up to 18 months. All sensors connect wirelessly to a router in the patient's home to transmit and store data to a secure cloud storage hosted by AntTail.

\section{Temperature measurements}

Deviations from the recommended range were defined as 1) $>30$ minutes below $2^{\circ} \mathrm{C}$ or above $8^{\circ} \mathrm{C}$ or 2 ) any duration below $0^{\circ} \mathrm{C}$. To distinguish transport from home storage, we defined "transport" as the period after distribution of the injector from the pharmacy until the first time the sensor measured a temperature below $8^{\circ} \mathrm{C}$. If the temperature never exceeded $8^{\circ} \mathrm{C}$ after distribution from the pharmacy, it was assumed that the product was properly stored during transport. From the moment the temperature of the product was below $8^{\circ} \mathrm{C}$, the product was considered "at home" (figure 1). We defined the moment of "use" when the temperature of the injector reached $>15^{\circ} \mathrm{C}$ and did not return below $8^{\circ} \mathrm{C}$.

\section{Statistical considerations and data analysis}

Demographic information was obtained from all patients at the time of recruitment and was presented using means (SD) and percentages of the study population. The quality of transport and home storage was assessed by the proportion of injectors stored within the SmPC recommended temperature range. Additional analyses were performed to assess the proportion of injectors stored below $0^{\circ} \mathrm{C}$ and above $20^{\circ} \mathrm{C}$ and to assess differences in storage conditions at home and during transport. Descriptive analyses were performed to evaluate the data from the patient questionnaires. Statistical analyses were done using SPSS statistics 22.0 (IBM, Armonk, NY, USA). 


\section{RESULTS}

\section{Storage conditions}

In total, 50 patients received 276 injectors with temperature sensors that generated $2,466,576$ measurements. Baseline characteristics of the patients are shown in table 1 . The mean injector storage time was $30.9 \pm 33.1$ days. Figure 2 shows that only $11.6 \%(n=32)$ of the injectors were stored within the recommended temperature range (RTR). Temperature excursions occurred both during transport and at home (figure 3). During transport, one in five injectors was stored outside the RTR. At home, only one in six injectors was adequately stored. Sixty-seven (24.3\%) injectors were stored below $2^{\circ} \mathrm{C}$ for $>30$ minutes. Of these, 31 (46.3\%) were stored $>30$ minutes below $0^{\circ} \mathrm{C}$ (figure 4). A total of 223 injectors (80.8\%) were stored above $8^{\circ} \mathrm{C}$ for $>30$ minutes. Of these, 81 (29.3\%) were stored above $8^{\circ} \mathrm{C}$ for more than 1 week before use and 65 (23.6\%) were ever above $20^{\circ} \mathrm{C}$ (figure 5). In all households at least one dispensed injector was stored outside the pre-defined range.

Table 1: baseline characteristics

\begin{tabular}{ll}
\hline & Participating patients $\mathbf{( n = 5 0 )}$ \\
\hline Age, mean (SD) & $53.2(14.3)$ \\
Male gender, N (\%) & $21(42.0)$ \\
Diagnosis, N (\%) & \\
Crohn's disease & $3(6.0)$ \\
Ulcerative colitis & $8(16.0)$ \\
\multicolumn{1}{c}{ Rheumatoid arthritis } & $8(16.0)$ \\
Spondyloarthritis & $11(22.0)$ \\
Psoriatic arthritis & $20(40.0)$ \\
\hline
\end{tabular}

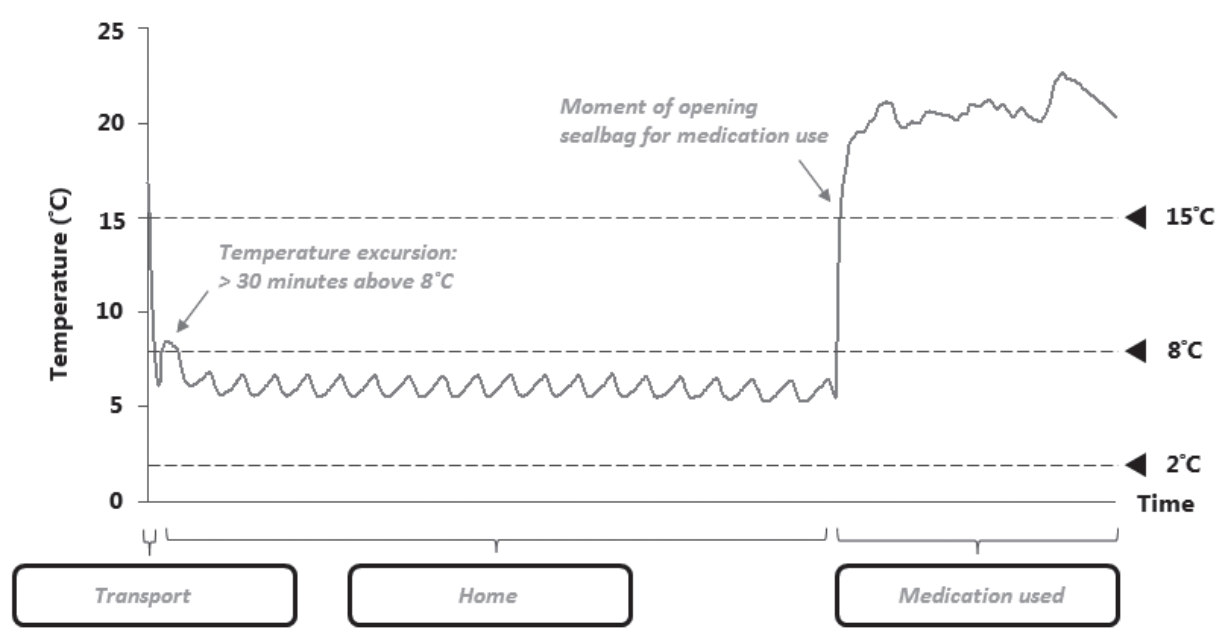

Figure 1. Storage temperature curve. 


\section{Questionnaire}

In total, 32 (64.0\%) patients completed the questionnaire on home storage conditions and redistribution of unused biologicals. Of these patients, one patient (3.1\%) stored the injector in the fridge-door, 8 patients $(25.0 \%)$ in the vegetable drawer, 18 patients (56\%) in the middle drawer and 5 patients (15.6\%) on the top drawer of the fridge. Twentyfive patients $(80.7 \%)$ found it comforting that storage conditions can be measured and 29 patients (96.7\%) would appreciate an alarm when their biological is not adequately stored. Thirty patients (96.8\%) are willing to accept unused medication when product quality is ensured. Twenty-eight patients (93\%) believe that measuring storage conditions of biologicals could improve quality of healthcare.

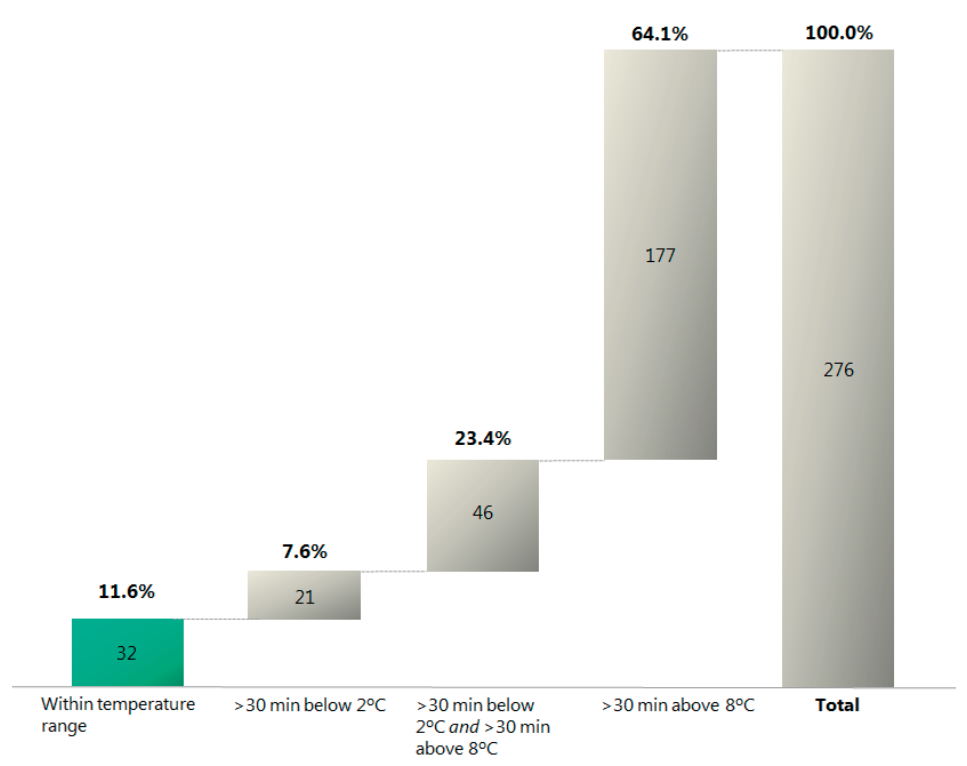

Figure 2. Proportion of biologicals stored within the recommended temperature range (N, \%).

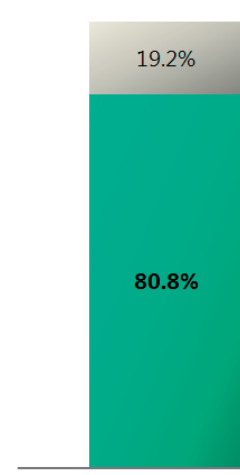

Transport

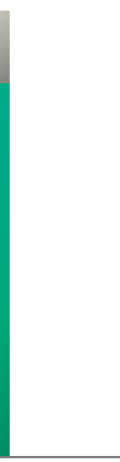

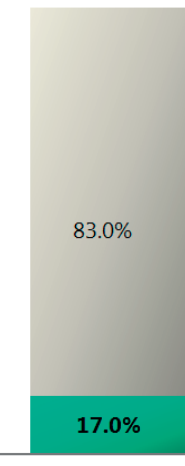

At home

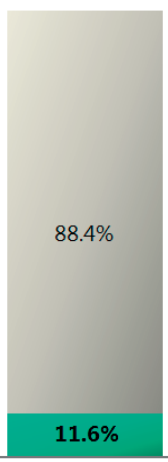

Total
Stored $>30 \mathrm{~min}$ below $2^{\circ} \mathrm{C}$ and/or $>30 \mathrm{~min}$ above $8^{\circ} \mathrm{C}$

Stored within recommended range

Figure 3. Temperature excursions during transport and at home. 


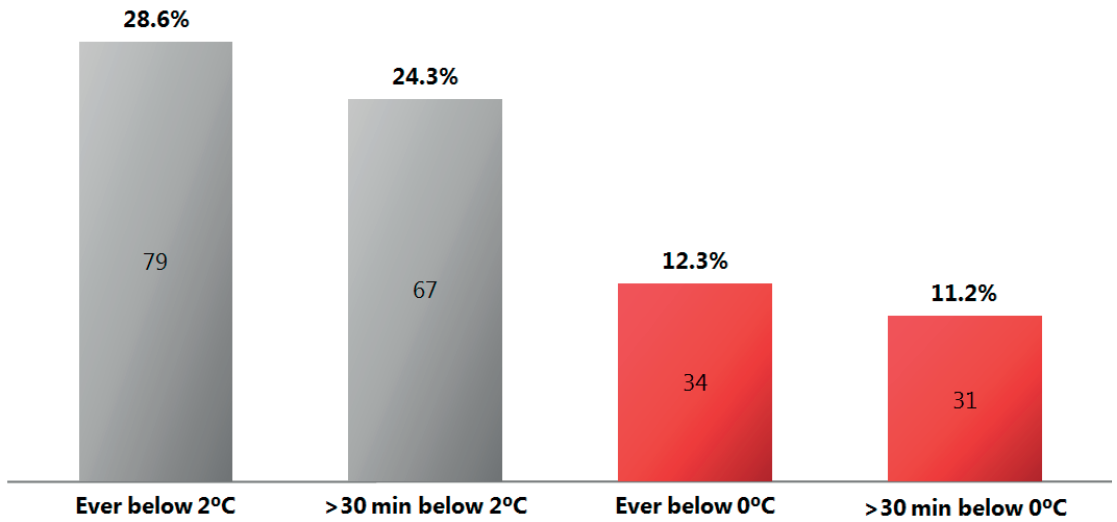

Figure 4. Temperature excursions below $2^{\circ} \mathrm{C}(\mathrm{N}, \%)$.

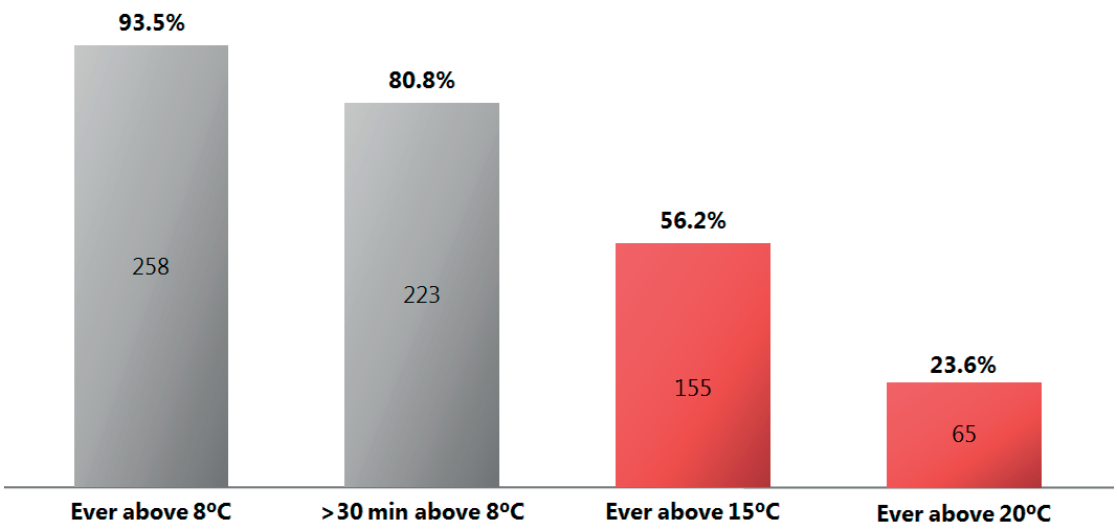

Figure 5. Temperature excursions above $8^{\circ} \mathrm{C}(\mathrm{N}, \%)$.

\section{DISCUSSION}

This study showed that, in patients' homes, only one in eight (11.6\%) biological injectors was stored within the recommended temperature ranges, which hinders redistribution of unused biologicals. On the other side, when product quality is ensured, $96.8 \%$ of patients are willing to accept unused medication.

Previous observational studies on home storage conditions of temperature-sensitive drugs show similar alarming results. Cuellar et al. found that $58.3 \%$ of patients stored their biological injectors outside the recommended temperature range of $2-8^{\circ} \mathrm{C}$ for more than two hours ${ }^{17}$. Probably owing to a longer follow-up period and a stricter definition of storage conditions, Vlieland et al. found a higher percentage of $93.3 \%$ of patients not storing their injectors within the recommended temperature ranges ${ }^{18}$. In contrast to 
the aforementioned studies, we packed each single injector with a temperature sensor in a sealed bag resulting in injector specific measurements. In addition, we distinguished between transport-storage and home-storage and added a questionnaire to the temperature measurements which provided insight on storage locations at patients' homes.

In our centre, patients receive their biological injectors at the hospitals' pharmacy in a cooler bag with a cold pack and are instructed to store their medication in the fridge. None of the patients achieved optimal storage, despite the fact that all patients who completed the questionnaire reported storage in the fridge during the study period. Improper storage may occur during transport or at home. Improper storage during transport might be due to storage too close to the cold pack, resulting in freezing of the product, or to too long of a delay before the injectors are placed in the fridge, resulting in melting of the cooling element and heating of the product. An explanation for improper storage at home may be that many household fridges have a $0^{\circ} \mathrm{C}$ vegetable drawer, which could lead to product freezing. In addition, Cuellar et al showed that an older fridge was a significant risk factor for inadequate storage, probably due to instability of the temperature ${ }^{17}$. Moreover, our study shows a large variation in storage conditions within one household suggesting temperature differences and fluctuations within the same fridge.

Storage outside the recommended temperature ranges and temperature fluctuations of these protein-based drugs may lead to protein denaturation and the irreversible formation of protein aggregates ${ }^{12,19}$. Protein aggregates may contribute to formation of anti-drug antibodies, which are found in 6-91\% of patients on biological therapy ${ }^{14,20-23}$ and are associated with adverse drug reactions ${ }^{11}$ and a diminishing treatment effect over time in a significant proportion of patients $24,25,26$.

For several other subcutaneous biologicals, i.e. adalimumab, etanercept and anakinra, it has been shown that injectors can be stored safely at temperatures up to a maximum of $25^{\circ} \mathrm{C}$ for a period of respectively 14 days $^{8}, 4$ weeks $^{10}$ and 12 hours $^{9}$. Although this has not yet been studied for golimumab, it indicates that especially temperatures below $0^{\circ} \mathrm{C}$, which occurred in our study in $12.3 \%$ of the injectors, may be harmful for product quality.

Limitations of this study were, firstly, that patients received 3 biological injectors per delivery during the study period. As a result, some injectors were only measured for a short period, possibly leading to an underestimation of our results. Secondly, assumptions were made regarding the transition from transport-storage to home-storage, the total home-storage time and the moment of injector use, which could have affected our results. Lastly, in this study we were not able to investigate the effect of improper storage on product quality, treatment effectiveness and disease outcomes. This has to be shown in future studies. 
Although we only studied home storage of golimumab, the data of this study reflect patients' home storage behaviour and can therefore be generalized to other subcutaneous biologicals. Given the finding that in none of the households perfect storage within the recommended temperature range was achieved, it is unfortunately not possible to formulate a recommendation on the optimal storage place within the fridge.

In conclusion, the majority of golimumab users store their biological injectors outside the recommended temperature ranges. This precludes guaranteed drug quality, which not only hinders redistribution of costly, unused biologicals, but also raises concern regarding the effectiveness of the drugs in these patients. The exact consequences of storage outside the manufacturers' recommended temperature ranges on product quality and treatment effectiveness need to be investigated. 


\section{REFERENCES}

1. van der Valk ME, Mangen MJ, Leenders $M$, et al. Healthcare costs of inflammatory bowel disease have shifted from hospitalisation and surgery towards anti-TNFalpha therapy: results from the COIN study. Gut. 2014;63(1):72-9.

2. Hallert E, Husberg M, Kalkan A, et al. Rheumatoid arthritis is still expensive in the new decade: a comparison between two early RA cohorts, diagnosed 1996-98 and 2006-09. Scandinavian journal of rheumatology. 2016:1-8.

3. Blankers I, Notenboom A, Schrijvershof C. Zorgkosten en maatschappelijke baten van reumatherapieën bij reumatoïde artritis. 2012.

4. Boonen A, Matricali GA, Verduyckt J, et al. Orthopaedic surgery in patients with rheumatoid arthritis: a shift towards more frequent and earlier non-joint-sacrificing surgery. Annals of the rheumatic diseases. 2006;65(5):694-5.

5. https://www.farmacotherapeutischkompas.nl (13 February 2017, date last accessed).

6. https://www.zorgprismapubliek.nl/ producten/ziekenhuiszorg/dure-geneesmiddelen (13 February 2017, date last accessed).

7. MSD bv. Simponi SPC. http://www.ema. europa.eu/docs/en_GB/document_library/EPAR_-_Product_Information/ human/000992/WC500052368.pdf February 2017, date last accessed).

8. Abbvie bv. Adalimumab SPC. http:// www.ema.europa.eu/docs/en_GB/document_library/EPAR_-_Product_Information/human/000481/WC500050870.pdf (13 February 2017, date last accessed).

9. Swedish Orphan International Ltd. Anakinra SPC. http://www.ema.europa.eu/docs/ en_GB/document_library/EPAR_-_Product_Information/human/000363/
WC500042310.pdf (13 February 2017, date last accessed).

10. Pfizer. Etanercept SPC. http://www.ema. europa.eu/docs/en_GB/document_library/EPAR_-_Product_Information/ human/000262/WC500027361.pdf February 2017, date last accessed).

11. Rosenberg AS. Effects of protein aggregates: an immunologic perspective. The AAPS journal. 2006;8(3):E501-7.

12. Zhang A, Singh SK, Shirts MR, et al. Distinct aggregation mechanisms of monoclonal antibody under thermal and freeze-thaw stresses revealed by hydrogen exchange. Pharmaceutical research. 2012;29(1):23650.

13. Luo Q, Joubert MK, Stevenson $R$, et al. Chemical modifications in therapeutic protein aggregates generated under different stress conditions. The Journal of biological chemistry. 2011;286(28):2513444.

14. Garces S, Demengeot J, Benito-Garcia E. The immunogenicity of anti-TNF therapy in immune-mediated inflammatory diseases: a systematic review of the literature with a meta-analysis. Annals of the rheumatic diseases. 2013;72(12):1947-55.

15. https://www.gfk.com (13 February 2017, date last accessed).

16. http://www.nrc.nl/nieuws/2014/06/24/ ziekenhuis-wil-tweedehands-medicijnvoor-kanker-opnieuw-voorschrijven-a1424120 (14 September 2016, date last accessed).

17. Cuellar MJ, Marco JL, Perez-Castello I, et al. [Quality of storage of thermolabile drugs in patients' homes]. Revista de calidad asistencial : organo de la Sociedad Espanola de Calidad Asistencial. 2010;25(2):649. Calidad en la conservacion de los medicamentos termolabiles en el ambito domiciliario. 
18. Vlieland ND, Gardarsdottir H, Bouvy ML, et al. The majority of patients do not store their biologic disease-modifying antirheumatic drugs within the recommended temperature range. Rheumatology. 2015.

19. Mahler HC, Friess W, Grauschopf U, et al. Protein aggregation: pathways, induction factors and analysis. Journal of Pharmaceutical Sciences. 2009;98(11):2909-2934.

20. Ding NS, Hart A, De Cruz P. Systematic review: predicting and optimising response to anti-TNF therapy in Crohn's disease - algorithm for practical management. Alimentary pharmacology \& therapeutics. 2016;43(1):30-51.

21. Vincent FB, Morand EF, Murphy $K$, et al. Antidrug antibodies (ADAb) to tumour necrosis factor (TNF)-specific neutralising agents in chronic inflammatory diseases: a real issue, a clinical perspective. Annals of the rheumatic diseases. 2013;72(2):165-78.

22. Bartelds GM, Krieckaert CL, Nurmohamed MT, et al. Development of antidrug antibodies against adalimumab and association with disease activity and treatment failure during long-term follow-up. Jama. 2011;305(14):1460-8.
23. Baert F, Kondragunta V, Lockton S, et al. Antibodies to adalimumab are associated with future inflammation in Crohn's patients receiving maintenance adalimumab therapy: a post hoc analysis of the Karmiris trial. Gut. 2016;65(7):1126-31.

24. Vittorio Grosso RG, Piercarlo Sarzi-Puttini, Fabiola Atzeni, et al. Golimumab Therapy Retention Rates in Patients with Rheumatoid Arthritis and Seronegative Spondyloarthritis: Data from the Italian Lorhen Registry. ACR Annual Meeting. 2014.

25. Menter A, Papp KA, Gooderham M, et al. Drug survival of biologic therapy in a large, disease-based registry of patients with psoriasis: results from the Psoriasis Longitudinal Assessment and Registry (PSOLAR). Journal of the European Academy of Dermatology and Venereology : JEADV. 2016.

26. Baert F, Noman M, Vermeire $S$, et al. Influence of immunogenicity on the long-term efficacy of infliximab in Crohn's disease. $\mathrm{N}$ Engl J Med 2003;348:601-8. 



\section{Chapter 10}

The prevalence of latent tuberculosis and hepatitis B after systematic screening of patients prescribed biological therapy in a low-endemic area 



\section{LETTER TO THE EDITOR}

We wish to provide some perspective with regard to the paper by Abitbol et al. entitled 'Negative screening does not rule out the risk of tuberculosis in patients with inflammatory bowel disease undergoing anti-TNF treatment: A descriptive study on the GETAID cohort ${ }^{1}$.

Biologicals are a powerful treatment for immune mediated inflammatory diseases (IMIDs), but associated with an increased risk for reactivation of latent infections such as tuberculosis (TB) or hepatitis B virus (HBV). ${ }^{2}$ Several guidelines recommend screening before commencing biological therapy. ${ }^{3}$ Abitbol et al. demonstrated that a negative screening does not rule out the risk of TB infection in patients with inflammatory bowel disease (IBD) undergoing anti-TNF therapy. ${ }^{1}$ In a retrospective study among 20 Swiss and French centres between 2001-2015, in total 44 IBD patients undergoing anti-TNF treatment, in whom the initial screening was negative, were identified with TB.

From our research we would like to emphasise not only the importance of screening, but also the monitoring during therapy. At our centre, located in a low-endemic area, we have implemented a hospital-wide systematic screening for all patients commencing biological therapy since 2012. The screening consists of a detailed medical history on risk factors for TB (i.e. previous diagnosis of TB, contact to a TB-infected person, previous living and travelling outside developed countries) and HBV (i.e. occupation, intravenous drug abuse, sexual behavior), interferon-gamma release assay (IGRA), HBV serology (i.e. HBs-Ag, anti HB-core) and a chest X-ray. To monitor patients during biological therapy, we developed MyBiologicalCoach, a telemonitoring system that, among other patientreported outcome measures, systematically screens for risk of infections and side-effects every 3 months.

From May 2012 through July 2015, 547 of 549 patients (99.6\%) prescribed biological therapy were screened, of whom $22(4.0 \%)$ tested positive on IGRA and were classified as having latent TB. Of these, 14 did not report any risk factor, 18 had always lived in the Netherlands and another 18 never travelled outside developed countries. Four patients had abnormalities on chest X-ray, 3 of them also tested positive on IGRA and the other one was diagnosed with sarcoidosis. All latent TB patients were treated with isoniazid and biological therapy was started. After a mean follow-up period of $30.9 \pm 8.8$ months none of the patients showed a reactivation of TB. One patient $(0.2 \%)$ tested positive for HBV without any risk factor; he did not commence biological therapy.

In contrast to the study by Abitbol et al., in which screening for latent TB was in most cases (57\%) performed using TST only, we used IGRA in all cases, which shows fewer false negative results. ${ }^{4}$ Despite this, the results underscore the importance of screening and monitoring for latent TB and HBV in IMID patients, even in a low endemic area. 
1. Abitbol $Y$, Laharie $D$, Cosnes J, Allez $M$, Nancey S, Amiot A, Aubourg A, Fumery M, Altwegg R, Michetti $P$, Chanteloup E, Seksik P, Baudry C, Flamant M, Bouguen G, Stefanescu C, Bourrier A, Bommelaer G, Dib N, Bigard M, Viennot S, Hebuterne X, Gornet J, Marteau P, Bouhnik Y, Abitbol V, Nahon S and the GETAID. Negative screening does not rule out the risk of tuberculosis in patients with inflammatory bowel disease undergoing anti-TNF treatment: a descriptive study on the GETAID cohort. J Crohns Colitis. 2016 Oct;10(10):1179-85.

2. Keane J, Gershon S, Wise RP, MirabileLevens E, Kasznica J, Schieterman WD, et al. Tuberculosis associated with infliximab, a tumor necrosis factor alpha-neutralazing agent. N Engl Med 2001; 345:1098-104.
3. lannone F, Cantini F, Lapadula G. Diagnosis of latent tuberculosis and prevention of reactivation in rheumatic patients receiving biologic therapy: international recommendations. The Journal of rheumatology Supplement. 2014 May; 91:41-6.

4. Menzies D, Pai M, Comstock G. Meta-analysis: new tests for the diagnosis of latent tuberculosis infection: areas of uncertainty and recommendations for research. Annals of internal medicine. 2007 Mar 6; 146 (5):340-54. 




\section{Chapter 11}

General discussion 

Inflammatory bowel disease (IBD) is a chronic condition of the gastrointestinal tract with Crohn's disease (CD) and ulcerative colitis (UC) as the main phenotypes. IBD patients risk recurrent unpredictable flares, complications, frequent surgeries and hospitalisations, and therefore the impact on patients' quality of life is high. Due to the early onset and chronicity, IBD profoundly affects educational level and work productivity with accompanying economic losses accounting for up to $31 \%$ of the total IBD-related healthcare costs ${ }^{1}$. The direct healthcare costs for IBD in the Netherlands exceed 300 million euros yearly. Despite significant advances in the management of IBD over the past decades, there is still no curative treatment and standard disease management based on treating symptoms alone did not sufficiently improve long-term outcome. Jeuring et al. assessed the impact of changing medical treatment options and management strategies over the past three decades on long-term disease outcomes in the Dutch IBD South Limburg cohort. This population-based study found that more recently diagnosed CD patients, i.e. diagnosed after the introduction of biologicals, had lower hospitalisation and surgery rates and fewer days of corticosteroid exposure during their disease course. This occurred in parallel with earlier and more frequent exposure to immunosuppressives and biologicals. However, despite high exposure to these costly drugs, the risk of disease progression from an inflammatory to a stricturing or penetrating phenotype has not changed over time ${ }^{2}$. Furthermore, data on work productivity and quality of life are lacking in these epidemiological studies. To further improve outcomes and prevent disease progression, more intensive management strategies focusing on tight control and tight monitoring have been studied and validated(3). Other proposed strategies address interventions on aspects that might influence disease activity, such as nonadherence to treatment, unfavourable nutritional status, smoking, and psychological factors. Implementation of such a holistic management strategy in the current traditional healthcare organisation is however challenging. Therefore, reorganisation of IBD healthcare is warranted. At the start of this project we hypothesised that tight remote monitoring of disease activity and other patient-reported outcome measures (PROMs) through telemedicine could improve the outcome and quality of care for IBD. In this thesis, we showed the results of several studies to validate this hypothesis.

\section{Remote monitoring of inflammatory bowel disease activity}

Mounting evidence shows that tight control of (sub)clinical mucosal inflammation is the key towards blocking disease progression and irreversible bowel damage resulting in complications, such as strictures, abscesses and fistulae ${ }^{4}$. These complications and subsequent surgery are the major drivers of impaired quality of life in IBD. Successful remote monitoring of disease activity requires PROMs validated to endoscopy, which is the gold standard to assess mucosal inflammation. The USA Food and Drug Administration has provided guidelines for development and validation of PROMs. They recommend that 
at least content validity (the extent to which an instrument measures the concept of interest), construct validity (relationships with another accepted measures of disease activity), criterion validity (the extent to which a PROM is related to a generally accepted gold standard measure), reliability (the extent to which the PROM yields consistent scores over time when no change is expected in disease activity) and responsiveness to change (the ability of a PROM to detect differences in scores over time) have to be investigated ${ }^{5}$. An extensive literature search for available PROMs measuring IBD activity was performed and presented in chapter 2. A systematic review of these PROMs showed that none of them met all the FDA recommendations for PROM-development. Only two articles reported on content validity and none of the reviewed PROMs was developed compared to endoscopy.

Therefore, we developed and validated a new PROM following the FDA recommendations and relative to endoscopy (chapter $\mathbf{3}$ ). The main purpose of this PROM was to identify patients at risk for active disease. Therefore, a sensitivity of at least $85 \%$, while maintaining sufficient specificity, was endeavored. The measurement properties of the newly developed PROM, the Monitor IBD At Home (MIAH) questionnaire, compared to endoscopy were unsatisfactory (sensitivity and specificity of $67.6 \%$ and $81.3 \%$ for CD patients and of $68.2 \%$ and $80.5 \%$ for UC patients, respectively) and comparable with the previously developed patient-reported mobile health index(6). This underscores the findings in the literature that symptoms only moderately correlate with endoscopic findings; $30 \%$ of IBD patients in clinical remission show endoscopic inflammation, and a substantial portion of IBD patients have IBS-like symptoms and positive clinical activity scores, without having mucosal inflammation ${ }^{7,8}$. A combination of clinical symptoms and biochemical biomarkers, such as C-reactive protein, thrombocytes, and especially fecal calprotectin, is able to improve the performance ${ }^{9,10}$, however the need for patients to visit the hospital or send fecal samples per mail still exists. Recently, a fecal calprotectin home-test was introduced and in chapter $\mathbf{3}$, we describe the performance of a combination of the MIAH questionnaire and the fecal calprotectin home-test. This combination improved the diagnostic accuracy to a sensitivity, specificity, positive predictive value and negative predictive value of $96.7 \%, 66.7 \%, 76.3 \%$ and $94.7 \%$ for CD patients and of $88.2 \%, 71.4 \%, 60.0 \%$ and $95.6 \%$ for UC patients, respectively, and thereby allows for close monitoring mucosal inflammation at home.

\section{Development of a new telemedicine system for all IBD patients}

Over the past decade, several trials assessed the possibilities of telemedicine to improve the outcome of IBD (see table 3 , chapter 4$)^{11-20}$. However, the telemedicine systems available at the start of our project were only suitable for specific subtypes of IBD, focused mainly on mild-to-moderate disease, and showed inconsistent results in trials. Furthermore, most systems lacked a framework for development (patient and clinician 
input), evaluation (methodology and trial outcomes), and implementation (financial and logistic hurdles, patients' and/or clinicians' resistance to change) compromising their implementation in routine clinical practice ${ }^{21}$. In chapter 4 , we describe the systematic development of the first telemedicine system, mylBDcoach, which enables homemonitoring of all subtypes of IBD patients. Through an iterative process with patients, nurses and gastroenterologists, monitoring modules were designed, and topics for e-learning modules selected. MyIBDcoach is ISO-certified, compliant with all European laws and therefore safety and privacy are guaranteed. A pilot study with mylBDcoach proved that the tool was feasible for use in routine care and well-accepted by patients and healthcare providers. Patients were compliant with the program, indicated that mylBDcoach facilitated communication with their healthcare providers and that the e-learning modules improved their knowledge about IBD (chapter 4).

\section{Reorganisation of IBD-care with telemedicine}

IBD care is traditionally organised by standard scheduled outpatient visits, with a frequency predominantly based on medical treatment and local policy, but independent of the occurrence of unpredictable flares. This might result in an inefficient and potentially costly way of medical resource use and patients' time. In addition, as abovementioned, treatment strategies for IBD are shifting from mere management of symptoms towards tight and personalised control of intestinal inflammation and timely intervention when inflammation (re-)occurs. This, together with the rising incidence of IBD, results in overburdened IBD clinics and escalating costs. The direct healthcare costs for IBD are mainly driven by medication costs, hospitalisations and outpatient clinic visits ${ }^{1,22,23}$. Structural healthcare reorganisation is warranted to improve efficiency of care, enable implementation of new management strategies in an overburdened healthcare setting, and constrain healthcare costs. Our hypothesis that telemedicine, when combined with adjustments in outpatient processes, contributes to quality of care improvement for IBD patients was studied in chapters 5 and 6 .

In chapter $\mathbf{5}$ we show that telemedicine enables healthcare professionals to implement a tight control strategy in IBD patients, while reducing the number of outpatient visits. This reduction in required outpatient visits frees up capacity at outpatient clinics to guarantee adequate access for those patients with complex disease or in need of urgent intervention. Additionally, telemedicine transforms traditionally scheduled outpatient care to on demand healthcare which enhances patient-empowerment. Tight monitoring, furthermore, allows for early detection of disease activity, early intervention in case of a relapse, and minimisation of the delay to treatment initiation. In our study we found that close monitoring with telemedicine reduced the number of hospital admissions, despite the same number of flares in both the intervention and control group, prudently suggesting that early detection of flares and early treatment interventions 
in combination with efficient communication might prevent hospital admissions. Trials with longer follow-up periods are required to determine whether telemonitoring can alter disease progression and improve long-term disease outcomes. The pragmatic study design of the mylBDcoach trial closely resembles routine practice in the Netherlands and facilitates implementation of novel telemonitoring care pathways in routine care as described in the valorization chapter in this thesis.

As described in chapter 5 , telemedicine reduces outpatient visits by $36 \%$ and hospitalisations by $50 \%$. This suggests that implementation of telemedicine could reduce healthcare costs. The results of a trial based cost-effectiveness analysis presented in chapter 6 indeed showed that telemedicine with mylBDcoach resulted in lower mean yearly costs of $€ 547$ per patient $(95 \% \mathrm{Cl}$, [€-1,029, $€ 2,143]$; mean costs of $€ 9481$ for standard care and $€ 8934$ for telemedicine).

Besides telemonitoring, mylBDcoach provides patient-tailored information (i.e. on medication adherence, nutrition, or smoking), a personal care plan, registration of PROMs, and easily accessible contact with the IBD nurse. After 12 months use of mylBDcoach, we found that medication adherence significantly improved. Nonadherence is a well-known phenomenon in IBD patients and is reported to be as high as $40 \%-60 \%{ }^{24}$. It has a significant impact on the risk of disease relapse, hospitalisation, colorectal cancer and thereby on healthcare costs and work absenteeism ${ }^{20,25-27}$. In addition, for 5-ASA use, annual healthcare costs were found to be $12.5 \%$ higher in non-adherent patients compared to adherent patients, despite increased medication expenditures(28). Also for non-adherent infliximab users, annual costs were $12 \%$ higher mainly due to more frequent outpatient visits, hospitalisations and emergency room visits(26). Several efficacious interventions have been reported to improve adherence to medication. First, disease-specific education on management algorithms and medical therapies have previously been shown to increase adherence ${ }^{18,25}$. Second, guided selfmanagement with personalised action plans in case of a relapse showed to improve UC patient-empowerment and medication adherence ${ }^{18,29}$. Implementation of such action plans in mylBDcoach, by which patients could immediately self-initiate treatment in case of symptoms, could further reduce the treatment delay and duration of flares and thereby the risk of disease progression. Furthermore, factors such as malnutrition, smoking, psychological problems, stressful life events and poor social support are considered to affect disease activity and quality of life(30). Collection of PROMs on these factors create awareness among both healthcare providers and patients. Development of standard procedures and education programs for all these aspects could further improve the long-term outcome of IBD in the future.

In chapters 7-9 we show that, by systematic measurement of patient-reported outcomes, valuable information on disease-related aspects as nutrition, psychological 
wellbeing, medication adherence, and medication side-effects, can be generated and used as leads for interventions on these aspects.

\section{Implementation and value for clinical practice}

Although the mylBDcoach trial convincingly showed that telemedicine reduces healthcare utilisation and costs while maintaining quality of care, broad implementation is currently hindered by a few barriers(31). The main obstacle is reimbursement; implementation of telemedicine is accompanied by initial costs, by structural license fees and by inevitable changes in the organisation of IBD units where tasks will need to be shifted from gastroenterologists to specialised nurses. If costs are not reimbursed, broad use of innovative care with telemonitoring will be unlikely. Therefore research focusing on economic evaluation of telemedicine interventions is important to help decision makers estimate the value of healthcare reorganisation with telemedicine towards reimbursement.

Currently, healthcare providers in the Netherlands receive one fixed payment that includes all services a patient may need during a period of time, but requires physical outpatient visits (volume-based payment). For eHealth consultations, however, efforts are not yet rewarded accordingly. In this context, value-based instead of volume-based care, is gaining ground. The key concept behind value-based healthcare is to improve quality of care while controlling costs, and reward high-value care instead of volume ${ }^{32,33}$. Improving quality of care is a continuous task for healthcare professionals and institutions. However, perspectives on what good quality of care is might differ between patients, healthcare workers, governments and hospitals (table 1). In literature, quality of care is commonly defined as a multifaceted goal aimed at improving disease outcomes by consistent delivery of evidence-based care to all patients, and decreasing practice variability leading to better individual outcomes, a healthier population and reduced costs (the triple aim)(34-36). Over the recent years, additionally, the subjective perception of health by patients is playing an increasingly important role in the assessment of quality and value of care ${ }^{37,38}$.

Quality can be measured using quality indicators (structure indicators, process indicators or outcome measures). Structure indicators are related to the structure of care delivery and describe the availability of healthcare professionals such as gastroenterologists, IBD-nurses, healthcare facilities and remote monitoring and communication tools. Process measures are related to the process of care delivery, for example the percentage of patients screened for tuberculosis prior to anti-TNF treatment (chapter 10). Outcome measures are related to the outcome of the delivered care, including PROMs that are related to outcomes that matters most to patients ${ }^{32,33}$.

In order to improve quality of care, and to benchmark and evaluate practice variation, systematic measurement of quality indicators as well as PROMs and patient-experiences 
is thus increasingly advised. For IBD, quality indicators are defined by the European Crohn's and Colitis Organisation, the IBD section of the NVMDL (Dutch organisation of gastroenterologists), and the International Consortium for Health Outcomes Measurement (ICHOM $)^{32,37}$. In this regard, healthcare workers are increasingly requested to register patients' perspectives with PROMs and quality indicators, which is challenging in an overburdened healthcare setting. A telemedicine system such as mylBDcoach enables automatic registration of quality indicators (the standard ICHOM set for IBD is available in mylBDcoach) and PROMs and thereby assists hospitals to implement value-based healthcare programmes.

Table 1. Perspectives on what good quality of care is might differ between patients, healthcare workers, governments and hospitals.

\begin{tabular}{l|l|l|l}
\hline \multirow{2}{*}{ Patients } & \multicolumn{1}{|c}{ Long-term disease outcome } & Healthcare workers \\
\cline { 2 - 3 } & $\begin{array}{l}\text { Quality of life } \\
\text { Personalised care } \\
\text { Patient-tailored information } \\
\text { Good communication } \\
\text { Patient-empowerment } \\
\text { Disability } \\
\text { Work productivity }\end{array}$ & $\begin{array}{l}\text { Implementation of a tight } \\
\text { control strategy } \\
\text { Monitoring of disease- } \\
\text { affecting factors for } \\
\text { targeted interventions } \\
\text { Registration of quality } \\
\text { indicators } \\
\text { Research }\end{array}$ & \multirow{3}{*}{ Hospitals } \\
\cline { 2 - 3 } & $\begin{array}{l}\text { Accessibility of healthcare } \\
\text { Indirect healthcare costs } \\
\text { Registration of quality } \\
\text { parameters }\end{array}$ & $\begin{array}{l}\text { Safety of care } \\
\text { Research }\end{array}$ & \\
\cline { 2 - 3 } & \multicolumn{2}{|c|}{ Direct healthcare costs } \\
\hline
\end{tabular}

\section{Directions for future IBD care}

Over the past decades treatment of IBD changed due to registration of an increasing number of new (biological) drugs, more aggressive management strategies, and targeted therapies. The current patient-stratification of this heterogeneous disease, based on clinical characteristics, however, does not adequately predict the disease course and lacks genetic and molecular markers. Overtreatment of patients with a favourable outcome is expensive and puts them at risk of possible severe side-effects of immunosuppressive treatments. Undertreatment of patients with an aggressive phenotype and delay of introduction of highly effective biologicals might lead to disease progression, surgery, hospitalisations and impaired quality of life.

Continuous collection of data from large cohorts on patients' characteristics, classic outcomes, PROMs and biomarkers via hospital information systems and telemedicine tools and converting these data into information can aid towards better patient stratification and personalised care pathways. Subsequent implementation of personalised management strategies, by which the most accurate treatment can be chosen for the 
right patient, at the right location at the right time, might reduce the under- or overuse of resources and control costs.

Remote monitoring of PROMs, furthermore, allows registration of disease-related factors that might influence disease activity such as stress, smoking and malnutrition (chapters 7 and 8). Telemedicine tools with inbuilt alarm triggers, such as mylBDcoach, create awareness on these factors and enable targeted intervention. In our clinic, currently 2 pilot studies are carried out with personalised intervention strategies. First, the e-learning module "stop smoking" is offered through mylBDcoach to all patients who actively smoke. After completion of this module, patients are contacted by an IBD-nurse and asked if they are motivated to stop smoking. If willing, patients are directly referred to the specialised "stop smoking" outpatient clinic. Secondly, fatigue is systematically monitored by myIBDcoach. In case of disabling complaints of fatigue, when a patient is in clinical and biochemical remission and when anemia is excluded, an intervention by a sport physiotherapist to improve physical condition is offered. In the near future, systematic interventions on work related problems and anxiety disorders will be evaluated. At present mylBDcoach is used in 17 hospitals in the Netherlands. The improved care-pathways based on data-analytics are shared and continuously improved within this network in close collaboration with the Dutch patient organisation (Crohn en Colitis Vereniging Nederland (CCUVN)).

Due to changes in treatment strategies towards often and earlier prescription of immunosuppressives, the number of patients exposed to immunosuppressives has exponentially increased. This leads to higher direct healthcare costs, but also raises concern about safety and side-effects. Currently, trials are investigating whether de-escalation of therapy is safe, whether subgroups of patients can be identified for whom de-escalation is most beneficial, and whether risk factors for recurrence of disease after de-escalation can be identified(3). In patients who discontinue treatment, close monitoring of disease activity is warranted to enable timely intervention in case of a relapse. In this situation, mylBDcoach together with home fecal calprotectin measurement offers unique opportunities for monitoring of IBD after treatment de-escalation.

\section{Concluding remarks}

Improving long-term outcome, quality of care and controlling costs is the responsibility of every healthcare facility treating patients with IBD. This thesis offers new insights into the use of remote monitoring to enable more efficient and affordable healthcare for chronic conditions. Implementation of telemedicine in IBD care bridges the gap between the healthcare professionals' requests for tight disease-monitoring and continuity of care in an overburdened outpatient setting and patients' demands for more involvement in disease management. Combining the current and future findings, tele- 
medicine systems can be a valuable tool for reorganising IBD care towards personalised and value-based healthcare (figure 1).

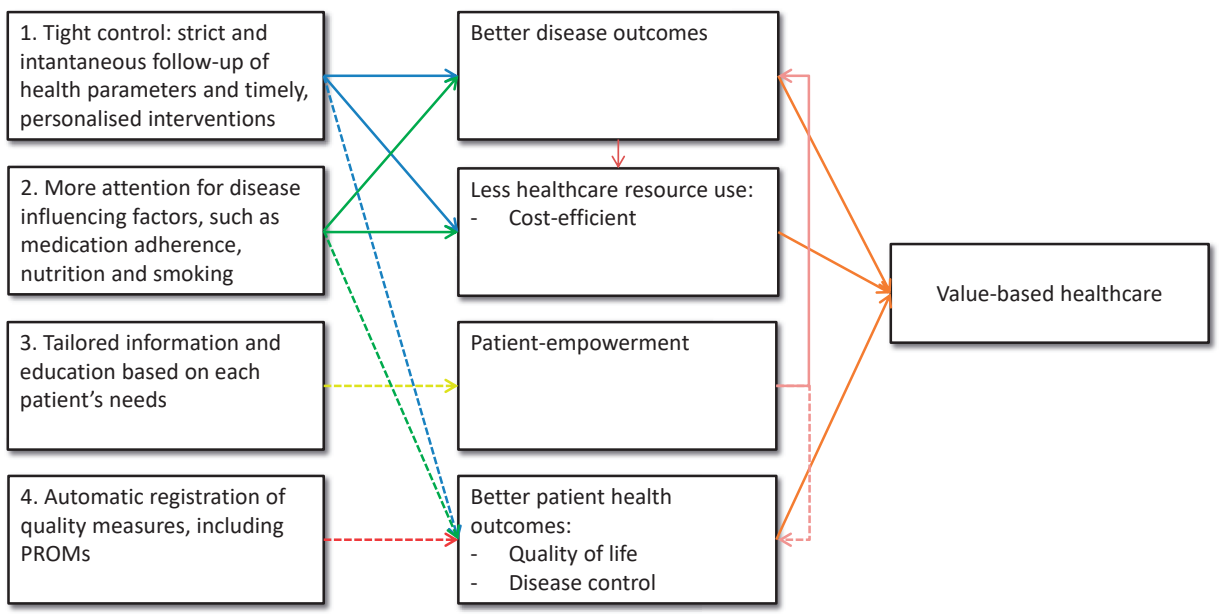

Figure 1. Schematic overview of the different functions of mylBDcoach, and on how these different functions together might result in an effective tool towards value-based healthcare. The straight lines were proven effective in this thesis; the dotted lines have to be investigated in future long-term studies. 


\section{REFERENCES}

1. van der Valk ME, Mangen MJ, Severs M, van der Have M, Dijkstra G, van Bodegraven $A A$, et al. Evolution of Costs of Inflammatory Bowel Disease over Two Years of Follow-Up. PloS one. 2016;11(4):e0142481. PubMed PMID: 27099937. Pubmed Central PMCID: 4839678.

2. Jeuring $S F$, van den Heuvel TR, Liu LY, Zeegers MP, Hameeteman WH, RombergCamps MJ, et al. Improvements in the Long-Term Outcome of Crohn's Disease Over the Past Two Decades and the Relation to Changes in Medical Management: Results from the Population-Based IBDSL Cohort. The American journal of gastroenterology. 2017 Feb;112(2):325-36. PubMed PMID: 27922024.

3. Colombel JF, Narula N, Peyrin-Biroulet L. Management Strategies to Improve Outcomes of Patients With Inflammatory Bowel Diseases. Gastroenterology. 2017 Feb;152(2):351-61 e5. PubMed PMID: 27720840 .

4. Colombel JF, Panaccione R, Bossuyt P, Lukas M, Baert F, Vanasek T, et al. Effect of tight control management on Crohn's disease (CALM): a multicentre, randomised, controlled phase 3 trial. Lancet. 2018 Dec 23;390(10114):2779-89. PubMed PMID: 29096949.

5. US Food and Drug Administration (FDA). Department of Health and Human Services (US) FDA CfDEaRC. Guidance for Industry. Patient-Reported Outcome Measures: Use in Medical Product Development to Support Labeling Claims. December 2009.

6. Van Deen WK, van der Meulen-de Jong $A E$, Parekh NK, Kane E, Zand A, DiNicola CA, et al. Development and Validation of an Inflammatory Bowel Diseases Monitoring Index for Use With Mobile Health Technologies. Clinical gastroenterology and hepatology : the official clinical practice journal of the American Gastroenterologi- cal Association. 2016 Dec;14(12):1742-50 e7. PubMed PMID: 26598228.

7. Baars JE, Nuij VJ, Oldenburg B, Kuipers EJ, van der Woude CJ. Majority of patients with inflammatory bowel disease in clinical remission have mucosal inflammation. Inflamm Bowel Dis. 2012 Sep;18(9):163440. PubMed PMID: 22069022.

8. Tomita T, Kato $\mathrm{Y}$, Takimoto M, Yamasaki $\mathrm{T}$, Kondo T, Kono T, et al. Prevalence of Irritable Bowel Syndrome-like Symptoms in Japanese Patients with Inactive Inflammatory Bowel Disease. Journal of neurogastroenterology and motility. 2016 Oct 30;22(4):661-9. PubMed PMID: 27193973. Pubmed Central PMCID: 5056576.

9. Minderhoud IM, Steyerberg EW, van Bodegraven AA, van der Woude CJ, Hommes DW, Dijkstra G, et al. Predicting Endoscopic Disease Activity in Crohn's Disease: A New and Validated Noninvasive Disease Activity Index (The Utrecht Activity Index). Inflamm Bowel Dis. 2015 Oct;21(10):24539. PubMed PMID: 26181428.

10. Bodelier AG, Jonkers $D$, van den Heuvel T, de Boer E, Hameeteman W, Masclee AA, et al. High Percentage of IBD Patients with Indefinite Fecal Calprotectin Levels: Additional Value of a Combination Score. Digestive diseases and sciences. 2017 Feb;62(2):465-72. PubMed PMID: 27933473. Pubmed Central PMCID: 5258807.

11. Cross RK, Jr. Telemanagement for inflammatory bowel disease. Gastroenterol Hepatol (N Y). 2014 Apr;10(4):255-7. PubMed PMID: 24976810. Pubmed Central PMCID: 4073538.

12. Cross RK, Arora M, Finkelstein J. ACceptance of telemanagement is high in patients with inflammatory bowel disease. J Clin Gastroenterol. 2006 Mar;40(3):200-8. PubMed PMID: 16633120. 
13. Cross RK, Cheevers N, Finkelstein J. Home telemanagement for patients with ulcerative colitis (UC HAT). Digestive diseases and sciences. 2009 Nov;54(11):2463-72. PubMed PMID: 19104937.

14. Cross RK, Cheevers N, Rustgi A, Langenberg P, Finkelstein J. Randomized, controlled trial of home telemanagement in patients with ulcerative colitis (UC HAT). Inflamm Bowel Dis. 2012 Jun;18(6):101825. PubMed PMID: 21688350. Pubmed Central PMCID: 3179574.

15. Cross RK, Finkelstein J. Feasibility and acceptance of a home telemanagement system in patients with inflammatory bowel disease: a 6-month pilot study. Digestive diseases and sciences. 2007 Feb;52(2):35764. PubMed PMID: 17211702.

16. Cross RK, Finkelstein J. Challenges in the design of a Home Telemanagement trial for patients with ulcerative colitis. Clin Trials. 2009 Dec;6(6):649-57. PubMed PMID: 19822631.

17. Elkjaer M, Burisch J, Avnstrom S, Lynge E, Munkholm P. Development of a Webbased concept for patients with ulcerative colitis and 5-aminosalicylic acid treatment. European journal of gastroenterology \& hepatology. 2010 Jun;22(6):695-704. PubMed PMID: 19543101.

18. Elkjaer M, Shuhaibar M, Burisch J, Bailey Y, Scherfig $H$, Laugesen B, et al. E-health empowers patients with ulcerative colitis: a randomised controlled trial of the webguided 'Constant-care' approach. Gut. 2010 Dec;59(12):1652-61. PubMed PMID: 21071584.

19. Pedersen N, Elkjaer M, Duricova D, Burisch J, Dobrzanski C, Andersen NN, et al. eHealth: individualisation of infliximab treatment and disease course via a self-managed web-based solution in Crohn's disease. Alimentary pharmacology \& therapeutics. 2012 Nov;36(9):840-9. PubMed PMID: 22971016.
20. Pedersen N, Thielsen $P$, Martinsen L, Bennedsen $M$, Haaber A, Langholz $E$, et al. eHealth: individualization of mesalazine treatment through a self-managed web-based solution in mild-to-moderate ulcerative colitis. Inflamm Bowel Dis. 2014 Dec;20(12):2276-85. PubMed PMID: 25248002.

21. Jackson BD, Gray K, Knowles SR, De Cruz P. EHealth Technologies in Inflammatory Bowel Disease: A Systematic Review. Journal of Crohn's \& colitis. 2016 Feb 29. PubMed PMID: 26928960.

22. van der Valk ME, Mangen MJ, Leenders M, Dijkstra G, van Bodegraven AA, Fidder $\mathrm{HH}$, et al. Healthcare costs of inflammatory bowel disease have shifted from hospitalisation and surgery towards anti-TNFalpha therapy: results from the COIN study. Gut. 2014 Jan;63(1):72-9. PubMed PMID: 23135759.

23. Bassi A, Dodd S, Williamson P, Bodger K. Cost of illness of inflammatory bowel disease in the UK: a single centre retrospective study. Gut. 2004 Oct;53(10):1471-8. PubMed PMID: 15361497. Pubmed Central PMCID: 1774248.

24. Lakatos PL. Prevalence, predictors, and clinical consequences of medical adherence in IBD: How to improve it? World journal of gastroenterology. 2009 Sep 14;15(34):4234-9. PubMed PMID: WOS:000269814900002. English.

25. Lakatos PL. Prevalence, predictors, and clinical consequences of medical adherence in IBD: how to improve it? World journal of gastroenterology. 2009 Sep 14;15(34):4234-9. PubMed PMID: 19750566. Pubmed Central PMCID: 2744179.

26. Lenti MV, Selinger CP. Medication nonadherence in adult patients affected by inflammatory bowel disease: a critical review and update of the determining factors, consequences and possible interventions. Expert Rev Gastroent. 2017 
Mar;11(3):215-26. PubMed PMID: WOS:000395088100004. English.

27. Wan GJ, Kozma CM, Slaton TL, Olson WH, Feagan BG. Inflammatory bowel disease: healthcare costs for patients who are adherent or non-adherent with infliximab therapy. Journal of medical economics. 2014 Jun;17(6):384-93. PubMed PMID: 24673303.

28. Higgins PD, Rubin DT, Kaulback K, Schoenfield PS, Kane SV. Systematic review: impact of non-adherence to 5-aminosalicylic acid products on the frequency and cost of ulcerative colitis flares. Alimentary pharmacology \& therapeutics. 2009 Feb 1;29(3):247-57. PubMed PMID: 18945258.

29. Kennedy AP, Nelson E, Reeves D, Richardson G, Roberts C, Robinson A, et al. $A$ randomised controlled trial to assess the effectiveness and cost of a patient orientated self management approach to chronic inflammatory bowel disease. Gut. 2004 Nov;53(11):1639-45. PubMed PMID: 15479685. Pubmed Central PMCID: 1774266.

30. van der Eijk I, Vlachonikolis IG, Munkholm P, Nijman J, Bernklev T, Politi P, et al. The role of quality of care in health-related quality of life in patients with IBD. Inflamm Bowel Dis. 2004 Jul;10(4):392-8. PubMed PMID: 15475747.

31. Tuckson RV, Edmunds M, Hodgkins ML. Telehealth. The New England journal of medicine. 2017 Oct 19;377(16):1585-92. PubMed PMID: 29045204.

32. van Deen WK, Esrailian E, Hommes DW. Value-based health care for inflammatory bowel diseases. Journal of Crohn's \& colitis. 2015 May;9(5):421-7. PubMed PMID: 25687204.

33. Porter ME. What is value in health care? The New England journal of medicine. 2010 Dec 23;363(26):2477-81. PubMed PMID: 21142528.

34. Berwick DM, Nolan TW, Whittington J. The triple aim: care, health, and cost. Health Aff
(Millwood). 2008 May-Jun;27(3):759-69. PubMed PMID: 18474969.

35. Siegel CA, Allen Jl, Melmed GY. Translating improved quality of care into an improved quality of life for patients with inflammatory bowel disease. Clinical gastroenterology and hepatology : the official clinical practice journal of the American Gastroenterological Association. 2013 Aug;11(8):908-12. PubMed PMID: 23747710.

36. Feuerstein JD, Castillo NE, Siddique SS, Lewandowski JJ, Geissler K, MartinezVazquez $M$, et al. Poor Documentation of Inflammatory Bowel Disease Quality Measures in Academic, Community, and Private Practice. Clinical gastroenterology and hepatology : the official clinical practice journal of the American Gastroenterological Association. 2016 Mar;14(3):421-8 e2. PubMed PMID: 26499928.

37. Huber M, Knottnerus JA, Green L, van der Horst H, Jadad AR, Kromhout D, et al. How should we define health? Bmj. 2011 Jul 26;343:d4163. PubMed PMID: 21791490.

38. Brook RH, McGlynn EA, Cleary PD. Quality of health care. Part 2: measuring quality of care. The New England journal of medicine. 1996 Sep 26;335(13):966-70. PubMed PMID: 8782507. 



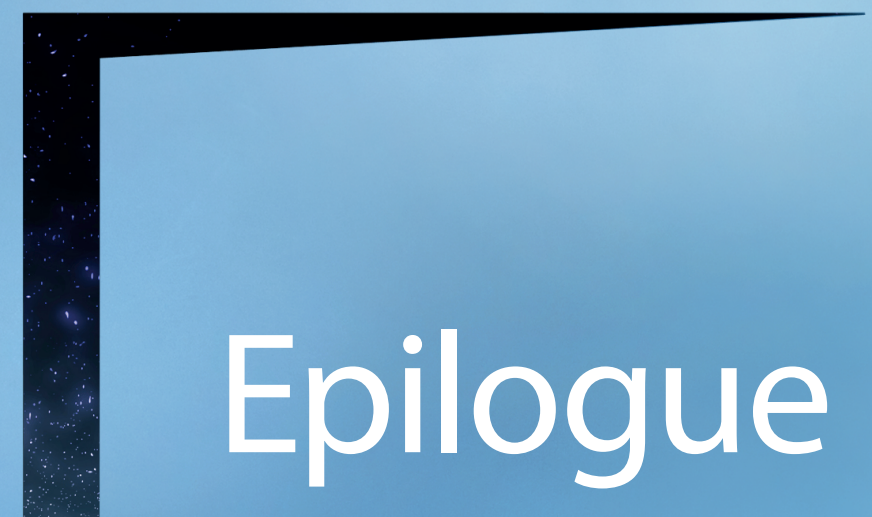



Summary 



\section{SUMMARY}

Inflammatory bowel diseases (IBD), comprising Crohn's disease (CD) and ulcerative colitis (UC), are chronic inflammatory disorders of the gastrointestinal tract characterised by periods of exacerbation and remission. The current treatment target for IBD is to achieve and maintain steroid-free clinical remission and to prevent structural bowel damage, such as fistulas, abscesses, intestinal strictures, and surgery. To achieve these targets, recent guidelines advocate more stringent management, involving tight control of disease activity and early intervention in patients with intestinal inflammation. Other interventions address aspects of inflammatory bowel disease that may influence disease activity, such as non-adherence to treatment, unfavourable nutritional status, smoking, and psychological factors. These personalised interventions were shown to reduce the rates of disease relapse, healthcare utilisation and absence from work in subsets of patients, but have not been systematically implemented in routine care. Implementing such a tight and personalised control strategy puts substantial pressure on patients' time and the capacity of outpatient clinics and it remains challenging to acquire all necessary information at the right moment for each individual patient. Furthermore, the heterogeneous nature of inflammatory bowel disease, combined with an absence of adequate markers for patient stratification, leads to under- or overuse of resources and subsequent costs. In this regard, telemedicine systems are promising to aid healthcare workers in implementing a tight control strategy and optimise efficiency of care at the same time. Telemedicine systems which have been used to manage chronic diseases, such as congestive heart failure and chronic obstructive pulmonary disease, allow for the strict and instantaneous follow-up of health parameters and timely, personalised interventions. Moreover, these systems can provide tailored information based on each patient's needs. This thesis focuses on telemedicine for IBD and describes the development of mylBDcoach, the first telemedicine system that monitors and registers disease activity in patients with all subtypes of inflammatory bowel disease.

\section{Part I: development of a telemedicine system for inflammatory bowel disease}

To facilitate broad implementation, mylBDcoach was developed for all subtypes of IBD patients, using a structured iterative process among the developer, delegates from the Dutch inflammatory bowel disease patient organisation (CCUVN), nurses, and gastroenterologists working in secondary and tertiary referral centres.

The first step in this process was to select valid patient-reported outcome measures (PROMs) to monitor disease activity and other disease-modifying factors, such as medication adherence, psychosocial factors and nutrition. In the context of tight control, PROMs monitoring IBD disease activity should accurately reflect mucosal inflammation and should be suitable for frequent and remote monitoring. An extensive literature 
review (chapter 2) on PROMs for IBD disease activity showed that none of the available PROMs met the criteria for PROM-development from the Food and Drug administration (FDA): at least data regarding content validity (patients' input and experience), construct validity (relationship with other accepted measures of disease activity), criterion validity (relationship with golden standard, i.e. endoscopy), reliability (measurement properties over time) and the ability to detect changes over time should be evaluated to determine their utility for clinical practice. In this regard, we decided to develop a new patientreported disease activity score following the FDA criteria. We found that a 5 -item patient-reported questionnaire for UC and a 6-item patient-reported questionnaire for $\mathrm{CD}$ in combination with a fecal calprotectin home-test could predict mucosal inflammation with a fecal sensitivity and specificity of $96.7 \%$ and $66.7 \%$ for CD patients and $88.2 \%$ and $71.4 \%$ for UC patients (chapter 3 ).

Besides continuous home-monitoring of disease activity and disease-related aspects (medication adherence, side-effects, malnutrition, smoking, quality of life, fatigue, lifeevents, work participation, stress, and anxiety and depression), mylBDcoach optimises disease knowledge and communication between patients and healthcare providers. The system furthermore provides e-learnings for patient empowerment. A pilot study with mylBDcoach proved that the tool was feasible for use in routine care and well-accepted by patients and healthcare providers. Patients graded the system with a mean of 7.8 of 10 , and $93 \%$ would recommend mylBDcoach to other patients (chapter 4).

\section{Part Il: efficacy of telemedicine for inflammatory bowel disease}

To evaluate the efficacy of telemedicine, we performed a pragmatic randomised multicentre trial in which telemedicine with mylBDcoach was compared to standard outpatient care. This trial, in which an unselected heterogeneous group of 909 IBD patients was included, showed that personalised telemonitoring reduced the number of outpatient visits by $36 \%$, and the number of hospitalisations by $50 \%$, while increasing adherence to medication (chapter 5). A cost-utility analysis showed that telemedicine with mylBDcoach was cost-effective and resulted in lower mean annual costs of $€ 547$ per patient, with equal quality of life. These data underscore the value of telemedicine for healthcare reorganisation towards more efficiency (chapter 6).

\section{Part III: personalised care with telemedicine}

Besides healthcare reorganisation, telemedicine enables continuous collection of data on quality metrics and patient-reported outcomes. This thesis shows that by systematic measurement of these outcomes, valuable information on disease-related aspects as nutrition, psychological wellbeing, medication adherence, and medication side-effects becomes available and can be used for timely personalised interventions. As described in chapters 7 and 8, novel perceived stress and an impaired nutritional status were 
identified as risk factors for future flares. During current traditional outpatient visits, these topics are often not discussed due to time constraints. Telemedicine can also be used to improve medication adherence and to monitor and improve medication storage behaviour (chapter 9). For IBD patients who use biologicals, we additionally developed a biological monitor which systematically screens for risk factors on latent tuberculosis and hepatitis $B$ and monitors medication side-effects. These data could be used for evaluation of care processes and optimisation of country-specific screening and vaccination protocols for patients using biologicals.

In conclusion, telemedicine systems are valuable to reorganise IBD care towards personalised and value-based healthcare. This thesis offers new insights into the use of remote monitoring to enable more efficient and affordable healthcare for IBD. Implementation of telemedicine bridges the gap between the healthcare professionals' requests for tight and personalised disease-monitoring and continuity of care in an overburdened outpatient setting and answers to patients' demands for more participation in disease management. 

Samenvatting 



\section{SAMENVATTING}

Dit proefschrift had tot doel meer inzicht te verkrijgen in de mogelijkheden van telemedicine voor management van inflammatoire darmziekten ("inflammatory bowel diseases", IBD). De ziekte van Crohn (CD) en colitis ulcerosa (UC) zijn chronische inflammatoire aandoeningen van het maagdarmkanaal en worden gekenmerkt door perioden van exacerbatie en remissie. Beide aandoeningen kunnen zich heterogeen presenteren, zoals blijkt uit verschillen in ziektelocatie, respons op behandeling en het optreden van complicaties. Het klassieke behandeldoel voor IBD is gericht op het verkrijgen van steroïde-vrije klinische remissie en om dit te behouden ter voorkoming van structurele darmbeschadiging, zoals fistels, abcessen, intestinale stricturen en operaties. Traditioneel bestaat de IBD zorg uit geplande routine polikliniek bezoeken met een frequentie die vooral is gebaseerd op de medicamenteuze behandeling en extra afspraken wanneer er een toename van klachten is. Echter, behandeling op basis van symptomen alleen heeft de ziekte-uitkomsten op lange termijn (aantal opvlammingen, corticosteroïd gebruik, ziekenhuisopnames en operaties) de afgelopen 20 jaar onvoldoende verbeterd. Daarom adviseren recente richtlijnen strengere monitoring van mucosale inflammatie en vroegtijdige interventie bij een opvlamming; de zogenaamde tight control strategie. Hiervoor is frequente controle van ziekteactiviteit noodzakelijk. Daarnaast worden vele relevante ziekte-aspecten, zoals therapietrouw, voedingstoestand en psychische klachten door de meeste MDL-artsen niet systematisch gevolgd terwijl monitoring en behandeling hiervan kan resulteren in betere ziekte-uitkomsten. Verzekeringsmaatschappijen, overheden en patiëntenorganisaties vragen steeds vaker om registratie van patiënt-gerapporteerde uitkomstmaten ("patient-reported outcome measures", PROMs), patiënt-gerapporteerde ervaringen en kwaliteitsparameters ter evaluatie van dure behandelingen. In de huidige organisatie van IBD zorg is registratie van al deze informatie op het juiste moment voor iedere individuele patiënt meestal niet haalbaar. Reorganisatie van de IBD zorg is daarom noodzakelijk, zeker omdat de incidentie van IBD stijgt.

Telemedicine maakt het door middel van monitoring op afstand mogelijk een tight control strategie te implementeren, waarbij gezondheidsparameters frequent kunnen worden gemonitord en onmiddellijke follow-up in de vorm van gepersonaliseerde interventies mogelijk is. Voor chronische obstructieve longziekten en hartfalen werden eerder al gunstige resultaten van telemedicine op de ziekte-uitkomsten gezien. Dit proefschrift richt zich op telemedicine voor IBD en beschrijft de ontwikkeling van mijnIBDcoach, de eerste telemedicine tool voor alle IBD patiënten. 


\section{Deel I: ontwikkeling van een telemedicine tool voor inflammatoire darmziekten}

De eerste stap in de ontwikkeling van een telemedicine tool was het selecteren van gevalideerde PROMs ten aanzien van ziekteactiviteit, maar ook ten aanzien van ziekteaspecten zoals therapietrouw, voedingstoestand en psychosociale factoren. PROMs gericht op het monitoren van ziekteactiviteit zijn idealiter gevalideerd ten opzichte van endoscopie (de gouden standaard voor het beoordelen van mucosale inflammatie) en geschikt voor frequent gebruik op afstand. Een uitgebreid literatuuronderzoek (hoofdstuk 2) toonde dat dat de beschikbare PROMs om IBD ziekteactiviteit te monitoren niet voldeden aan de criteria voor PROM-ontwikkeling van de Food and Drug Administration (FDA): om de klinische toepasbaarheid te evalueren moeten ten minste gegevens bekend zijn ten aanzien van de content validiteit (input en ervaring van patiënten), construct validiteit (relatie met andere geaccepteerde meetinstrumenten voor ziekteactiviteit), criterium validiteit (relatie met de gouden standaard (in dit geval endoscopie)), betrouwbaarheid (consistentie in het produceren van gelijksoortige resultaten onder gelijke condities) en het vermogen om veranderingen in ziekteactiviteit over een tijdsperiode te meten. Hoofdstuk 3 beschrijft de ontwikkeling van een nieuwe PROM voor het meten van ziekteactiviteit volgens de FDA-criteria. De monitor IBD at home score, een 5-item vragenlijst voor UC en een 6-item vragenlijst voor CD in combinatie met een fecaal calprotectine thuistest kan mucosale inflammatie voorspellen met een sensitiviteit en specificiteit van $96.7 \%$ en $66.7 \%$ voor CD-patiënten en $88.2 \%$ en $71.4 \%$ voor UC-patiënten.

De volgende stap bestond uit het vormgeven van de overige functies van de nieuwe telemedicine tool mijnIBDcoach. MijnIBDcoach is een persoonlijke webpagina en monitort naast ziekteactiviteit ook PROMs ten aanzien van therapietrouw, voedingstoestand, rookgedrag, bijwerkingen van geneesmiddelen, arbeidsparticipatie, kwaliteit van leven en angst en depressie. Gebruikers worden periodiek uitgenodigd een vragensessie in te vullen waarvan de resultaten worden samengevat in een behandeloverzicht. Wanneer antwoorden een alarmgrens overschrijden, zorgen ze voor een signaal in de backoffice in het ziekenhuis waar de patiënt onder controle is. Er kan dan direct een behandeladvies worden gegeven, aanvullend onderzoek worden ingezet of worden besloten een afspraak op de polikliniek te maken. Gebruikers kunnen ook berichten sturen via de beveiligde netwerkomgeving. Naast de monitoringsfunctie biedt mijnIBDcoach een brede waaier aan kennismodules aan, zoals over zelfmanagement, geneesmiddelen, stoppen met roken, voeding en het belang van therapietrouw. Een pilotstudie liet zien dat zowel patiënten als zorgverleners erg tevreden waren over het gebruik van mijnIBDcoach en dat de compliantie met het systeem hoog was (hoofdstuk 4). 


\section{Deel II: effectiviteit van telemedicine voor inflammatoire darmziekten}

Het effect van mijnIBDcoach werd na de pilotstudie onderzocht en in een gerandomiseerde multicenter studie waarin telemedicine werd vergeleken met de reguliere zorg. Deze studie, waarin een niet-geselecteerde heterogene groep van 909 IBD-patiënten was opgenomen, toonde aan dat patiënten door gepersonaliseerde telemonitoring significant minder (36\%) vaak op de polikliniek bij de MDL-arts en verpleegkundige hoefden te komen en het aantal ziekenhuisopnames met $50 \%$ verminderde (hoofdstuk 5). Verder was het gebruik van mijnIBDcoach veilig: de studie toonde geen verschillen aan tussen beide groepen met betrekking tot het aantal opvlammingen van de ziekte, het gebruik van corticosteroïden als rescue medicatie, het aantal SEH bezoeken en het aantal IBD gerelateerde operaties. Patiënten in de mijnIBDcoach groep waren even tevreden over de kwaliteit van de zorg als de patiënten in de reguliere zorg groep. Ten slotte zagen we dat de therapietrouw significant verbeterde onder patiënten die mijnIBDcoach gebruikten.

De belangrijkste redenen genoemd in de literatuur waarom eHealth toepassingen nog niet op grote schaal zijn geïmplementeerd, zijn onvoldoende samenwerking tussen IT-ontwikkelaars en gebruikers (hulpverleners/patiënten) bij de ontwikkeling, de ontwikkeling van systemen voor kleine niches/specifieke (kleine) patiënten categorieën en vooral het gebrek aan goede studies die de effecten, maar ook kosten van eHealth systemen aantonen. Om deze reden werd mijnIBDcoach ontwikkeld in nauwe samenwerking met artsen, IBD-verpleegkundigen en de patiënten van de Crohn en Colitis Ulcerosa Vereniging Nederland en is het programma geschikt voor monitoring van alle typen IBD patiënten. Een kosten-utiliteitsanalyse toonde aan dat telemedicine met mylBDcoach kosteneffectief was en resulteerde in een gemiddelde kosten reductie van $€ 547$ per patiënt per jaar met gelijkblijvende kwaliteit van leven en verbetering van kwaliteit van zorg. Deze gegevens onderstrepen de waarde van telemedicine voor reorganisatie van de gezondheidszorg (hoofdstuk 6).

\section{Deel III: gepersonaliseerde zorg met telemedicine}

Naast reorganisatie naar doelmatigere zorg maakt telemedicine continue registratie van gegevens mogelijk voor kwaliteitsmetingen en onderzoek. Dit proefschrift laat zien dat door systematische registratie van PROMs waardevolle informatie kan worden gegenereerd en kan worden gebruikt als aanknopingspunt voor gepersonaliseerde interventies. Zoals beschreven in hoofdstukken 7 en 8 blijken stress en een verminderde voedingsstatus een risicofactor voor het uitlokken van opvlammingen. Tot dit moment bleven deze onderwerpen vaak onderbelicht in een regulier polikliniekbezoek. Patiënten die mijnIBDcoach gebruiken ontvangen voorafgaand aan een polikliniekbezoek een vragenlijst die klachten op fysiek, emotioneel, sociaal of praktisch vlak onder de aandacht brengt. Dit maakt een poliklinisch bezoek aan de MDL-arts efficiënter en pa- 
tiëntgerichter en garandeert daarmee dat alle relevante onderwerpen worden besproken en dat patiënten waar nodig naar andere specialisten kunnen worden doorverwezen. Telemedicine kan ook worden gebruikt om het gedrag rondom medicatie-inname te evalueren en door middel van interventies daarop kan therapietrouw verder worden verbeterd (hoofdstuk 9). Voor IBD-patiënten die biologicals gebruiken werd mijnBiologicalcoach ontwikkeld: een extra module die systematisch risicofactoren voor latente tuberculose en hepatitis B screent voorafgaand aan start van biological therapie en daarnaast de bijwerkingen van deze medicatie monitort (hoofdstuk 10). Deze gegevens kunnen worden gebruikt voor de evaluatie van zorgprocessen en de optimalisatie van landelijke screening- en vaccinatieprotocollen voor patiënten die biologicals gebruiken.

Dit proefschrift biedt nieuwe inzichten in het gebruik van telemedicine teneinde de IBD zorg te reorganiseren naar gepersonaliseerde en doelmatigere zorg. Implementatie van telemedicine slaat een brug tussen de wens van hulpverleners om een tight control strategie te implementeren voor de groeiende groep IBD-patiënten ondanks beperkte middelen en de vraag van patiënten naar meer participatie bij hun behandeling. Daarnaast biedt het programma mogelijkheden om de zorg te verbeteren door registratie van PROMs en kwaliteitsparameters die gebruikt kunnen worden voor value-based healthcare. 


Valorisation 



\section{VALORISATION}

Inflammatory bowel disease (IBD) is a chronic heterogeneous condition of the gastrointestinal tract that requires life-long continuous and tight monitoring to prevent complications such as fistulae, abscesses, surgeries and hospitalisations. The disease itself and especially these complications are responsible for a diminished quality of life in IBD patients. In the current traditional overburdened outpatient setting, implementation of a tight control strategy is challenging and costly. Optimisation of quality of care is an important task of healthcare professionals and facilities but due to increasing healthcare expenditures, professionals are stimulated to develop innovative and creative ideas to improve outcome and quality of care but control costs. This thesis showed that telemedicine enables implementation of a tight control strategy resulting in better health outcomes without increasing healthcare costs.

\section{Value for patients}

Value of care for patients is determined by two factors: health outcomes and healthcare costs ${ }^{1}$. This thesis showed that both factors were positively influenced by the use of telemedicine. The mylBDcoach trial showed that care via telemedicine contributed to strict monitoring and instantaneous action in case of a relapse. Most probably this was responsible for the $50 \%$ reduction in hospitalisations and thereby better health outcome. As expected, incorporation of telemedicine in IBD-care resulted in cost-savings. Furthermore, patients reported that mylBDcoach resulted in time-savings because they only had to visit the hospital when necessary and they could fill out monitoring sessions at a for them convenient moment and location. A recently performed survey among 7500 IBD patients highlighted 5 areas related to quality of IBD care from the patients' perspective: (1) quality of specialist communication, (2) whether the review consultation was long enough, (3) failure to share information in the past 2 years, (4) no access to a dietitian and (5) speed of advice in case of flare ${ }^{2}$. As patients were involved in this project from the early beginning, mylBDcoach also monitors outcomes that matter most to them, such as quality of life, nutrition, (work)disability and psychological problems. Monitoring on these aspects enables professionals to implement a more personalised and holistic treatment approach with targeted interventions, such as a referral to physiotherapists, dietitian or a psychologist. We furthermore expect that due to the information function of mylBDcoach and due to insight in their personal care plan, patients' self-management and empowerment will be improved. From the literature, we know that this positively influences quality of

Patient: MylBDcoach helps to keep track of my illness and I can find information easily. If it goes bad, the line with your doctor is very short and prevents you from waiting too long with serious complaints. By intervening more quickly on an approaching flare, you will prevent yourself from becoming seriously ill. That greatly improves quality of life. 
life. Patients furthermore experienced an easy and effective way of communication with their healthcare providers trough mylBDcoach. We believe that broad implementation of telemedicine in parallel with reorganisation of care can further improve long-term disease outcome and thereby patients' quality of life. We had an intensive collaboration with patients during the different phases of this project, and close contact with the patient organisation CCUVN. The fact that we easily included 909 patients in the mylBDcoach trial, underscores that myIBDcoach is of value for IBD patients.

\section{Value for healthcare professionals}

Improving quality and value of care is a continuous task for every healthcare professional. To achieve better health outcomes, recent studies show that patients' symptoms and mucosal inflammation need to be tracked closely. Close disease monitoring in a traditional healthcare setting is however challenging due to limited medical and financial resources and more so since the incidence of IBD is increasing. Additionally, due to increasing healthcare costs, healthcare professionals are forced to register disease outcomes and quality parameters increasing the administrative burden. In this regard, telemedicine tools are valuable for monitoring patients at home between outpatient visits and assist healthcare professionals in implementing such a tight control strategy and for automatic registration of quality parameters.

This thesis showed that telemonitoring in combination with patient-tailored information, a personal care plan, and easy, accessible contact with the IBD nurse, resulted in a reduction of healthcare utilisation and hospital admissions and thereby in costs. Additionally, IBD telemanagement creates fast access to healthcare professionals and frees up capacity at the outpatient clinics for those patients with complex disease or in need of urgent action. Furthermore, mylBDcoach focuses on all aspects of this complex disease correlated with the disease course, such as smoking, medication adherence, nutrition or psychological factors. These aspects tend to receive little attention during traditional outpatient visits. Patients using mylBDcoach receive a questionnaire prior to an outpatient visit, including the IBD control questionnaire, which is a sensitive instrument for measuring overall disease control from the patients' perspective, and the "Lastmeter", which is a questionnaire that indicates if there are any inconveniences on physical, emotional, social or practical areas. This together makes the outpatient visit with the gastroenterologist more efficient and patient centered and guarantees that all relevant topics will be discussed and patients will be referred to other specialists whenever necessary. In the MUMC+ we developed a precision medicine model for IBD management, in which care

Gastroenterologist: MylBDcoach monitors disease activity, but also all different aspects of this complex disease that matter to patients. Such a holistic approach results in more intensive consultations, but it also enriches my work. I believe that tight control and such a holistic approach will improve disease outcomes for IBD on the long-term. 
pathways are reorganised with mylBDcoach towards value-based healthcare (see figure 1). After diagnosis, patients start using mylBDcoach and receive immediately adequate education. The follow-up exists of one yearly outpatient visit; in between patients will be telemonitored and mainly managed by specialised IBD-nurses. For each patient, PROMs and patient-reported experience measures (mylBDcoach), classical outcome measures, process indicators and costs (structured registration in hospital information system) are continuously registered and coded. These data are stored in a data-hub and processed to optimise patient-stratification and care pathways for these groups.

\section{Standard care}
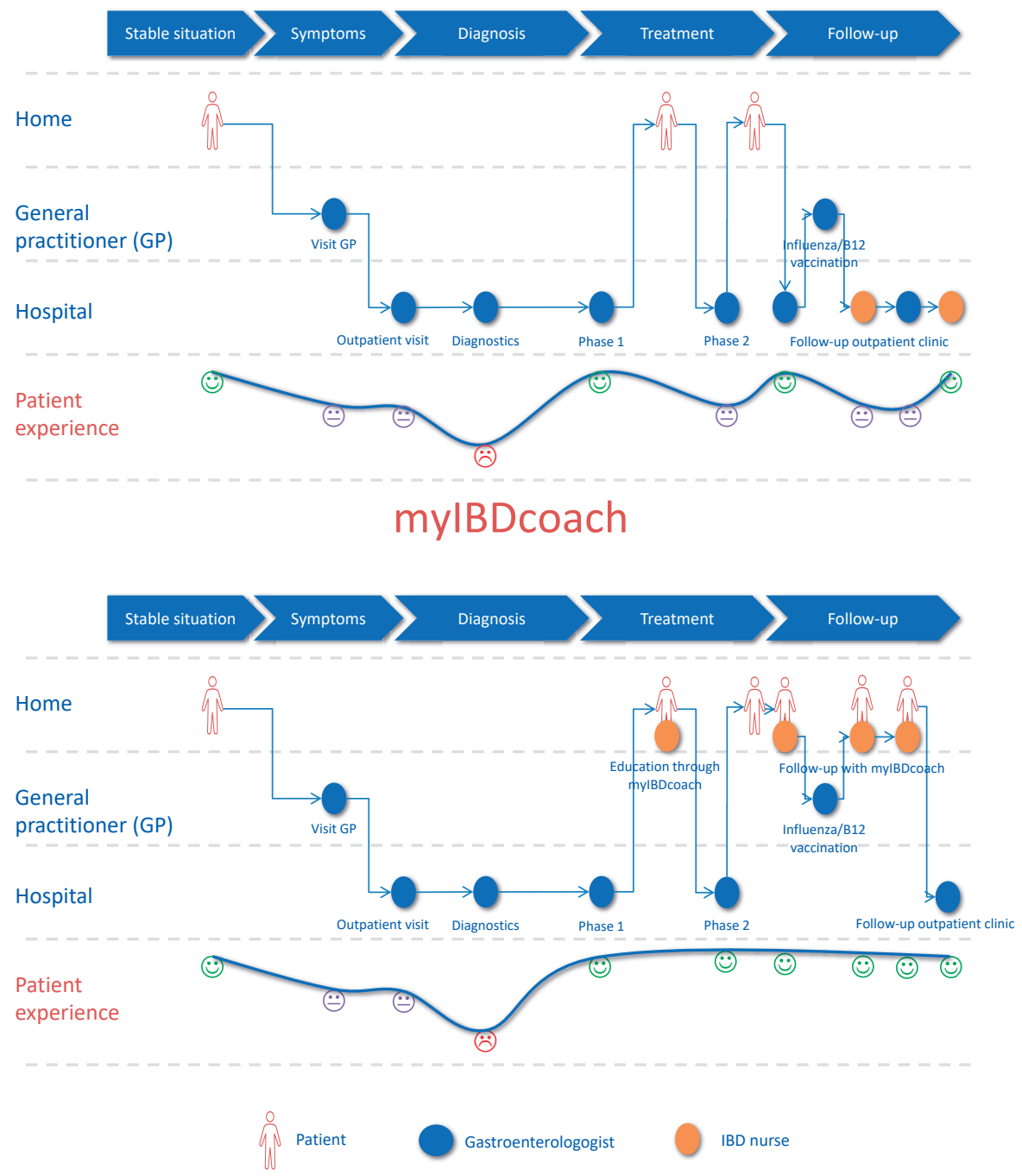

Figure 1. Care pathways with and without mylBDcoach. 


\section{Value for society}

In addition to more efficient organisation of IBD healthcare, better accessibility of care for IBD patients and a reduction in healthcare costs, this thesis also showed that telemedicine contributes to a reduction in indirect healthcare costs. Due to the early onset and chronicity, IBD profoundly affects work productivity with accompanying economic losses. In the myIBDcoach trial we asked patient to report their hours of sick leave from work and converted these hours into economic losses from a societal perspective, which was $€ 1,886$ for mylBDcoach users and $€ 2,058$ for patients receiving standard care. Using mylBDcoach, patients only have to visit the hospital when necessary; they can fill out questionnaires at any suitable moment and do not need to ask free from work. In addition, by lowering patients' disease burden and improving patient-empowerment, patients will probably experience less inconvenience of their disease in daily life and work.

In the Netherlands, where around 80,000 patients suffer from IBD, implementation of telemedicine with mylBDcoach would result in a yearly cost saving of 44 million Euro for society. Furthermore, by generating data on quality indicators, telemedicine with myIBDcoach enables benchmarking of IBD clinics and evaluation of practice variation towards better quality of care.

\section{Value for research}

MylBDcoach enables structured registration of PROM data from large patient cohorts. These data can be used for research purposes. Furthermore, mylBDcoach, in combination with at home fecal calprotectin monitoring, is an excellent tool for treatment strategy trials. Currently, several trials are investigating whether de-escalation or episodic administration of biologicals is safe and whether risk factors for recurrence of disease after de-escalation can be identified. In patients who discontinue treatment, close monitoring of disease activity is warranted to enable timely intervention in case of a relapse.

\section{Overall and future value}

This thesis showed that telemedicine with mylBDcoach bridges the gap between healthcare workers' requests for tight disease monitoring and continuity of care in an overburdened outpatient setting, patients' demands for more involvement in disease management and more attention to physical, emotional an practical aspects of the disease, and better accessibility of IBD care due to more efficient use of resources. The common benefit for all stakeholders is that implementation of mylBDcoach resulted in better disease outcome with lower costs. These results were needed to help decision makers in estimating the value of telemedicine for IBD. Over the past years this project received much attention (inter)nationally by patients, gastroenterologists, nurses, pharmaceutical industry, governments and insurance companies. Also, people outside the 
IBD field were interested. We were invited to present our research at large international congresses and on meetings of decision makers in the Netherlands. This resulted in research prizes, but also in a healthcare innovation award, nomination for the Dutch Value Based HealthCare prize, a nomination as Zinnige Zorg Initiative (Meaningfull Care Initiative) by the insurer VGZ, and the use of mylBDcoach as best practice example by the Federation of Dutch University Medical Centres (NFU) ${ }^{3}$, by the Dutch Healthcare Authority (NZA) ${ }^{4}$ and by the Dutch Patient Federation. At present, mylBDcoach is used in routine care in 17 hospitals throughout the Netherlands. The optimised mylBDcoach care pathways are shared within this network. Since mylBDcoach will be reimbursed from January 2019, we expect a further adoption of mylBDcoach in the Netherlands. Next, the National Health Service from the United Kingdom, and different hospitals around the world showed their interest in a translated version of mylBDcoach for use in their IBD clinic. 
1. Porter ME. What is value in health care? The New England journal of medicine. 2010;363(26):2477-2481.

2. Irving P, Burisch J, Driscoll R, et al. IBD2020 global forum: results of an international patient survey on quality of care. Intestinal research. 2018;16(4):537-545.
3. Nederlandse Federatie van Universitair Medische Centra. Bouwstenen voor werken aan waardegedreven zorg. https:// www.nfukwaliteit.nl/pdf/Bouwstenen_ voor_werken_aan_waardegedreven_zorg. pdf. 2018.

4. Nederlandse Zorgautoriteit. Wegwijzer bekostiging e-health voor 2019: overzicht per zorgsector. https://puc.overheid.nl/ nza/doc/PUC_240745_22/2/. 2018. 


\section{'Minder opnamen van darmziekte-patiënten dankzij online begeleiding'}

https://www.nu.nl 15 juli 2017 12:58

\section{De e-health-toepassing MijnIBDCoach, die helpt bij de begeleiding van patiënten met een chronische inflammatoire darmaandoening (IBD) zoals Crohn, blijkt succesvol.}

De toepassing zorgt ervoor dat het aantal ziekenhuisopnamen is gehalveerd, er minder polibezoeken plaatsvinden en dat er een betere therapietrouw is. Dat blijkt uit een onderzoek onder bijna duizend patiënten in verschillende Nederlandse ziekenhuizen, onder leiding van het Maastricht UMC+.

MijnIBDCoach laat de patiënt op een interactieve manier over zijn ziekte leren en laat hem of haar communiceren met zijn behandelaar. Die kan op zijn beurt de patiënt op afstand volgen en indien nodig actie ondernemen.

De helft van de onderzoekdeelnemers mocht de toepassing gebruiken. Uit het onderzoek (zaterdag gepubliceerd in het wetenschappelijke tijdschrift The Lancet) blijkt dat het aantal patiënten dat in het ziekenhuis opgenomen moest worden, met 50 procent is verlaagd in vergelijking met de groep die de toepassing niet gebruikte.

Wat betreft bezoeken aan de polikliniek is er een afname van 39 procent geconstateerd. Ook zijn patiënten die gebruik maken van de toepassing meer tevreden over de kwaliteit van zorg.

\subsection{Nederlanders}

Meer dan 80.000 Nederlanders hebben in Nederland last van een chronische darmziekte. De ziekte van Crohn en colitis ulcerosa zijn de twee voornaamste vormen van chronische ontstekingsziekten van de darm.

"Dit bewijst de meerwaarde en potentie van e-health toepassingen voor het efficiënter inrichten van de zorg", aldus maag,- darm-, leverarts Marieke Pierik.

"De tool levert dus een waardevolle bijdrage aan de zorg voor patiënten met een chronische darmaandoening. Willen we de kosten in de toekomst beheersbaar blijven houden, dan zijn structurele veranderingen in de zorg nodig. E-health toepassingen, zoals MijnIBDcoach, zijn uitermate geschikt om het primaire zorgproces efficiënter in te richten, zonder het belang en de behoeften van de patiënt uit het oog te verliezen." 

Publications, presentations and awards 



\section{PUBLICATIONS}

\section{9}

MJ de Jong, AERCH Boonen, M Romberg-Camps, A van Bodegraven, N Mahmmod, $T$ Markus, G Dijkstra, AAM Masclee, B Winkens, A van Tubergen, DM Jonkers, AE van der Meulen-de Jong, MJ Pierik. Cost-effectiveness of telemedicine-directed specialised care versus standard care for inflammatory bowel disease: the mylBDcoach trial. Submitted.

\section{8}

MJ de Jong, JHRJ Degens, TRA van den Heuvel, M Romberg - Camps, B Winkens, T Markus, AAM Masclee, A van Tubergen, DMAE Jonkers, MJ Pierik. Development and validation of a patient-reported score to screen for mucosal inflammation in inflammatory bowel disease. J Crohns Colitis. 2018 Nov 24. doi: 10.1093/ecco-jcc/jjy196

DSJ Wintjens, MJ de Jong, A van der Meulen-de Jong, M Romberg-Camps, M Becx, B Winkens, AAM Masclee, DMAE Jonkers, MJ Pierik. Novel perceived stress and life events precede flares of inflammatory bowel disease: a prospective 12-month follow-up study. J Crohns Colitis. 2018 Oct 29.doi: 10.1093/ecco-jcc/jjy177.

MJ de Jong, MJ Pierik, A Peters, M Roemers, F van der Heijden, V Hilhorst, A van Tubergen. Exploring conditions for redistribution of anti-tumor necrosis factors to reduce spillage: A study on the quality of anti-tumor necrosis factor home storage. J Gastroenterol Hepatol. 2018 Feb;33(2):426-430.

MJ de Jong, D Roosen, A Peters, AAM Masclee, V Verstraeten, A van Tubergen, MJ Pierik. The prevalence of latent tuberculosis and hepatitis $B$ found after systematic screening of patients starting with biological therapy in a low-endemic area. J Crohns Colitis. 2018 Jan 5;12(1):124-125.

\section{7}

MJ de Jong, AE van der Meulen-de Jong, MJ Romberg-Camps, MC Becx, JP Maljaars, M Cilissen, AA van Bodegraven, N Mahmmod, T Markus, WM Hameeteman, G Dijkstra, AAM Masclee, AERCH Boonen, B Winkens, A van Tubergen, DM Jonkers, MJ Pierik. Telemedicine enables inflammatory bowel disease patients to safely shift from examination room-based to personalised care: a pragmatic randomised multicentre trial with mylBDcoach. Lancet. 2017 Sep;390(10098):959-968. 
MJ de Jong, R Huibregtse, AAM Masclee, DMAE Jonkers, MJ Pierik. Patient-reported outcome measures for use in clinical trials and clinical practice in inflammatory bowel diseases - A systematic review. Clin Gastroenterol Hepatol. 2018 May;16(5):648-663.e3.

MJ de Jong, AE van der Meulen-de Jong, M Romberg-Camps, J Degens, M Becx, T Markus, H Tomlow, M Cilissen, N Ipenburg, M Verwey, L Colautti-Duijsens, W Hameeteman, AAM Masclee, DMAE Jonkers, MJ Pierik. Development and feasibility study of a telemedicine tool for all IBD patients: mylBDcoach. Inflamm Bowel Dis. 2017 Apr;23(4):485-493.

\section{5}

K Cox-Limpens, E Strackx, D Van den Hove, JR van Ekkendonk, MJ de Jong, LJ Zimmerman, HW Steinbusch, JS Vles, AW Gavilanes. Fetal Asphyctic Preconditioning Protects Against Perinatal Asphyxia-Induced Apoptosis and Astrogliosis in Neonatal Brain. CNS Neurol Disord Drug Targets. 2015;14(1):33-40.

\section{4}

MJ de Jong, JJ Korterink, MA Benninga, M Hilbink, J Widdershoven, MJ Deckers-Kocken. Dientamoeba fragilis and chronic abdominal pain in children: a case-control study. Arch Dis Child. 2014 Dec;99(12):1109-13. doi: 10.1136/archdischild-2014-305942 


\section{SCIENTIFIC PRESENTATIONS}

MJ de Jong, AE van der Meulen-de Jong, MJ Romberg-Camps, MC Becx, JP Maljaars, M Cilissen, AA van Bodegraven, N Mahmmod, T Markus, WM Hameeteman, G Dijkstra, AAM Masclee, A Boonen, B Winkens, A van Tubergen, DM Jonkers, MJ Pierik. Personalized care with telemedicine for inflammatory bowel disease is cost-effective. A cost-utility analysis of the mylBDcoach trial.

UEGW, Vienna, Austria, 2018 [oral presentation]

MJ de Jong, AE van der Meulen-de Jong, MJ Romberg-Camps, MC Becx, JP Maljaars, M Cilissen, AA van Bodegraven, N Mahmmod, T Markus, WM Hameeteman, G Dijkstra, AAM Masclee, A Boonen, B Winkens, A van Tubergen, DM Jonkers, MJ Pierik. Telemedicine for management of inflammatory bowel disease (mylBDcoach): a pragmatic, multicentre, randomised controlled trial.

$12^{\text {th }}$ congress of ECCO, Barcelona, Spain, 2017 [oral presentation]

Digestive disease week, Chicago, United States, 2017 [oral presentation]

EasyM Congress, Berlin, Germany, 2017 [oral presentation]

Falk symposium, Madrid, Spain, 2017 [oral presentation].

NVGE, Veldhoven, the Netherlands, 2017 [oral presentation]

Wetenschapsdag Interne Geneeskunde, Maastricht, the Netherlands, 2017 [oral presentation]

NVMDL symposium, Amsterdam, the Netherlands, 2017 [oral presentation]

ICC dag, Amsterdam, the Netherlands, 2017 [oral presentation]

MJ de Jong, A van Tubergen, A Peters, AAM Masclee, V Verstraeten, MJ Pierik. A feasibility study with the telemedicine tool myBiologicalcoach in The Netherlands.

$11^{h}$ congress of ECCO, Amsterdam, the Netherlands 2016 [poster]

MJ de Jong, D Roosen, A Peters, AAM Masclee, V Verstraeten, A van Tubergen, MJ Pierik. The prevalence of latent tuberculosis and hepatitis $B$ found after systematic screening of patients starting with biological therapy in a low-endemic area.

$11^{\text {th }}$ congress of ECCO, Amsterdam, the Netherlands 2016 [poster]

Digestive disease week, San Diego, United States 2016 [poster]

MJ de Jong, JHRJ Degens, TRA van den Heuvel, M Romberg - Camps, B Winkens, T Markus, AAM Masclee, A van Tubergen, DMAE Jonkers, MJ Pierik. Validation of a patientreported score to screen for mucosal inflammation in inflammatory bowel disease.

NVGE, Veldhoven, the Netherlands 2015 [oral presentation]

$11^{\mathrm{h}}$ congress of ECCO, Amsterdam, the Netherlands 2016 [poster]

UEGW, Vienna, Austria, 2016 [oral presentation] 
MJ de Jong, MJ Pierik, A Peters, M Roemers, F van der Heijden, V Hilhorst, A van Tubergen. Exploring conditions for redistribution of anti-tumor necrosis factors to reduce spillage: A study on the quality of anti-tumor necrosis factor home storage. J Gastroenterol Hepatol. 2018 Feb;33(2):426-430.

$11^{\text {th }}$ congress of ECCO, Amsterdam, the Netherlands 2016 [digital oral presentation]

MJ de Jong, JHRJ Degens, TRA van den Heuvel, M Romberg - Camps, B Winkens, T Markus, AAM Masclee, A van Tubergen, DMAE Jonkers, MJ Pierik. Development of a patient reported disease activity score to predict mucosal inflammation in IBD.

$10^{\text {th }}$ congress of ECCO, Barcelona, Spain 2016 [poster]

MJ de Jong, AE van der Meulen-de Jong, M Romberg-Camps, J Degens, M Becx, T Markus, H Tomlow, M Cilissen, N Ipenburg, M Verwey, L Colautti-Duijsens, W Hameeteman, AAM Masclee, DMAE Jonkers, MJ Pierik. Development and feasibility study of a telemedicine tool for all IBD patients: mylBDcoach.

$9^{\text {th }}$ congress of ECCO, Copenhagen, Denmark 2014 [digital oral presentation] 


\section{AWARDS}

2016

Best oral presentation wetenschappelijk symposium AtriumMC

2017

Young ECCO abstract award

2017

Best oral presentation Falk Symposium

2017

Takeda Young-ICC research award, $2^{\mathrm{e}}$ prijs

2017

Wetenschapsdag Interne Geneeskunde, beste publicatie 2017

2018

UEGW travel grant 

Dankwoord 



\section{DANKWOORD}

Aan iedereen die heeft bijgedragen aan de totstandkoming van dit proefschrift en aan iedereen die met me mee reist in dit leven.

Wellicht was u degene die de kansen zag, me het vertrouwen bood, de kritische vragen stelde en inspireerde tot het schrijven van dit proefschrift.

Of degene die mij met visie en toewijding heeft begeleid en het vertrouwen, de motivatie en de vrijheid heeft gegeven te ontwikkelen als onderzoeker, arts en mens.

Of een van de collega's die zorgden voor een gezellig welkom op de UNS ter afwisseling van de 67.618 kilometers treinreis die moesten worden afgelegd. Er wordt wel gezegd dat promoveren een eenzame bezigheid is, maar met jullie om me heen heb ik dat nooit zo ervaren.

Of was jij een van de collega's met wie de vrijdagmiddag-fiets-borrel werd opgericht, die overigens ook gewoon op woensdagmiddag na het werk kon plaatsvinden, inclusief zonnige borrel in het Limburgse land.

Of een van de collega's met wie congressen op de meest geweldige locaties werden bezocht, zenuwen voor praatjes werden gedeeld, maar met name ook successen werden gevierd. Wat een geluk dat jullie vriend(inn)en werden.

Of die collega met wie "even snel" een taco gekocht werd over de grens in Tijuana, waarbij geen rekening gehouden werd met de lange Mexicaanse rij voor de douane waardoor die belangrijke meeting bijna gemist werd.

Of die andere collega met wie, tussen de serieuze zaken door, Limburgs werd geleerd en plannen werden gesmeed voor wereldreizen, carnaval en dart/kras toernooien.

Of zat u wellicht in de commissie en nam u voor mij de tijd tussen alle belangrijke en tijdrovende bedrijven door dit proefschrift te lezen en erover te oordelen.

Of ben jij die lieve vriendin voor het leven, metgezel tijdens prachtige reizen waarbij de meest wonderlijke avonturen zijn ontstaan.

Of die lieve vriendin sinds het klimrek in groep 1, die hetzelfde academisch pad bewandelde en waarmee kritische observaties over de medische wetenschap werden gedeeld onder het genot van Lebkov koffie. 
Of het luisterend oor in Rotterdam, met wie het grote geluk dat vriendschap heet op ieder mogelijk moment wordt gevierd (met of zonder geheime kast). Ik dacht dat ik wist wat attent was, totdat ik jullie leerde kennen.

Of een van die lieve betrokken jaarclubvriendinnen, met wie de vanzelfsprekendheid van onze vriendschap ons al jaren lang samen brengt, overal ter wereld.

Of die dierbare vriend, met wie sinds de studententijd in Maastricht een trouwe vriendschap is ontstaan, en die het voorbeeld gaf en inspireerde om onderzoek te gaan doen.

Of de lieve schoonmoeder, die met eindeloze interesse en betrokkenheid promotieverhalen aanhoorde en aanvoelde wanneer een lekkere pan moksi alesi het verschil kon maken.

Of was jij een van die talrijke collega's die zorgden voor een warme overgang van onderzoek naar kliniek.

Of die lieve ouder, die altijd aanmoedigde kansen te benutten, geduldig en met interesse de verschillende opties aanhoorde en vervolgens de mogelijkheden gaf dit alles te beleven.

Of dat lieve broertje, dat mij precies een jaar geleden het goede voorbeeld gaf en nu naast mij staat op deze bijzondere dag. Je maakt me een supertrotse zus.

Of behoor jij tot het selecte gezelschap van onze dierbare extended family.

Of mijn reisgezel op de wereld en in het leven. Miguel, jij bent de beste reden om na een werkdag weer naar huis te gaan. Je stimuleert me tot het hoogst haalbare en met jouw talent, doorzettingsvermogen en moed heb je me laten zien dat alles mogelijk is als je maar groots denkt en durft. Op naar het kleine grote avontuur dat op ons wacht. La vida es un carnaval!

Mijn dank aan jullie allen is groot, groter dan uit te drukken in tekst. Hopelijk vangt u dit in een blik wanneer ik u de volgende keer tref. 


Curriculum Vitae 



\section{CURRICULUM VITAE}

Marin Joanne de Jong was born on May $21^{\text {st }} 1988$ in Wageningen, the Netherlands. After graduating high school (Pantarijn Gymnasium, Wageningen), she studied medicine at the University of Maastricht. During her master, she did her internship ophthalmology at Kasturba Medical College in Manipal, India and her internship pediatrics at Universidad de La Sabana in Bogotá, Colombia. After acquiring her Medical Doctor's degree, she started working as a resident (ANIOS) at the department of internal medicine at the Gelderse Vallei, Ede. In 2013, she started with the research project described in this thesis: "The PROMise of remote monitor-

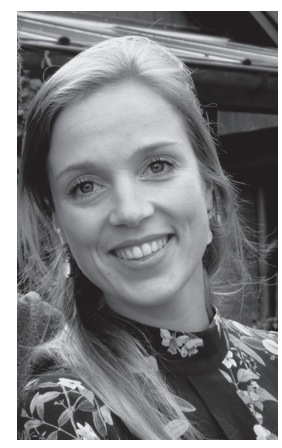
ing to improve quality of care for inflammatory bowel disease", supervised by dr. Marieke Pierik, dr. Astrid van Tubergen and prof. dr. Ad Masclee at the Maastricht University Medical Centre, Maastricht. During this project, she had the opportunity to present her work on several international conferences and to publish manuscripts in international peer reviewed medical journals. As of July 2017, she started her gastroenterology training at Leiden University Medical Centre and Haga Hospital in The Hague. 
